n. (1)

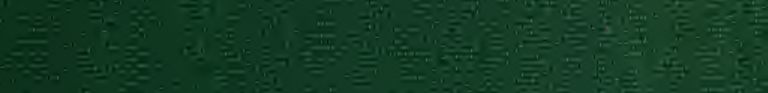

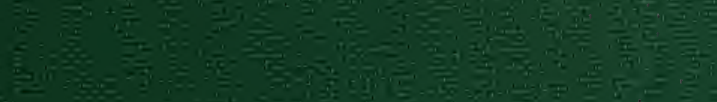

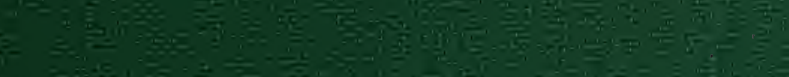







\title{
RECHERCHES
}

\section{ANATOMIQUES ET PHYSIOLOGIQUES}

\author{
SUR \\ LES HEMIPTÈRE,
}

ACGOMPAG NÉES

DE CONSIDÉRATIONS RELATIVES A L'HISTOIRE NATURELLE ET A LA CLASSIFICATION DE CES INSECTES. 



\title{
RECHERCHES
}

\section{ANATOMIQUES ET PHYSIOLOGIQUES}

\author{
$8 \boldsymbol{U}$ \\ LES HEMIPTËRES, \\ ACCOMPAGNÉES
}

DE CONSIDÉRATIONS RELATIVES A L'HISTOIRE NATLREILE ET A LA CLASSIFICATION DE CES INSECTES;

\section{PAR M. LÉON UUFOUR,}

Doctenr-Médecin de la Faculte de Paris, Correspondant de l'Iustitut (Acad. des Sciences), Chevalier de la Légion-d'Honneur; Correspondant de l'Acadimie royale de Médecine, de la Société Philomatique, de celle d'Histoire naturelle; de la Société Linnéenne de Bordeaux, de celle de Medecine de Toulouse, de celle des Sciences médicales de Ia Moselle, de celle de Botanique de Ratisbonne; membre de la Société Entomologique de France, etc.

"miraalu. huateros, taurorumque colla, et truces in "sublime jactus : tigrium rapinas, leonum jubas, quum "rcrum natura nusquam magis, quam in minimis, tota sit. "Quapropter quasn, ne nostra legentes, quoniam ex his "spernunt multa, etiam relata fastidio, damnent, quum in " contemplatione naturce nihil possit videri supervacuum." Plinir Nat Hist. lib. XI, cap. 2

\section{INTRODUCTION.}

Ce n'est pas seulement à rechercher et à connaître les productions naturelles qui, par leur grandeur, sont à la portée facile de ses sens, que l'homme avide d'instruction doit consacrer ses soins et ses loisirs; il trouvera des sujets tout aussi dignes de son culte dans les êtres qui, par leur petitesse, occupent les derniers degrés de l'échelle orga- 
nique, et semblent défier son attention. Le gigantesque baobab, la prodigieuse baleine, l'éléphant massif, l'orgueilleux vir sapiens, n'ont pas plus coûté au créateur que l'impalpable byssus, le goujon, le lombric et la punaise. Les uns comme les autres sont l'objet constant de ses soins conservateurs; les uns comme les autres déploient aux yeux du naturaliste des merveilles sans nombre, tous ont de justes droits à nos invesligations et à notre étude.

Les insectes hexapodes sont partagés en deux grandes divisions, d'après la structure de leur bouche. Les uns, munis de mandibules et de mâchoires mobiles, sont appelés broyeurs ou mâcheurs; les autres, destinés à sucer des alimens liquides au moyen d'un bec ou d'une trompe, sont désignés, par opposition aux premiers, sous le nom de suceurs. Les coléoptères, les orthoptères, les névroptères, les hyménoptères, etc., appartiennent à la première division, tandis que les hémiptères, les lépidoptères, les diptères, etc., se rangent dans la seconde. J'ai déjà, dans un travail assez considérable sur l'anatomie des coléoptères, soumis en $1_{22}$ au jugement de l'Institut, qui l'a accueilli favorablement, et dans quelques Mémoires particuliers, publié mes recherches sur l'organisation viscérale d'un grand nombre d'insectes broyeurs ( I ). J'ai aussi fait connaître, dans des écrits insérés dans divers journaux scientifiques, l'anatomie de plusieurs insectes suceurs (2). Je viens présenter aujourd'hui et les résultats de mes

(1) Recherches anatom. sur les Carabiques etsur plusieurs autres Coléoptères (Annales des Sciences nat., par MM. Audouin, Brongniart et Dumas, 1824$1825-1826$ ). - Sur les Scolies et autres hyménoptères (Journ. de Phys., sept. 1818). - Sur les Labidoures (Annales des Sciences nat., 1828). - Sur le Scorpion (Jouru. de Phys., 1817).

(2) Recherches anatom. sur la Nèpe et la Ranatre (Ann. génér. des Sciences phys. de Bruxelles, r 820 ).- Sur l'orga ne digestif de quelques Diptères (Journ. de Phys., 1820). - Sur les Cigales (Annales des Sciences nat., 1825). - Sur l'Hippobosque (Ib., 1825). 
nombreuses dissections sur les Hémiptères, et quelques considérations physiologiques, en attendant que je puisse successivement offrir sur les autres ordres d'Insectes un semblable travail, et préparer ainsi de solides matériaux pour un ouvrage qui embrassera l'ensemble de l'organisation, tant extérieure qu'intérieure, de tous les Insectes en général.

Fidèle au plan que j’ai dejà adopté en pareille matière, je suivrai dans l'exposition anatomique des Hémiptères le cadre entomologique le plus récent de $\mathbf{M}$. Latreille, faisant partie de la nouvelle édition ( 1829 ) de l'ouvrage important ayant pour titre, le Règne arimal, etc., par M. le baron Cuvier. Mes dissections me confirment de jour en jour l'excellence de cette classification et son admirable harmonie avec les caractères fournis par les viscères. Il n'a fallu rien moins que le savoir profond, la rare perspicacité de notre illustre entomologiste, pour avoir prophétisé en quelque sorte, dans l'établissement de ses familles naturelles, les analogies anatomiques qui leur correspondaient. C'est un trait de génie auquel je m’estime heureux d'offrir un hommage, en le contirmant par des preuves matérielles.

Dans ce travail comme dans ceux que j’ai déjà publiés sur l'anatomie des Insectes, je me suis imposé une réserve extrême quant à l'établissement de principes trop généraux. " Nos erreurs, comme l'a sagement écrit M. Destutt de Tracy, dérivent de notre trop grande précipitation à généraliser, et de notre ardeur à tout réduire en principes. "Sans m'écarter néanmoins des bornes de la prudence et de la circonspection, j’ai pensé que les recherches entomologiques multipliées auxquelles je me suis livré avec persévérance pendant un fort grand nombre d'années, m'autorisaient à grouper celles de ces recherches qui se 
rapprochaient par des analogies constantes, et à les signaler à l'attention. J'ai d'ailleurs donné au travail actuel, ainsi que l'indique son titre, une direction différente de celle que j'avais adoptée jusque alors, puisque non-seulement je décris la forme et la structure matérielles des organes, mais je cherche à me rendre raison du but vital de ces organes, à connaître leurs fonctions, à en exposer, en un mot, la physiologie. Dans cette donble étude pleine d'attraits, j'ai été frappé de voir que les parties constitutives des diver's appareils organiques des Insectes, de ces petits êtres relégués si loin dans le vaste tableau de l'animalité, se retrouvaient avec la même destination physiologique, avec le nême nom que dans les animaux qu'une organisation plus compliquée, et considérée comme plus parfaite, a placés au premier étage, dans celui-là même qui s'est établi le suprêne dominateur de tous. Cette admirable conformité d'organisation entre des êtres si distans dans l'échelle zoologique ne devient-elle pas un puissant motif d'encouragement et de satisfaction pour le zootomiste qu'un esprit de philosophie dirige dans ses difficiles investigations? C'est là un des plus beaux côtés sous lesquels on puisse envisager l'Entomotomie. Les mêmes raisons qui ont dirigé plus spécialement mon étude vers la recherche des analogies organiques ont aussi commandé ma sobriété pour les innovations terminologiques. La similitude des fonctions, quelles que soient la forme et la structure des organes qui y président, et la classe à laquelle appartiennent les animaux, doit entraîner, suivant nous, celle de la nomenclature. On sert d'autant plus efficacement la science qu'on la hérisse moins de difficultés, et que l'on fatigue moins la mémoire et l'esprit de ceux qui s'y adonnent. Personne n'est plus pénétré que moi de l'importance des noms, et Linnæus a dit avec raison, dans 
son immortelle Philosophie botanique : Nomina si nescis, perit et cognitio rerum. Mais sans prétendre ici infirmer les travaux des savans qui ont créé de nécessaires dénominations pour des choses qui en manquaient ou qui en avaient d'insignifiantes, je me plais à répéter qu'il faut ètre fort circonspect dans cette création. Toutefois, malgré ma sobriété, je n'ai pu me dispenser d'employer quelques termes nouveaux ou spéciaux, et jen fixerai la signification, la valeur, dans les généralités qui précéderont la description des appareils organiqnes.

Malgré les difficultés et souvent les dégoûts qu'entraîne la dissection des Hémiptères, j’ai la satisfaction de présenter un ensemble de faits anatomiques bien constatés sur des espèces assez nombreuses, appartenant non-seulement à toutes les familles établies dans cet ordre, mais à presque tous les groupes génériques. Il est permis de prévoir que le temps n'est pas très éloigné où l'on pourra, dans le cadre méthodique des Insectes, accompagner l'expression des caractères purement entomologiques de celle des traits fournis par l'organisation viscérale. Cette corrélation, cette harmonie réciproque entre l'extérieur et.l'intérieur, entre la physionomie et la splanchnologie, formeront sans contredit la base la plus solide d'une classification vraiment philosophique. M. Latreille en a fait un heureux essai dans son dernier onvrage, quant aux grandes divisions. Je me hasarderai, à la fin de mon travail, à encadrer dans un tableau les traits anatomiques distinctifs des Hémiptères, soit pour les sections et les familles, soit pour les genres et même un certain nombre d'espèces saillantes.

Comme je suis profondément pénétré de la vérité de ce vieil adage : Errare humanum est, je tiens à signaler d'une manière non équivoque les espèces sur lesquelles j'ai porté le scalpel, afin que les savans qui se livreront à de sem- 
blables investigations puissent à bon droit ou confirmer les faits que j'énonce, ou redresser mes erreurs. Il importe avant tout qu'on ne trompe point la science, et que la vérité paraisse dans tout son jour. J'ai donc cru indispensable, non seulement de donner pour chaque espèce un signalement aphoristique avec une courte synonymie et quelques détails descriptifs lorsqu'ils devenaient absolument nécessaires, mais encore de faire précéder l'exposition anatomique par quelques considérations sur les formes extérieures, ainsi que sur les habitudes des familles, des genres et des espèces. Ces considérations, qui tendent à mettre en regard et le but et les moyens de l'organisme, doivent relever aux yeux du naturaliste l'importance réciproque des caractères fournis par l'Entomologie et par l'Anatomie; elles inspirent aussi un intérêt mieux senti pour l'étude des Insectes.

L'organisation splanchnique des Hémiptères, et en général celle des Insectes suceurs, est plus rapprochée du type simple que celle des Coléoptères et des Insectes broyeurs; en sorte que dans une classification qui aurait pour base l'anatomie, ou qui serait fondée sur la prééminence des actes de l'organisme, ils doivent être placés plus loin des Coléoptères qu'on ne l'a fait dans les cadres entomologiques les plus récens. Je pense donc que, dans la méthode naturelle, il convient de leur assigner un rang immédiatement après, et non avant les Hyménoptères. Pour peu que l'on réfléchisse à la supériorité de l'intelligence et de l'industrie des insectes de ce dernier ordre sur ceux qui forment l'objet de mon travail actuel, on se convaincra de la justesse de mon assertion.

Quoique les travaux monographiques de Wolf, de Stoll, de Schellenberg, de Fallen et de quelques auteurs, aient pour but spécial l'illustration des Hémiptères, il n'en 
est pas moins vrai que cet ordre d'insectes se trouve un des plus négligés, des plus arriérés, soit pour la connaissance des espéces, soit surtout sous le rapport de leurs mœurs, de leurs habitudes et de leur genre de vie. A en juger par leur organisation viscérale, et celle-ci met le physiologiste à mème d'en déduire des actes ou des fonctions que l'observation directe n'a pas encore constatés, il nous resterait beaucoup à apprendre pour compléter leur histoire naturelle. Ce n'est point ici le lieu d'énumérer les services que l'Anatomie peut rendre à l'Entomologie, taut pour la distinction positive des sexes que sous beaucoup d'autres points de vue; je les signalerai à mesure qu'ils se présenteront en traitant des espèces.

Pour éviter des répétitions superflues, toujours fastidieuses quand il s'agit de simples détails d'anatomie, je ne décrirai d'une manière circonstanciée que les viscères du genre principal de la famille. Celui-ci devient alors, sous le rapport de son organisation, le type des autres genres. Il ne restera ensuite à signaler que les particularités ou les nuances anatomiques propres à chacune des espèces disséquées. J'ai en portefeuille une surabondance de matériaux descriptifs et de dessins dont la réunion était indispensable pour constater les analogies ou les identités anatomiques; mais je n'ai point jugé à propos d'en grossir mon livre pour peser inutilement sur la science, et c'est pour l'acquit seul de ma conscience que je les conserve inédits.

Les zootomistes se sont peu occupés jusquà ce jour de l'organisation viscérale des Hémiptères; il n'est parvenu à ma connaissance aucun ouvrage spécial sur cette matière, et mes recherches auraient au moins sous ce rapport le faible mérite de la nouveauté. Swammerdam a consacré dans sa Bible de la nature un article, mais fort incomplet, sur l'appareil générateur de la Nèpe et de la Ra-

4. Savans étrangers. 
natre ( $\mathrm{I}$ ), et j’ai moi-même publié, il y a dix ans, l'anatomie détaillée de ces denx Hydrocorises (2), Ramdohr, dans son excellent Truité sur l'organe digestif des Insectes, a décrit celui de plusieurs Hémiptères; mais il s'est exclusivement borné à ces organes (3). Il est bien fàcheux que ce savant entomologiste n'ait pas étendu ses recherches aux autres appareils organiques. M. Marcel de Serres, dans quelques Mémoires oì il s'est imprudemment complu à généraliser, n'a émis que des notions fort vagues sur la splanchnologie de ces insectes (4). Eufin j’ai publié assez récenment les résultats de mes dissections sur les Cigales (5). Tels sont les antécédens de l'ouvrage que je présente aujourd'hui ; tel est, je crois, l'état actuel de la Science sur l'anatomie des Hémiptères.

La marche que je suivrai dans l'exposition de mes recherches entomotomiques sur les Hémiptères, différera peu de celle que je me suis déjà tracée dans mon travail relatif aux Coléoptères. Ainsi je vais examiner successivement, d'abord les appareils organiques qui président aux fonctions principales, puis quelques organes spéciaux. Je consacrerai donc un premier chapitre à l'appareil digestif, en y adjoignant le tissu adipeux splanchnique;

Un second à l'appareil génital;

Un troisième à l'appareil respiratoire;

Un quatrième à l'appareil sensitif;

(i) Des Scorpions aquatiques ailés (Collect. acad., tome V, page I46).

(2) Voyez ci-dessus la note 2.

(3) Abhand lung uber die Verdauungs werkzenge der insecten ( $18 \mathrm{I} \mathrm{I})$. - Je dois à l'extrême obligeance de mon ami le docteur Jourdain, anjourd'hui Médecin en chef de l'hôpital militaire de Phalsbourgo, la traduction de cet ouvrage.

(4) Observations sur les usages des diverses parties du Tube intestinal des insectes; - Sur les usages du Vaisseau dorsal. (Annales du Muséum d'Histoire naturelle de Paris, 1813.)

(5) Voyez ci-dessus la note 2. 
Un cinquième à l'organe odorifique.

Un sixième à ce qu'on appelle vaisseau dorsal.

Mais ávant d'aborder la description de ces appareils organiques, je vais, ainsi que je me le suis proposé plus haut, commencer la revue de la classification actuelle des Hémiptères, en me permettant quelques observations critiques, et je la continuerai au fur et à mesure que l'exposition successive des viscères nous mettra à même d'en dérouler le tableau.

Je me suis déjà expliqué sur la place respective que doivent occuper les Hémiptères dans le cadre général des insectes. M. Latreille les partage, d'après la structure de leurs ailes, en deux grandes sections, les Hétéroptères et les Homoptères. Cette division, parfaitement naturelle sous le rapport de la construction extérieure, de la physionomie et du genre de vie de ces insectes, est aussi légitimée par l'organisation viscérale.

\section{SECTION PREMIÈRE. HÉTÉROPTERES.}

Leur bec naît dı front, et les étuis ou hémélytres, le plus souvent membraneux à l'extrémité, sont demicoriaces dans le reste de leur étendue. D'après la considération de leur genre de vie, et celui-ci n'est qu'une conséquence de l'organisation, M. Latreille les divise en deux familles seulement, celle des Géocorises et celle des $H_{y}$ drocorises.

Le désir de simplifier, par des réductions, la classification des animaux, entraîne souvent à violer les rapports naturels, en cumulant dans une même enceinte des genres fort étonnés de leur rencontre. M. Latreille me paraît avoir encouru ce reproche dans la formation de la famille des Géocorises, telle qu'il l'a établie dans son derI8. . 
nier ouvrage (I); il était bien plus rapproché des vrais principes d'une généalogie naturelle des Hémiptères dans son Genera, publié plus de vingt ans auparavant (2). Sans m'engager ici dans des discussions qui seraient hors de mon sujet, je pense que les familles établies dans les Hétéroptères par mon respectable et savant ami, doivent ètre converties en tribus, lesquelles se subdiviseraient en groupes naturels qui fonderaient à juste titre des familles. Je n'entreprendrai point cette réforme, qui, je le répète, n'est pas de ma compétence actuelle, et je suivrai le cadre déjà adopté. Toutefois je crois qu'une troisième famille (ou tribu, suivant ınoi) doit être comprise dans la section des Hétéroptères, et trouver sa place naturelle entre celles qui existent déjà. Cette nouvelle famille, dont j'indiquerai plus bas les caractères, s'appellera, en adoptant pour sa dénomination les mêmes bases que pour les autres, les Amphibicorises.

\section{FAMILLE PREMIÈRE. GÉOCORISES.}

Les Géocorises ou Punaises terrestres comprennent des Hémiptères que Linnæus avait placés dans son genre Cimex, et qui, entre autres caractères, sont remarquables par l'odeur plus ou moins forte et tenace qu'ils exhalent. Des traits nombreux, fournis soit par la configuration extérieure, soit par la diversité du genre de vie, soit enfin par l'organisation viscérale, autorisent à établir dans cette tribn plusieurs groupes génériques naturels qui penvent constituer des familles.

(1) Le Règne animal, etc. Nouv. édit., 1829, tom. V.

(2) Genera Crustac. et Ins.; 1807 , tome III. 
GENRE I. SCUTELLERA, SCUTELLERE.

ESPÉCE I. SCUT. NIGRo-LINEATA, Latr., Gen. Cr. et Ins., T. III, p. 113. - Panz., Faun., fasc. 1, fig. 2.

La Punaise inamoise. Geoffr., ins. Par., tom. I, p. 468.

Rubra thorace lineis sex, scutello quatuor nigris; abdomine maculis marginalibus punctisque per sex lineas ordinatis, nigris. Latr., 1. c.

Hab. in umbelliferis. Long. 4 lin.

Partie coriacée des hémélytres rouge, et la membraneuse noire. Ailes enfumées, avec la nervure marginale rouge. Région dorsale de l'abdomen très noire.

Obs. Il est douteux que cette espèce, bien figurée par Panzer, soit la même que celle de Linnæus et de Fabricius, qui, d'après ces auteurs, aurait trois raies seulement à l'écusson, et le fond de l'abdomen jaune.

\section{CHAPITRE PREMIER.}

APPAREIL DIGESTIF.

La digestion est la fonction principale de tous les animaux en général, puisqu'elle sert à la conservation de l'individu. Aussi les organes qui l'exercent doivent-ils être placés en première ligne pour l'établissement des grandes coupes ou divisions qui servent à grouper ceux de ces animaux qui ont entre eux des ressemblances de conformation générale et de genre de vie. Elle consiste, dans le plus petit des Hémiptères comme dans l'homme, à introduire dans le corps des substances alimentaires prises au dehors, et qui par le jeu, l'action successive des diverses parties de l'appareil, sont convenablement élaborées, puis converties en deux parties dont l'une est destinée à réparer, à entretenir le corps, et dont l'autre, réduite à l'état d'excrément, doit être rejetée comme inutile. 
Quoique les Hémiptères aient tous pour bouche un bec articulé, destiné à extraire par succion les liquides dont ils se nourrissent, ils présentent néanmoins entre eux de grandes différences, et pour la nature de l'aliment qu'ils prennent, et pour leurs habitudes. Ainsi les uns vivent de sucs végétaux de diverses qualités, les autres pompent les humeurs d'animaux de classes différentes; il en est de tout-à-fait sédentaires, et il y en a qui sont d'une grande locomobilité; ceux-ci circulent an grand air, ceux-là se cachent dans les lieux obscurs; quelques-uns vivent constamment dans l'eau, quelques autres, véritables amphi-: bies, ont une vie tantôt aquatique, tantôt aérienne; enfin, on en voit qui séjournent à l'état de larve sous la terre, tandis qu'à celui d'insectes parfaits ils sont exclusivement liabitans de l'air. Toutes ces modifications dans les habitudes entraînent des nuances correspondantes d'organisation, ou, si l'on veut, des conditions organiques particulières président à chacune de ces différences dans le genre de vie.

Qu'on ne s'imagine point que les insectes dont j'essaie l'organographie, eucore qu'ils soient destinés à ne prendre qu'une nourriture liquide, aient pour bec une simple pompe aspirante ou un suçoir proprement dit. Ne faut-il pas, pour puiser cette nourriture, vaincre la cohésion des tissus organiques qui la contiennent? L'infecte punaise, la cigale, ne sont-elles pas obligées de percer, de déchirer le derme animal et la fibre végétale pour s'abreuver de leurs sucs? Leur bec est donc un composé de lames acérées et tranchantes, d'instrumens piquans et perforans. Ce n'est point encore tout. La nature, aussi ingénieuse pour les formes que conséquente pour le fond, ne renonce jamais d'une manière brusque et absolue au type de sa création. Ainsi, non-seulement vous retrouvez dans le bec des 
Hémiptères des pièces constitutives qui ont des traits d'analogie avec les mandibules et les mâchoires des inseetes broyeurs, mais vous rencontrez des espèces dont les pattes antérieures sont parfaitement comparables par leur forme, leur structure et leurs attributions, aux mandibules les mieux organisées de quelques insectes carnassiers, notamment à celles de plusieurs Arachnides. Ces pattes sont destinées à saisir une proie vivante, à la déchirer, à la triturer. La Phymate, la Naucore et autres Hémiptères qui vivent de rapine, sont dans ce cas."

$\mathrm{Si}$ la salive ne servait qu'à ramollir, à délayer les alimens introduits dans la bouche, ainsi qu'on le dit en parlant des grands animaux, on n'en verrait pas la nécessité dans les Hémiptères, puisque ces insectes vivent exclusivement de liquides : cependant ils sont tous pourvus de glandes salivaires bien caractérisées; celles-ci sont situées non dans le voisinage de la bouche, mais généralement suspendues dans le thorax. Leurs canaux afférens s'ouvrent à l'origine de l'œsophage, et il n'est pas rare qu'il existe des bourses destinées à tenir en réserve la salive.

Le tube digestif des Hémiptères est un organe musculomembraneux, constamment placé, ainsi que celui de tous les insectes en général, au-dessus du système nerveux rachidien et de l'appareil générateur, et au-dessous du cordon appelé vaisseau dorsal; il est aussi en rapport plus ou moins immédiat avec des lambeaux ou des lobules dn tissu adipeux splanchnique. Sa longueur varie suivant les familles et les genres; il est rare qu'elle ne dépasse pas une fois au moins celle de tout le corps de l'insecte, et le plus souvent elle l'excède de quatre, de einq, de six et même de dix fois. Dans son trajet de la bouche à l'anus, cet organe se fléchit ou se reploie en circonvolutions plus ou moins nombreuses; il présente des dilatations ou des 
poches, quelquefois des anastomoses; enfin il offre dans ses diverses parties des modifications de texture relatives aux fonctions à remplir. Dès sa sortie de la tête, il s'engage entre les deux cordons nerveux qui naissent du ganglion cérébral, et qui lui forment comme un collier. Il s'accompagne de branches et de rameaux trachéens plus ou moins multipliés, qui non-seulement lui forment des brides pour le maintenir en place, mais qui pénètrent son tissu et en activent la vitalité.

Deux tuniques principales composent la texture de cet organe, l'une externe, l'autre interne. Je n'ai point constaté l'existence d'une troisième tunique intermédiaire, que Ramdohr attribne à tous les insectes, et qu'il appelle floconneuse. La tunique externe est contractile et musculeuse, formée de denx plans de fibres, l'un longitudinal, l'autre annulaire; elle est toujours lisse et glabre à l'extérieur, c'est-à-dire que jusqu'ici je n'ai jamais observé dans aucune espèce d'Hémiptère ces villosités on papilles qui hérissent certaines parties du canal alimentaire de quelques familles des Coléoptères, spécialement des carnassiers. La tunique interne qui représente la muqueuse digestive des grands animaux est très délicate, lisse, pellucide, et il n'est pas toujours facile de la mettre en évidence. On voit que cette texture est conforme au but physiologique que doit remplir l'organe. Il est facile de se convaincre par les vivisections, non-seulement des mouvemens vermiculaires et péristaltiques qui résultent de l'action combinée des deux plans de fibres, mais des divers modes de contraction qui tous tendent à mêler, à ballotter les ingesta, à leur imprimer une direction tantôt progressive, tantôt rétrocessive, qui, d'une part, favorise la formation et la séparation du chyle pour l'acte nutritif, et qui, de l'autre, procure l'expulsion du résidu excrémentitiel de la digestion. 
Si on ne voulait envisager la division du canal digestif des Hémiptères que sous le point de vue physiologique, on n'y établirait er général que deux portions distinctes: l'une, commençant à la bouche et se terminant immédiatement après l'insertion des vaisseaux hépatiques, serait destinée à recevoir, à élaborer les matériaux alimentaires, à leur donner les conditions propres à être employés pour l'acte nutritif; l'autre comprendrait depuis l'insertion biliaire jusqu'à l'anus, et servirait exclusivement à contenir le superflu de la nutrition ou les excrémens. Mais dans l'esprit qui a dirigé mes recherches, il me paraît plus convenable de procéder à cette étude par l'examen combiné des caractères anatomiques et des fonctions.

La première poche du canal de la digestion est une dilatation de l'œsophage, qui, par sa comparaison avec celle de plusieurs oiseanx, doit porter le nom de jabot; elle u'existe pas dans tous les Hémiptères, et elle est plus ou moins prononcée suivant son degré de plénitude. Une contracture annulaire, siége d'une valvule, la sépare de la poche suivante. C'est dans le jabot que séjournent d'abord pendant un certain temps les alimens; c'est là qu'ils subissent, par leur combinaison avec la salive, une première élaboration digestive, un commencement d'animalisation. Aucun Hémiptère ne m'a offert de gésier comme on en voit dans les Orthoptères et dans plusieurs familles de Coléoptères. La liquidité de la nourriture des Hémiptères leur rendait parfaitement inutile cet organe de trituration.

Dans mon travail anatomique sur les Coléoptères, j’ai désigné la portion du tube digestif qui suit le jabot, et qui se continue jusqu'à l'insertion hépatique, sous le nom de ventricule clyylifique, d'après ses attributions physiologiques. Elle correspond, et par sa position et par ses

4. Savans étrangers. 
fonctions, au duodénum et à l'intestin grêle des grands animaux. Cette dénomination est pareillement applicable aux Hémiptères. Toutefois cet organe h'a pas des limites aussi faciles à déterminer dans la plupart de ceux qui appartiennent à la section des Homoptères, où le canal digestif présente des anastomoses fort singulières. Quoi qu'il en soit, la matière alimentaire en passant successivement dans les diverses poches on les différentes flexuosités du ventricule chylifique, et en obéissant aux mouvemens péristaltiques de celui-ci, s'y combine soit avec le liquide hépatique, soit peut-être aussi avec quelques humeurs sécrétées par les parois mêmes de l'organe, et c'est là qu'elle revêt les qualités qui la rendent propre à l'assimilation.

Le ventricule chylifique forme dans les Hétéroptères près des quatre cinquièmes de la longueur totale du tube digestif, et il débute par une dilatation, une poche constante plus ou moins boursouflée, à parois plus épaisses, plus contractiles, où les ingesta séjournent un certain temps, et qui m'a paru mériter le nom particulier d'estomac. Il est généralement moins long et à tuniques moins épaisses dans les Homoptères.

Dans quelques genres de la tribu des Géocorises, le ventricule chylifique présente vers sa terminaison une configuration et une texture particulières qui semblent constituer un organe, et que j'examinerai bientôt.

J'ai réservé la dénomination d'intestin à cette portion seule du canal alimentaire qui est clestinée à recevoir les matières excrémentitielles. Il suit immédiatement le ventricule chylifique, et se termine par l'anus; il est fort court dans les Hétéroptères, comparativement au reste du tube digestif, et se présente sous la forme d'une poche ovale, turbinée ou conoïde. Dans les Hydrocorises, il offre en 
général un renflement latéral plus ou moins prononcé, qui jouit des attributions de la vessie natatoire des poissons, et qui doit porter ce nom. L'intestin des Homoptères est beaucoup plus long et plus grêle que celui des Hétéroptères, et souvent reployé sur lui-même.

L'organe hépatique ou biliaire existe dans tous les Hémiptères, à l'exception de ceux de la familledes Aphidiens, qui ne m'en ont pas offert le moindre vestige; il consiste, ainsi que celui des insectes des autres ordres, en un certain nombre de vaisseaux ordinairement très déliés, filiformes, d'une texture très délicate et fragile, plus ou moins variqueux et repliés, insérés à l'extrémité postérieure du ventricule chylifique ou à l'origine de l'intestin. Ces vaisseaux, essentiellement sécréteurs, sont destinés à verser dans le canal alimentaire, pour le complément de l'acte digestif, un liquide de nature biliaire, ou vert, ou jaunâtre, ou brun, ou violet, rarement incolore. Il n'y en a jamais plus de quatre, et leurs insertions ont toujours lieu sur une seule portion du tube digestif.

Cet organe présente dans les Hémiptères quelques modifications que je vais signaler rapidement. Dans les premiers genres des Géocorises, il n'y a que deux vaisseaux hépatiques, sous la forme de deux arcs diversement reployés, et ils s'implantent par quatre bouts distincts à un réservoir utriculiforme, une véritable vésicule biliaire. Dans d'autres geures de cette même famille, il y a quatre de ces vaisseaux flottans par un bout, et il n'existe point de vésicule biliaire. Les Amphibicorises ressemblent, pour leur organe hépatique, aux Géocorises de la première division, tandis que les Hydrocorises ont deux vaisseaux biliaires à quatre insertions, et point de vésicule. Les Homoptères sont dépourvus de vésicule biliaire; il y a quatre vaisseaux hépatiques distincts et flottans par un bout dans les Ci- 
gales; ils se réunissent par paires dans quelques Fulgorelles. Ces vaisseaux sont très courts et rudimentaires dans la Psylle; ils ont dans la Dorthésie la forme de deux anneaux implantés par un col commun fort court.

Telle est l'exposition sommaire de l'appareil digestif des Hémiptères. Je vais maintenant aborder la description spéciale des nombreuses modifications qu'il présente dans les diverses coupes génériques établies dans cet ordre d'insectes; et à cet effet j'examinerai dans des articles séparés, $\mathbf{I}^{\circ}$. le tube alimentaire avec les vaisseaux hépatiques; $2^{\circ}$. les glandes salivaires; $3^{\circ}$. le tissu adipeux splanchnique.

ARTICLE PREMIER.

Du tube alimentaire et des vaisseaux hépatiques.

L'intimité des connexions anatomiques du tube alimentaire et des vaisseaux hépatiques, leur dépendance physiologique réciproque, l'avantage qu'il y a de suivre sans interruption leur concours simultané pour l'accomplissement de l'acte digestif, enfin le désir d'éviter des longueurs et des répétitions, m’ont déterminé à ne point exposer ces deux organes dans deux articles séparés, comıne je l'ai déjà fait ailleurs. Quant aux glandes salivaires, quoique concourant à la même fonction, elles forment néanmoins ủn appareil isolé, un système à part, un organe en quelque sorte détaché, qui réclame une étude et des considérations spéciales.

Le canal digestif de la Scutellera nigro-lineata n'a que trois fois environ la longueur de tout son corps, et les divers replis qu'il forme sont maintenus par des trachées capillaires assez lâches. L'œesophage est court, grêle comme un cheveu à son origine; il se renfle ensuite en un véritable 
jabot oblong ou conoïde, plus ou moins apparent suivant certaines conditions digestives, et logé dans le mésothorax. Une contracture brusque et circulaire, siége d'une valvule calleuse, sépare le jabot du ventricule chylifique; celui-ci est dilaté dans son tiers antérieur en un sac allongé, bosselé, comme boursouflé, surtout vers son origine, et rempli d'une masse alimentaire qui n'est point un liquide, mais une pulpe dont la couleur varie suivant les sucs végétaux qui serrent à la nourriture de l'insecte. Ce sac boursouflé est un véritable estomac qui occupe une partie du métathorax et de la cavité abdominale; il dégénère en arrière en un tube grêle, filiforme, semi-diaphane, flexueux ou replié sur lui-même, comparable à l'intestin gréle des grands animaux. Ce tube, dans sa position naturelle, a un de ses replis qui passe sous l'estomac. Il se termine constamment en arrière par une poche ovoïde ou elliptique de mêne texture que lui, et n'offrant ni à son origine ui à sa terminaison aucune trace de valvule. Cette seconde poche gastrique renferme une pâte analogue à celle de l'estomac, mais plus élaborée, et ordinairement d'un jaune vert: une espèce de col tubuleux, de peu de longueur, la termine en arrière.

A partir de ce col, la portion du tube alimentaire comprise entre ce point et la vésicule biliaire est occupée par un organe fort singulier, constant dans les individus d'une même espèce, et qui n'offre rien d'analogue dans les autres ordres d'insectes. Cet organe, qui mérite de fixer notre attention, paraît exclusivement propre à certains Géocorises, tels que les Scutellères, les Pentatomes et quelques espèces du genre Coré. D'autres Cimicides, malgré qu'ils aient avec ces derniers des affinités très marquées, soit sous le rapport des caractères entomologiques, soit sous celui des moeurs et du genre de vie, en sont néanmoins 
entièrement dépourvus, ainsi que nous le verrons plus bas.

Dans la $S c$. nigro-lineata, cet organe se présente sous la forme de quatre semi-boyaux grêles, pellucides, marqués en travers de petites raies blanchâtres, ou mieux de plissures parallèles; ils sont plus ou moins tordus en spirale sur eux-mêmes et autour d'un axe fictif; ce qui leur donne de la ressemblance avec une torsade d'épaulette militaire. Ces semi-boyaux sont maintenus plus ou moins rapprochés en colonne par une membrane intercalaire, d'une minceur et d'une pellucidité qui la rendent presque imperceptible. Comme je l'ai déjà dit, ils prennent naissance au col qui termine en arrière la seconde poche gastrique, et cette origine a lieu brusquement par un bout arrondi et saillant; ils se termiuent de la même manière, immédiatement avant la vésicule biliaire. Une tunique fort mince et translucide forme leur enveloppe extérieure. Les plissures transversales, qui sont plus ou moins saillantes suivant quelques conditions relatives sans doute à l'acte digestif, semblent autoriser à présumer une disposition intérieure valvulaire ou cloisonnée. Soumis à une forte lentille du microscope, on voit ramper à leur surface une grande quantité de trachéoles; circonstance qui contribue à donner de l'importance physiologique à cet organe.

Malgré des investigations attentives et fréquemment réitérées sur ce point délicat d'anatomie entomologique, je ne saurais disconvenir que je suis loin d'être fixé sur la structure intime et surtout sur les fonctions de ces cordons semi-tubuleux. Ces plissures s'ouvrent-elles dans l'intérieur du canal alimentaire par des orifices linéaires impossibles à constater? cela ne paraît pas improbable. De nouvelles dissections plus adroites ou plus heureuses, 
celles surtout qui s'exerceraient sur des Cimex exotiques d'une grande taille, pourront sans doute résoudre un jour ce problème entomologique. En attendant, et sans rien préjuger sur la solution de celui-ci, je me servirai pour désigner cet organe du terme provisoire de cordons valvuleux.

Ceux-ci, quoique nullement microscopiques, paraissent avoir échappé aux recherches de M. Marcel de Serres, à en juger par la description incomplète qu'il donne du Cimex nigricornis, insecte qui appartient au genre Pentatome, dont toutes les espèces à ma connaissance ont cet organe, et par l'exposition des caractères anatomiques qu'il assigne à l'ordre des Hémiptères (I).

Ramdohr, dans son Traitésur les organes digestifs des insectes, mentionne ces cordons valvuleux sous la dénomination assez insignifiante d'estomac de punaise ( W V anzen Magen) ; il les considère aussi comme des demi-tubes réunis entre eux latéralement par une membrane làche, de manière que leur ensemble représente un canal quadrangulaire. Suivant cet auteur, ils seraient composés de denx ordres de faisceanx musculaires : les uns, qüil appelle transversaux, se continueraient sans interruption sur la membrane intermédiaire; les autres, semi-annulaires, seraient raides et repliés (2). Mes observations directes ne mont pas encore mis à même de confirmer celles de Ramdohr sur ce point.

L'intestin de notre Scutellère, ou la portion du canal digestif qui renferme les excrémens, consiste en une grande poche ovale, arrondie ou conoïde, contenant un

(1) Observations sur les diverses parties du tube intestinal des insectes, p. 88 (18ı3). Observations sur les usages du vaisseau dorsal, elc., p. 1 76 .

(2) Ouvrage cité, p. $189(181 x)$. 
liquide excrémentitiel jaunâtre, et se rétrécissant en arrière pour se terminer à l'anus. Il peut être comparé indifféremment ou au colon, ou au ccecum, ou au rectum des grands animaux. J'ai souvent vu soit des Scutellères, soit des Pentatomes que l'on irritait, lancer par l'anus, comme moyen défensif, le liquide stercoral, qui du reste m'a paru inodore.

L'organe hépatique de la Scutellère et celui des genres voisins, consiste en vaisseaux sécréteurs et en un réservoir ou vésicule, destiné au séjour de la bile. Les vaisseaux biliaires ne sont qu'au nombre de deux, un pour chaque côté; mais ils s'insèrent au réservoir par quatre bouts distincts, et chacun d'eux forme ainsi une anse dont les nombreuses flexuosités sont souvent inextricables et agglomérées à la partie postérieure de l'abdomen; leur longueur égale quatre ou cinq fois celle de tout le corps de l'insecte. Ils sont simples, c'est-à-dire non ramifiés, semblables au fil le plus délié, remarquables par leur couleur d'un vert plus ou moins foncé, qui passe au bleu par la macération. Cette couleur est entièrement due à l'humeur biliaire qu'ils renferment, car leurs parois sont pellucides et d'une texture si délicate, si fragile, qu'il est très difficile de les dérouler dans leur intégrité. En approchant de leur insertion à la vésicule, ces vaisseaux sont entièrement décolorés et diaphanes.

La vésicule biliaive est une poche membraneuse, translucide, ovalaire ou arrondie; elle s'abouche, presque sessile ou par uu col peu distinct, à l'origine et sur le côté de l'intestin. C'est vers son fond et latéralement que s'insèrent deux à deux les vaisseaux hépatiques.

Le réservoir de la bile communique directement avec la poche intestinale qui renferme les excrémens, et on peut en le pressant faire refluer dans cette poche le liquide 
qu'il contient. Cette disposition anatomique de l'appareil biliaire dans les Géocorises est peu favorable, il faut en convenir, a l'explication physiologique de sa fonction, et on serait excusable de considérer cet appareil comme un organe spécial des sécrétions excrémentitielles, ou comme un organe urinaire. Une semblable méprise deviendrait d'autant plus facile pour l'entomotomiste, que celui-ci aurait borné ses dissections aux Scutellères et aux Pentatonies, Hémiptères dans lesquels l'existence des cordons valvuleux peut en imposer pour des vaisseaux biliaires. Mais lorsqu'on a étendu ses recherches aux autres genres, on se convainc que les cordons valvuleux disparaissent entièrement, tandis que l'appareil hépatique est constant dans tous. N'est-il pas possible d'ailleurs que cette communication directe entre la vésicule biliaire et l'intestin ne soit qu'apparente? Et si l'on fait passer, lorsque la vie est éteinte, le liquide de l'une dans l'autre, doit-on en inférer que les choses se passent ainsi lorsque l'insecte jouit de toutes les prérogatives de l'existence et de la santé? Et qui nous dit encore que cette transfusion, opérée par pression, n'est pas simplement le résultat de la rupture de quelque valvule ou soupape intérieure qui, dans l'exercice normal des fonctions, force le liquide à refluer dans le ventricule chylifique? Au reste, la nature, dont les ressources sont infinies, sait atteindre un même but par des moyens très différens; et nous croyons avoir mis notre amour-propre à couvert en appliquant à ces cas le nom d'anomalie. Reconnaissons donc ici, comme dans beaucoup d'autres circonstances, la nécessité de multiplier les faits, et de les constater sévèrement avant de nous élever à l'établissement de principes ou de règles.

4. Savans étrangers. 
EsPĖGE 2. SCUT. MAURA.

Tetyra maura. Fabr., Rhyng., p. 136.

Obtuse ovata, fermigineo vel testaceo-cinerea; antennis sub lamina prothoracis recipiendis; scutello utrinque puncto subcalloso albido (vel nullo); capite lineolis duabus impressis subparallelis; tibiis tetragonis brevissime spinulosis.

Hab. in graminosis, cerealibus presertim. Long. 4 r/2 lin.

La $S c$. maure se rencontre communément sur les épis de froment, dont elle pique et suce les grains encore tendres. Elle varie beaucoup pour les nuances de sa couleur, et il est présumable que les espèces décrites par Fabricius, sous les épithètes de hottentotta, nigra et peut-être picta, ne sont que des variétés d'un seul et même type.

Obs. Les antennes et les flancs du prothorax de cet insecte ont une structure remarquable qui a échappé à l'observation des entomologistes, et qui doit le faire placer sinon dans un genre nouveau, du moins dans une division particulière du genre, avec la $\boldsymbol{S} c$. maroccana Fabr. Le bord antérieur et interne de ces flancs est détaché en forme de lame arrondie, et reconvre entièrement, dans le repos, l'insertion des anteunes. Lorsque l'animal est surpris, ces derniers organes, insérés beaucoup plus en arrière que dans la $S c$. rayée, disparaissent en s'enfonçant sous la lame en question, et vont se coucher à côté l'un de l'autre contre le rostre, dans la rainure du sternum. Le premier article des antennes est plus allongé que dans d'autres espèces, aminci vers sa base et légèrement arqué, ainsi que le second, pour se prêter à la retraite de l'organe dans la coulisse sternale. J'observerai aussi que la partie coriacée ou opaque des hémélytres est bien moins étendue que dans la Sc. rayée, ainsi qu'on peut s'en convaincre par la figure que j'en donne.

Des dissections soigneuses et répétées ne mont fait 
découvrir dans l'appareil digestif de la $\boldsymbol{S} c$. maure qu'un seul trait qui peut devenir sous ce rapport un caractère distinctif comparativement à l'espèce précédente. Ce trait est fourni, comme nous le verrons plus bas, par la glande salivaire. Quant au tube alimentaire et à ses annexes, ils n'offrent avec ceux de la $S c$. rayée aucune différence appréciable.

\section{GENRE II. - PENTATONA, PENTATOME.}

Olivier, qui créa ce genre sur l'existence de cinq articles aux antennes, y avait compris le précédent. Les Pentatomes ne diffèrent effectivement des Scutellères que par un écusson moins grand, qui ne recouvre point les hémélytres, et ne se prolonge pas jusqu'au bout de l'abdomen.

Ils se nourrissent aussi des sucs de divers végétaux.

Espéce I. PENT. gRISEA. Latr., Hist. nat., etc., T. XII, p. 192. Cinex Griseus. Fabr., Rhyng., p. i71. - Panz., fasc. 33, fig. 19 .

Ovata, supra obscure grisea; thoracis angulis obtusis, anticis brevissime unidentatis; abdominis marginibus albido maculatis; corpore subtus pallidiori punctis nigris orbiculatis adsperso; ventre spina acutissima antice producta.

Hab. freq. in cultis. Long. 6 lin.

Quatrième et cinquiène articles des antennes mi-partis blancs et noirs; le troisième souvent blanchâtre à sa base. Membrane des hémélytres ordinairement marquée de points brunâtres. Ecusson blanc sale à sa pointe, et deux points noirâtres avant celle-ci.

Le canal digestif du $P$. gris ne présente pas quant à sa longueur, au nombre et à la forme de ses dilatations, ainsi qu'à sa structure générale, de différence essentielle avec celui que je viens de faire connaître dans la Scutellère rayée; ainsi il serait superflu d'en consigner ici la des- 
cription. Je me bornerai à exposer les modifications suivantes. Les cordons valvuleux ont ici une conleur rosée très marquée, qui passe soùvent au rougeâtre; ils sont un peu plus gros que dans les Scutellères, et leur extrémité postérieure offre un renflement de forme olivaire, souvent décoloré ou même blanchâtre, et qui, dans certains cas (rares à la vérité), s'efface entièrement. Les vaisseaux hépatiques ont une couleur vert-de-gris ou vert-émeraude très prononcée, et ne diffèrent point, non plus que la vésicule biliaire, de ceux du genre précédent.

Espèce 2. PENT. JUNIPERINA. Latr., 1. c.

Cim. juniperinus. Lin. - Fabr., 1. c. , p. 167. - Panz., fasc. 33 , fig. 16 .

La Punaise verte. Geoffr., ins. Par., I, p. 164.

Ovata flavo-virescens, nigro impresso-punctata; thoracis mutici hemelytrorumque margine externo tenui, pedibusque flavis; antennis tarsisque rifescente-rubris; spina ventrali antice producta.

Hab. in hortis graminosisque. Long. 5 lin.

Commun dans nos contrées (Saint-Sever; Landes), où le genièvre est très rare. Région dorsale de l'abdomen très noire, avec une fine bordure jaune. Membrane des hémélytres d'un blanc diaphane, comme vernissée. Bord externe noirâtre en-dessous. Ecusson le plus souvent jaunâtre à sa pointe.

Le canal digestif du $P$. du génevrier est organisé comme celui du $P$. gris; mais les cordons valvuleux sont blanchâtres et non renflés à leur bout postérieur. 
Espèce 3. PENT. DISSIMILIS.

Cim. Dissimilis. Fabr., 1. c., p. 167. - Panz., fasc. 33, fig. 15.

Ovata, supra viridis, subtus, antennis pedibusque rubroferrugineis; thorace inermi; abdominis dorso atro-violaceo; hemelytrorum membrana fumoso-anea.

Hab. freq. in hortis. Long. 5 lin.

D'un vert un peu obscur, couvert de points enfoncés, noirs. La couleur rougeâtre des antennes, des pattes et du ventre, s'affaiblit beaucoup par la dessiccation. Ailes enfumées. Quelquefois les pattes d'un jaune pâle, avec les tarses ferrugineux. Région de l'anus souvent de cette dernière couleur.

Son tube alimentaire, les cordons valvuleux et l'appareil hépatique ressemblent à ceux du $P$. du génevrier.

Espèce 4. PENT. SMARAGDULA.

Cim. smaragdulus. Fabr., 1. c., p. 167 .

Ovata, late viridis, antennarum articulis $3^{\circ}$ apice $4^{\circ} 5^{\circ}$ que rufo sanguineis; thorace mutico; scutello basi punctis tribus flavis, alioque atro immerso utrinque; abdominis dorso concolori, ventre carinato; segmentis abdominalibus utrinque dente nigro minuto armatis.

Var. torquata. - Thoracis capitisque tertia parte antica albido flavescente.

Cim. torquatus. Fabr., 1. c., p. 166.

Hab. satis freq. in hortis Gallice merid. occid. (SaintSever). Long. 6 lin.

Corselet et abdomen avec une légère bordure jaunâtre. Tarses avec quelques poils roussâtres. Membrane des hémélytres et ailes diaphanes.

Obs. Je l'ai fréquemment trouvé accouplé avec le Cin. torquatus Fabr., et cette variété fort remarquable est indépendante du sexe. J'ai aussi rencontré à la fin de 
l'automne des individus de cette même espèce, dont la couleur verte était devenue d'un gris rougeâtre ou rouillé.

Le conduit digestif du $P$. émeraude et ses annexes ne diffèrent point de celui de l'espèce précédente. I.es boursouflures de l'estomac sont seulement beaucoup plus prononcées que dans les autres Pentatomes, et rappellent celles qui caractérisent la poche gastrique de la Sangsue.

Espèce 5. PENT. BACCARUM. Latr.

Cim. baccarum. Fabr., 1. c., p. 172. - Panz., fasc. 33, fig. 20.

Ovata, griseo-virescens, nigro-punctata; thoracis mutici dimidia parte postica hemely trorumque corio (in vivo) rubescentibus; -membrana basi macula fiusca; scutelli apice albido; abdominis lateribus maculis bifudis nigris; antennis alboannulatis, tuberculo radicali extus subspinoso.

Hab. freq. in hortis, graminosis, etc. Long. 5 lin.

Hémélytres en-dessous d'un rouge sanguin vif, pointillé de noir.

Son canal alimentaire ne diffère de celui du $P$. gris que par l'incoloration des cordons valvuleux, qui sont diaphanes et non renflés à leur bout postérieur.

Espèce 6. PENT. ORNATA. Latr.

Cim. ornatus. Fabr., 1. c., p. 172. - Panz., fasc. 33, fig. 21.

La Punaise rouge du chou. Geoffr., ins. Par., I, p. 469.

Ovata, atro ruboque varia, capite, antennis, pedibusque atris; hemelytrorum membrana atra, albido tenuiter marginata; capitis margine elevato.

Hab. freq. in cruciferis oleraceis. Long. $4 \mathrm{I} / 2$ lin.

Son organisation intérieure présente plusieurs particularités que nous exposerons en passant en revue les divers appareils.

La longueur de son tube alimentaire surpasse un peu plus de quatre fois celle du corps de l'insecte; ainsi il a 
plus d'étendue que celui des autres Pentatomes. Cet organe ne présente du reste, dans sa configuration et sa structure, aucune différence bien remarquable. Les cordons valvuleux sont plus gros, plus turgescens, moins tordus et moins rayés en travers que dans les précédens Géocorises. Leur coulenr est variable; le plus souvent ils sont d'un blond pâle, avec leur bout postérieur d'un jaune vif, renflé en olive comme dans le $P$. gris. J'ai trouvé parfois ces cordons entièrement jaunes. Les vaisseaux hépatiques ne sont point ici colorés en vert.

Espèce 7. PENT. ACUMINATA. Latr., Gen. Cr., III, p. i 15. Elia acuminata. Fabr., 1. c., p. 18g. - Panz., fasc. 32, fig. 17. La Punase a tète longue. Geoffr., I, p. 473.

Ovato-elliptica, antice attenuata, dilute flavescens, supra nigricanti longitrorsum lineata; antennarum articulis ultinis rufo-sanguineis; abdoninis dorso atro margine flavicanti.

Hab. in graminosis. Long. 3 s/2 lin.

Rien dans la configuration et la structure du canal digestif qui s'éloigne du type générique. Les cordons valvuleux sont blanchâtres, très variqueux, et non renflés au bout.

Espèce 8. PENT. APARINES. Nob.

Edessa marginata. Fabr., 1. c., p. r54.-Panz., fasc. 33, fig. 14.

Ovato-rotunda, griseo-ferruginea; clypeo rotundato integro; thoracis lateribus dilatato-rotundatis subreflexis macula antica albida; scutelli apice, abdoninis maculis lateralibus antennarumque annulis albidis; pedibus albis nigro-punctatis; ventre aneo-maculato.

Hab. in Galio apärine (Saint-Sever), Long. 3 lin.

Ce Pentatome se trouve plus spécialement sur le grateron (Galium aparine Lin.), dont il pique et suce les fruits. Cette particularité, qui est un trait essentiel dans 
l'histoire naturelle de cet insecte, justifie la dénomination spécifique par laquelle j'ai remplacé celle de Fabricius, qui n'exprime qu'un caractère vague. Panzer, qui l'a très bien figuré, mais qui sans doute ne l'a vu que dans un état de dessiccation, dit à tort que les taches sont jaunes. Membrane des hémélytres d'un gris bronzé relevé de nervures rameuses. Une grande tache bronzée quadrilobée à la base du ventre dans la femelle; une large plaque de cette couleur dans le mâle.

Le tube alimentaire de la $P$. du grateron ne diffère pas de celui des espèces précédentes. La portion filiforme qui succède à l'estomac est seulement un peu moins longue: je la trouve remplie, ainsi que la seconde poche gastrique, par une pulpe verdâtre. Les cordons valvuleux sont blanchâtres ou semi-diaphanes, avec leur bout postérieur tantôt d'un jaune vif, tantôt incolore, peu ou point renflé. Les vaisseaux hépatiques sont verdâtres. L'intestin renferme une pâte stercorale d'un jaune orangé.

\section{GENRE III. - COREUS, CORÉ.}

Aux caractères génériques exposés dans les divers ouvrages d'Entomologie, j'ajouterai que dans toutes les espèces soumises à mes dissections, le troisième et le quatrième segment dorsal de l'abdomen présentent au milieu de leur bord postérieur un lobe plus on moins arrondi, logé dans une échancrure correspondante du segment qui le suit. J'ajouterai aussi que l'étude de la configuration du bout de l'abdomen, dans les deux sexes, peut fournir d'excellens caractères divisionnaires: Ainsi, dans les nombreuses espèces de ce genre, il est un groupe caractérisé par l'abdomen tronqué en arrière et entier dans les mâles, dentelé ou lobé dans les femelles. Ce groupe naturel, par sa construction et sa physionomie, et qui pourrait cons- 
tituer un genre propre, comprend les $C$. marginatus, chloroticus, sulcicornis, quadratus, scapha, spiniger, etc.

Les Corés habitent, comme les Pentatomes, diverses plantes, et se nourrissent de sucs végétaux.

Espèce 1. Coreus marginatus. Fabr., l. c., p. 192.

La Punaise a bec. Geoffr., ins. Par., I, p. 446.

Rufo-fuscus abscurus, punctato-scabriusculus; capite inter antennas bicuspidato; antennis rufo-ferrugineis; articulo primo crassiori subtriquetro scabroso ultimoque obscurioribus; thoracis lateribus dilatato subreflexis, angulis obtuse spinosis; abdominis lateribus dilatatis, elevatis, acutis; hemelytrorum membrana fusco-renea; femoribus scabroso-denticulatis.

Hab. in dumetis, hortis, etc. Long. 6 lin.

Le Coré borlé habite diverses plantes, mais plus spécialement la ronce et l'ancholie. C'est en juillet que l'accouplement a lieu.

Nous venons de voir que le trait le plus distinctif du tube alimentaire des Scutellères et des Pentatomes est d'avoir quatre cordons valvuleux qui précèdent la vésicule biliaire. Dans les Corés, que M. Latreille a eu le tact de placer immédiatement après les Pentatomes, ces cordons existent encore, mais au nombre de deux seulement, et il est digne de remarque qu'après ce genre et l'Alyde, qui n'en est qu'un démembrement, cet organe disparaît; que même quelques espèces de Corés et d'Alydes en sont tout-à-fait dépourvues.

Dans le Coré bordé, le canal de la digestion a la même longueur respective, la même configuration et la mème structure générale que celui des Pentatomes. Le jabot est conoïde, souvent presque insensible lorsqu'il est vide et contracté. L'estomac éprouve les mêmes variations que le jabot: il est parfois si dilaté par les alimens, que ses bour-

4. Savans élrangers. 
souflures s'effacent, et si c'est par de l'air qu'il se trouve distendu, ses parois musculo-membraneuses paraissent d'une extrême minceur, translucides et comme scarieuses. La seconde poche gastrique est un renflement sphéroïdal ordinairement adhérent, par d'imperceptibles trachéoles, au conduit tubuleux qui le précède : elle renferme une bouillie rougeâtre ou jaunâtre. Le col qui sépare cette poche des cordons valvuleux est beaucoup plus long que dans les Pentatomes. Comme je l'ai déjà dit, il n'y a que deux de ces cordons au lieu de quatre. Dans leur position naturelle, ils forment diverses flexuosités, et représentent une fraise élégante, une sorte de mésentère; ils sont diaphanes, et rayés de blanc en travers. L'intestin ou le sac stercoral est plus développé que dans les Géocorises précédens, et rappelle la vessie natatoire de quelques insectes aquatiques; il déborde de beaucoup l'insertion de la vésicule biliaire, et contient un liquide excrémentitiel d'un brun sanguinolent, que l'insecte fait jaillir par l'anus lorsqu'on l'inquiète. Les vaisseaux hépatiques sont évidemment au nombre de quatre, repliés, entortillés, et remplis non d'une bile verte comme dans les Pentatomes, mais d'une humeur blanchâtre opaque. Ces vaisseaux ont un bout borgne, flottant, plongé dans le tissu adipeux de la partie postérieure de l'abdomen, tandis que par l'autre bout ils s'insèrent isolément par paires, de chaque côté de la vésicule biliaire. Celle-ci est un sac membraneux, ovalaire, transversal, implanté sur le milieu de la longueur de l'intestin, et sessile, c'est-à-dire dépourvu de col. 
Espéce 2. CoR. CHLOROTICUS. Nob.

Oblongus supra cum antennis rufo-ferrugineus, subtus cum pedibus flavo-virescens; thoracis angulis posticis brevissime subacutis; hemelytrorum membrana anea venoso-striata; pedibus inermibus, tarsis pallide rufis.

Hab. in buxo, myrto Gallice merid. Long. 5-6 lin.

J'ai rencontré le Coré chlorotique soit en Espagne, soit dans la Provence, soit enfin aux environs de Saint-Sever (Landes). Il est en-dessus d'un roux ferrugineux assez vif, qui s'affaiblit par les progrès de la dessiccation. La couleur du dessus du corps finit aussi par devenir d'un blanchâtre sale, et les pattes roussissent. La tête et le premier article des antennes n’offrent ni épines ni aspérités. L’abdomen de la femelle se termine par six dents obtuses; celui du mâle est entier.

Le $C$. chlorotique doit se ranger dans la même division que le $C$. carré. Il a des rapports avec le $C$. insidiator Fabr. (Coqueb., Illustr., tab. 19, fig. 6); mais il en diffère surtout en ce que les angles postérieurs du corselet de ce dernier se prolongent en une épine bien marquée.

Le canal alimentaire de notre Coré ne présente, quant à la configuration et à la structure de ses diverses parties, aucune différence avec celui du $C$. bordé. La même description peut s'adapter aux deux espèces.

Espèce 3. Cor. QUADRATUS. Fabr., I. c., p. r99. - Mas. COR. RномвEUS ej. Ib. - Femina.

Depressus glaber, supra griseo-testaceus subtus pallide flavescens; capite inter antennas in acumen producto; antennarum articulo primo triquetro, obscuro, terminali fusco; thoracis margine dilutiori subserrulato, angulis posticis subacutis; abdomine dilatato rhomboideo; hemelytrorum membrana griseo-renea; pedibus simplicissimis flavo-pallidis.

Hab. in pratis dumetisque. Long. 4 1/2 lin.

La longueur de son tube digestif ne surpasse pas plus de 
trois fois celle de son corps; il ressemble du reste à celui du $C$. bordé. L'estomac renferme une pulpe alimentaire blanche, et la seconde poche gastrique une jaune. Les cordons valvuleux sont diaphanes.

Espèce 4. COR. NUGAX. Latr., Hist. , T. XII, p. 207.

La Punaise brune, a antennes et pattris panachées. Geoffr., ins。

$$
\text { Par., I, p. } 449 \text {. }
$$

Ovato-oblongus, supra planus antice attenuatus obscure reneus impresso-punctatus; capite inter antennas producto bifido; scutelli apice extimo, abdominis maculis lateralibus, antennarum pedumque annulis albidis.

Hab. in hortis pratisque. Long. 5 lin.

Antennes et pattes légèrement velues. Dernier article des antennes allongé, cylindrique, glabre, ou tout au plus velouté.

Obs. Ce Coré, par son corselet horizontal et rétréci en avant, ainsi que par la forme des articles de ses antennes, et par la structure générale de son corps, pourrait à bon titre former un genre distinct. Il ne rentre dans aucune des, divisious établies par MM. Lepelletier et Serville (Encycl.) , pour faciliter la détermination des espèces.

La longueur de son tube alimentaire égale quatre fois celle du corps. L'estomac est allongé, très boursouflé, comme froncé, rempli d'une pulpe blanche. La seconde poche gastrique était allongée et non ellipsoïdale dans les individus, en petit nombre, que j'ai disséqués : peut-être cette configuration était-elle accidentelle. Il y a une paire de conduits valvuleux, blanchâtres. Les vaisseaux hépatiques sont presque diaphanes. La vésicule biliaire est ovalaire, sessile. L'intestin est une poche plus ample et moins allongée que celle du $C$. bordé. 
Espéce 5. Cor. hirticornis. Fabr., 1. c., p. 198. - Panz., fasc. $9^{2}$, fig. 17 .

Oblongus, depressus, supra fusco-rufescens, subtus pallidus, villosus hispidusque; capite utrinque antice unidentato; antennis hispido-scabris, articulo terminali nigro cylindrico acuto; thoracis lateribus serrato-spinosis; abdominis apice emarginato-bidentato; femoribus posticis scabris subtus ad apicem incequaliter serrato-spinosis.

Hab. in graminosis, dumetis, etc. Long. 4 lin.

Ocelles ferrugineux, saillans. Membrane des hémélytres roussâtre, avec les nervures rameuses. Abdomen profondément échancré à son extrémité dans les deux sexes; sa région dorsale d'un jaune rougeâtre, avec sa base noire. Pattes velues; jambes plus pâles.

Le $C$. hirticorne a le même genre de vie que le $C$. bordé, et sa structure extérieure n'a présenté aux entomologistes aucun trait saillant qui dût les autoriser à l'en séparer génériquement. Cependant son organe digestif présente un caractère négatif fort singulier, c'est l'absence complète des cordons valvuleux : on n'y en découvre aucun vestige. C'est encore là une de ces exceptions bizarres, une de ces anomalies dont la nature mystérieuse semble vouloir entraver notre tendance à lui imposer des lois. Du reste, à cette exception remarquable près, le tube alimentaire de ce Coré est organisé sur le mème plan que celui du $C$. bordé. Seulement cette portion du ventricule chylifique qui dans ce dernier est le siége des cordons valvuleux, est ici moins longue, et la poche stercorale est moins développée.

Obs. Le Cor. scabricornis de Panzer (fasc. 99, fig. 2 I), qui a l'abdomen échancré à son extrémité, et la même structure générale que le $C$. hirticorne, dont il est d'ailleurs bien distinct comme espèce, doit ètre aussi, suivant 
toutes les apparences, dépourvu des cordons valvuleux du ventricule chylifique.

EsPĖce 6. COR. P ANZERI. Nob.

Cor. crassiconnis. Panz., fasc. $9^{2}$, fig. 18 , non Fabr.

Oblongus, griseus, subpubescens; capite antice utrinque breviter unidentato; antennarum articulo terminali elongatofusiformi obscuriori; scutello apice albido obtuso subcochleato; hemelytris fenestratis; membrana alisque albo-diaphanis; abdominis marginibus nigro-maculatis, pedibus nigro-punctatis.

Hab. freq. in hortis pratisque. Long. 3 lin.

Ocelles roussâtres, distans, assez gros. Corselet trapézoïdal, un peu déclive en avant, marqué de points enfoncés noirs.

Obs. Cette espèce, avec le $C$. capitatus de Panzer (fasc. 92, fig. 13), qui n'est point celui de Fabricius; avec le C. magnicornis de Fallen (Monogr., p. 59), avec le $C$. capitatus de Fabricius, avec les $C$. errans et clavicornis du mềme auteur, et peut-être avec les deux espèces mentionnées ci-dessus, devra par la suite constituer un genre nouveau.

Le $C$. de Panzer a un appareil digestif organisé comme celui du $C$. hirticorne. Les cordons valvuleux du ventricule chylifique manquent absolument.

\section{GENRE IV. - ALYDUS, ALYDE.}

M. Latreille n'avait considéré dans son Genera les Alydus de Fabricius que comme des Corés à corps étroit et allongé, et, dans cette circonstance, il avait pressenti l'organisation viscérale de ces insectes. Ce savant, qui depuis jugea que ce genre devait être décidément adopté, le plaça par mégarde après les Lygées, dans la première édition du Règne animal. Plus tard il ne manqua pas de 
saisir la filiation naturelle des Alydes, et dans la nouvelle édition de ce dernier ouvrage ( 1829$)$ il leur a assigné leur véritable rang immédiatement après les Corés, et avant les Lygées.

Le canal alimentaire des deux espèces d'Alydes soumises à mon scalpel va nous offrir, relativement aux cordons valvuleux, une observation analogue à celle que nous ont déjà fournie les Corés. Ces cordons existent dans l'une de ces espèces, et ne se rencontrent pas dans l'autre. Ces deux Alydes doivent, sans aucun doute, être placés dans deux genres distincts, comme on peut s'en convaincre par l'étude comparative des caractères anatomiques et entomologiques.

Espèce I. ALYDUS geranti. Nob., fig. i6.

Subvillosus, supra fusco-ceneus impresso-punctatus; thoracis hemelytrorumque margine tenui, puncto minuto calloso in thoracis margine postico, scutelli apice extimo, abdominisque maculis lateralibus albidis; antennarum articulis intermediis, tibiisque, exceptis apicibus rufo-pallidis; tibiis posticis arcuatis subferrugineis; abdominis dorso sanguineo; hemelytrorum membrana subcenea; femoribus posticis crassioribus aculeis 4 vel 5 armatis.

Hab. in geraniis, in hortis pratisque. Long. 5 lin.

Tète offrant dans les individus bien frais des traits ou raies longitudinales rougeâtres: Ocelles assez gros, rubis. Premier article des antennes noir; le second et le troisième d'un roux pâle, avec l'extrémité noire; le dernier un peu plus long que le précédent, cylindrique, d'un roux obscur. Bec roussâtre, n'atteignant pas la troisièmẻ paire de pattes. Corselet presque carré, et en plan légèrement incliné. Un point calleux blanchâtre au milieu de son bord postérieur. diles semi-diaphanes. Premier segment dorsal de l'abdomen noir, les autres rougeâtres, avec un point noir un 
peu saillant à droite et à gauche de chacun d'eux; le troisième et le quatrième ont, comme dans les Corés, un lobe arrondi. Ventre d'un gris roussâtre, avec les stigmates noirs. Quelques points et une raie latérale obscurs dans le mâle. Premier article des tarses brun, plus long que les deux autres ensemble. Deux petites pelottes sous les ongles. Tibias postérieurs cambrés, surtout dans le mâle, fauves, avec leur base et leur extrémité noires; ils se terminent par une pointe saillante. Cuisses postérieures amincies vers leur base, armées en-dessous tantôt de quatre, tantôt de cinq épines crochues, et, entre les dernières de celles-ci, de petites aspérités ou dentelures.

L'Alyde du géranium diffère de l' $A$. calcaratus de Fabricius.

Son tube digestif a, lorsqu'il est déployé, trois fois la longueur de tont le corps de l'insecte. L'œsophage est capillaire, droit, semi-diaphane, avec une teinte rougeâtre, et s'implante brusquement sur l'origine du ventricule chylifique, sans aucune trace de jabot. L'estomac est allongé, plus ou moins boursouflé, blanchâtre, occupant le métathorax et la base de la cavité abdominale. II est suivi d'un tube filiforme, flexueux et replié sur luimême, présentant avant sá terminaison le renflement ellipsoïdal que j’ai désigné sous le nom de seconde poche gastrique; après celle-ci un tube assez court, parfaitement nu, c'est-à-dire sans aucune trace des cordons valvuleux. L'appareil hépatique ressemble à celui du $C$. bordé. Les quatre vaisseaux biliaires sont diaphanes, assez gros, et ne paraissent point variqueux. La vésicule est sessile à l'origine et sur le côté de la poche stercorale ou intestin. Celui-ci ne déborde pas sensiblement à sa naissance la vésicule biliaire, mais il a assez d'ampleur, et dégénère en arrière en un conduit tubuleux qui s'ouvre par l'anus. 
Espèce 2. ALYDUS APTERUS. Nob. fig. 18.

Apterus, linearis, glaber, nigro-ceneus; hemelytris abdomine duplo brevioribus membrana destitutis, impresso-punctatis; thoracis hemely trorum abdominisque lateribus albidis; pedibus inermibus, tarsis antennarumque annulis duobus pallidis.

Hab. in graminosis Gallice merid. occid. (Saint-Sever). Long. 5 lin.

Tête de la largeur du corselet, marquée sur le vertex d'une ligne médiane enfoncée. Ocelles très rapprochés. Antennes fort grêles, insérées sur une apophyse du front, en avant des yeux. Premier article tout noir, conoïde, le deuxième et le troisième blanchâtres au centre, le dernier cylindrique, allongé, roussâtre. Bec ne dépassant point la seconde paire des pattes. Corselet de la largeur de l'abdomen, fortement ponctué dans sa moitié postérieure. Écusson en triangle allongé et pointu. Hémélytres obliquement taillées en biseau à leur extrémité. Abdomen canaliculé par le relèvement de ses côtés; sa bordure blanche, formée par la saillie de la membrane souple qui sépare les segmens dorsaux des ventraux.

L'Alyde aptère exhale comme le précédent une odeur spéciale un pen acescente. Il s'accouple au mois de mai. La femelle est plus grande que le mâle, et, dans une gestation avancée, son abdomen est énormément distendu et comme fusiforme, avec une large bordure blanche formée par le dédoublement dont je viens de parler.

Son canal alimentaire a un peu moins de longueur que celui de l'espèce précédente. Il offre du reste la même conformation, la même structure générale, avec cette différence très essentielle que la vésicule biliaire est précédée par deux cordons valvuleux disposés comme ceux du Coré bordé, et d'une teinte rosée; ces cordons sont 
variqueux ou plissés en travers. Les vaisseaux hépatiques ont une couleur verte assez intense, et sont assez gros, vu l'étroitesse de l'insecte. La vésicule biliaire est presque carrée et insérée sessilement sur le côté de l'origine du sac stercoral.

\section{GENRE V. - PYRRHOCORIS, PYRRHOCORE.}

Le Cimex apterus de Linnæus a une physionomie, une structure et des habitudes qui en forment une espèce en quelque sorte isolée dans le genre des Lygées, où Fabricius et la plupart des auteurs l'ont compris. Aussi Rodhe, dans une thèse sur une nouvelle classification des Hémiptères, soutenue en 1814 , sous la présidence du professeur Fallen, à Lund, a-t-il créé pour cet insecte un genre nouveau, sous la dénomination de Pyrrhocoris. Indépendamment des traits entomologiques dont l'absence complète des ocelles est le principal, l'organisation viscérale de cet Hémiptère justifie sa séparation comme genre propre. MM. Lepelletier et Serville, auteurs de l'article Salde de l'Encyclopédie méthodique, n'ayant pas sans doute connaissance de la thèse précitée, ont compris le Cimex apterus dans le genre Astemma, tandis que M. Latreille, tout en conservant ce dernier genre dans la nouvelle édition du Règne animal (r829), mentionne dans les Lygées le Géocorise dont il est ici question.

Espéce I. PYRRHOCORIS APTERA.

I,yg Æus apterus. Fabr., l. c., p. 227.

La Punaise rovge des Jardins. Geoffr, , I. c., I, p. 440. Aptera, ovato-oblonga, glabra, atro rubroque varia; thoracis macula transversa atra; hemelytris abdomine dimidiobrevioribus subtruncatis macula rotunda, puncto, margine scutellari apiceque tenui, atris; femoribus anticis in utroque sexu subtus minute tridentatis.

Hab. freq. in malvaceis. Long. 3 1/2 lin.

Cet insecte a l'habitude de se réunir en sociétés assez 
nombreuses, en véritables troupeaux. Il vit spécialement sur diverses malvacées, dont il pique les capsules; il n'exhale, quand on le manie, aucune mauvaise odeur; il s'accouple au commencement de juin. Geoffroy et quelques autres auteurs ont rencontré des individus de cette même espèce pourvus d'ailes. Je possède aussi dans ma collection un individu mâle ailé, pris dans le midi de l'Espagne; ces ailes sont parfaitement propres au vol, et d'un gris un peu bronzé, avec des nervures canaliculées. Outre cela, les hémélytres se terminent par une portion membraneuse tout-à-fait noire, avec des nervures relevées. La larve a le même genre de vie que l'insecte parfait; mais il n'est pas rare de rencontrer ses troupeaux dans les lieux abrités du grand jour, tels que sous les tas de plantes pourries, les écorces d'arbres, etc.

Le canal digestif de la Pyrrhocore est un peu plus long que celui des Géocorises précédens, puisqu’il surpasse cinq fois la longueur du corps; il présente d'ailleurs les mêmes dilatations, comme l'indiquent les figures qui accompagnent mon travail; mais les cordons valvuleux n'y existent point, l'organe hépatique y revêt des traits particuliers que j'exposerai bientôt, et l'intestin ou la poche stercorale y est encore plus ample que dans les Pentatomes. Dans quelques circonstances, le tube filiforme qui suit l'estomac offre distinctement, au microscope, des fibres transversales ou annulaires, excepté à un petit étranglement qui précède la seconde poche gastrique. Cette structure, qui n'est pas toujours sensible, est exprimée dans l'une des figures.

La portion du tube alimentaire qui, dans les Scutellères et les genres voisins, est le siége de ces cordons valvuleux dont les fonctions sont encore un mystère, est fort remarquable dans la Pyrrhocore, par l'existence de 
plusieurs appendices vésiculaires latérales, plus ou moins prononcées suivant certaines conditions. Ces vésicules, qui ont aussi été mentionnées sous cette même dénomination par Ramdohr (1. c., p. 193), sont situées vers l'extrémité postérieure dı tube : on les prendrait au premier coup d'ceil pour de simples caroncules de la membrane musculaire du conduit digestif; mais leur organisation utriculaire et membraneuse est mise en évidence par les verres amplifians. Elles sont en nombre variable; mais ordinairement on en compte six ou sept, et leur disposition n'offre rien de symétrique. Dans quelques circonstances favorables, elles sont ovoüdes, distendues; dans l'autres je les ai trouvées tellement affaissées ou ratatinées, qu'il aurait été difficile d'en soupçonner l'existence si des dissections antérieures ne les eussent évidemment constatées. Dans certains cas fort rares je n'en ai rencontré qu'une seule de chaque côté, mais un peu plus développée. Ne faut-il pas considérer ces utricules comme le rudiment, le vestige d'un organe qui a disparu? Ne sont-elles pas ici le simulacre imparfait et fugitif des cordons valvuleux? Enfin leur forme, leur texture, leur isolement, ne semblent-ils pas devoir fortifier l'idée émise plus haut, que ces derniers ne sont peut-être que de longues valvules celluleuses?

Dans les Géocorises dont nous venons d'étudier l'appareil biliaire, il n'existe qu'un seul réservoir hépatique, et celui-ci s'abouche à l'origine et sur le côté de la poche des excrémens. Dans la Pyrrhocore il y a deux vésicules biliaires sphéroïdales, insérées l'une à droite, l'autre à gauche de l'extrémité postérieure du ventricule chylifique, justement entre les utricules vestigiaires de celui-ci, et un léger bourrelet circulaire, indice d'une valvule que je nommerais presque iléo-cœcale. Il n'y a pour chacun de 
ces réservoirs sphéroidaux qu'un seul vaisseau biliaire, quoique celui-ci $y$ ' ait deux insertions bien distinctes et séparées. Les replis de ce vaisseau sont agglomérés à la partie postérieure de la cavité abdominale, et tellement entrelacés d'imperceptibles trachées, qu'il faut une patience éprouvée pour les dérouler sans les rompre. Ce vaisseau a un aspect variqueux, une texture fragile, et il renferme une humeur d'une teinte verdàtre.

\section{GENRE VI. - LYGEUS, LYGÉE.}

Ce genre, établi par Fabricius, a été beaucoup restreint dans ces derniers temps. Ce nom est plus spécialement affecté aujourd'hui à quelques Géocorises longilabres, à corps ovale-oblong, à antennes filiformes de quatre articles insérées à la partie inférieure des côtés de la tête, à deux ocelles saillans placés entre les yeux, à pattes simples, à crochets des tarses garnis d'une pelotte profondément bilobée, etc.

Ils paraissent se nourrir du suc de diverses plantes.

ESPÈce 1. LYG. LAGENIFER. Nob.

Oblongus, rubro nigroque varius; thoracis lateribus maculaque dorsali lageniformi rubris; hemelytrorum fascia transversa punctoque in margine scutellari nigris, membrana obscure nigra basi maculis tribus albis; ventre punctis utrinque quatuor antennis, scutello pedibusque nigris.

Rarissime in floribus (Saint-Sever). Long. 6 lin.

Il ressemble entièrement, pour sa forme, au $L$. equestris Fabr, ; mais il est plus grand que lui, et autrement coloré. Il exhale une odeur point désagréable d'éther acétique : sa couleur noire est légèrement saupoudrée de cendré. Dessus de la tête occupé par une grande tache rouge profondément et étroitement échancrée au devant. Dos du corselet offrant, comme l'indique la figure 23 ci- 
jointe, une tache rouge représentant un vase élégant, une sorte de bouteille qui reposerait sur un pied, et dont le gouleau se terminerait par un évasement transversal. Région dorsale de l'abdomen rouge, avec cinq points noirs sur chaque bord latéral; la ventrale ayant de chaque côté une série longitudinale de quatre points noirs, avec le bord antérieur des segmens noir au centre et sur les côtés. Région pectorale du corselet marquée à droite et à gauche de trois grandes taches rouges. Ailes blanchâtres, avec la nervure extérieure rouge.

Il y a trente ans que je découvris pour la première fois ce rare Lygée aux environs de Saint-Sever. Je viens d'y en rencontrer un individu que j'ai sacrifié à l'anatomie, à cause de sa taille; c'était une femelle.

Le conduit alimentaire du Lygée lagénifère égale, quand il est déployé, quatre fois la longueur de son corps. L'œsophage, capillaire à son origine, et d'une texture diaphane, ne m'a point paru se dilater en un jabot distinct. Le ventricule chylifique commence par un estomac boursouflé, allongé, blanchâtre, d'un tissu mou et expansible, occupant une partie du thorax et de l'abdomeu. Cet estomac dégénère, en arrière, eu un tube filiforme replié sur Iui-même, d'une couleur jaunâtre; avant sa terminaison à la vésicule biliaire, il présente un renflement ovalaire, de forme variable. Une sorte de col fort court sépare brusquement cette seconde poche gastrique de la vésicule biliaire. Celle-ci, dans son état de plénitude, est assez grosse, presque globuleuse, remplie d'un liquide limpide; elle recoit de chaque côté deux insertions des vaisseaux hépatiques. Ces derniers, d'abord atténués, puis plus gros et comme variqueux, sont incolores, extrêmement repliés sur eux-mêmes; ils ne forment pour chaque côté qu'une seule anse à double insertion. Un petit col 
fort court, mais assez distinct, unit la vésicule biliaire à la poche excrémentitielle, et cette union ne m'a point paru latérale. L'intestin est un sac dilaté, conoïde, renfermant un liquide fécal d'une couleur obscure.

Espèce 2. LYG. HYOSCIAMI. Fabr., 1. c., p. 2 I 8. - Panz., fasc. 79 , fig. 21 .

La Punaise rouge a ceoix de chevalier. Geoffr., l. c. , p. $44 \mathrm{I}$.

Osato-oblongus, rubro nigroque varius, pubescenti-subvillosus; capitis vertice rubro; thoracis margine antico maculisque duabus subbilobis nigris; scutello rubro basi nigro; hemelytris rubris macula inedia margineque scutellari nigris; membrana immaculata reneo-diaphana; ventre rubro punctis nigris triplici serie; antennis pedibusque nigris.

Hab. in pratis, hortis, etc. Long. 4 lin.

Le canal digestif de ce Lygée a la plus grande analogie de longueur, de configuration et de structure avec celui de l'espèce précédente, et je serais obligé de me répéter de point en point si je voulais en exposer la description.

\section{GENRE VII. - CAPSUS, CAPSE.}

C'est aussi Fabricius qui a fondé cette dénomination générique, adoptée par M. Latreille pour des Géocorises longilabres distincts des précédens, non-seulement par la gracilité brusque des deux derniers articles des antennes, par la villosité de celles-ci, par l'absence d'ocelles, par des pattes grêles et très fragiles, mais par un caractère saillant fourni par la structure de l'organe génital externe des femelles; c'est l'existence d'un oviscapte logé dans une rainure longitudinale des derniers segmens ventraux de l'abdornen, oviscapte analogue à celui qui est propre aux Cicadaires. MM. Lepelletier et Serville (Encycl. méth.) ont aussi signalé ce caractère, mais sans entrer dans des détails. J'exposerai ceux-ci à l'article des organes génitaux. 
ludépendamment de ces traits, je remarque dans toutes les espèces de Capsus soumises à mon observation, que l'extrémité de la portion coriacée de l'hémélytre forme une pièce triangulaire, séparée du reste par un pli transversal ou une articulation propre, qui lui permet des mouvemens spéciaux; cette pièce est assez brusquement déclive en arrière. La partie membraneuse des hémélytres ne présente qu'une seule nervure placée en arc vers sa base. Une figure rend sensibles ces caractères génériques, qui n'ont point été saisis par les entomologistes. Enfin j’ajouterai que dans ce genre, ainsi que dans le suivant, il y a dans les deux sexes sept segmens stigmatifères à la région ventrale de l'abdomen.

Les Capses habitent tous sur les plantes, sont agiles, et assez prompts à s'envoler.

EsPÉCE i. CAPSUS TRICOLOR. Fabr., I. c., p. 2/46. - Panz., fasc. $9^{3}$, fig. 20.

La Punaise safranée. Geoffr., l. c., I, p. 444.

Ovatus, ater rufusve, glaber, nitidus, punctatus; thorace antice impunctato, hemelytris macula apicali coccinea; membrana nigra basi macula albida; antennarum articulis duobus ultimis pallidis.

Hab. in hortis, urtica dioica presertim. Long. 3 lin.

Ce Capse est fort commun en été dans nos jardins. Sa couleur est très variable: les mâles sont plus souvent noirs, et les femelles roussâtres; il est des individus qui ont le corselet noir, avec une bordure rousse. Les pattes sont roussâtres, avec les cuisses en grande partie noires.

Le tube digestif du Capse tricolor a environ trois fois la longueur du corps de l'insecte. L'œsophage ne m'a pas paru se renfler en un jabot; malgré cela je suis loin d'ex- clure l'existence de celui-ci, attendu que je l'ai bien clai- 
rement vu dans les Miris. L'estomac est allongé, boursouflé, rempli d'une pulpe alimentaire le plus souvent jaunàtre, quelquefois orangée. Dans les divers individus que j'ai disséqués je n'ai point rencontré à la suite de l'estomac, ainsi que dans la plupart des Géocorises précédens, un tube filiforme, long et replié sur lui-même, mais un renflement irrégulièrement ovö̈de, séparé de lui par un étranglement. Une autre dilatation, analogue à la seconde poche gastrique des Pentatomes, suit immédiatement ce renflement. J'observerai que les étranglemens placés sur le trajet du ventricule chylifique ne présentent dans leur structure aucun indice de valvule; circonstance qui peut bien rendre variables le volume, la configuration et même l'existence de ces renflemens. Quoi qu'il en soit, la dernière dilatation s'amincit en arrière pour s'aboucher latéralement à l'origine du véritable intestin. Celui-ci ressemble, pour sa forme et sa grandeur, au renflement qui le précède; il contient un liquide excrémentitiel brunâtre, et s'atténue en arrière pour aboutir à l'anus.

L'organe hépatique de ce Capse est fort différent de celui des Hémiptères dont j'ai précédemment exposé l'appareil digestif, et se rapproche au contraire beaucoup de celui de la Punaise des lits, comme nous le verrons plus bas. Il n'y a ici aucune trace de réservoir ou de vésicule biliaire. Les vaisseaux hépatiques, que j’ai été assez heureux pour dérouler complètement malgré leur extrême fragilité, sont au nombre de deux seulement, un pour chaque côté. Ils sont longs, grêles, fort repliés, d'une teinte verdâtre, et variqueux, excepté en approchant de leur point d'insertion; ils s'implantent par quatre bouts distincts, ncn pas à l'origine de l'intestin lui-même, comme un examen superticiel pourrait le faire croire,

4. Savans étrangers. 
mais tout-à-fait à l'extrémité de la portion tubuleuse de la dernière poche ventriculaire.

\section{GENRE VIII. - MIRIS, MIRIS.}

Le caractère le plus saillant qui distingue les Miris des Capses, c'est que leurs antennes sont insensiblement atténuées de la base à la pointe, et très glabres.

Espèce i. MiRIS CARCELII. Encycl. méth., T. X, p. 325.

Ovato-oblongus ater glaber, thoracis marginibus (posteriori excepto) scutellisque apice rubris; hemelytris rubris maculis duabus ovatis distinctis membranaque atris; pedibus simplicihus, abdominis margine rubro.

Hab. in hortis, pratis frequens (Saint-Sever). Long. 4 lin.

Variat in utroque sexu thorace rubro maculis duabus atris.

Espèce commune dans nos contrées, sur diverses plantes, rencontrée aussi dans l'Anjou par M. Carcel. Ventre tantôt tout-à-fait noir, à l'exception de l'auus, tantôt marqué d'une raie latérale rouge. Cuisses postérieures quelquefois rougeâtres à leur base. Toutes ces variations indépendantes du sexe.

L'organe de la digestion de ce Miris, quoique formé sur le même plan que celui du Capse, présente néanmoins quelques légères différences. Ainsi l'œsophage, presque capillaire à son origine, se renfle ensuite en un jabot oblong assez marqué. Au lieu du grand renflement ovoïde, qui dans l'espèce précédente suit l'estomac, cette portion du ventricule chylifique forme ici une courbure ou une anse cylindroïde. La seconde poche gastrique est séparée de celle-ci par une coarctation assez brusque. L'intestin est un sac ovale, conoïde. Les vaisseaux hépatiques sont au nombre de quatre, flottans par un bout, et insérés isolément par l'autre à l'extrémité du ventricule chylifique. 
Espèce 2. MIRIS NANKINEA. Nob.

Ovato-oblongus, niger, thorace scutello, hemelytrisque testaceo-nanhineis; membrana maculaque ad scutelli basim atris; femorum basi abdominisque lateribus rufis.

Hab. in pratis, ericetisque (Saint-Sever). Long. 4 lin.

Le Miris nankin a la forme et la grandeur dn précédent : il est plus rare.

Espèce 3. MIRIS COCCINEA. Nob.

Ovato-oblongus niger, thorace, scutello hemelytrisque coccineis; membrana maculaque ad scutelli basim atris; abdominis lateribus anoque rubris.

Hab. in pratis (Saint-Sever). Long. 4 lin.

L'appareil digestif du Miris écarlate et du Miris nankin ne diffère en rien de celui du Miris de Carcel.

\section{GENRE IX. - PHYMATA, PHYMATE.}

M. Latreille créa le premier ce genre d'Hémiptères, et le nom de Phymata qu'il lui imposa fut arbitrairement changé en celui de Syrtis par Fabricius. Une structure singulière et bizarre, une physionomie hétéroclite, rendent ces Géocorises fort remarquables. On n'a encore rencontré qu'une seule espèce de ce genre en Europe, et c'est celle qui a été soumise à mes investigations anatomiques. Quoique connue depuis long-temps, elle a été mal étudiée, comme on va le voir.

Avant tout jobserverai que l'organisation viscérale de la Phynate, celle surtout de son appareil salivaire, confirment pleiuement la place assignée à ce genre par M. Latreille à la suite des Miris et à la tète des Acanthia primitifs de Fabricius. Ces caractères anatomiques, et l'existence de deux articles seulement aux tarses, fonr 
nissent des raisons légitinıes d'ériger en une famille distincte les genres Phymata, Tingis, Aradus et Cimex.

Les auteurs se répétant les uns les autres, et sans doute induits en erreur en invoquant la loi de l'analogie, ont avancé que les tarses des Phymates étaient composés de trois articles. Il n'y en a réellement que deux, au moins dans l'espèce européenne; le premier est petit, fort court, difficile à mettre en évidence parce qu'il est caché par les poils qui garnissent l'extrémité tarsienne du tibia; le second très long, cylindroïde, se termine par deux crochets ou ongles simples, médiocrement arqués, dépourvus de pelottes.

Les pattes antérieures sont ravisseuses, c'est-à-dire conformées de manière à exercer la préhension sur une proie vivante; ce qui fait présumer que ces Hémiptères font la chasse à de faibles et petits insectes qu'ils sucent. Ces pattes, courtes et robustes, sont, ainsi que le dit M. Latreille, en forme de serre monodactyle de Crustacés; elles se composent $I^{\circ}$. d'une hanche de deux articles, dont celui qui se fixe au corps est bien plus long, cylindroïde, garni à son bord inférieur d'aspérités, tandis que le second, fort petit, s'implante sur la face interne de la cuisse, près de l'extrémité postérieure de celle-ci, et non tout-à-fait à son bout : ce mode d'articulation à pivot donne une grande latitude aux mouvemens; $2^{\circ}$. d'une cuisse élargie en raquette triangulaire, hérissée à son bord supérieur d'aspérités qui correspondent à celles du premier article de la hanche. A la faveur de cette structure, la cuisse, en se contractant sur la hanche, saisit et serre fortement une proie entre ces aspérités, pour la rapprocher du bec. Le bord antérieur de la cuisse est taillé en biseau tranchant, et se termine inférieurement par une dent pointue; $3^{\circ}$. d'une pièce en forme d'ongle ou d'ergot 
long et arqué, qui tient lieu de tarse et de tibia, et qui dans la rétraction se couche sur le côté interne du bord antérieur de la cuisse, en formant la pince avec la dent qui termine ce bord; ainsi cet ongle n'est reç ni dans une rainure ni dans un canal, comme on l'a avancé. Le bord correspoudant de la cuisse est, ainsi que je l'ai dit, taillé en biseau, et cette configuration est très propre à favoriser l'acte préhensif.

Dans notre Phymate il y a un écusson distinct, triangulaire, pointu, qui n'est nullement un prolongement du corselet, ainsi que le prétendent quelques auteurs.

ESPÈce I. PHYMATA CRASSIPES. Latr.

SYRTis CRassipes. Fabr., 1. c., p. 121. - Panz., fasc. 23, fig. 24 .

La Punaise a pattes de crabe. Geoffr., 1. c., I, p. 447.

Fusco-rufescens, subtus cum antennis pedibusque pallidior; capite supra plano scabriusculo apice bifido; antennarum articulo terminali elongato cylindrico-subfusiformi; thoracis dorso bicarinato, illius abdominisque lateribus dilatatis reflexis, dentatis; abdomine utrinque ad basim albido; tibiis tetragonis asperulis.

Hab. in graminosis sepibusque. Long. 3 1/2 lin.

Cet insecte, rare dans nos contrées, vole avec agilité, et n'exhale, quand on l'irrite, aucune odeur appréciable.

Le canal alimentaire de la Phymate crassipède n'a pas plus de deux fois et demie la longueur de son corps. L'œsophage, capillaire dès sa sortie de la tête, se dilate ensuite en une portion conoïde qui ne m'a pas paru distincte $d u$ ventricule chylifique par une coarctation. Cielui-ci est allongé, replié, boursouflé, à peu près d'un même diamètre dans toute son étendue, c'est-à-dire sans distinction ni d'estomac, ni de portion filiforme, ni de seconde poche gastrique. Les vaisseaux hépatiques, inco- 
lores, très entortillés, et non sensiblement variqueux, sont au nombre de deux, s'abouchant par quatre insertions isolées àutour de l'extrémité postérieure du ventricule chylifique. L’intestin destiné au séjour des matières fécales est une poche dilatée, conoïde, amincie en arrière pour la formation de l'anus.

\section{GENRE X. - ARADUS, ARADE.}

Ce genre, institué par Fabricius et maintenu par M. Latreille, est des plus naturels. Les espèces qu'il renferme sont remarquables par la dépression, la minceur de leur corps, ce qui leur permet de s'insinuer sous les écorces des arbres morts, où elles passent leur vie ordinairement réunies en sociétés. Il paraît qu'elles s'y nonrrissent de petites larves.

Un caractère assez saillant paraît avoir échappé aux cntomologistes, ou aura été mal apprécié par eux; c'est que les Aradus, ainsi que les Phymates et la Punaise, n'ont que deux articles aux tarses. Les figures que j'en donne suppléeront à de plus amples détails sur ce point.

Espèce 1. ARADUS AVENIUS. Nob. fig. 36.

$$
\text { An A. L.EVIS? Fabr., l. c., p. IIg. }
$$

Ovatus, planissimus, fusco-piceus, lovis, muticus; capite, antennis, thoraceque nigris; hemelytris homogeneis, subaveniis, nigro-fumosis ante basin pallidis; antennarum articulis duobus primis ovato-turbinatis; scutello apice rotundato; alis subnullis.

Hab. sub arborum cortice (Saint-Sever). Long. I 1/2 lin.

Espèce fort singulière, qui doit mème faire modifier dans les auteurs l'expression des caractères habituels du genre. Corps encore plus plat que celui de la Punaise les lits, comme membraneux. Tête munie d'un col fort court, mais distinct, offrant au-devant des yeux une 
petite saillie tronquée pour l'insertion de l'antenne. Bec plus court que la tête. Bord antérieur du. corselet présentant un léger relief plus luisant, festonné en arrière. Hémélytres dépourvues de partie membraneuse, par conséquent de texture homogène, et n'ayant qu'un vestige de nervure à leur base seulement. Ces deux traits paraisseut exclusivement propres à notre espèce. Ailes blanches, fort petites, rudimentaires. Dernier segment de l'abdomen entier dans la femelle, échancré, et muni d'une pièce conoïde obtuse daus le màle. Les larves ont une couleur ferrugineuse, et sont couvertes de points et de taches noirs arrondis, de diverse grandeur, disposés symétriquement en séries longitudinales.

Le conduit alimentaire de l'Arade sans nervures a une longueur qui ne surpasse pas trois fois celle de son corps. L'œsophage, d'une ténuité plus que capillaire, est droit, assez long, et ne m'a offert aucune trace de l'existence d'un jabot. Le ventricule chylifique, brusquement distinct de l'cesophage par son gros calibre, est simplement cylindroïde et uni dans cette portion que j'ai désignée, dans les autres Géocorises, sous le nom d'estomac. Un renflement લllipsoïdal ou irrégulier, mais toujours placé sur le còté, par l'effet de l'inflexion de l'organe, est séparé de cette première poche gastrique par un étranglement marqué, et s'amincit en arrière pour recevoir aussitôt l'insertion desvaisseaux hépatiques. L'intestin, ou la partie du tube digestif qui succède à cette insertion, est proportionnellement plus long dans l'Arade que dans les autres Géocorises; il débute par une portion plus grèle, qui, avant de se terminer à l'auus, présente un léger renflement.

Les vaisseaux hépatiques présentent dans l'Arade une disposition toute particulière dont je n'ai encore ren- 
contré aucun exemple dans les Hémiptères que j’ai disséqués; ils sont gros, vu la petitesse de l'insecte, blanchâtres ou diaphanes et très variqueux dans la plus grande partie de leur étendue. Il ne m'est pas bien démontré s'ils sont au nombre de quatre flottans par un bout, ou de deux seulement sous la forme d'une anse très repliée, parce qu'il m'a été impossible de les déployer dans leur in tégrité. On concevra sans peine les difficultés de la dissection d'un insecte mince comme du papier, et qui n'a qu'une ligne et demie de longueur. Ce que je puis affirmer, c'est que de chaque côté ces vaisseaux se réunissent deux à deux en un conduit commun assez long, nullement variqueux, qui par son diamètre se confond avec le tube digestif, où il s'insère. Aussi ce tube paraît-il en cet endroit comme partagé en trois branches égales.

\section{GENRE XI. - CIMEX, PUNAISE.}

Espèce I. CIMEX LECTULARIUS.

M. Latreille a consacré avec raison l'ancienne dénomination de Cimex à la seule Punaise des lits, que Fabricius a placée dans son genre Acanthia. Je ne vois pas sur quel fondement quelques auteurs ont avancé que cet insecte n'était pas d'origine européenne, et qu'il avait été introduit dans notre vieux continent après la découverte de l'Amérique : on va même jusqu'à assigner les années 1666 ou r6 7 o comme l'époque de son introduction en Angleterre par des vaisseaux venus du Nouveau-Monde. Que l'Angleterre n'ait connu qu'alors la Punaise, que quelques contrées septentrionales de l'Europe aient l'avantage de ne pas la posséder encore, ainsi que le dit Fallen dans sa Monographie des Cimex de la Suède, je ne le contesterai point; mais la connaissance de la Punaise des lits est aussi antique que celle du Pou et de la Puce. Non-seulement 
Dioscoride en parle, ainsi que l'a observé M. Latreille, mais il n'est pas permis de douter qu'Aristote n'ait voulu désigner cet insecte, lorsque, dans son Histoire des animaux, il a dit (lib. V, c. xxxr): Quce ex numero insectorum non carne vivunt, sed carnis viva humore aluntur, ut pediculi, pulices, cimices, hac, etc. Cette désignation de trois insectes essentiellement domestiques et parasites de l'espèce humaine ne confirme-t-elle pas pleinement mon assertion?

Il manquait au complément de. l'histoire naturelle de la Punaise de mettre au jour les merveilles de son organisation intérieure. Malgré les dégoûts d'une semblable dissection, je croịs être parvenu, sinon à remplir complètement, du moins à beaucoup diminuer cette lacune.

Avant de me, livrer à l'exposition viscérale de cet insecte, je consignerai ici une observation assez curieuse. Au commencement d'avril i $8{ }_{2} 6$ j'avais placé dans un verre bien clos un certain nombre de punaises adultes pour. les disséquer. Vers la fin de ce même mois il en restait encore trois. Je scellai exactement le verre qui les renfermait, et je l'abandonnai dans un coin de mon laboratoire. Au mois d'avril 1827 , c'est-à-dire après un an révolu, je retrouvai ces trois punaises vivantes et assez agiles. De ce fait on peut tirer la double conséquence que i l'existence des punaises, sous l'état d'insectes parfaits, peat se prolonger au-delà d'une année, et que ces Hémiptères peuvent supporter, sans périr, une privation complète de nourriture pendant plus d'un an.

Le tube digestif de la Punaise des lits est trois ou quatre fois plus long que son corps. L'cesophage, court et capillaire, dégénère insensiblement en un jabot conoïde peu marqué. Le ventricule chylifique débute par un estomac oblong, plus ou moins boursouflé; le plus souvent rempli

4. Savans étrangers. 
d'une pulpe alimentaire sanguine. Vient ensuite un tube grêle intestiniforme, flexueux ou reployé, qui, avant l'insertion des vaisseaux hépatiques, fait une circonvolution sur lui-même. Dans ce trajet il présente quelques légers renflemens très variables; mais on ne retrouve plus ce sac ellipsoïdal, cette seconde poche gastrique qui s'observe constamment dans les Pentaîomes, les Corées et les genres voisins. La portion du canal digestif destinée au séjour des matières excrémentitielles est remarquable par son ampleur; c'est un sac pyriforme plus ou moins distendu par une pâte stercorale d'un brun sanguin. A son origine il reçoit un peu latéralement le ventricule chylifique, et il se rétrécit en arrière en un tube fort court qui s'ouvre à l'anus.

Les vaisseaux hépatiques s'insèrent par quatre bouts isolés et bien distincts tout-à-fait à l'extrémité postérieure du ventricule chylifique. J'ai déjà dit plus haut qu'ils ont la plus grande analogie avec ceux des Capses. Tous mes efforts, toute ma patience, ont échoué pour déployer sans les rompre ces fragiles canaux sécréteurs et conducteurs de la bile. N'y en a-t-il que deux en forme d'arcs entortillés, dont les deux bouts rapprochés vont s'implanter au canal digestif, ou sont-ils au nombre de quatre, dont une extrémité est libre, fermée et flottante? c'est ce que l'observation directe ne m'a pas encore démontré. Quoi qu'il en soit, ces vaisseaux ont une capillarité beaucoup moins fine que ceux de la plupart des insectes de cette taille; ils sont blanchàtres, et ne m'ont point paru variqueux. Il n'y a point de vésicule biliaire.

\section{GENRE XII. - REDUVIUS, RÉDUVE.}

Les Réduves sont organisés de manière à vivre de rapine : ils font la chasse à d'autres insectes qu'ils sucent. 
Ils ont, à cet effet, un bec court, conique, très piquant; des pattes assez robustes, terminées par des ongles crochus, et dont les antérieures ont souvent des organes particuliers de préhension, sous la forme de pelottes spongieuses.

Espèce I. REDUVIUS STRIDULUS. Fabr., 1. c., p. $268 .-$ Encycl. méth., pl. 373 , fig. 37-40.

Ater, nitidus, subvillosus; thoracis lobo antico lineola dorsali impressa; hemelytrorum corio rubro, margine interno maculis duabus atris, membrana nigro-fumosa basi macula magna aterrina; abdonine rubro, ano nigro; tibïs anticis apice incrassatis subtus subspongiosis.

Hab. in agris subque plantis exsiccatis in sylvis. Long. 5 lin.

Lobe antérieur du corselet offrant dans les individus récemment métamorphosés quatre raies dorsales, glabres, noires sur un fond grisâtre, dont les latérales sont bifides. Écusson largement triangulaire, pointu, avec un relief en forme d'Y. Ailes enfumées, avec les nervures costales rougeâtres. Cuisses antérieures renflées, cambrées.

Les tibias antérieurs de cet insecte ont une conformation et une structure qui méritent une description particulière; ils paraissent avoir une grande ressemblance avec ceux du $R$. guttula Fabr., à en juger par la fig. 2 I du fascicule so r de Panzer. Je ne connais pas ce dernier Hémiptère, que M. Latreille rapporte à son genre $\mathrm{Nabis}$. Ce tibia, dans notre Réduve, se renfle insensiblement d'arrière en avant. Quand on l'examine en-dessus avec une forte loupe, on voit que son extrémité antérieure présente un lobe arrondi, légèrement déprimé, c'est-àdire placé un peu au-dessous du niveau du corps du tibia. Ce lobe, qu'un examen peu scrupuleux croirait distinct du tibia par une articulation, donne insertion dans le milieu de son disque au tarse. Le dessous de l'extrémité

$$
24 .
$$


renflée đu tibia présente une véritable paume ou pelotte, qui, au microscope, est revêtue d'un d'uvet serré, disposé commé les' crin's d'unè brosse ou' bien plutôt comme le tissu d'un velours. Cette texture, qui à la simple loupe semble spongieuse, est très favorable à l'acte préhensif; elle s'observe aussi aux tibias intermédiaires', mais d'une manière beaucoup moins prononcée. Les tarses antérieurs de notre Réduve ne semblent composés que de dẹx articles; s'il en existe un troisième, ce que la plus forte loupe ne démontre pas, il a une petitesse rudimentaire.

Les antennes du Réduve stridulant présentent une structure singulière, sur laquelle les entomologistes ont gardé le silence, à l'exception de M. Latreille, q'ùi en a dit quelque chose. Cette structure se rencontre aussi, mais' d'une manière moins prononcée, dans d'autres espèces de ce même genre. Le troisième article offre à son insertion avec le second un renflement sphéroïdal aminci en avant et en arrière, et parfaitement glabre, tandis que le reste de l'antenne est velu. Cette espèce de rotule ou de condyle pourrait être facilement prise, par un ceil peu attentif ou peu sévère, pour un article distinct; mais une forte loupe, et surtout le microscope, font reconnaître évidemment que son col antérieur n'est qu'une continuation de la troisième pièce de l'antenne. Le second et le quatrième articles ont aussi à leur base un renflement glabre, mais infiniment moins prononcé. L'existence de ces condyles, qu'il faut regarder sans doute comme un perfectionnement de l'organisation, a pour lout essentiel de favoriser la variété des mouvemens de l'antenne, et de se prêter ainsi à l'exercice plus étendu de ses fonctions comme organe tentaculateur.

Lorsqu'on saisit ce Réduve, il fait entendre un cri particulier, une stridulation qui lui a valu son épithète 
nominative: Ce bruit est produit par le froissement répété du cou contre l'ouverture correspondante du corselet.

Le tube alimentaire de cet insecte présente une grande analogie de configuration et de structure avec celui de: la Punaise des lits, et confirme ainsi l'identité qu'ili y a entre ces deux Géocorises, sous le rapport de: leur genre de vie. On sait qu'ils se nourrissent l'un et l'autre en suçant les animaux. La longueur de ce tube n'excède pas plus de trois fois celle de son corps. L'œsophage se renfle en un jabot conoïde souvent peu prononcé. L'estomac est une dilatation oblongue, boursonflée, remplie d'une pâte alimentaire blanchâtre ou jaunàtre; il est suivi d'un conduit filiforme, replié sur lui-même, et sans aucune trace d'une seconde poche gastrique. Après l'insertion des vaisseaux hépatiques, on voit une valvule annulaire marquée extérieurement par une coarctation; puis vient la poche des excrémens, qui est ample, conoïde, et rétrécie en arrière pour aboutir à l'anus.

Les vaisseaux biliaires sont moins longs et un peu plus gros que ceux de la plupart des autres Géocorises; ils sont diaphanes, peu ou point variqueux, et au nombre.de deux seulement, s'abouchant par quatre implantations distinctes autour de l'extrémité postérieure du ventricule chylifique, immédiatement avant la valvule qui sépare ce dernier de l'intestin proprement dit.

lispèce 2. Redur. Personatus. Fabr., 1. c., p. 267.-Panz., fasc. 28 , fig. 22 .

La Punaise-Mouche. Geoffr., 1. c., I, p. 436, pl. 9, fig. 3.

Fusco-nigricans villosus; scutello acutissimo; hemelytris homogeneis $s$. totis coriaceo-membranaceis.

Hab. scepius in domibus. Long. 7-8 lin.

Cet insecte, quoique mentionné dans presque tous les ouvrages d'Entomologie, est peu commun et assez mal 
décrit. Il est surprenant que les auteurs de notre époque n'aient point signalé un trait organique fort remarquable, fourni par la texture de ses hémélytres, et qui n'avait point échappé à Geoffroy. La portion membraneuse de ces étuis, malgré l'assertion contraire de Rodhe (I) et la figure de Panzer, est tout-à-fait nulle, et leur consistance est homogène dans toute leur étendue.

L'organisation du canal digestif et de l'appareil biliaire du Réluve masqué ressemble à celle de l'espèce précédente, et mes observations sur ce point confirment celles de Ramdohr, qui a décrit et figuré ces organes (2). Je ferai seulement la remarque que, dans le petit nombre d'individus que j'ai disséqués, l'cesophage était capillaire jusqu’à l'origine du ventricule chylifique, c'est-à-dire qu'il n'y avait pas de jabot.

\section{GENRE XIII. - NABIS, NABIS.}

Ce genre, fondé par M. Latreille sur un démembrement des Réduves, diffère de ces derniers par l'insertion des antennes, qui est plus essentiellement latérale; par la longueur du bec, qui atteint la troisième paire des pattes; paí l'absence de cou à la tête, enfin parce que le corselet n'est pas bilobé.

Les Nabis vivent de rapine ainsi que les Réduves.

EsPÈce r. NABIS DORSALIS. Nob., fig. 55.

Testaceo-rufescens, glabra, oblonga; alis nullis; hemelytris concoloribus abdominis longitudine; abdomine supra atro; femoribus anticis crassioribus; tibiis anterioribus subtus minutissime biserrulatis.

Hab. in graminosis haud infrequens (Saint-Sever). Long. $21 / 2-3$ lin.!

Espèce nouvelle, essentiellement distincte du Nabis

(1) L.c.

(2) L. c., p. 193, tab. XXIl, fig. 5 . 
cendré d'Olivier (Encycl., $n^{\circ} 2$ ). Sa couleur est d'un roux pâle, testacé, à l'exception des yeux et de la région dorsale de l'abdomen, qui sont noirs. La tête a un peu de noir sut le vertex, et deux petites lignes enfoncées qui partent d'entre les yeux, lisses. Yeux très saillans, arrondis. Bec roussâtre, grêle, dépassant un peu l'origine des dernières pattes. Antennes très fines, presque de la longueur du corps. Corselet cylindroïde, mais un peu dilaté dans son tiers postérieur, marqué d'une ligne médiane noirâtre. Écusson triangulaire parfois d'une teinte obscure. Hémélytres avec des nervures assez prononcées et une cellule bien marquée; leur portion membraneuse courte, avec des nervures simples. Ailes absolument nulles. Dos de l'abdomen noir luisant, avec les bords roussâtres. Segment anal conico-triangulaire, débordant les hémélytres, et un peu velu. Pattes d'un roux pâle. Cuisses antérieures plus grosses, conoïdes, légèrement comprimées, garnies à leur bord inférieur d'un duvet très fin, serré, moelleux, sensible à une forte loupe. Tibia antérieur armé en-dessous d'une double rangée de petites dents microscopiques brunâtres. Tarses de trois articles distincts, vélus endessous. Deux ongles simples, noirs, sans pelotte. Une petite pointe sternale bien saillante entre les origines des pattes antérieures.

Le tube alimentaire du Nabis dorsal diffère peu de celui des Réduves. Le jabot est à peiue sensible : une valvule annulaire le sépare de l'estomac; celui-ci est allongé, boursouflé. La portion tubuleuse qui le suit est moins étendue que dans le genre précédent. Les vaisseaux hépatiques sont semi diaphanes, très variqueux, fort entortillés. La poche stercorale est fort grosse, et avant de se terminer à l'anus dégénère en un conduit tubuleux. 


\section{GENRE XIV. - PELOGONUS.}

M. Latreille fonda, il y a plus de vingt-cinq ans, le genre Pelogontes sur un hémiptère découvert aux environs de Bordeaux, 'par M. Dargelas, aujourd'hui directeur du Jardin botanique de cette dernière ville. Malgré 'l'ancienneté de cette date et la description parfaite qu'en a donnée'le savant professeur de Paris, cet insecte.est peu connu de la'plupart des entomologistes, et la science réclamait qu'on en donnât une figure exacte. J'ai cherché à remplir cette lacune.

Dans son Histoire naturelle des crust. et des ins. (1805), M. Latreille rangea cet hémiptère dans la famille des Cimicides et le comprit dans le genre Acanthia, qui correspond aux Salda de Fabricius. Mais, dans son Genera ( 1807 ), il le plaça, non sans doute sans quelque hésitation, en tête de la famille des Hydrocorises, sous le nom générique qu'il porte aujourd'hui. Enfin, dans son dernier ouvrage, publié en 1829 , et faisant partie de la seconde édition du Règne animal, par Cuvier, il a cru devoir exclure le Pelogone de la famille des 'Hy'drocorises; et revenant à la première inspiration de son tact entomologique, il a de nouveau replacé ce genre dans sa trop immense famille des Géocorises.

Si l'on soumet à 'une étude attentive la structure extérieure; l'organisation viscérale, et les habitudes des genres 'Leptopus, acanthia et Pelogenus, on verra que ce petit gronpe d'hémiptères riverains doit constituer une famille propre, dent la place naturelle est à la fin de la tribu des Géocorises, et à laquelle on pourrait peut-être adjoindre le genre exotique Galgulus.

Les caractères génériques exprimés dans le Genera de M. Latreille (tome III , page 142 ), sont parfaitement 
conformes à ceux que j’ai moi-même observés, à l'exception d'un seul trait relatif à la longueur des tarses. Je dois redresser ici une erreur qui n'est peut-être qu'une inadvertance, mais qui est répétée par tous les entomologistes. Contre l'assertion de mon illustre ami, les tarses des pattes intermédiaires ne ressemblent point à ceux des pattes postérieures; ils présentent au contraire la plus grande conformité de structure avec les tarses antérieurs. Ainsi, les tarses antérieurs et internédiaires sont beaucoup plus courts que les postériears, et des deux articles qui les composent, le premier ou le basilaire est d'une extrême briéveté. Ces mêmes articles, dans les pattes de derrière, sont grêles, longs comparativemeut aux précédens, bien distincts et presque égaux entre eux. Les figures grossies que je donne des trois pattes mettent en évidence ces caractères et dissiperont toutes les incertitudes.

Le Pélogone diffère surtout de ses congénères l'Acanthia et le Leptopus, par la longueur de son bec, qui dépasse les insertions des pattes postérieures, et par ses antennes plus courtes que la tête, insérées et abritées sous les yeux.

Espèce 1. Pelogonus marginatus. Lat., fig. 58.

Ovatus, obtusus, supra nigro-fuscus opacus, subtus cinereoplumbeus subsericeus; capite ceneo transversim subtiliter striato; thoracis lateribus antice marginato-subreflexis lutescenti subpellucidis, margine postico macullulis tribus, elytrorumque margine externo basilari tenuiter lutescentibus; elytris homogeneis cinereo-albicante macullulatis; pedibus testacen rufis, femoribus obscurioribus.

Hab. ripas herbosas Gallice meridionalis et Hispanice. Long. 2 lin.

Le Pélogone est essentiellement riverain, et je suis 4. Savans élrangers. 
porté à croire qu'il se nourrit en suçant des animalcules. Il court assez vite et se dérobe en sautant, à la main qui veut le saisir. Il commence à paraître en avril, et on le trouve encore en novembre. Il exhale, quand on l'irrite, l'odeur spéciale des punaises. Considéré sous le rapport de la géographie entomologique, c'est un insecte qui habite la zone méridionale et subméridionale de l'Europe, ou en d'autres termes, la zone de l'olivier et celle du maïs. Comme je l'ai déjà dit, M. Dargelas le découvrit le premier aux environs de Bordeaux; M. Latreille l'indique à Brive, qui est déjà moins méridional que Bordeaux ; je le trouvai assez abondamment, en 1806 , sur les bords du Gardon, tout près du pont du Gard (Hérault); il n'est pas rare sur les rives de l'Adour et des ruisseaux marécageux de Saint-Sever (Landes); et je l'ai rencontré en Espagne, soit sur les bords de l'Ebre en Arragor, soit sur ceux du Francoli en Catalogne. Enfin, je ne serais pas surpris, vu qu'il cohabite fréquemment avec le Tridactylus variegatus, qu'on le découvrît aux environs de Lyon, où M. Foudras a observé ce dernier orthoptère, sur l'histoire duquel il a publié des détails pleins d'intérêt.

La larve du Pélogone, un peu moins grande et plus arrondie que l'insecte parfait, a la même structure générale que ce dernier, aux élytres et aux ailes près, dont il n'existe aucun vestige. Elle habite sous le sable humide, au milieu des racines, mais on la force à paraître à la surface du sol, en pressant celui-ci avec les pieds, comme pour l'Hétérocère et le Dryops. Elle ne saute point; sa couleur est noirâtre, mais fréquemment salie par le sable ou la terre. Je n'aperçois aucune trace des ocelles, et les yeux n'offrent point l'échancrure qui caractérise ceux de l'insecte ailé. Le bord antérieur de la tête, un peu 
en forme de museau, a des cils raides, un peu réfléchis en haut, formant un véritable râteau. Ce trait, exclusivement propre à la larve, annoncerait, si l'observation directe ne me l'avait pas déjà appris, qu'elle a l'habitude de se terrer ou de vivre dans des clapiers. Les bords du thorax sont jaunâtres, dilatés, planes et non réfléchis. Les tarses des pattes postérieures ne sont ni aussi grêles ni aussi longs que ceux de l'insecte parvenu à sa dernière métamorphose; ils sont aussi gros et à peine un peu plus longs que ceux des autres pattes.

Par son appareil digestif, le Pélogone présente quelques traits qui rappellent celui des Amphibicorises et des Hydrocorises; mais il en offre de plus nombreux et de plus essentiels qui lui revendiquent une place dans les Géocorises.

Son tube alimentaire a une longueur qui égale un peu plus de deux fois celle du corps de l'insecte. L'osophage, d'une ténuité capillaire, traverse les deux premières parties du thorax. Le ventricule chylifique, brusquement distinct de l'cesophage, débute dans le métathorax par un renflement oblong, d'une configuration variable suivant son degré de plénitude, tantôt en forme de calebasse, tantôt plus ou moins boursouflé. Bientôt après qu’il est parvenu dans la cavité abdominale, il dégénère en un conduit filiforme reployé en anse ou flexueux; et avant sa terminaison, indiquée par l'intersection des vaisseaux hépatiques, il offre constamment une petite dilatation ovalaire. J'ai toujours rencontré dans ce ventricule une pulpe alimentaire blonde, homogène, et ses parois, observées à la loupe, présentent un pointillement particulier plus on moins apparent, suivant quelques conditions digestives qu'il est difficile de préciser. Ce pointillement semble produit par des glandules ou des cryptes nichés an-dessous 
de la tunique externe de l'organe. Les vaisseaux hépatiques, blanchâtres, très déliés, variqueux, ou plutôt très linement flexueux, forment deux grandes anses diversement reployées, implantées par quatre insertions distinctes autour du bourrelet, souvent effacé, qui termine en arrière le ventricule chylifique. La première portion ou la portion grêle de l'intestin est courte, et s'insère, ainsi que dans les Notonectes, sur le côté d'un cacum plus ou moins dilaté. Ce dernier s'atténue insensiblement pour se terminer à l'anus.

\section{FAMILLE SECONDE. LES AMPHIBICORISES.}

Les Hydromètres de Fabricius, qui renferment les genres Hydrometra, Velia et Gerris de M. Latreille, démentent par leur genre de vie aquatique ou du moins amphibie, le nom de Gréocorises imposé à la famille dans laquelle notre célèbre entomologiste les a compris. Leur physionomie, la forme allongée de leur corps, qui est raide, formé de tégumens durs et fragiles, leurs pattes longues et fort grêles, qui leur servent de rames, leurs habitudes et surtout leur organisation intérieure ou viscérale, me semblent réclamer en leur faveur l'établissement d'une famille particulière qui, comme je l'ai déjà dit, se trouverait intermédiaire entre les Géocorises et les Hydrocorises. Cette famille avait d'abord été créée en 1804 par M. Latreille, sous le nom de Plotères (Rameurs), dans son Histoire naturelle des Crustacés et des Insectes. Plus tard, dans son Genera (1807), cet auteur se contenta de placer ces insectes dans une section de sa famille des Cimicides. Enfin, tout récemment ( 1829 ), il leur a assigné un rang à la fin de la nombreuse famille des Géocorises. 
GENRE XV. - GERRIS, GERRIS.

Aux traits caractéristiques assignés à ce genre par M. Latreille, j'en ajouterai un assez remarquable, fourni par la structure des antennes, et dont j’ai déjà produit un exemple à peu près semblable en parlant du Reduvius stridulus. Avec le secours de la loupe, on aperçoit entre la seconde et la troisième pièce de l'antenne, un article supplémentaire fort petit, mais bien distinct, qui, soumis au microscope, paraît turbiné et glabre, tandis que le reste de l'antenne, sous le même verre amplitiant, est velu. Un semblable article, mais à peine apparent et rudimentaire, s'observe aussi entre la troisième et la dernière pièce de l'antenne. Les figures qui accompagnent mon travail complètent ma description.

Les Gerris nageant sans cesse à la surface des eaux, saisissent, au moyen de leurs pattes antérieures, les petits insectes, et sont ainsi carnassiers : les mâles sont plus petits que les femelles souvent d'un tiers. MM. Lepelletier et Serville ont avancé une assertion contraire à l'article Gerris de l'Encyclopédie méthodique (tome X, p. 266). Lorsque j'exposerai mes recherches sur les organes génitaux de ces insectes, je prouverai par des faits anatomiques que ces entomologistes ont été induits en erreur.

ESPÈCE I. GERRIS CANALIUM. Nob., fig. 59 .

CIMEX NAJAX, var. APTERA. Deg. (ex Latreille).

Omnino aptera (adulta); supra fusco-olivacea, oculo armato aneo-pubescens, antennis pedibusque concoloribus; subtus sericeo-argentea; abdominis apice in dentem validum acutissimum utrinque producto.

In rivulis, canalibus (Saint-Sever). Long. 5-6 1/2 lin.

Il n'est mentionné ni dans Fabricius ni dans la plupart des ouvrages d'Entomologie; il est plus grand que le 
G. paludum. C'est peut-être de cette espèce que Geoffroy a entendu parler lorsqu'à la suite du G. lacustris il a dit : "Ce qu'il y a de plus singulier, c'est qu'il s'accouple " souvent avant que d'être parfait, n'ayant encore ni ailes " ni étuis. " (Hist. Ins. Par., I, p. 463.) La dissection de cet insecte prouve, comme on le verra, qu'il est complètement aptère dans toutes les époques de sa vie.

Le tube alimentaire du Gerris des canaux présente, lorsqu'il est étendu, une longueur triple de celle de tout son corps, et ses flexuosités sont maintenues en place au moyen de brides trachéennes fort déliées. L'œsophage, d'abord capillaire, se renfle insensiblement en un jabot conoïde peu prononcé. Le ventricule chylifique a des parois assez épaisses, et lorsqu'on les déchire, les lambeaux se recoquillent comme dans les tissus qui jouissent d'une certaine élasticité. Il débute, ainsi que dans la plupart des Hémiptères précédens, par un estomac boursouflé, en grande partie logé dans le thorax, et rempli tantôt d'une pulpe alimentaire d'un rouge marqué, comme si cet insecte se nourrissait de sang, tantôt d'une pâte d'un jaune pâle ou cannelle. En pénétrant dans la cavité abdominale, l'estomac dégénère en un tube filiforme et lisse, qui rétrograde pour former une anse constante. Une seconde poche gastrique ovale-oblongue termine, comme dans les Pentatomes et genres voisins, la portion tubuleuse du ventricule chylifique dont elle est séparée par un petit étranglement. L'intestin proprement dit est une poche oblongue et conoïde.

L'appareil hépatique des Amphibicorises ressemble, par la présence d'une vésicule biliaire bien distincte, à celui des premiers genres de la famille des Géocorises. Les vaisseaux sécréteurs de la bile sont au nombre de deux, diaphanes, assez gros, le plus souvent lisses, parfois un 
peu variqueux; ils forment chacun une anse à nombreux replis, les uns s'avançant jusqu'à l'estomac, les autres s'agglomérant autour de l'intestin. Ils s'implantent par quatre bouts distincts, un peu rétrécis, les uns au-dessus, les autres au-dessous d'une vésicule biliaire, globuleuse, sessile, pellucide, qui semble comme interposée entre la seconde poche gastrique et l'intestin, et que l'on croirait un renflement de l'une ou de l'autre de ces portions du tube digestif.

Espèce 2. GERRIS PALUDUM. Latr., Gen., III, p. 183.

$$
\text { G. LACUSTR1S ejusd., ib. }
$$

Supra fusco-olivacea, subtus sericeo-cinerea; thorace utrinque in tuberculum prominente; abdominis margine elevato rufescente; segmento dorsali ultimo utrinque in dentem producto; pedibus nigro-piceis; hemelytris nigro-fumosis, nervis prominulis fusco-olivaceis, metathorace subtus unituberculato.

Hab. in risulis, fossis, lacubus. Long. 5 lin.

Indépendamment des traits énoncés dans ce signalement, le Gerris des marais offre à la partie antérieure du corselet une petite ligne médiane roussâtre parfois presque effacée. I.e bord externe du thorax présente aussi à la loupe un peu de cette dernière couleur; mais c'est un caractère fort peu saillant. Dans nos individus, les pattes, surtout les cuisses, ont une couleur livide, et l'anus n'est point roussâtre.

J'ai apporté dans les investigations anatomiques relatives à cette espèce les mêmes soins que pour la précédente, et je n'ai pu trouver dans son appareil digestif qu'une légère différence dans la glande salivaire, dont je parlerai ailleurs. Ainsi tout ce que j'ai dit sur le tube alimentaire et les vaisseaux hépatiques $\mathrm{du} G$. des $\operatorname{canaux}$ 
est applicable sans restriction à ces mêmes organes dans le $G$. des marais.

Ramdohr a aussi décrit et figuré le canal du $G$. lacustris ( 1 ); il ressemble parfaitement à celui des deux espèces que j’ai disséquées. Il a seulement représenté l'estomac sans aucune trace de boursouflures; il le dit très lisse, ce qui sans doute est accidentel, et il donne le nom de pilore à ce que j'appelle vésicule biliaire.

\section{GENRE XVI. - VELIA, VÉLIE.}

C'est M. Latreille qui a institué ce genre, parfaitement naturel, aux dépens de quelques espèces d'Hydromètres de Fabricius. Les $V$ élies, au lieu de nager par saccades à la manière des Gerris, marchent ou courent sur la surface des eaux tranquilles ombragées, et se nourrissent, comme ces derniers, en suçant de petits insectes. La composition de leurs antennes a aussi beaucoup d'analogie avec celle de ces mêmes organes dans les Gerris; car avec le secours de la loupe on reconnaît un petit article supplémentaire entrc la seconde et la troisième pièce, ainsi qu'on peut le voir dans les figures que je donne de cet insecte.

Les tarses des Vélies sont de trois articles distincts, garnis en dessous d'un duvet très fin, serré, disposé comme celui du velours, et imperméable; ce qui donne à ces insectes la faculté de se teuir ct de courir sur l'eau sans se mouiller.

(i) L. c., p. 195, tab. XXIII, fig. 1 . 
Espèce i. Velia cUrrens. Fig. 65. - Latr., Gen. Cr., III, p. 133 .

Hydrometra currens. Fabr., 1. c., p. 259. - Coqueb., Illust.; tab. xix, fig. I I (mediocr.).

Aptera, nigro-subcenea; thorace maculis duabus anticis sericeo-argenteis; abdominis marginibus fulvis nigro-punctatis; ventre fulvo; maris femoribus posticis incrassatis bidentatis serrulatisque.

Hab. in fontibus umbrosis (Saint-Sever). Long. 4 lin.

Tête offrant à la loupe une légère rainure médiane. Corselet marqué de points enfoncés, dont quelques-uns forment une série transversale tout près de son bord antérieur. Base dorsale de l'abdomen avec quelques reliefs, dont un médian, bien plus prononcé dans la femelle que dans le mâle, semble représenter un écusson. Abdomen en gouttière, offrant dans les individus mâles bien conservés une tache oblongue, d'un blanc nacré, sur le bord latéral de chaque segment: ces taches ne paraissent point dans la femelle, parce que les rebords tranchans de l'abdomen s'inclinent l'un vers l'autre; ce qui rend la région dorsale bien moins large dans ce sexe que dans l'autre. Bords de l'abdomen roussâtres, avec une petite tache triangulaire noire à l'angle de chaque segment : ces bords se terminent en arrière en pointe. Dans l'échancrure limitée par ces deux pointes est placée une pièce dépendante de l'appareil génital, et plus grande, plus saillante dans le mâle que dans la femelle. Ventre fauve, avec une bordure noire. Pattes assez robustes, d'un-fauve plus ou moins obscur. Cuisses postérieures du mâle grandes, renflées, armées en-dessous de deux dents pointues, sursaillantes, et de très petites dentelures ou aspérités sensibles à la loupe; celles de la femelle simples et sans dents. Jambes postérieures du mâle garnies vers leur extrémité 4. Savans érangurs. 26 
de quelques légères aspérités. Tarses de trois articles, dont le premier beaucoup plus court; le dernier tronqué obliquement pour l'insertion des ongles.

La Vélie vagabonde vit en sociétés assez nombreuses dans les fontaines rurales ombragées; elle n'est pas rare aux environs de Saint-Sever (Landes).

Les larves sont noirâtres, et vivent en commun avec les individus adultes. Leur abdomen se termine en pointe, et ses bords à peine palifiés ne dépassent pas le niveau de la région dorsale. On observe une petite tache rousse sur le milieu du premier segment de l'abdomen. Le dessous de celui-ci est d'un gris pâle, avec une rangée de taches noires sur les flancs.

J'ai eu de fréquentes occasions d'étudier et de disséquer les deux sexes de cet Amphibicorise, et je ne vois pas sur quoi se fondent MM. Lepelletier et Serville (Encycl. méth., t. X, p. 780 ) pour regarder l'Hydrometra aptera de Fabricius comme le mâle de son $H$. currens. Je les crois deux espèces bien distinctes.

Le canal digestif de la Vélie ressemble beancoup pour sa longueur, sa forme et sa structure, à celui des Gerris. Le ventricule chylifique, observé à une forte loupe, présente dans toute son étendue un pointillement particulier qui fait présumer l'existence de cryptes dans l'épaisseur de sa tunique. La vésicule biliaire est moins développée et les vaisseaux hépatiques sont plus sensiblement variqueux que dans le genre précédent. L'intestin est gros, dilaté, turbiné, rempli d'une pulpe excrémentitielle brunâtre.

\section{FAMILLE TROISIEME. LES HYDROCORISES.}

M. Latreille, dans ses derniers ouvrages, a restreint à une seule et même famille les Hémiptères qui vivent 
habituellement dans le sein des eaux, soit à l'état de larves, soit à celui d'insectes parfaits, et il leur a donné la dénomination significative d'Hydrocorises ou Punaises d'eau. En étudiant, d'après les principes de la méthode naturelle, les formes, les habitudes et l'organisation des genres compris dans ce groupe, on se convaincra, je pense, de la nécessité de le convertir en tribu ou en section, et de revenir à la première idée de l'illustre fondateur des familles des insectes, qui, dans son Précis des caractères génériques, en $179^{5}$, avait réparti ces Hémiptères dans deux familles séparées, l'une composée des genres Ranatra et Nepa; l'autre renfermant les Naucoris, Notonecta et Corixa. Cette même distribution a été adoptée en 18 ז4, sans qu'on en ait indiqué la source primitive, par Rodhe (l. c., p. 14), qui a désigné la première famille sous le nom d'Hydrocorides, et la seconde sous celui de Naucorides. M. Latreille, dans la nouvelle édition du Règne animal, en 1829 , a saisi bien mieux encore la filiation naturelle des Hémiptères aquatiques. Il a régénéré, sans les circonscrire définitivement, deux familles qui ne sauraient manquer d'être regardées comme légitimes : l'une, les Nípides, comprendra les genres Galgulus, Naucoris, Belostoma, Nepa et Ranatra; l'autre, les Noctonectides, sera formée des Corixa, Notonecta et Plea.

\section{GENRE XVII. - NAUCORIS, NAUCORE.}

Les Naucores, par leur structure extérieure, leurs habitudes et leur organisation viscérale, forment un genre intermédiaire entre les Nèpes et les Corises, et sembleraient justifier la fusion de ces divers genres en une seule famille; cependant le plus grand nombre des traits entomologiques leur revendiquent plus légitimement une 26 . 
place à la tête des Népides. Ces Hémiptères aquatiques, munis d'un bec très piquant et de pattes antérieures ravisseuses, sont insectivores; ils sont plus voraces que la plupart des autres Hétéroptères cohabitans de l'eau, et ils paraissent être supérieurs à ceux-ci en courage et en force. J'ai souvent remarqué que placés dans un même bocal avec des Notonectes, des Corises et diverses larves, ils finissaient par les dévorer toutes. Ils supportent facilement la captivité pendant plusieurs mois. On les voit rarement à la surface de l'eau, comme les Corises et les Notonectes, et ils ne rampent point dans la vase, comme les Nèpes et les Ranatres. Ils se tiennent au milieu des charagues, des conferves et autres plantes touffues, pour y chasser leur proie. Les espèces ailées quittent souvent le soir leur demeure aquatique et s'envolent, soit pour poursuivre les petits insectes dans les airs, soit plutôt pour rechercher une localité plus appropriée.

Les pattes antérieures des Naucores offrent une structure fort singulière, et c'est leur trait anatomique extérieur le plus caractéristique. Qu'il me soit permis d'en offrir ici une figure et une courte description (fig. 75). Ces pattes ne sont ni natatoires ni ambulatoires; elles ont par leur configuration une ressemblance frappante avec les mandibules de quelques Arachnides, notamment des Mygales, ou avec les pieds-mâchoires des Crustacés, et elles doivent avoir les mêmes fonctions, c'est-à-dire servir à saisir, à déchirer leur proie, à la broyer en quelque sorte pour la rendre plus propre à être dévorée par la succion. Elles manquent absolument de tibia et de tarse proprement dits, et se composent $\mathrm{I}^{\circ}$ d'une hanche conoüde, bien moins grosse que celle des autres pattes, articulée ou plutôt implantée par son sommet sur la base de la cuisse, de manière que celle-ci peut exercer des mouvemens 
d'opposition vague et de circumduction ; $2^{\circ}$ d'une cuisse large, ovalaire, comprimée d'avant en arrière, dépourvue de cette pièce intermédiaire qu'on désigne ordinairement sous le nom de trochanter, et dont le bord inférieur, un peu tranchant, est garni d'un duvet fort court, disposé en brosse; $3^{\circ}$ enfin d'un ongle corné très simple, aussi long que la cuisse, légèrement arqué, assez robuste, susceptible d'une opposition bornée, c'est-à-dire du seul mouvement de flexion et d'extension, et destiné, en se couchant sur la crête duvetée de la cuisse, à former pince avec celle-ci, pour exercer la préhension. Je renvoie à l'explication des planches ce qui concerne les autres pattes des Naucores.

\section{Espèce i. NAUCoRIS APTERA. Nob.}

$$
\text { N. Maculata. Fab., l. c., p. } 10 .
$$

La Naucore. Geoffr., Ins. Par., I, p. 474, pl. Ix, fig. 5.

Aptera livido-virescens capite punctis macululisque fuscis; thorace maculis quatuor longitudinalibus aliaque antica dorsali subbiloba, fuscis; hemelytris homogeneis abrupte in apicem obtusum attenuatis.

Hab. in aquis stagnantibus. Long. 4 lin.

Geoffroy a évidemment confondu cette espèce avec la suivante, et quoique dans l'exposition des traits génériques il ait parlé de l'existence des ailes, je pense avec M. Latreille que la Naucore qu'il a décrite et figurée est notre $N$. aptère. Celle-ci ne diffère pas seulement de la $N$. cimicoïde par l'absence des ailes, les cinq taches $d u$ corselet et une plus petite taille, elle s'en distingue encore par la texture et la forme de ses hémélytres. Ces dernières sont dans la $N$. aptère, homogènes dans toute leur étendue, et terminées en pointe arrondie, tandis que dans l'espèce suivante elles sont membraneuses dans leur tiers 
postérieur, et largement tronquées à leur extrémité. La vue comparative des figures qui représentent les hémélytres de ces deux espèces, suppléera à d'autres détails descriptifs.

Le canal digestif de la $N$. aptère a une longueur triple de celle de tout le corps de l'insecte, et des brides trachéennes nombreuses, fort déliées, le maintiennent en place. L'œesophage se renfle à peine vers sa terminaison. L'estomac est oblong, boursouflé, variable pour sa forme, rempli d'une pulpe alimentaire blanchâtre, et logé dans la cavité thoracique. Il est suivi d'un tube filiforme, reployé en une anse constante qui se termine par une seconde poche gastrique ellipsoïdale. Les parois de ces diverses parties $d u$ ventricule chylifique sont assez épaisses, et présentent à la loupe un pointillé particulier, plus on moins prononcé suivant certaines conditions. Ces points, soumis à une forte lentille du microscope, font naître l'idée de cryptes logés au-dessous de la tunique extérieure de l'organe; ils sont parfois d'une couleur brunâtre, mais souvent aussi incolores. Une portion assez grêle d'intestin succède à l'insertion des vaisseaux hépatiques, et est suivie d'une poche turbinée très dilatable, tantôt brunâtre, tantôt diaphane, suivant qu'elle renferme ou non des excrémens. Cette poche, comparable au cæcum, est fort remarquable par l'existence, à sa base, de deux oreillettes ou espèces de caroncules que j'ai toujours rencontrées dans un état d'affaissement, ridées, ratatinées, et terminées par un filet presque imperceptible, qui est peut-être un ligament. Il n'est pas improbable que ces oreillettes se gonflent par des gaz au gré ou suivant les besoins de l'animal, et font l'office de vessies natatoires.

Les vaisseaux hépatiques de la Naucore sont capillaires, 
blanchâtres ou diaphanes, entortillés autour de l'intestin, et d'une texture très fragile. Je les ai cependant déroulés dans leur intégrité, et je me suis convaincu qu'il n'y en a que deux; mais ils s'implantent par quatre bouts distincts autour de l'extrémité postérieure du ventricule chylifique. D'après cela on voit qu'ils ont la forme d'un arc diversement replié. Il n'y a aucune trace de vésicule biliaire.

EsPĖCE 2. NAUC. CIMICOIDES. Fabr., l. c., p, I Io. - Latr., Gen. Cr., III, p. I 46. - Panz., fasc. $9^{5}$, fig. 16.

Alata livido-virescens; thorace maculis duabus magnis transverso-quadratis epunctis minimis fuscis; hemelytrorum membrana late truncata; alis magnis albo-lacteis.

In aquis stagnantibus. Long. 6 lin.

Le tube alimentaire de cette espèce n'a offert à mes investigations aucune différence essentielle avec celui de la précédente; j'ai seulement reconnu que la première poche du ventricule chylifique, ou l'estomac, au lieu d'être simplement boursouflée à son origine, présente des étranglemens nombreux et irréguliers qui lui donnent un aspect bizarre. Les dessins qui représentent l'appareil digestif des deux espèces rendent superflue toute description.

\section{GENRE XVIII. - RANATRA, RANATRE.}

Espìce I. RAN. LINEARIS. Fabr., I. c., p. I19. - Panz., fasc. 95 , fig. 15 .

Le Scorpion aquatique a corps allongé. Geoffr., I. c., i, p. 48o, tab. $x$, fig. $x$.

C'est la seule espèce de ce genre qui existe en Europe, et elle est trop connue pour insister sur sa description. 
Elle rampe au fond des eaux, dans la vase ou au milieu des plantes aquatiques; elle est carnassière, et se nourrit de petits insectes qu'elle suce après les avoir saisis avec les tenailles de ses pattes antérieures.

J'ai publié en 1820 (Ann. gén. des Sciences phys. de Bruxelles, $7^{\circ}$ vol.) l'Anatomie, avec figures, de la Ranatre et de la Nèpe. Je vais la reproduire ici, mais avec des additions et des changemens importans qui résultent des nouvelles dissections auxquelles je me suis livré depuis cette publication.

Le tube alimentaire de ces deux Népides a deux fois la longueur de leur corps. L'œesophage grêle, lisse et d'une texture musculo-membraneuse, est tout d'une venue. Il est parfois jaune orangé, ou même d'un rouge sanguin bien prononcé; ce qui dépend du liquide alimentaire qu'il renferme. Le ventricule chylifique est brusquement distinct de l'osophage et par sa grosseur et par sa texture. Tantôt dilaté dès son origine en un renflement sphéroïdal, ainsi que je l'ai souvent observé dans la Nèpe; tantôt cylindroïde, il dégénère insensiblement en un long tube filiforme reployé ou flexueux. Cet organe, dont la longueur surpasse deux fois celle de tout le reste du canal digestif, est remarquable par l'aspect pointillé ou granuleux de ses parois. Celles-ci semblent, à l'œil nu, comme finement réticulées; mais avec le secours des verres amplifians, on reconnaît que ces points saillans sont des glandules ou des cryptes nichés dans leur épaisseur. Cette texture glandulaire m'a paru plus prononcée et plus uniformément répandue dans la Ranatre que dans la Nèpe. Ce dernier insecte a aussi plus habituellement le ventricule chylifique terminé par un léger renflement ovalaire. L'intestin se distingue surtout du ventricule précédent par la texture de ses tuniques, qui sont lisses, 
c'est-à-dire dépourvues de cryptes glanduleux. Sa première portion est droite, assez courte, cylindroïde ou rarement bosselée au dehors, parfois d'une teinte jaunâtre. Elle s'abouche latéralement dans un cacum très dilatable, destiné à remplir les fonctions de vessie natatoire, comme dans le Dytique, l'Hydrophile et autres insectes aquatiques. Ce cacum, que l'on pourrait aussi bien appeler un rectum, varie pour sa forme et son développement: il s’atténue un peu en arrière pour se terminer à l'anus. 11 m’a présenté dans la Nèpe des différences fort remarquables de couleur, dont je ne saurais m'expliquer la réritable cause. Tantôt je l'ai rencontré très ample et plein d'un liquide incolore; tantôt dans un état de vacuité, il était d'un rouge briqueté très foncé; enfin, à diverses reprises, j’ai trouvé cette vessie d'un noir de charbon profond avec de très légères stries transversales. La figure que j'en donne exprime ce trait.

Les vaisseaux hépatiques des Népides sont au nombre de deux seulement, implantés par quatre insertions distinctes autour de la terminaison du ventricule chylifique, immédiatement avant la valvule annulaire qui sépare celui-ci de l'intestin. Chacun d'eux forme donc une grande anse dont les flexuosités, làchement enchevêtrées avec les ramifications trachéennes, s'enlacent autour du canal digestif. Ils sont lisses, c'est-à-dire non variqueux, tantôt blancs, tantôt diaphanes et d'une texture délicate.

\section{GENRE XIX. - NEPA, NÈPE.}

Espèce i. N. CINEREA. Lin. - Fabr., l. c., p. I07. - Panz., fasc. 95 , fig. 14 .

Le Scorpion aquatique a corps ovale. Geoffr., l. c., i, p. 48 i.

Il serait encore superflu de décrire cet insecte qui

4. Savans étrangers. 
est aussi commun que la Ranatre et qui a les mêmes habitudes et le même genre de vie qu'elle.

\section{GENRE XX. - $C O R I X A$, CORISE.}

Ce genre, fondé par Geoffroi et débaptisé arbitrairement par Fabricius, qui l'a appelé Sigara, se compose d'Hémiptères aquatiques carnassiers fort remarquables par la structure insolite et hétéromorphe de leurs pattes. Celles-ci semblent destinées, les antérieures à la préhension, les intermédiaires à une sorte d'ambulation dans l'eau, et les postérieures uniquement à la natation. Je vais consacrer quelques lignes à l'exposition de cette structure, qui me paraît avoir été incomplètement décrite et mal figurée par les auteurs.

Les pattes antérieures sont fort courtes, comparativement aux autres, et insérées si près de la tête, qu'on les prendrait volontiers pour des mandibules ou des pieds-mâchoires. Elles paraissent, en effet, remplir la double fonction de ces derniers. La cuisse, de forme cylindroïque, tient an thorax par une hanche fort courte, sans la pièce intermédiaire appelée trochanter. Le tibia, pour ainsi dire rudimentaire ou vestigiaire, est représenté par un article dont la forme et la brièveté rappellent la rotule ou genou des pattes des arachnides. Le tarse, d'une seule pièce qui égale en longueur la cuisse, est arqué et entièrement dépourvu d'ongle; mais il est organisé de manière à saisir, à retenir, à déchirer une proie. Convexe en dehors et concave en dedans, il est garni sur ses deux bords de longues soies cornées, raides et un peu arquées, qui représentent, surtont celles du bord inférieur, une sorte de peigne à longue pointes parallèles. Outre cela, la face interne du tarse est divisée, suivant sa longueur, en deux plans ou facettes, par une fine arète armée aussi 
d'une série de soies courtes, serrées, raides et droites, qui doivent produire l'effet d'une scic. Ajoutons pour le complément du mécanisme ou de la fonction de ces pattes, que les deux tarses, agissant de concert, forment, par leur connivence, en même temps une cage et une pince dont la faculté préhensive s'exerce avec d'antant plus d'énergie que ces membres sont courts et assez robustes.

Les pattes intermédiaires sont plus longues, plus minces que les deux autres paires, et d'une configuration ordinaire, c'est-à-dire composées d'une hanche, d'un trochanter, d'une cuisse, d'un tibia, d'un tarse et d'ongles. Elles sont garnies de piquans entremêlés de poils rares. Leur tarse, d'une seule pièce cylindrique et allongée, se termine par deux ongles aussi longs que lui, presque droits, grèles, faibles, rapprochés et même contigus dans l'état de repos, susceptibles de s'écarter au gré de l'insecte. Ces pattes paraissent surtout destinées, en s'accrochant aux corps environnaus, à fixer l'animal lorsqu'il veut ou guetter ou dévorer sa proie. J'ai souvent observé les Corises suspendues entre deux eaux sur un support, à la faveur des ongles des tarses intermédiaires, et maintenues dans leur équilibre horizontal par les mouvemens insensibles des pattes postérieures, qui alors faisaient à la fois l'office et de balanciers et de nageoires. J'ai bien constaté aussi dans ce cas, que les pattes intermédiaires et les antérieures concourent à exercer la progression lorsque l'insecte est immergé.

Les pattes postérieures sont, comme je l'ai dit plus haut, essentiellement natatoires. La cuisse est glabre, à l'exception de quelques petites aspérités près de son extrémité tibiale. La jảmbe, plus courte qu'elle, présente plusieurs séries longitudinales de spinules et. quelques poils fins. Mais c'est le tarse qui mérite plus spécia- 
lement notre attention. Il constitue véritablement une rame et une nageoire; il est aplati, lancéolé, formé de deux pièces, dont la terminale, bien plus courte, est tout-à-fait dépourvue d'ongles; il est garui, soit sur ses bords, soit sur son disque, près de ceux-ci, de franges ou de barbes fines, souples, serrées, susceptibles de s'étaler largement dans l'eau, et plus longues, plus fournies au hord inférieur qu'au supérieur. Ce dernier, indépendamment de ces franges natatoires, est armé de petits piquans.

Olivier et M. Latreille décrivent les antennes de la Corise comme composées de quatre articles. L'examen scrupuleux que j'en ai fait, soit à la loupe, soit an microscope, ne m'en a mis en évidence que trois, dont le premier court, cylindroïde; le second allongé, conoïde; le troisième ou le terminal grêle, subuliforme. Ces articles, soumis au foyer d'une forte lentille, paraissent velus.

Espèce r. CORIXA STRIATA. Latr., Hist. nat. Ins., t. XII, p. 289.

Sigara striata. Fabr. , 1. c. , p. 104.-Panz., fasc. 5o, fig. 23.

LA Corise. Groffr., l. c., I, p. 478, pl. 9, fig. 7 .

Testaceo-flavescens, thorace lineis nigris transversis, subtilissimis; divisis vel subanastomosantibus; hemelytris nitidis, signaturis nigris numerosissimis sub lente flexuoso-reticulatis.

Hab. in aquis stagnantibus. Long. 5 lin.

Le canal digestif a, dans la Corise, tout au plus deux fois la longueur du corps de cet insecte. Des trachées d'une extrême finesse le pénètrent et lui forment des rênes qui le maintiennent dans sa position. L'œesophage est capillaire et se prolonge jusque vers le milieu du thorax. Il n'y a aucun indice de l'existence d'un jabot. Si, en approchant de sa terminaison, l'œesophage se renfle insensi- 
blement, il est facile de se convaincre, avec le secours de la plus faible lentille du microscope, que ce renflement n'est dû qu'à une plus grande épaisseur de la tunique externe seule; car la cavité linéaire du tube qui forme son axe a d'un bout à l'autre le même diamètre. L'estomac, inégal et boursouflé à son origine, est en grande partie logé dans la cavité thoracique et a parfois une teinte verdâtre. Il n'est pas immédiatement suivi, ainsi que dans la Naucore, d'un tube filiforme distinct; il diminue insensiblement de diamètre, et présente ordinairement, avant l'insertion hépatique, un renflement ovalaire qui rappelle la seconde poche gastrique des Géocorises, mais qui, dans quelques conditions, est entièrement effacé. Un léger bourrelet circulaire, un peu calleux, termine en arrière le ventricule chylifique et est l'indice d'une valvule intérieure; il est suivi d'une portion intestinale grêle et droite dont les tuniques sont bien plus épaisses que le reste de l'organe; ce qui rend sa surface un peu inégale et ridée. J'observe que la face inférieure de cette portion d'intestin est creusée d'une gouttière médiane assez profonde. Elle s'amincit en arrière pour s'implanter sur la base d'un sac stercoral ou cæcum assez ample; je dis s'implanter, parce qu'il n'y a pas un abouchement bout à bout, et que le point d'insertion, débordé en avant par le sac en question, paraît latéral. Ce cœcum, qui dans la Corise ainsi que dans quelques genres voisins, me paraît devoir remplir les fonctions de vessie natatoire, a un volume et une configuration variables : il présente à son origine une ou deux boursouflures distinctes; quand il est bien distendu il a une forme arrondie, et se termine en arrière en un tube cylindroïde dont l'ouverture extérieure est l'anus.

Les vaisseaux hépatiques de la Corise forment deux 
anses longues et flexueuses qui s'insèrent, par quatre bouts isolés, immédiatement avant le bourrelet valvulaire qui termine en arrière le ventricule chylifique. Ces vaisseaux, d'une texture fragile, sont ou lisses ou repliés en festons, ou très variqueux, suivant certaines conditions. De fines trachéoles les retiennent appliqués sur les parois du tube alimentaire. Ils sont tantôt d'un blanc de craie, tantôt d'un gris blanchâtre, suivant le degré d'élaboration de la bile. La portion par laquelle ils s'implantent autour du veutricule chylifique est, dans une étendue de quelques millimètres, sensiblement plus grêle que l'autre, et toujours diaphane. Les figures expriment ce trait particulier.

Espèce 2. COR. HIEROGLYPHICA. Nob., fig. 85.

Testaceo-flavescens; thorace lineis nigris subtilissimis, transversis, simplicibus; hemelytris cinereo-pallidis nitidis signaturis nigris, irregularibus, interruptis, subconcatenatisque; tarsis posticis concoloribus.

Hab. in aquis stagnantibus (Saint-Sever). Long. 2 lin.

Elle est plus petite que la Corise rayée (striata. Latr., Hist. t. XII, p. 289) qui se trouve dans les mèmes eaux. Fond du corselet d'un gris cendré un peu argenté, traversé par neuf lignes noires parallèles. Mouchetures des hémélytres ressemblant, à la loupe, à des caractères hiéroglyphiques noirs. L'examen comparatif des figures qui représentent les hémélytres de cette espèce et de la Corise rayée, mettra suffisamment à inême d'apprécier leur différence spécifique.

L'appareil digestif de la Corise hiéroglyphique ne m'a rien présenté qui ne confirme ce que j’ai dit sur l'espèce précédente. 


\section{GENRE XXI. - NOTONECTA, NOTONECTE.}

Les Notonectes, que Geoffroi a appelées Prinaises à avirons, à cause de la forme et de l'usage des pattes postérieures, sont des Hémiptères aquatiques qui de tout temps ont fixé l'attention des entomologistes par leur attitude singulière dans l'eau. Elles nagent sur le dos, de manière que le ventre est supérieur ou tourné en haut, et c'est cette singularité que Linnæus a si bien exprimée par le nom, d'étymologie grecque, qu'il leur imposa. Une région dorsale relevée en dos d'àne ou en carène arrondie, et revêtue d'un velouté qui la rend imperméable, des franges fines et nombreuses qui garnissent soit les pattes postérieures, soit les bords de l'abdomen et du thorax, soit enfin, en double rangée, nne légère crête médiane de la paroi ventrale, et qui s'étalent ou se ploient au gré de l'insecte, comme de véritables nageoires, favorisent et cette attitude en supination, et la prestesse des mouvemens natatoires de la Notonecte. Puisque la nature, qui semble souvent se faire un jeu de produire des exceptions bizarres qui attesten l'immensité de ses ressources, avait condamné cet animal à passer sa vie dans une posture renversée, il fallait bien, pour le maintien de son existence, qu'elle hui donnât une organisation en harmonie avec cette attitude; c'est aussi dans ce but que la tête est fortement inclinée sur la poitrine; que les yeux, de forme ovalaire, peuvent exercer la vision en haut et en bas; que les pattes antérieures, ainsi que les intermédiaires, agiles et arquées, uniquement destinées à la préhension, peuvent se dẹ́bander en quelque sorte, à la faveur des hanches allongées qui les fixent au corps, et accrocher solidement leur proie avec les griffes robustes qui terminent leurs tarses. Pour ne point grossir ces pages, je renvoie à l'ex- 
plication des figures quelques détails de structure relatifs aux pattes postérieures et à l'abdomen.

Les Notonectes sont, dans tous leurs états, des insectes essentiellement carnassiers; et quand on les saisit sans précaution, ils font avec leur bec des piqûres fort douloureuses. Ils sont très inhabiles à la marche, et lorsqu'on les place hors de l'eau, sur le sol, on les voit toujours sauter par saccades irrégulières.

Espèce 1. Not, glaUCA. Lin. - Fabr, , l. c., p. го2. - Panz., fasc. 3, fig. 20 .

La grande Punaise a avirons. Geoffr., l. c., I, p. 476 , pl. 9 , fig. 6 .

Capite, thorace pedibusque luteo-virescentibus nitidis; scutello atro, opaco; hemelytris nunc griseo-luteis, nunc nigroferrugineis plus minusve rufo-maculatis.

Hab. in aquis stagnantibus. Long. 6 lin.

Le tube alimentaire de la Notonecte a la plus grande ressemblance de conformation et de structure avec celui des Naucores, et il présente, comme dans ces dernières, quelques variétés accidentelles de configuration. Sa longueur dépasse cinq fois environ celle du corps de l'insecte.

- L'œsophage se renfle insensiblement en un jabot conoïde 'peu marqué. L'estomac forme une dilatation allongée, plus ou moins déprimée et boursouflée, d'un blanc jaunâtre : il a des parois assez épaisses; il est suivi d'un tube filiforme plus long que lui, flexueux ou replié, d'un aspect pointillé, terminé par un renflement brusque, globuleux, assez gros (an moins lorsque l'organe est dans des conditions digestives favorables), après lequel a lieu l'insertion hépatique. Une anse intestinale d'un diamètre égal au tube filiforme dont je viens de parler, mais nullement pointillée, snccède à cette dernière insertion, et en est séparée 
par un léger bourrelet. Cette anse s'insère latéralement à une poche cæcale plus ou moins développée, et destinée à devenir au besoin une vessie natatoire : celle-ci dégénère en un conduit tubuleux qui s'ouvre à l'anus.

Les vaisseaux hépatiques de cet insecte n'offrent pas de différence appréciable avec ceux des Corises; ils sont amincis un peu avant leur insertion, et une forte lentille du microscope met en évidence leur texture variqueuse. Ils sont ordinairement blanchâtres ou semi diaphanes et très grêles.

La description que Ramdohr nous a laissée du canal digestif de la Notonecte glauque (l. c., p. 195, tab. xxiı, fig. 4, 5) s'accorde assez avec la nôtre; mais cet auteur ne fait point mention du renflement globuleux très remarquable qui termine le ventricule chylifique; ce qui tient sans doute à ce que les individus disséqués par ce savant entomotomiste avaient subi quelque jeûne prolongé. La figure qui représente cet organe est défectueuse sur plusieurs points.

\section{SECTION II. HOMOPTERES.}

M. Latreille comprend dans cette section les Hémiptères dont le bec naît de la partie inférieure de la tête, dont les hémélytres, le plus souvent en toit, sont homogènes, c'est-à-dire partout demi membranenx et d'une texture analogue à celle des ailes. Ils diffèrent autant des Hétéroptères par leur physionomie, leur genre de vie et les caractères entomologiques, que par leur organisation viscérale.

\section{FAMILLE QUATRIÈME. LES CICADAIRES.}

Cette famille, que M. le professeur Duméril a désignée sous le nom de Collirostres, à raison de la position de leur

4. Savans étrangers. 28 
bec, me paraît devoir être convertie en une tribu. Quoique les insectes qui y sont compris se nourrissent tous exclusivement du suc des végétaux, quoiqu'ils se ressemblent et par leur structure générale et par leurs habitudes, ils offrent néanmoins, soit dans les caractères purement entomologiqnes, soit dans leur organisation viscérale, plusieurs traits qui militent en faveur de leur séparation en un certain nombre de groupes naturels. Ces groupes ont été parfaitement saisis par M. Latreille; mais ils doivent constituer des familles particulières. Il y aurait alors trois de celles-ci, savoir : Ies Procigales ou Cigales chanteuses, les Fulgorelles et les Cicadelles.

J'ai publié dans les Annales des Sciences naturelles, en 1825 , mes recherches anatomiques sur quelques-uns de ces insectes. J'en reproduirai ici l'extrait, afin de ne point laisser de lacune importante dans mon travail, et j'y ajouterai ce que l'observation directe m'a appris depuis lors, soit sur ces mêmes Cicadaires, soit sur plusieurs autres genres ou espèces dont j’ai fait la dissection.

\section{PROCIGALES. \\ GENRE XXII. - $C I C A D A$, CIGALE.}

Les Cigales proprement dites sont des insectes dont les auteurs les plus anciens ont fait mention, et qui ont acquis une certaine célébrité par leur chant ou plutôt par le son rauque et monotone, la stridulation qu'elles font entendre pendant les ardeurs de la canicule. Toutefois , malgré cette célébrité, leur histoire naturelle est encore enveloppée de beaucoup d'incertitudes, et il reste à confirmer par des observations positives plusieurs faits consignés dans les ouvrages qui traitent de ces insectes. Ainsi il serait intéressant et même utile d'être fixé sur le degré de confiance qu'il faut accorder à ce passage d'Aristote 
(Hist. anim., lib. V, cap. $\mathrm{xxx}$ ) où il dit, en parlant des nymphes des Cigales, qu'il appelle Tettigometra: Gustu suavissima sunt antequam cortex rumpatur. Et plus bas, à l'occasion des Cigales elles-mèmes : Et ante coütum mares suaviores sunt; a coütu femince, quippe qua ova candida gustu habeant grata. Les Cigales étaient donc chez les anciens Grecs un mêts rechierché! Et non-seulement ce mets n'est plus usité aujourd'hui, mais nous ignorons la manière dont ils l'apprêtaient. Les savans que le Gouvernement a envoyés en Morée sous la direction M. Bory de Saint-Vincent, pour en explorer les productions naturelles et les monumens antiques, pourront peutêtre fixer nos incertitudes à ce sujet.

Les Cigales sont des insectes essentiellement habitans des contrées chaudes, et encore faut-il que celles-ci soient plus ou moins peuplées d'arbres, ainsi que l'avait très bien observé Aristote. Elles ne sauraient vivre là où cette double condition ne se rencontre point.

Espèce I. CICADA ORNI. Lin. - Panz., fasc. 5o, fig. 22.

Cigale de moyenne grandeur. Réaum., Mém., t. V, p. 15 i, pl. $x 6$, fig. 7 .

La Cigale panachée. Geoffr., 1. c., I, p. 429.

Nigrescens griseo-pulverulenta; prothoracis tergo lineolis nigris impressis variegato; mesothorace supra littera $M$ resupinata, rufo-testacea notato; segmentis abdominalibus rufomarginatis; hemely tris margine interno punctis sex nigris cum maculis quatuor interioribus anastomosantibus.

Hab. in pinetis quercetisque Gallice merid. Long. I poll.

La Cigale de l'orne est l'espèce la plus commune dans le midi occidental de la France, où il n'existe pas un seul pied d'orue; elle est surtout excessivement répandue dans 28. 
les forêts de pin maritime qui abondent entre Bayonne et Bordeaux.

Il est permis d'élever des doutes sur l'assertion répétée dans plusieurs livres, que les piqûres faites par cette Cigale à l'arbre dont elle porte le nom, déterminent l'écoulement de la manne.

Son tube alimentaire a une longueur bien plus considérable que celui des Hémiptères hétéroptères, puisqu'elle égale environ dix fois celle de son corps; il se reploie par conséquent en de nombreuses circonvolutions. Il est d'une texture fort délicate. L'œsophage se dilate insensiblement en un jabot peu prononcé. Le ventricule chylifique débute constamment par un estomac courbé en anse, à parois minces, lisses et diaphanes, dilaté à droite en un petit cul-de-sac latéral, et s'abouchant du côté opposé daus une poche oblongue plus ou moins boursouflée, soutenue par un ligament suspenseur fibro-inembraneux, tantôt plissée, ratatinée, tantôt lisse ou simplement lobée, suivant son degré de plénitude. Cette poche dégénère en arrière en un tube intestiniforme très replié, qui égale en longueur la moitié de tout le canal alimentaire, pointillé de jaune ou de blanc, allant se dégorger dans la poche elle-même, à côté de l'insertion hépatique. Cette disposition insolite du ventricule chylifique qui se dégorge dans lui-même, en constituant un cercle complet, forme le trait le plus caractéristique de l'appareil digestif des Cicadaires. L'intestin proprement dit naît du cul-de-sac de l'estomac, et présente à son origine un bourrelet valvulaire; il est filiforme, diversement reployé, et se dilate avant sa terminaison à l'anus, en une poche stercorale constante, à parois musculo-membraneuses.

Les vaisseaux hépatiques sont au nombre de quatre, très entortillés, variqueux, diaphanes et fragiles; flottans 
par un bout, ils s'insèrent isolément par l'autre entre le cul-de-sac de l'estomac et l'embouchure de la portion intestiniforme du ventricule chylifique.

EsPÈCE 2. CICADA PLEBEZA. Lin.

Tetrigona plebeia et T. fraxini. Fabr, 1. c., p. 40.

La grande Cigale. Réaum., ins., t. V, p. i5 1, pl. 16, fig. 1-6.

Nigra, thorace variegato; elytris, alis abdomineque supra immaculatis operculis magnis. Oliv., Encycl. méth., $\mathrm{n}^{\circ} 33$.

Celle-ci reconnaît plus spécialement pour patrie la zone des oliviers.

Son tube digestif n'offre aucuue différence appréciable avec celui de l'espèce précédente.

Le professeur Meckel, d'après un article consigué dans l'ouvrage de Ramdohr ( 1 ), s'est aussi occupé de la dissection de cette même espèce; mais il a donné une description bien incomplète de son organisation viscérale. $\mathrm{Il}$ attribue à la portion récurrente du ventricule chylifique (qui est pour lui l'intestin) la faculté de sécréter une humeur spéciale pour la digestion, et il parle de l'existence de six vaisseaux biliaires, qui très positivement ne sont qu'au nombre de quatre.

\section{FULGORELLES.}

L'étude de l'organisation viscérale des Fulgorelles, à laquelle je n'ai eu occasion de me livrer que lorsque j'avais déjà disséqué un assez grand nombre de Cigales proprement dites et de Cicadelles, est venue me fournir une nouvelle preuve de la circonspection qu'il faut apporter dans l'établissement des règles générales, surtout dans une science qui, ainsi que l'Entomotomie, peut être consi-

(1) Ramdohr, 1. c., p. 201.-Meckel, Beytr. z. verz. Anat. Heft, I, p. I, tab. I, fig. r. 
dérée comme étant encore au berceau. Tous les insectes de la grande famille ou plutôt de la tribu des Cicadaires, soumis jusque alors à mes vivisections, étaient remarquables par la complication de leur canal alimentaire, dont une portion récurrente s'abouche à l'estomac de manière à former un cercle complet, et dont le tube intestinal proprement dit a une origine insolite. Cette organisation singulière, ces connexions bizarres, dont l'explication physiologique n'est pas peu embarrassante, semblaient d'autant plus propres à devoir constituer un trait commun à toutes les Cicadaires, que je les avais constatées dans les plus grandes Cigales comme dans les plus petites Cicadelles; mais le scalpel porté dans les viscères des Fulgorelles a démenti cette invocation, en apparence fondée, de la loi d'analogie.

Ces derniers insectes occupent dans le cadre entomologique de M. Latreille une place intermédiaire aux Cigales et aux Cicadelles. Mais si, comme il est permis de le croire, les grandes Fulgores exotiques, telles que les $F$. laternaria et candelaria, ont un tube alimentaire organisé sur le même plan que celui de notre $F$. europaea, et si dans la classification on accorde à la considération de l'appareil digestif la valeur qu'il mérite, il faudra donner aux Fulgores la prééminence sur les Cigales, et les placer en tête des Collirostres ou Cicadaires.

\section{GENRE XXIII. - FULGORA, FULGORE.}

' Espèce i. F. EURop ÁA. Fabr., l. c., p. 5. - Panz., fasc. 20 , fig. 16 .

Fronte conica, corpore viridi, alis hyalinis reticulatis.

Fabr., l. c.

Hab. in pratis, sepibus. Long. 4 1/2 lin.

Le conduit digestif de la Fulgore européenne n'a guère 
plus de trois fois la longueur de tout le corps de l'insecte; il est d'une texture délicate et fragile comme celui des autres Cicadaires. L'assophage se dilate en un jabot plus ou moins marqué, à parois pellucides. L'estomac forme une poche ovalaire dont les boursouflures sont assez prononcées, et qui est logée dans le thorax. Un ligament suspenseur assez fort, et d'apparence charnue, se fixe d'une part à l'endroit où l'estomac dégénère en un conduit tubuleux, et de l'autre dans la tête; ce ligament, qui s'atténue en avant, peut en imposer pour le cordon ou vaisseau dorsal, mais en est bien distinct. Le tube filiforme qui succède à l'estomac, et qui, suivant moi, fait partie du ventricule chylifique, au lieu d'être récurrent et dirigé en avant ainsi qu'on le voit dans les Cigales, se fléchit en une anse latérale allongée dont les branches, rapprochées et presque partout contiguës, sont maintenues en place par d'imperceptibles vaisseaux aérifères. Après l'anse en question, le tube digestif, sans changer de diamètre ni de texture, reçoit les conduits biliaires, et presque immédiatement après se renfle en un cacum oblong, plus ou moins rempli d'une pulpe excrémentitielle verdâtre, et qui s’atténue en arrière pour se terminer à l'anus.

Les vaisseaux hépatiques s'insèrent, comme je viens de l'insinuer, un peu avant la poche stercorale; il y en a quatre très simples, moins longs et plus grêles que dans les Cigales, jaunâtres et variqueux, excepté près de leur origine, où ils sont unis et diaphanes, comme c'est l'ordinaire. Ils se dirigent en arrière, et leur bout flottant se perd dans le tissu adipeux qui avoisine le cæcum et les organes génitaux. Leur implantation ventriculaire est parfaitement distincte et à nu; elle a lieu latéralement et par paires rapprochées. 
GENRE XXIV. - CIXIUS, CIXIE.

ESPÈce 1. C. 5 - Costatus. Nob.

Niger, glaber, thoracis dorso lineis 5 elevatis, oculorum orbita, prothorace pedibusque testaceo-variegatis; hemelytris griseis, nervis subtiliter fusco-punctatis, abdominis segmentis rufo tenuiter marginatis.

Hab. in pratis siccis. Long. 2 1/4 lin.

La'Cixie à cing cótes a toute la structure et la physionomie de la $C$. nerveuse, mais elle est plus petite qu'elle et en est très distincte comme espèce, soit par les cinq lignes longitudinales saillantes de son corselet, soit par la teinte grisâtre des hémélytres. Je ne la trouve point mentionnée dans les ouvrages d'entomologie qui sont à ma disposition.

Le canal alimentaire de la Cixie ressemble parfaitement, et par sa structure et par sa configuration, à celui de la Fulgore européenne; en sorte que la description de l'un s'adopte de point en point à celle de l'autre.

Les vaisseaux hépatiques, d'un jaune soufré, très variqueux et comme articulés, sont au nombre de quatre, ainsi que dans la Fulgore; mais ils présentent cette particularité, en quelque sorte générique, qu'ils se réunissent deux à deux, avant leur insertion au ventricule, en un col bien distinct, assez long, diaphane et lisse.

\section{$\checkmark{ }^{O}$ GENRE XXV. - ISSUS, ISSUS.}

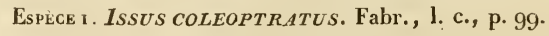

Cicada coleoptrata. Panz., l. c., fasc. 2, fig. 6. (Optima.)

La Cigale bossue. Geoffr., 1. c., I., p. 418, n 7 .

Griseo pallide virescens, hemelytris abdomine longioribus apice rotundatis medio subgibbosis, inter nervos nigro-reticulatis, puncto distincto nigro in medio alioque subsuturali notatis; alis nervoso reticulatis.

Hab. in pratis, dumetis. Long. 3-3 ז/2 lin.

Il y a entre le canal alimentaire de l'Tssus et celui des 
Fulgorelles précédentes une conformité vraiment admirable, ainsi que le prouve suffisamment la figure que j'en donne. Les vaisseaux hépatiques n'ont pas un col distinct comme daus la Cixie; ils ressemblent à ceux de la Fulgore.

\section{CICADELLES.}

Je répéterai, relativement aux Cicadelles, ce que j’ai dẻjà avancé en parlant des Fulgorelles, sous le rapport de leur classification. C'est que l'organisation de leur appareil digestif les rapproche plus des Cigales proprement dites que des Fulgores, et conséquemment les Cigales doivent être colloquées après les Fulgorelles et avant les Cicadelles.

\section{GENRE XXVI. - CENTROTÚS, CENTROTE.}

Espèce 1. C. Cornutus. Fabr., 1. c., p. 19, Panz., fasc. 5o, fig. 19 .

Le petit Diable. Geoffr., 1. c., I, p. 423, pl. 9 , fig. 2.

Thorace bicorni nigro postice subulato longitudine abdominis, alis fuscis. Fabr., l. c.

Hab. in sepibus salicetisque. Long. 3 lin.

Cet insecte sauteur, remarquable par sa construction bizarre, est trop connu pour que j'insiste sur sa description.

Le Centrote cornu a un tube alimentaire dont la configuration et la structure générales ont une grande analogie avec celui de la Cigale. Cet organe est proportionnellement aussi long, et les diverses parties qui le constituent offrent entre elles le même mode de connexion. La seule différence bien appréciable qui existe, c'est qu'au lieu de l'anse gastrique des Cigales, le Centrote n'a qu'une poche fort courte; mais celle-ci a également un cul-de-sac latéral, et elle

4. Savans étrangers. 
s'abouche de la même manière soit à l'œesophage, soit à la portion renflée du ventricule chylifique, soit à l'intestin proprement dit. Les vaisseaux hépatiques ne diffèrent pas non plus de ceux de la Cigale par leur nombre, leur forme, leur couleur et leur insertion.

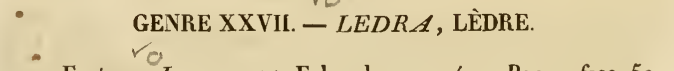

Espéce 1.L. AURITA. Fabr., 1. c., p. 24. - Panz., fasc. 5o, fig. 18 .

Le grand Diable. Geoffr., l. c., I, p. 423, pl. 9 , fig. I.

Griseo, viridirubroque variegata punctata; capite semi-rhomboideo, carina in medio lineari et tuberculo utrinque; thorace utrinque in auriculam rotundatam crenatam dilatato; scutello apice elevato; hemelytris nervosis subpunctatis.

Hab. in pratis. Rarissima. Long. 7 lin.

Le canal digestif de la Lèdre a une longueur un peu moindreque celui des Cigales, auquel il ressemble du reste par la délicatesse de sa texture et ses connexions insolites. L'œsophage se dilate en un jabot oblong bien prononcé, séparé de l'estomac par nn étranglement. Le ventricule chylifique débute par un estomac qui, au lieu d'être courbé en anse comme dans les Cicadaires chanteuses, est placé à la file du jabot, allongé, droit, ridé ou boursouflé, d'une couleur jaunâtre rouillée. Il est suivi d'un conduit tubuleux intestiniforme reployé, plus ou moins pointillé, allant par une portion récurren te s'aboucher à la partie inférieure de l'origine mème de l'estomac, de manière à former, ainsi que dans les autres Cicadelles, un cercle complet. L'intestin naît tout près de cette derrière embouchure. Il est très grêle, fort délicat, délié comme un fil, proportionaellement moins long, moins replié que celui de la Cigale, 
et remplid'une pulpe excrémentitielle blanchâtre opaque. II se renfle à peine avant sa terminaison à l'anus.

Les vaisseaux hépatiques, au nombre de quatre, sont d'une fragilité désespérante pour l'anatoniste. Ils sont diaphanes, moins variqueux que ceux des Cigales, mais ayant le même mode d'insertion ventriculaire.

\section{GENRE XXVIII. - CERCOPIS, CERCOPE.}

Espèce I. C. SANGUINOLENTA. Germ. Mag., i 818 , p. 44.

Cicada sanguinolenta. Lin. (excl. syn.)

Atra, nitida, punctata; glatra, subnitida; hemelytro singulo macula oblonga in margine scutellari, altera ante medium, rotundata discoidali, fasciaque pone medium transversa subsinuatr, rubris; abdominis dorso lateribusque, femorum apice tibiarumque basi rubris.

Hab. in graminosis Gallize meridionalis. Long. $4 \mathrm{r} / 2$ lin.

Jusqu'à préseut j'avais toujours pensé, avec la plupart des entomologistes, qu'il fallait rapporter à cette espèce les figures de Panzer, (fasc. 33., fig. I2), et de Geoffroi ( pl. 8, fig. 5); mais M. Germar regarde ces dernières comme appartenant à sa $C$. vulnerata, et croit que l'espèce linnéenne en est distincte; je me soumetsà sa décision.

Le canal digestif de la $C$. sanglante a, lorsqu'il est déployé, environ cinq ou six fois la longueur de tout le corps de l'insecte. Il a la plus grande ressemblance de configuration et de structure avec celui de la Lèdre. L'estomac est une dilatation oblongue, diaphane, plus ou moins boursouflée. Le conduit tubuleux filiforme qui lui succède, est d'abord jaunâtre ou pellucide, non pointillé; il se distingue ensuite soudainement, et peut-être par une valvule circulaire interne, d'une autre portion également filiforme, un peu plus grosse, récurrente, d'un blanc mat pointillé; couleur qui semble due à une sorte de pulpe 
chimeuse. Cette distinction, quoique constante, n'est pas toujours facilement mise en évidence. Ce tube ventriculaire se comporte comme celui des Homoptères précédens, c'està-dire qu'il remonte vers l'origine de l'estomac, où il s'abouche en s'amincissant un peu. L'intestin proprenent dit ne diffère point de celui de la Lèdre. Les vaisseaux hépatiques, pareillement au nombre de quatre, flottans par un bout, sont diaphanes et tellement variqueux, excepté dans le voisinage de leur iusertion, qu'on les croirait tordus en spirale. Ils accompagnent et entourent l'intestin comme dans la Cigale.

\section{GENRE XXIX. - APHROPHORA, APHROPHORE.}

M. Germar a imposé cette dénomination générique à un petit groupe de Cicadelles compris dans les Cercopes de M. Latreille. Des jambes postérieures à deux ergots, deux ocelles distincts, placés sur le vertex, et une carène médiane linéaire sur la tête et le corselet, en forment les traits extérieurs les plus caractéristiques. Leurs larves, qui habitent sur les plantes, ont la singulière faculté de sécréter une humeur écumeuse au milieu de laquelle elles vivent. C'est cette habitude qui leur a valu le nom d'Aphrophore, qui signifie porte-écume, et celui de baveuses, sous lequel les jardiniers les connaissent.

\section{ESYÈCE 1. A. SPUMARIA. Germ.}

Cercopis spumaria. Fabr., 1. c., p. $9^{5}$.

La Cigale bedeaude. Geoffr., I., p. 416.

Grisea, nigro-impresso-punctata, hemelytris nigrescentibus maculis duabus lateralibus albo-hyalinis; abdomine nigro dorso rufécente.

Hab. in hortis, pratis, etc. Long. 4. lin.

Le conduit alimentaire des Aphrophores est encore 
formé sur le même plan général d'organisation que celui des Cicarlelles précédentes. Comme dans mon travail précité sur l'anatomie des Cigales, j’ai aussi publié la description de l'appareil digestif de l'Aphrophore écumeuse, je me dispenserai de la reproduire ici, et j'y suppléerai avantageusement pour la science par celle de l'Aphrophore des saules.

EsPÈce 2. APHROPHORA SALICINA.

Cicada salicina. Gmel, in Lin. Syst. nat., ed. 13, p. 2109.

Cicada spumaria salicis. Deg., ins. 3, p. $180, \mathbf{n}^{\circ}$ 2. (ex Gmel.)

Griseo-testacea, subvirescens, unicolor, subtiliter impressopunctata; hemelytro singulo pone medium puncto discoidali pallide flavescente vix distincto; abdomine nigro, segmentis margine rufescentibus, pedibus rufescentibus.

Hab. frequentissime in salicetis (St-Sever). Long. 4 lin.

Elle a la forme, la grandeur, la physionomie, et tous les traits génériques de l'Aphrophore écumeuse; mais elle en est très distincte comme espèce. Les hémélytres ont une couleur grise testacée, verdâtre, uniforme. La loupe y découvre de très petits points calleux jaunâtres qui donnent naissance à un poil fort court, et l'œil nu en aperçoit un plus grand et constant, placé un peu au-delà du milieu sur la nervure médiane; mais peu apparent. Les ailes, à peine enfumées, ont les nervures noires.

Cette espèce, omise dans les ouvrages de Geoffroi, de Fabricius, d'Olivier et de M. Latreille, n'avait pas échappé, à ce qu'il paraît, aux recherches de de Géer. Elle est extrêmement commune daus nos saussaies.

Le canal digestif de l'Aphrophore des saules ressemble beaucoup à celui de la Cercope, et conséquemment à celui des Cigales propres. Sa longueur ne dépasse pas plus de quatre ou cinq fois celle de tout le corps de l'insecte. Aus- 
sitôt après avoir franchi le prothorax, l'œsophage se dilate en un jabot assez ample qu'une contracture bien marquée sépare de l'estomac. Celui-ci ne m'a offert aucune trace ni du bourrelet en godet ni de la poche particulière ridée ou boursouflée que j'ai signalés dans l'Aphrophore écumeuse. Cette première poche gastrique est une dilatation simple, de forme variable, à parois translucides, qui dégénère insensiblement en arrière en un long canal filiforme plus ou moins flexueux ou reployé qui rebrousse chemin, en un mot, qui devient récurrente pour aller s'aboucher dans l'estomac. Ce canal, dans ce trajet circulaire, n'offre pas partout la même organisation. Sa première portion, ou celle qui succède immédiatement à l'estomac, présente constamment dans une certaine étendue un peu plus de grosseur, une texture plus délicate, et, ainsi que dans le Cercope, un pointillé particulier qu'on serait tenté de regarder comme formé par des cryptes muqueux nichés dans l'épaisseur de ses tuniques. Cette portion pointillée est séparée par un léger bourrelet, indice présumé d'une valvule annulaire, d'une autre portion lisse, unie, plus déliée, à parois peut-être plus denses, allant s'insérer brusquement ou plutôt s'implanter dans l'estomac, non loin de l'origine de celui-ci. Vis-à-vis cette implantation, mais sur un côté opposé, naît l'intestin proprement dit, sous la forme d'un tube plus grêle que le canal précédent, lisse, imponctué, qui, après quelques flexuosités, se termine par une poche excrémentitielle oblongue qui précède l'anus.

Les vaisseaux hépatiques de notre Aphrophore ont la plus grande ressemblance, soit par leur texture, soit par leur mode d'insertion, avec ceux de la Cigale. Ils frappent l'reil de l'entomotomiste par leur couleur d'un brun chocolat violacé, et par les festons réguliers que leurs bords offrent à la loupe, excepté à leur origine où ils sont incolores et 
SUR LES HÉMIPTÉRES.

lisses. Il y en a quatre bien distincts, mais tellement entortillés autour de l'intestin, qu'il est difficile de les dérouler saus les rompre; flottans par un bout qui est fermé, on, comme on dit, borgne, ils prennent naissance par l'autre, à côté de l'origine de l'intestin.

\section{FAMILLE CINQUIÈME. LES PSYLLIDES.}

M. Latreille, dans son Genera, en I 807 , avait fondé une famille distincte des Psyllides avec les genres Psylla et Livia. Il avait parfaitement jugé alors, d'après la structure extérieure, les habitudes et le genre de vie de ces insectes, qu'ils devaient constituer un groupe isolé et bien circonscrit formant la chaîne d'union et de séparation entre les Cicadelles et les Pucerons. Cet illustre entomologiste, trop facilement entrainé depuis par des idées de réduction, a compris, en 1829 , ces mèmes insectes dans la famille des Aphidiens, à la tête desquels il s'est contenté de les placer.

La situation et la forme de leur bec, la composition de leurs antennes, leurs ocelles, leur métamorphose, la structure de leurs pattes, propres à sauter, enfin leur organisation splanchnique, revendiquent à juste titre le maintien ou le rétablissement de la famille naturelle des Psyllides, en lui conservant, dans le cadre entomologique, la place qui lui a été assignée par M. Latreille.

\section{GENRE XXX. - PSYLLA, PSYLLE.}

Geoffroi, qui le premier institua ce genre aux dépens de quelques Chermes de Linné, y a compris des insectes assez dissemblables entre eux, pour autoriser l'établissement de nouvelles coupes génériques, lorsqu'on se donnera la peine de les soumettre à une étude spéciale comparative. 
Espéce I. PSYLLA FICUS. Latr., Hist. nat., t. XII, p. ${ }^{379}$. La Psylle du figuier. Geoff., Ins. Par. , I, p. 484, pl. 10 , fig. 2. Le faux Pugeron du figuier. Réaum., Mém., t. III, p. 35 i, pl. 29, fig. $17-24$.

Chermes ficus. Lin. - Fabr., 1. c., p. 506.

Nunc virescens, nunc subtestacea; antennis villosis crassiusculis articulo ultimo minuto emarginato bisetoso; ocellis rubicundis; hemelytris diaphanis, nervis distiche ciliatis; tibiis posticis apice uno latere serrato-pectinatis; scutello bispinoso; metathorace subtus utrinque unicuspidato, unguibus antennarumque apice atris.

Hab. in ficu carica. Long, vix 2 lin.

On voit, par ce signalement, que cet insecte, quoique connu et décrit par plusieurs auteurs, avait été peu sévèrement étudié; il varie par sa couleur, et ces variations sont indépendantes du sexe : tantôt il est entièrement vert, et tantôt d'un roux pâle ou livide, avec le ventre verdâtre. Parmi les individus verts, il en est qui ont la région dorsale de l'abdomen très noire, et d'autres dont le tergum du thorax est marqué de taches roussâtres. Les antennes, constamment d'un roux obscur, et fortement hérissees de poils noiràtres, sont d'une épaisseur uniforme dans toute leur étendue; l'insecte les tient dirigées en avant et un peu divergentes. Filles sont composées de dix articles bien comptés, cylindroïdes, à l'exception du premier qui est plus gros, plus court, plus ou moins arrondi; et du deruier, qui, en quelque sorte rudimentaire, est fort petit, un peu comprimé, échancré en avant, avec une soie divergente et raide aux pointes de l'échancrure. Le troisième article est le plus long de tous. Les yeux, assez grands, saillans et brunâtres, sont tout-à-fait latéraux et distans. Les ocelles, au nombre de trois, dont 
un derrière chaque œil, et le troisième au-dessous de l'échancrure du front, ressemblent à de très petits rubis. Le prothorax est fort étroit, presque linéaire. L'extrémité postérieure du métathorax, ou l'écusson, est constamment terminée par deux pointes distinctes, un peu relevées, qui, au premier coup d'œil, semblent appartenir à l'abdomen, qu'elles débordent un peu. La partie de la région sternale du métathorax, que M. Audouin désigne sous le nom d'épimère, est large, et se termine en arrière par un stylet particulier, spiniforme, dont les auteurs n'ont point parlé, et qui doit servir soit à produire, soit à favoriser l'action de sauter. Ce caractère s'observe aussi dans la Psylle de l'aune, qui est d'ailleurs une espèce très distincte de celle du figuier. Les pattes sont ou verdâtres ou roussâtres; mais les ongles, ainsi que les quatre ou cinq dents de peigne acérées et unilatérales qui s'observent à l'extrémité tarsienne du tibia, sont noirs. Ce dernier trait, qui n'est point mentionné dans les ouvrages, n'est pas étranger à la production du saut. Le bec de notre Psylle n'est point placé, comme l'avancent la plupart des entomologistes, précisément entre les pattes antérieures, mais en arrière de cette double articulation, comme l'avait très bien ohservé Geoffroy. Les hémélytres ou ailes supérieures dont je présente ici une figure très exacte, sont diaphanes, avec quelques mouchetures noirâtres à leur bord supérieur ou interne, et parfois une teinte brune qui accompagne quelques nervures. Je renvoie à l'explication des figures ce qui concerne ces dernières, qui sont bordées de barbes ou de cils couchés fort remarquables.

Cet insecte n'est pas rare sur le figuier; il se tient habituellement soit à la face inférieure des feuilles, soit le long des jeunes pousses, qu'il suce pour sa nourriture. 
Il y demeure presque immobile, mais il se dérobe en santant avec prestesse aussitôt qu'on cherche à le saisir avec les doigts. Il commence à paraître vers la fin de mai, et on en trouve encore d'accouplés vers la mi-octobre. Je suis porté à croire que dans cet intervalle de temps il se produit plus d'une génération. Les plus grands individus acquièrent à peine deux lignes de longueur.

Il serait superflu d'insister sur la description de la larve, que notre inimitable Réaumur a fait connaître avec son exactitude accoutumée. J'ajouterai seulement à ce qu'il en a dit, que ses antennes sont d'une seule pièce et velues en-dessus.

La dissection de la Psylle s'accompagne de difficultés incroyables; et je suis forcé d'avouer que, malgré une patience cent fois éprouvée, il me reste encore quelques doutes, quelques incertitudes sur son organisation viscérale.

Dans tous les animaux en général, c'est à la tête que l'appareil digestif prend naissance. La Psylle, avec un petit nombre d'autres insectes, forme une exception remarquable à cette règle: sa tête n'offre aucune trace ni de bouche, ni de suçoir. Nous venons de voir que son bec est situé sous le thorax, un peu en arrière de l'articulation des pattes antérieures; c'est donc de ce point que part son tube alimentaire. La configuration singulière, les connexions insolites de ce dernier organe, ne sont pas moins faites pour exciter notre surprise et notre embarras, que celui de la Cigale et des Cicadelles. L'cesophage a une si grande ténuité, il est si démesurément long, si diaphane, si fragile, qu'il se dérobe le plus souvent aux investigations les plus attentives, et $j$ 'avais déjà disséqué plus de vingt individus, que je désespérais de pouvoir me fixer positivenent sur sa direction et ses 
rapports; mais enfin j'ai eu la rare satisfaction de le voir dans toute son intégrité. Plus délié qu'un cheveu, il se porte, d'un trait, depuis l'origine $\mathrm{du}$ bec jusque vers le tiers postérieur du corps; là il s'insère à un renflement plus ou moins prononcé, qu'à raison de sa position j'ai long-temps cru faire partie de l'intestin proprement dit, et qui doit cependant porter le nom d'estomac. Celui-ci paraît effectivement postérieur à une autre portion du canal digestif qu'il précède dans les autres insectes; en sorte que, dans la Psylle, la plus grande partie de l'organe alimentaire semble avoir éprouvé un renversement de haut en bas ou plutôt d'avant ell arrière. L'estomać. ou cette première poche gastrique où s'abouche l'œsophage, dégénère en un tube court, plus ou moins boursouflé, ployé sur lni-même, qui se dirige d'arrière en avant pour se continuer en un anneau ou collier qui représente la portion récurrente des Cigales. Cet anneau, dont les parois sont minces, lisses et pellucides, forme la partie la plus grosse, la plus apparente de tout l'appareil digestif. Le microscope y découvre çà et là des espèces de mouchetures blanches qui ne sont que des flocons alimentaires coagulés, contenus daus sa cavité. L'une des denx moitiés de cette anse annulaire, et j'ai toujours trouvé que c'était la gauche, s'amincit un peu en arrière pour recevoir les vaisseaux hépatiques. Immédiatement à côté de l'insertion gastrique de l'cesophage, par conséquent tout près de l'origine de l'estomac, naît l'intestin proprement dit, conduit tubuleux très délié, capillaire, qui se porte en arrière, et ne m'a présenté aucune dilatation appréciable.

Je n'ai encore rencontré dans aucun insecte des vaisseaux hépatiques aussi courts que ceux de la Psylle. Ils sont en quelque sorte rudimentaires, et annoncent 
d'avance que cet organe cessera d'exister dans des insectes voisins, mais placés plus bas dans l'échelle animale. Nous verrons bientôt qu'en effet les Pucerons n'offrent aucun vestige d'appareil biliaire. Cette considération, qui a beaucoup de valeur dans la classification anatomique, devrait peut-être engager à placer les Psyllides immédiatement avant les Aphidiens proprernent dits, et à donner la prééminence sur elles à la Dorthésie, où nous allons trouver un organe hépatique bien mieux caractérisé. Quoi qu'il en soit, les vaisseaux biliaires de la Psylle sont, malgré leur briéveté, assez gros et très apparens. Il y en a quatre bien distincts, assez distans l'un de l'autre, insérés séparément et en quelque sorte implantés à nu sur cette portion de l'anneau ventriculaire, qui est un peu atténnée. Leur insertion a lien d'une manière irrégulière, c'est-à-dire qu'elle ne se fait pas, comme dans les autres insectes, sur une même ligne circulaire : l'inspection des figures rend cette disposition patente. J'ai rencontré ces vaisseaux le plus souvent d'un jaune plus ou moins foncé, quelquefois d'un vert émeraude dont l'intensité est variable. Ils sont variqueux, comme festonnés, et leur bout libre et borgne est assez obtus.

\section{GENRE XXXI. - DORTHESIA, DORTHÉSIE ( 1 ).}

C'est avec beaucoup d'hésitation que $\mathbf{M}$. Latreille, dans son dernier ouvrage ( 1829 ), a conservé la Dorthésie parmi les Grallinsectes, et il termine l'article qui la concerne en disant que cet insecte est plus voisins des Pucerons que des Cochenilles. Ses tarses, d'un seul article et terminés par un seul crochet, la rapprochent sans doute

(1) Genre isole. 
de ces derniers; mais le nombre des articles des antennes, la locomobilité constante des femelles, et l'absence de toute mutation considérable de forme, l'en éloignent beaucoup. Ces derniers caractères, un bec court placé dans l'entredeux des pattes antérieures, et quelques traits de son organisation splanchnique, lui donnent de l'analogie avec les Psyllides. Mais des viscères qui ont un degré de plus de perfection que ceux de ces dernières, et surtout le développement de l'organe hépatique, semblent lui revendiquer, dans le cadre entomologique, une place avant la Psylle, ainsi que je viens de le faire remarquer à l'article de celle-ci. Toutefois je pense que, dans l'état présent de la science, la Dorthésie forme un genre isolé qui ne saurait encore être incorporé dans les familles établies, et qui, par des découvertes ultérieures, pourra sans doute constituer un groupe particulier.

Il paraît que les yeux de la Dorthésie ont éludé les investigations des divers entomologistes qui ont décrit cet insecte, car il n'en est point fait mention dans leurs ouvrages. Ces organes de la vue consistent en deux boutons saillans, oblongs, oliviformes, lisses, c'est-à-dire non réticulés, placés sur les côtés de la tète, un peu en arrière de l'insertion des antennes. Celles-ci sont filiformes, dirigées habituellement en avant, et composées de huit articles seulement, cylindroïdes, dont le premier est plus gros et plus court que les autres. Les tarses ne sont très positivement formés que ả'un seul article, et celui-ci se termine par un ongle unique modérément arqué. Le bec est court, assez gros, obtus, hérissé de quelques poils, placé entre les articulations des pattes antérieures. Il n'y a point d'oviscapte. 
Espèce i. Dorthesia CHARACIAs. Bosc. - Latr. Gen. Cr. et Ins., t. III , p. 173 .

Coccus ciraracias. Dorth., Journ. de Phys. (1785). - Oliv., Encycl. méth., Cochenille, $\mathrm{n}^{\circ} 19$.

Coccus dubius. Fabr. - Panz., fasc. 35, fig. 2 I (bona).

Femina. - Aptera, lamellis niveis ceraceo-amylaceis nunc squamiformibus seriatim imbricatis, nunc in caudam sacciformem crassam retusam sulcatam coadunatis eleganter obtecta; pedibus antennisque nudis fusco-piceis.

Hab. in euphorbia characias, rubo, urtica, geranio, etc. Long. 2 I/2 lin.

Tout le corps de cet insecte est enveloppé, cuirassé par une substance d'un blanc pur, d'un aspect semblable à l'amidon, d'une consistance concrète, solide, analogue à celle de la cire, glabre et nullement cotonneuse ni duvetée, élégamment disposée par lamelles ou écailles d'inégale longueur, mais symétriquement rangées, que l'on peut enlever sans blesser l'animal. La région dorsale offre quatre séries de ces lamelles, dont les extérieures, plus longues, se contournent un peu en approchant de la partie postérieure. La tête est abritée par deux tubercules conoïdes de cette substance. La queue, dont la longueur surpasse celle de tout le corps, est un grand sac obtus, trouqué, que l'on peut détacher tont d'une pièce. Elle est cannelée en-dessus, unie en-dessous; et dans les femelles fécondées elle renferme un duvet cotonneux où sont déposés les ceufs. I,es pattes sont nues et brunâtres, ainsi que les antennes, et la loupe y découvre des aspérités qui sont de petits poils raides.

L'enveloppe de la Dorthésie lui donne une forme et une grandeur qui sont loin de représenter celles de son propre 
corps. Panzer l'a bien figurée avec son test on sa cuirasse. Le dessin (fig. 102) que joffre de cet insecte dépouillé de celle-ci, pourra servir à compléter son histoire; son corps n'a pas alors plus d'une (ligne et demie de longueur. II est arrondi, légèrement déprimé sur les côtés, et composé de dix segmens (sans y comprendre la tête) qui imitent des rides transversales. Les cinq premiers sont un pen plus larges que les quatre suivans. Le dernier est enchâssé dans une large échancrure de celui qui le précède, et est percé d'un trou qui doit être ou la vulve ou l'anus. L'enveloppe cutanée de cet insecte est roussâtre, et, soumise au foyer du microscope, elle paraît toute convertc de très petites aspérités qui servent à fixer les lamelles du test.

Toutes mes recherches pour découvrir un mâle de la Dorthésie ont été infructueuses jusqu'à ce jour. J'attacherais un grand prix à la connaissance et surtout à la dissection de ce sexe, que Dorthès et, d'après lui, Olivier, disent dépourvu de bec, par conséquent condamné à ne point prendre de nourriture. Il est permis d'élever des dontes sur cette assertion.

Lorsqu'on pratique sur le dos de cet insecte une légère incision qui n'intéresse absolument que la cuticule, on voit s'échapper une humeur noirâtre qui, dans l'eau, se convertit en une pulpe incohérente d'un gris vert. Celleci m'a semblé logée entre la pean et une membrane sous-jacente péritonéiforme assez épaisse et d'un tissu comme spongieux. On peut présumer que ce dernier est l'organe essentiellement sécréteur de la matière du test, laquelle, après avoir été convenablement élaborée, est transmise au dehors ou exsudée par les pores de la peau, qui la modèlent en même temps.

L'appareil digestif de la Dorthésie a bien plus d'analogie avec celui des Cicadelles et de la Psylle qu'avec celui 
des Pucerons, et je répète encore ici que le développement de son organe hépatique lui donne, dans la méthode naturelle, la prééminence sur la Psylle. Son tube alimentaire naît, comme dans cette dernière, entre les insertions des pattes antérieures, où se trouve le bec. Il est proportionnellement plus long que celui des Pucerons, et s'il était déployé il aurait environ trois fois la longueur du corps de l'insecte. L'asophage, bien plus court que celui de la Psylle, est à son origine d'une ténuité plus que capillaire. Il m'a paru ensuite à peine renflé en un jabot oblong. Il s'abouche brusquement à un estomac d'abord dilaté, puis se continue en un tube grêle comme un fil, à parois minces et pellucides, se courbant pour revenir en sens inverse de sa première direction, en un mot, récurrent, et allant se terminer, par une insertion à nu, non loin de son origine, de manière à former un cercle complet. L'intestin proprement dit, naît, comıne celui des Cigales, de l'estomac lui-même, par une implantation brusque vis-à-vis du point où se termine la portion récurrente du ventricule chylifique. Il est d'abord grêle comme un cheveu, assez long, et va s'insérer sur le côté et presqu'à l'extrémité postérieure d'une poche en cul-de-sac, oblongue, semblable à la vessie natatoire de quelques insectes aquatiques. Cette bourse cæcale, que j’ai trouvée remplie d'un liquide excrémentitiel clair comme de l'eau, dépasse de beaucoup, par son extrémité borgne et arrondie, l'insertion de l'intestin grêle, puis elle s'amincit en arrière pour aller se terminer à l'anus.

L'organe hépatique de la Dorthésie a une coufiguration, un développement et un mode d'insertion qui lui sont propres, et qui forment un des traits remarquables de son organisation viscérale. Lorsqu'on fait l'ouverture 
de l'abdomen par la région dorsale, c'est le premier viscère qui se présente au scalpel, et il égale presqu'en grosseur le tube alimentaire lui-même. Il consiste en deux vaisseaux biliaires, grands comparativement à la taille de l'insecte, variqueux, comme entrecoupés d'espace en espace, de couleur blonde ou roussâtre, reployés chacun en une anse ou plutôt en un anneau qui se prolonge jusqu'à l'extrémité postérieure de l'abdomen, aboutissant tous deux à un seul commun, fort court et décoloré, qui se fixe vers le milieu de la portion récurrente du ventricule chylifique. On voit que ce dernier siége d'insertion s'observe aussi dans la Psylle, et cette considération anatomique justifie le rapprochement de ces deux genres d'insectes dans le cadre entomologique.

\section{FAMILLE SIXIÈME. LES APHIDIENS.}

En abordant l'histoire anatomique des Pucerons, de ces insectes que les prodiges de leur fécondité innée et en quelque sorte virginale, et de leur génération vivipare, ont rendus célèbres; de ces insectes qui ont exercé la sagacité, la patience des Leeuwenhoek, des Bonnet, des Réaumur, des Lyonet, et tout récemment encore de M. Duvau (I), on s'écrie avec Pline, Rerum natura nusquam magis quam in minimis tota est! Il était en effet réservé à ces êtres qui, par leur petitesse, leur obscurité, et surtout leur conservation difficile pour les collections, semblaient voués au mépris ou à l'indifférence, d'attirer, de fixer l'attention soutenue des plus graves observateurs, et de dévoiler au zoologiste les phénomènes organiques les plus singuliers, les problèmes physiologiques les plus irrésolubles.

(1) Nouvelles Recherches sur l'Histoire naturelle des Pucerons (présentées à l'Académie des Sciences, ${ }_{1825}$ ).

4. Savans étrangers. 
Je répéterai ici ce que j’ai déjà dit, à l'occasion des Psyllides, que les Aphidiens doivent, dans un cadre entomologique basé sur les rapports naturels, constituer une famille parfaitement distincte de la précédente, ainsi que M. Latreille l'avait d'abord établie dans son Genera. Toutefois, on n'y comprendra point le genre Thrips, qui, d'après les observations de M. Straus, devra peut-être rétrograder ver's un autre ordre d'insectes.

\section{GENRE XXXII. - APHIS, PUCERON.}

Malgré tout l'intérêt qu'ont inspiré les Pucerons aux scrutateurs de la nature, il est vrai de dire qu'on s'est plus occupé à étudier leurs mœurs, leur genre de vie et leur mode de propagation, qu'à déterminer rigoureusement leurs nombreuses espèces, et à y établir de nouveaux genres que semble réclamer l'état actuel de l'entomologie. Je partage, sous ce rapport, le sentiment de MM. Lepeletier et Serville, auteurs de l'article Puceron, dans l'Encyclopédie méthodique.

Les espèces, sur lesquelles j’ai plus spécialement dirigé mes investigations anatomiques, sont les suivantes :

EsPÈce. 1. APHIS ROSA. Lin.

Le Puceron du rosiek. Réaum., Mem., t. III , pl. 21 , fig. 1-4.

Ovato-oblongus, antice attenuatus, virescens; abdomine bicorniculato; corniculis elongatis subteretibus nigris; appendice anali ovato-oblongo virescenti; antennis setaceis corpore longioribus; alis diaphanis.

Hab. in rosa summitatibus. Long. I lin.

EsPĖCE 2. APHIS PAPAVERIS. Fabr., Ent., syst. IV , p. 218.

Ovatus nigro-carbonarius opacus, antennis pedibusque pallidis; antennis setaceis corpore longioribus; abdomine bicorniculato, comiculis concoloribus teretibus; appendice anali subclavato, alis diaphanis costa virescenti.

Hab. in papavere somnifero, blito vulgari, etc. Long. I lin. 
ESPÈCE 3. APHIS LONGIPES. Mihi.

Ovatus, niger, obscurus, glaber, nudus; antennis piceis sex articulatis corpore brevioribus; articulo ultimo exciso-subulato; prothoracis dorso plano transverso utrinque impresso; rostro thorace vix longiore; abdomine bituberculato; ano inermi, pedibus piceo-nigris, tibiis posticis longioribus arcuatis: alis maculis cluabus magnis atris subfenestratis.

Hab. in summitatibus quercus tauzin et quercus roboris. Long. I $1 / 2 \mathrm{lin}$.

Ce n'est ni l'A. quercus, ni l' $\mathcal{A}$. roboris des auteurs.

EsPÈce 4. APHIS PINI MARITIMA. Mihi.

Ovatus nigro-obscurus, plus minusve albo-farinosus, villosulus; antennis sex art iculatis corpore brevioribus; rostro corporis fere longitudine; metathoracis dorso trituberculato; pedibus posticis longioribus; alis diaphanis costa obscure virescenti.

Hab. in summitatibus pini maritince, Long. $11 / 2$. lin.

Il est distinct de l' $A$. pini de Linnæus, figuré par Panzer (fasc. $9^{5}$. fig. i 7.$)$; mais il pourrait bien se rapprocher de l'A. pineti. Fabr., Ent., syst. IV, p. 219.

Cette espèce, ainsi que la précédente, rentre avec les A. picea, pini, populeti, de Panzer, et autres analogues, dans la seconde division judicieusement établie par M. Latreille, dans son Genera, et qui peut être convertie en un genre propre.

Les Pucerons, ordinairement réunis par sociétés, par troupeaux, ou, pour parler plus correctement, par tribus, s'établissent sur les sommités tendres des plantes, ou sur les feuilles des arbres. Ils y enfoncent leur bec et y puisent les sucs végétaux les plus subtils. Quelques-uns d'entre eux, inoculant sans doute dans le tissu végétal quelque humeur âcre spéciale, y déterminent des irritations nu- 
tritives, des excroissances, des espèces d'hy pertrophies qui prennent des formes plus ou moins constantes, le plus souvent caverneuses ou vésiculaires.

L'appareil digestif des Pucerons présente une exception fort remarquable, unique, suivant moi, je ne dis pas seulement dans l'ordre des Hémiptères, mais même dans la classe entière des insectes; c'est l'absence absolue des vaisseaux hépatiques. Ce trait négatif forme le caractère anatomique le plus distinctif de la famille des Aphidiens. Et qu'on ne s'imagine point que la petitesse de ces animaux soit un obstacle à la découverte des conduits sécréteurs de la bile. Dans les nombreuses autopsies entomologiques auxquelles je me suis.livré, j’ai très souvent mis en évidence cet organe dans des insectes du double plus petits que les Pucerons. Il en est même parmi ces derniers qui ont une taille très favorable aux dissections, tels que le Puceron longipède, celui du pin maritime, celui du sau$l e$, etc. Ramdohr ( $\mathrm{r}$ ), qui a décrit et figuré le canal alimentaire d'un Puceron du pommier, ne fait non plus aucune mention de l'appareil biliaire de cet insecte. Enfin, ce qui. me semble une preuve assez solide de la non-existence de cet organe, c'est que dans les $P$ sylles, qui précèdent les Pucerons dans le cadre entomologique, les vaisseaux hépatiques offrent déjà une dégénération très marquée, et sont réduits à un état rudimentaire.

Le tube alimentaire des Pucerons a environ trois fois la longueur du corps de l'insecte, et forme par conséquent dans sa position naturelle plusieurs circonvolutions. L'œsophage a une ténuité plus que capillaire, et son insertion à l'estomac est le plus souvent brusque, c'est-à-dire qu'il y

(1) Abhandlung über die Verdaungs werkzeuge der Insecten, p. 198, tab. xxvi, fig. 4 . 
paraît implanté. Cette dernière poche gastrique se présente sous la forme d'une dilatation plus ou moins prononcée, suivant certaines conditions digestives, et peut-être aussi suivant les espèces. Je l'ai constamment trouvée ovoïde ou turbinée dans les Pucerons du rosier et du pavot, tandis qu'elle est à peine sensible dans le $\boldsymbol{P}$. longipède, et dans celui du pin maritime. L'estomac dégénère ou se continue en un conduit tubuleux filiforme, reployé, rempli d'une pulpe blanchâtre homogène. Ce tube, avant sa terminaison à l'anus, se renfle de nouveau en un cæcum oblong constant, que j'ai très souvent trouvé plein d'une humeur excrémentitielle limpide.

La texture du tube digestif des Pucerons est musculomembraneuse, fort délicate, et cet organe est lisse à l'extérieur, c'est-à-dire dépourvu de papilles et de villosités.

\section{FAMILLE SEPTIÈME. LES GALIINSECTES.}

GENRE XXXIII. - COCCUS, COCHENILLE.

Je n'ai point, relativement aux Gallinsectes, d'observations anatomiques qui me soient propres; mais pour ne point laisser dans mon travail une lacune importante, j'emprunterai au traité intéressant de Ramdohr, sur les organes digestifs des insectes (I), ce qui concerne le tube alimentaire de la Cochenille de laune. (Coccus alni. Lin.) Cet organe a la plus grande analogie de forme et de texture avec celui des Pucerons. Sa longueur égale trois fois celle du corps de l'insecte. L'oesophage est court et capillaire. L'estomac présente d'abord un renflement ovalaire, puis dégénère en un tube filiforme reployé. Une dilatation allongée que l'auteur désigne sous le nom d'in-

(i) L. c., p. 198, tab. xxvi, fig. $2-3$. 
testin gréle, succède au tube précédent, et se termine par un rectum moins gros que lui, marqué de plis transversaux.

Ainsi que dans les Pucerons, il n'existe dans cette Cochenille aucune trace de vaisseaux biliaires.

\section{ARTICLE II.}

\section{Des Glandes salivaires.}

Quand on inquiète ou qu'on irrite un Hémiptère, avec le soin d'examiner attentivement son bec, on voit se présenter à l'extrémité de celui-ci une gouttelette d'un liquide incolore et inodore qui est une véritable salive. J'ai déjà, daus des écrits publiés à diverses époques, signalél'existence, jusqu'alors peu ou mal connue, d'un appareil organique propre à la sécrétion de la salive, dans un grand nombre d'insectes d'ordres différens. Ainsi on le trouve, sous une forme simplement rudimentaire, dans quelques familles des Coléoptères, notamment dans les Mélasomes, les Taxicornes, les Trachélides, les Rhincophores et les Aphidiphages. Il est bien mieux conditionné dans les Orthoptères, les Hyménoptères, les Diptères, les Lépidoptères et plusieurs Aptères. Mais c'est surtout dans la plupart des Hémiptères que l'appareil salivaire revêt les caractères propres à un organe essentiellement sécréteur, puisqu'il se compose $1^{\circ}$ de glandes proprement dites, où s'élaborent les matériaux primitifs de la sécrétion; $2^{\circ}$ de conduits $e x$ créteurs destinés à verser dans la bouche, ou à l'origine de l'cesophage, le liquide sécrété; $3^{\circ}$ enfin le plus souvent de réservoirs ou bourses pour le séjour et la conservation de celui-ci.

Ramdohr (I) a consacré, dans les généralités de son

(1) $L$ c., p, 54 et suiv. 
ouvrage précité, un paragraphe à l'appareil salivaire des insectes, et il l'a décrit aussi à l'article qui concerne chaque espéce; mais ce savant entomotomiste a, dans la plupart des cas, incomplètement vu cet organe, et mal saisi, je pense, les attributions des diverses parties qui le constituent. C'est ainsi que dans les Cimex, il désigne sous le nom de réservoir ou vésicule l’organe que je regarde comme sécréteur et que j'appelle glande, tandis que les véritables réservoirs sont simplement qualifiés par lui de vaisseaux salivaires.

Les glandes salivaires des Hémiptères ne sont point toujours, comme celles des animaux des classes supérieures, situées à la tête dans le voisinage de la bouche. Disposées de chaque côté du tube ảlimentaire, et suspendues par leurs canaux excréteurs, elles occupent la cavité du thorax et atteignent même quelquefois celle de l'abdomen. Ce n'est point dans la bouche qu'elles versent le produit de leur sécrétion, puisqu'il est reconnu que ces insectes n'ont pas de cavité buccale; mais bien à l'origine de l'œsophage, de nuanière que la salive se mêle aux alimens soit à leur passage, soit dans le jabot, lorsque celui-ci existe. La configuration et la texture de cet appareil présentent, suivant les familles et les genres, des différences ou des modifications dans l'exposition desquelles je vais entrer.

La Scutellère rayée a une paire de glandes salivaires situées, une de chaque côté, dans la cavité du thorax, où elles sont libres, en quelque sorte flottantes, et maintenues seulement par des trachées et les conduits excréteurs. Chacune de ces glandes est un corps, une espèce de sachet assez grand comparativement aux organes sécréteurs des insectes en général. Sa forme est irrégulière, mais bien circonscrite et assez élégante; sa couleur d'un blanc opaloïde ou semi diaphane, sa texture vésiculeuse en appa- 
rence, mais celluleuse à l'intérieur; sa consistance callosogélatineuse, sa surface lisse, son enveloppe formée par une membrane pellucide assez épaisse. Cet organe sécréteur, plus ou moins déprimé, est bilobaire, c'est-à-dire formé de deux lobes, l'un antérieur, l'autre postérieur, adossés et sans doute communiquant ensemble par leurs bases tronquées, d'où partent les conduits excréteurs. Le lobe antérieur est simple, terminé en avant en une pointe obtuse semblableà un doigt de gant, dilaté en arrière, et plus ou moins sinueux sur un de ses bords latéraux. Le lobe postérieur, plus grand que le précédent, est dilaté en avant et divisé sur ses côtés en plusieurs digitations allongées semblables à des boyaux borgnes. De ces digitations les unes sont simples, les autres inégalement bifides. Cette glande offre à la loupe une surface élégamment brodée par des ramifications trachéennes qui partent d'un tronc commun, divisé en deux branches pour chacun des lobes de l'organe.

Les conduits excréteurs sont au nombre de deux pour chaque glande salivaire, un pour le lobe antérieur, un autre pour le postérieur. Ils ont la finesse d'un cheveu. Leur insertion a lieu à la surface inférieure de l'organe, à l'endroit où les deux lobes de celui-ci s'adossent. De cette double insertion isolée ils vont s'ouvrir à l'origine du tube digestif de l'insecte. Ils sont l'un et l'autre du même diamètre, de la même structure; mais celui qui appartient au lobe postérieur est infiniment plus long et fléchi en nombreux festons, ordinairement accolés contre la paroi inférieure du canal alimentaire. Ces conduits, dans leur marche en grande partie récurrente, s'accompagnent d'une fine trachée. Lorsqu'on les soumet à une forte lentille du microscope pour en étudier la structure intime, on reconnaît qu'ils sont essentiellement constitués, ainsi que la 
plupart des canaux excréteurs des insectes en général, $\mathrm{I}^{\circ}$ par une enveloppe ou tunique extérieure assez épaisse, quoique pellucide, et d'un tissu contractile; $2^{\circ}$ par un tube inclus extrêmement délié, qui forme l'axe du conduit et qui, à la simple loupe, paraît d'un blanc nacré, quoiqu'il n'appartienne certainement pas à une trachée.

De chaque côté de l'origine de l'cesophage, on trouve dans la Scutellère une bourse ou réservoir salivaire sous la forme d'un boyau borgne, grêle comme un fil, blanchàtre, flottant par un bout, plus ou moins replié, mais assez long, lorsqu'il est déronlé, pour atteindre la cavité abdominale. Ce réservoir est placé au-dessous des glandes salivaires et du canal digestif, de manière qu'il faut enlever ces derniers organes pour le bien voir dans sa position naturelle. La petitesse de toutes ces parties ne m'a point permis de constater par l'observation directe le mode de connexion de ces bourses avec les conduits excréteurs de la salive. Indépendamment de cette paire de réservoirs salivaires filiformes, j'ai, dans quelques dissections, cru reconnaître l'existence d'une seconde paire, mais excessivement courte, débordant à peine le contour de la tête, et placée plus près de la ligne médiane du corps. Je n'ai point acquis sur ce point d'anatomie le degré de certitude nécessaire pour oser l'exprimer dans les dessins annexés à mon travail. Mais je suis d'autant plus porté à croire à l'existence réelle de cette seconde paire de bourses salivaires, qu'elle se rencontre plus développée dans des genres très rapprochés de la Scutellère, comme on le verra bientôt.

La glande salivaire de la Scutellère maure, quoique formée sur le même plan que celle de la précédente espèce, présente néanmoins dans sa configuration un trait bien tranché qui contirme ce que j'ai dit plus haut, relativement à la possibilité de séparer génériquement cet insecte des 4. Savans étrangers. 
autres $S$ cutellères. Le lobe antérieur de cette glande est profondément divisé jusqu’à sa base en cinq ou six digitations simples et d'inégale longueur. Le postérieur est aussi partagé en lanières, mais plus nombreuses, plus grêles, et dont quelques-unes sont bifides. Les conduits excréteurs et les bourses salivaires sont comme dans la Scutellère rayée.

Dans les diverses espèces du genre Pentatome dont j'ai fait la dissection, l'appareil salivaire offre, à peu de chose près, la même structure, la même organisation que celui des $S$ cutellères. La différence la plus appréciable est relative à la forme de la glande proprement dite. Le lobe postérieur de celle-ci ne présente des digitations que dans la Pentatome du grateron, placée par Fabricius dans son genre Edessa : encore ces digitations sont-elles fort courtes et disposées, ainsi que l'indique la figure, au nombre de trois de chaque côté de la base de ce lobe. Celui-ci est très simple dans les autres espèces, mais tantôt dilaté à sa base et terminé en une queue plus ou moins allongée, comme dans les $P$. grise, rufipède, du genévrier, des baies, et orvée; tantôt cylindrö̈de d'un bout à l'autre, et semblable à un boyau, ainsi qu'on le voit dans les $P$. émeraude et dissemblable. Du reste, cette configuration présente encore quelques légères différences, suivant certaines conditions difficiles à déterminer. Quant aux conduits excréteurs ou efférens, ils sont absolument les mêmes que dans le genre précédent.

Les bourses salivaires sont évidemment au nombre de deux paires dans les $P$. rufipède et des baies, et d'une seule dans les autres espèces. Les bourses les plus internes, les plus rapprochées de l'axe du corps, sont plus courtes que les autres, ordinairement droites, et prolongées jusqu'à l'origine de la cavité abdominale. Elles m'ont paru d'une mème ventue, cylindroïdes dans la première de ces deux espèces, 
et très distinctement atténuées, vers leur insertion, en un col capillaire dans la seconde.

L'appareil salivaire des Corés a la même couleur, la même organisation intime que celui des Géocorises précédens; mais il offre dans quelques espèces des modifications de forme assez remarquables pour ètre mentionnées. La glande dans le $\boldsymbol{C}$. bordé est formée de trois lobes an lieu de deux. Le plus postérieur de ces lobes est profondément divisé en cinq digitations inégales, l'antérieur en deux ; l'intermédiaire, simple et allongé, est légèrement renflé dans son milieu. Il n'y a cependant que deux conduits efférens; ce qui fait présumer que le lobe intermédiaire est confluent par sa base avec l'un des autres. Le plus long de ces canaux n'est pas uniformément capillaire et fléchi en nombreux festons comme celni des Scutellères et des Pentatomes; il est sensiblement renflé dans une assez grande étendue de sa partie moyenne et atténué à ses deux extrémités. Il a du reste la même structure intérieure, et le tube inclus ne partage point le renflement de sa gaîne ou enveloppe contractile. Les ligures qui accompagnent mon texte dispensent d'autres détails. Ce Coré a deux paires de réservoirs salivaires longs, filiformes, plus ou moins accolés au canal digestif, et quelquefois ayant une teinte vert-pistache, surtont les plus rapprochés de l'axe du corps.

La glande salivaire du $C$. chlorotique a le globe antérieur simplement fourchu, le postérieur divisé smr un seul côté seulement en plusieurs digitations simples ou bifides, lintermédiaire allongé, renflé vers le milieu, fusiforme. Dans le $C$. folátre, la forme de la glande qui sécrète immédiatement la salive se rapproche plus de celle des Pentatomes que de celle des espèces précédentes. Elle n'est composée que de deux lobes, l'un et l'autre très simples; mais elle est proportionnellement plus courte et plus grosse 
que dans la plupart des autres Géocorises. Les canaux efférens ressemblent à ceux du $C$. bordé. Je n'y ai reconnu qu'une seule paire de réservoirs salivaires qui sont filiformes et assez longs pour pénétrer dans la cavité abdominale.

En décrivant le tube digestif du $C$. hirticorne, nous avons vu qu'il manquait des cordons valvuleux qui caractérisent celui des autres espèces du même genre. Cet insecte va nous offrir aussi dans son appareil salivaire des traits qui le distinguent des autres Corées. Il y a pour chaque côté deux glandes, mais accolées l'une à l'autre, et sans doute confluentes. Chacune d'elles est formée de deux lobes comme dans les Pentatomes. Le lobe antérieur, bien plus court que le postérieur, est divisé, pour l'une des glaudes, en deux digitations oblongues, et simplement échancrées en cœur pour l'autre. Le lobe postérieur est très simple. II n'y a que deux canaux efférens pour cette double glande; ce qui suppose leur confluence. Je n'y ai apercu qu'une seule paire de bourses salivaires filiformes, atteignant la base de l'abdomen.

Dans les Alydes, les glandes où se prépare la salive sont plus grêles, plus allongées que dans les Géocorises précédens, mais d'ailleurs d'une texture parfaitement analogue. Elles sont doubles pour chaque côté dans l'A. du géranion, et triples dans l' $A$. aptère. Leur contiguité, leur adhérence, mefont soupconner, ainsi quedans le C. hirticorne, qu'elles confluent ensemble. Considérées isolément, elles diffèrent peu par leur configuration de celle des Pentatomes. Le lobe an térieur est plus court que le postérieur; l'un et l'autre sont très simples et terminés en pointe. Les conduits excréteurs ressemblent à ceux des Corées, c'est-à-dire que le plus long est renflé vers le milieu. L’A. du géranion a deux paires de bourses salivaires filiformes, dont l'une, plus longue, pénètre dans l'abdomen. 
La glande salivaire de la Pyrrhocore est double pour chaque côté; mais les deux corps qui la constituent sont en partie superposés, et je les crois confluens par le point de leur contact. Chacun d'eux a un lobe antérieur et un lobe postérieur; mais la grandenr relative de ceux-ci est inverse de celle des autres Géocorises. Le lobe antérieur est le plus long; il est très simple. Le postérieur est brièvement trilobé dans l'un de ces corps et arrondi dans l'autre. 11 y a deux condnits excréteurs uniformément capillaires, comme ceux des Pentatomes, mais moins longs, moins flexuenx quedans ces derniers. On ne rencontrequ'une seule paire de bourses salivaires, et elles sont filiformes.

L'organe sécréteur de la salive ne se compose dans le Lygée lagénifère que d'une glande à deux lobes pour chaque côté. Mais ces lobes ont une figure et une disposition particulières. L'antérieur est transversal, cylindroïde, et semblable à un grand bourrelet; le postérieur est partagé en deux digitations principales, dont l'une est simple et plus grande, et l'autre bifide. Les conduits efférens ressemblent à ceux des Pentatomes. Celui du lobe postérieur est fort long, fléchi en très nombreux petits festons, et uniformément capillaire. Les réservoirs salivaires sont filiformes, et il y en a un seul de chaque côté.

La glande salivaire du Lygée de la jusquiame diffère de celle de l'espèce précédente, et ressemble plutôt à celle des Corées. Elle se compose d'un corps glandulaire, analogue pour sa configuration à celui desPantatomes; et d'un autreallongé, simple, accolé et parallèle au côté du premier. Celui-ci a son lobe antérieur simple, et le postérieur unilobéà sa base.

L'appareil salivaire présente dans les Capsus, les Miris, lesPlymata, une disposition, une forme particulières qui constituent un des traits anatomiques les plus distinctifs de ces genres. 
Dans le Capse tricolor, il y a pour chaque côté, d'abord une glande d'une configuration et d'une texture analogues à celles des Géocorises que nous venons d'examiner, puis une seconde glande distincte de la précédente. La première se compose de deux lobes très simples, dont le postérieur est plus long. Les conduits excréteurs sont capillaires, et celui du grand lobe a plus de longueur que l'autre, sans en avoir autant que dans les Lygées. La seconde glande n'est pas toujours facile à mettre en évidence, à cause de sa petitesse, de sa diaphanéité et de sa position. C'est un corps d'apparence vésiculaire, d'une senle pièce, pellucide, ovale-oblong ou réniforme, suivant son degré de turgescence, fixé, eu quelque sorte collé, an moyen de brides trachéennes, à la face inférieure et latérale de l'estomac. Un conduit efférent capillaire s'insère près de son bout antérieur, mais un pen latéralement, et va s'ouvrir, en cótoyant l'œsophage, vers l'origine de celui-ci. En étudiant an microscope la texture de ce conduit, on se convainct qu'elle a la plus grande analogie avec celle de tous les vaisseaux excréteurs des autres glandes salivaires, c'est-àdire qu'il renferme un axe tubuleux à bords parfaitement parallèles. C'est surtout ce inode d'organisation qui m'a déterminé à considérer ce corps vésiculifor me plutôt comme une glande que comme un réservoir. Ce Capsus est-il pourvu de bourses salivaires, et doit-on considérer comme telles deux corps oblongs et d'une teinte verdâtre, placés un de chaque côté, à l'issue de la têté ? Ces corps ne sontils que de simples sachets adipeux? J'avoue que je ne me troure pas suffisamment éclairé pour décider la question.

Dans le Miris de Carcel on trouve, ainsi que dans le Capsus, deux glandes salivaires distinctes pour chaque côté. L'une est conformée comme celle des Pentatomes, ainsi qu'il est facile de s'en convaincre par l'inspection des fi- 
gures. Les lobes qui la constituent sont simples, et le postérieur, prolongé en une sorte de boyau plus ou moins boursouflé, est le plus souvent courbé en hameçon. L'autre se présente sous la forme extérieure d'un sac ou d'une utricule diaphane, ovalaire, un peu contractée vers son milieu comme certaines calebasses. Un filet trachéen, presque imperceptible, le suspend par son petit bout à l'extrémité postérieure de la glande précédente. Ises connexions insolites des conduits excréteurs de ces deux glandes en forment le trait anatomique le plus caractéristique, et rendent leur dissection d'une extrême difficulté. Celui du lobe antérieur de la glande principale est, comme d'ordinaire, plus long que l'autre; il se renfle insensiblement dans une assez grande étendue de sa partie moyenne, comme on le voit dans l'un des canaux efférens des Corées. Il se dirige d'abord vers la tête, et un ceil peu attentif croirait qu'il y pénètre; mais il se réfléchit sur lui-même, rebrousse chemin et va s'aboucher dans un sinus commun dont je parlerai bientôt. Le conduit excréteur du lobe postérieur de cette même glande est uniformément capillaire et se porte en arrière pour s'ouvrir dans le sinus. Celui de la glande supplémentaire ou utriculiforme s'implante brusquement à son gros bout, est fort court, capillaire, et se dégorge aussi dans le sinus en question. Celui-ci, dont je n'ai encore rencontré aucun exemple dans les autres insectes, est formé par la réunion, la confluence de cinq conduits destinés à l'excrétion du fluide salivaire, savoir : deux qui partent de la glande principale, un qui vient de l'autre glande, et deux qui naissent du sinus même et s'introduisent dans la tête pour verser la salive dans la bouche. Je n'ai point reconnu de bourses salivaires.

L'appareil salivaire de la Phymate a beaucoup d'ana- 
logie avec celui du Miris, et justifie, comme je l'ai déjà dit ailleurs, la place assignée à ce genre par M. Latreille. Il y a aussi deux glandes de chaque côté. La glande principale eșt allongée, cylindroïde, grêle comme un fil; son lobe antérieur est court et très obtus, le postérieur est fort long; leurs deux conduits excréteurs sont, contre l'ordinaire, égaux entre eux et remarquables par lenr briéveté. L'autre glande, ou la supplémentaire, a l'apparence d'une vésicule conoïde ; elle est collée contre l'estomac, où elle est principalement fixée par un filet trachéen qui termine la pointe acérée de la glande. Le conduit excréteur est très simple et s'insère latéralement avant son extrémité antérieure, pour se porter ensuite directement dans la tête.

La petitesse de l'Aradus avenius ne m'a pas mis à même de constater par l'observation directe l'existence de son organe sécréteur de la salive; mais il est permis de présumer qu'il doit avoir beaucoup d'analogie avec celui du genre suivant.

L'organisation de l'appareil salivaire de la Punaise des lits, quoique ne démentant point par certains traits celle des genres avec lesquels elle est groupée, offre cependant une configuration qui lui est propre. J'ai distinctement reconnu, pour chaquếcôté, deux glandes, dont l'une ou l'autre pourrait être, non sans quelque apparence de raison, prise pour un réservoir. La glande principale, du moins celle qui, par sa position, représente l'organe que j’ai désigné sous cette dénomination, est un corps ovoïde, simple, c'est-à-dire sans distinction de lobes ou de pièces conniventes, tout-à-fait saillant à l'ouverture cesophagienne de la tète et paraissant sessile. Ses parois pellucides laissent apercevoir à la loupe une humeur intérieure avec une nuance roussâtre ou ambrée. 
Son bout antérieur, légèrement atténué, se termine par un col ou canal excréteur fort court qui à son entrée dans la tête se divise aussitôt en deux branches capillaires comme lui. Cette bifurcation qui est, à proprement parler, le vestige des deux conduits efférens qui caractérisent l'organe salivaire des Pentatomes et autres Géocorises, ne vient-elle pas confirmer la dénomination de glande principale que l'analogie m'a fait donner à ce corps? Ne nous fouruit-elle pas une des nombreuses preuves de la marche graduée de la nature dans les changemens de forme et de texture des organes? Il est nécessaire, pour mettre en évidence les deux branches en question, de briser avec précaution le crâne de l'insecte et d'en enlever les rragmens. L'exiguité de toutes ces parties rend cette dissection des plus délicates. Toutefois, avec le secours d'une forte lentille du microscope, je me suis assuré que la structure du col et de ses branches ressemblait à celle des canaux excréteurs des autres Hémiptères, c'est-à-dire qu'ils sont formés d'une tunique extérieure contractile, et d'un tube inclus strié en travers et plus ou moins nacré. La seconde glande salivaire de la Punaise des lits se présente sous la forme d'une capsule sphérique ou ovoïle que son extrême petitesse et sa pellucidité ne rendent sensible qu'à un cil exercé, armé d'une forte loupe. Pour la découvrir, il faut arracher avec soin la tête de la Punaise, après avoir préalablement ouvert et écartelé le corselet, car la glande est logée dans l'intérieur de ce dernier. C'est sans doute à son degré de plénitude qu'il faut attribuer la différence de sa configuration, que j'ai trouvée le plus souvent globuleuse, mais quelquefois ovalaire. Dans tous les cas elle renferme un liquide absolument incolore, crystallin. Le canal déférent est un filet d'une ténuité presque imperceptible,

4. Savans étrangers. 
qui, d'une part, s'insère brusquement à la glande, et, de l'autre, va, en longeant l'œsophage, s'enfoncer dans la tête.

L'appareil salivaire du Réduve stridulant a plus d'analogie avec celui des Capses qu'avec celui des autres Géocorises. Il consiste aussi en deux paires de glandes d'une forme plus ou moins allongée. Le lobe postérieur de la glande principale surpasse cinq ou six fois en longueur son lobe antérieur. Il est droit on courbé, simplement renflé à sa base ou diversement boursouflé, susceptible, eu un mot, de quelques variations accidentelles dont j'ai représenté quelques-unes. Deux conduits excréteurs, courts, égaux entre eux, non flexueux et uniformément capillaires, naissent de l'entre-deux des lobes, mais à la face inférieure de l'organe. Ces conduits, le plus souvent contigus ensemble, prennent leur origine (au moins l'un d'eux) à une petite dilatation arrondie qui paraît dépendre du lobe postérieur. Un ligament d'une ténuité plus que capillaire s'attache au bout du petit lobe, et s'insinuant dans l'intérieur de la tête, sert à fixer tout l'organe. Ce ligament, dont je n'ai point encore fait mention dans les Géocorises précédens, se rencontre néanmoins dans plusieurs d'entre eux. La seconde paire de glandes salivaires est plus rapprochée de l'axe dı corps que la première. C'est un corps d'apparence utriculaire à parois pellucides et fort délicates, tantôt fusiforme, c'est-à-dire ventru dans son milieu, tantôt très allongé et presque cylindroïde, ce qui dépend de son plus ou moins de turgescence. De fines et nombreuses trachéoles le fixent, le collent, pour ainsi dire, contre la paroi inférieure de l'estomac; en sorte qu'il faut être très exercé dans les investigations de ce genre pour le découvrir et le dégager de ses liens. Elle n'a pas de connexion avec la précédente, 
et on n'y reconnaît aucune trace de lobe. Un conduit excréteur, plus long que ceux de la glande principale, mais du même diamètre et de la même texture, s'insère brusquement, non à l'une de ses extrémités, mais latéralement vers son tiers antérieur. Il pénètre dans la tète à côté des précédens, et j’ai été assez heureux pour le poursuivre, sans le rompre, jusqu'à son embouchure dans le pharynx.

L'organe salivaire a, dans le Pélogone, une configuration et une structure qui n'offrent qu'une faible analogie avec celui des familles voisines. Il consiste, pour chaque còté, en une glande proprement dite et en un réservoir. $1^{\circ}$ La glande, ou l'organe essentiellement sécréteur, est formée par une agglomération de six sachets subvésiculeux, presque diaphanes, dont quatre, groupés au centre, ressemblent à des boursouflures sphéroïdales. Le cinquième est antérieur, ovale-oblong; et le sixième, plus allongé que le précédent, forme à la glande une espèce de queue. De la partie inférieure de l'organe partent, comme dans les Cimex, deux conduits efférens dont la finesse, bien plus que capillaire, ne m'a pas empêché de constater l'existence, et qui, beaucoup plus courts que ceux de la plupart des Géocorises, se dirigent sans flexuosités vers l'orifice de l'œesophage. $2^{\circ}$ Le réservoir salivaire est une sorte de boyau comme suspendu à la partie postérieure de la tête et qui dépasse la glande par sa longueur. Ses parois minces et pellucides lui donnent l'aspect vésiculeux; sa forme allongée varie suivant son degré de plénitude; il est parfois renfléà son bout flottant, et plus étroit vers sa partie moyenne; il pénètre dans l'arrière-bouche par un col d'une grande ténuité.

L'organe destiné à la sécrétion salivaire va nous présenter, dans les Amphibicorises, quelques traits qui con- 
courent avec ceux fournis par les autres appareils organiques, à légitimer leur établissement en une famille particulière. Il se compose, ainsi que dans plusieurs des genres précédens, de deux paires de glandes dont l'une pourrait bien n'être qu'un réservoir. Examinons-les dans les Gerris. La glande principale ou externe, celle qui, par sa situation dans le thorax, sa couleur opaloïde, sa structure vésiculeuse et sa configuration générale, ressemble à celle de la plupart des Géocorises que je viens de décrire, est formée de deux pièces contiguës par leurs bases et sans doute communiquant ensemble. La pièce antérieure est simple, renflée à sa base et terminée par un prolongement grêle, capillaire. La postérieure est divisée assez profondément en deux lobes conoïdes inégaux, prolongés aussi en longs filets tubuleux, déliés comme un cheveu. Dans le Gerris des canaux le filet qui termine le plus grand de ces lobes se courbe ordinairement en sens inverse de sa première direction et se porte d'arrière en avant vers la tête. Immédiatement après sa courbure il se divise en deux. Dans quelques circonstances plus rares, car je ne l'ai encore observé qu'une seule fois, ce filet ne se courbe point, et ses branches se portent en arrière jusqu'à la cavité abdominale. Malgré tout le soin que j'ai mis dans mes investigations, je n'ai pu découvrir qu'un seul conduit excréteur ou efférent à cette glaude. Comme ce fait est insolite, je n'ose point le donner pour incontestable. Ce conduit est capillaire, court, comparativement à celui des Pentatomes, et naît du point de contiguité des deux pièces de la glande à la région inférieure de celle-ci. La seconde glande salivaire des Gerris consiste en un groupe ou agglomération arrondie d'utricules, les unes ovales, les autres sphéroïdes, sessiles, diaphanes, remplies d'une humeur visqueuse : ces utri- 
cules sont au nombre d'une vingtaine environ. Deux conduits efférens parfaitement distincts, plus déliés qu'un cheveu, partent du milieu des utricules et appartiennent sans doute à deux grappes confondues. Ces conduits pénètrent dans la tête en passant entre l'œsophage et le canal excréteur de la glande principale.

Je n'ai que des notions anatomiques incomplètes sur l'appareil salivaire de la Vélie. Sa glande salivaire m'a paru bilobce en arrière ainsi que celle des Gerris, et elle ne m'a offert non plus qu'un seul conduit excréteur. Quant à la seconde, elle présente des différences avec celle du genre précédent. Elle est essentiellement formée d'une grosse bourse ovalaire couronnée en avant par quelques utricules arrondies, et elle se dégorge dans le pharynx par deux cananx excréteurs.

L'organe qui préside à la préparation de la salive présente, dans les Hydrocorises, une structure plus compliquée, un degré de plus de perfection que celui des Géocorises et des Amphibicorises.

La glande salivaire des Naucores est une grappe de granulations arrondies ou ovales, sessiles, très serrées entre elles, et d'un blanc opaloïde. Elle est oblongue dans la $\boldsymbol{N}$. cimicoïde, plus courte, plus ramassée dans la $N$. aptère. Elle présente en avant un petit lobe distinct, pareillement granulé, qui rappelle celui des Géocorises; et en arrière, un simple renflement ovale plus ou moins prononcé suivant certaines conditions. Les granulations de ce dernier sont beaucoup moins saillantes que dans le reste de la glande. Deux conduits efférens, courts et capillaires, partent d'entre les lobes de celle-ci pour se rendre à l'origine du tube digestif. On retrouve dans les Naucores de véritables réservoirs salivaires analogues à ceux que j'ai fait connaître dans les Pentatomes. 
et les Corés. Il n'y en a qu'une seule paire; ils se présentent sous la forme de deux bourses allongées plus ou moins cylindroïdes, collées, à la faveur de fines trachéoles, contre les parois postérieures du canal alimentaire, et attéuuées en avant en une sorte de col capillaire.

II y a dans la Niepe et la Ranatre une glande salivaire de chaque côté. Elle consiste, ainsi que celle de la Naucore, en une grappe formée de granulations sessiles, arrondies, semi diaphanes et fort pressées. Cette grappe, qui occupe l'intérieur du thorax, paraît simple au premier coup d'cil; mais une dissection attentive y reconnaît deux grappes d'une même texture et communiquant ensemble, dont l'une, bien plus petite et antérieure, ne semble qu'une appendice de l'autre, et se termine en avant par un ligament d'une extrême ténuité qui se fixe dans l'intérieur de la tête. Dans la Ranatre la grande et la petite grappe semblent confluentes à l'endroit de leur contiguité, et il part de ce point un conduit excréteur qui ne tarde point à se diviser en deux brauches. Dans la $N$ èpe la grappe appendiculaire est bien distincte de la principale. Son extrémité postérieure émet un tube excréteur assez court, mais bien sensible, qui débouche dans la graude grappe. Celle-ci envoie à l'origine du bec deux conduits efférens dont le plus externe part d'un renflement sphéroïdal, lisse et simple. Il y a dans ces Hydrocorises deux paires de réservoirs pour la salive. L'une, filiforme, plus ou moins adhérente aux parois du caual digestif par d'imperceptibles trachées, est beaucoup plus longue que l'autre, pénètre jusque dans la cavité abdominale et se fait remarquer par une grande dilatation ellipsoïdale vers son milieu. Elle a proportionnellement plus de longueur dans la Ranatre que dans la Vìpe. L'antre paire de réservoirs, placée tout-à-fait au-des- 
sous de l'œesophage, a la forme de deux bourses cylindroïdes-obtuses, membraneuses, blanches dans le premier de ces insectes, d'un janne citron pâle dans le second. La glande salivaire de la Corise ressemble bien plus à celle des Pentatomes qu'à celle des Hydrocorises. II n'y en a qu'une pour chaque côté, et elle ne se compose point de granulations agglomérées en grappe; elle consiste, ainsi que dans la plupart des Géocorises, en deux pièces ou lobes adossés par leurs bases et très simples. Le lobe antérieur est moins grand que le postérieur: l'un et l'autre sont assez gros et très obtus. Deux conduits efférens, courts et capillaires, naissent de la rainure transversale qui sépare les deux lobes, mais à la face inférieure de l'organe. J'ai tronvé dans cet insecte une paire de réservoirs salivaires plus rapprochés de l'axe du corps que les glandes. Chacun d'eux est une vésicule sphéroïdale remplie d'une humeur limpide, et suspendue à un col tubuleux plus délié qu'un cheveu.

L'appareil destiné à la sécrétion salivaire présente dans la Notonecte une configuration et une structure particulières. On éprouve ici, comme dans les Réduves et autres Géocorises voisins, un véritable embarras pour la dénomination respective de la glande et $d u$ réservoir, à cause de la ressemblance de ces deux parties. Un certain tact acquis par l'entomotomie pratique autorise seul la préférence du nom que j'impose à chacune de ces dernières. La glande salivaire, on l'organe auquel je donne cette dénomination, fondée surtout sur la texture du conduit efférent, se trouve placée, contre l'ordinaire, plus près de l'axe du corps que le réservoir. Elle est plus grande et plus facile à mettre en évidence que ce dernier; sa forme est conoïde, allongée, plus ou moins effilée en arrière suivant son degré de turgescence; elle se ter- 
mine en avant par une sorte de tête tantôt sphéroïdale, tantôt semblable à une crosse. Celle-ci est séparée de la portion conoïde par un étranglement, un véritable col; mais il n'y a pas ici, comme daus les glandes salivaires des Géocorises, adossement, par leurs bases, de deux pièces ou lobes distincts : aussi n'y a-t-il qu'un seul conduit efférent. Les deux glandes convergent l'une vers l'autre par leurs extrémités effilées. Celles-ci se terminent par un ligament propre d'une excessive capillarité, et les deux ligamens se réunissent en un tronc commun qui se fixe vers le milieu de l'estomac.

La tête de la glande énet, par sa partie antérieure, un conduit excréteur capillaire assez court, et celui-ci, que j'ai long-temps cru se porter directement à l'origine du bec, va s'aboucher, ainsi que des dissections récentes (juillet 1829 ) me l'ont très positivement démontré, dans le réservoir dont je parlerai bientôt. Ce conduit, soumis au foyer de la lentille microscopique, présente la structure propre aux canaux excréteurs des glandes salivaires en général. Ainsi il se compose d'un tube inclus dans une enveloppe contractile. Toutefois ce tube inclus pourrait échapper à des investigations peu attentives, soit à cause de la finesse et de la translucidité de l'enveloppe, soit parce qu'on ne lui observe point les stries transversales qui le caractérisent ordinairement.

Le réservoir salivaire de la Notonecte a toutes les apparences d'une véritable glande. Il est plus petit et surtout plus court que l'organe sécréteur dont je viens de donner la description. Il est comme enseveli au nilieu du tissu adipeux qui garnit la région pharyngienne de l'insecte et ne déborde point la tête. Si, dans la figure qui accompagne mon texte, le réservoir est en entier mis en évidence, c'est qu'il a fallu pour cela violer sa 
situation naturelle et ses rapports. Ce qui lui donne une grande ressemblance avec une glande, c'est qu'il est formé de deux pièces ou de deux lobes contigus par leurs bases, mais distincts. Le lobe antérieur est petit, globuleux; le postérieur oblong, conoïde ou parfois ventru. Deux conduits capillaires s'insèrent dans l'entre-deux des lobes; l'un est le canal excréteur de la glande qui vient apporter dans le réservoir le produit de la sécrétion pour y être élaboré; l'autre, qui ne présente point au microscope le tube inclus qui caractérise le premier, est un peu moins délié et s'enfonce dans la tête.

Dans la Cigale l'organe essentiellement sécréteur de la salive consiste, pour chaque côté, en une paire de glandes arrondies, formées par l'agglomération d'une vingtaine environ d'utricules subdiaphanes, ovoïdes, oblongues ou allongées. Ces glandes, placées en arrière l'une de l'autre, mais bieu séparées, communiquent ensemble par un conduit intermédiaire d'une teinte jaune qui aboutit à leur centre. La glande antérieure a des utricules plus allongées que l'autre et uniformes. Dans sa situation naturelle elle est presque entièrement logée dans le crâne de l'insecte. 11 m'a fallu violer cette situation pour la mettre en évidence dans la figure que j'en doune. Les utricules de la glande postérieure sont inégales entre elles, celles du centre étant plus courtes, plus arrondies que celles du pourtour. Malgré des recherches fréquemment réitérées avec le secours des verres amplifians, je n'ai point été assez heureux pour confirmer l'existence du conduit par lequel la glande verse le produit de sa sécrétion dans la bouche. Dans mon premier travail sur l'anatomie de la Cigale, j'ai décrit ce conduit comme s'unissant avec celui du còté opposé pour former un col commun de dégorgement.

4. Savans étrangers. 
Au milieu de l'appareil salivaire on rencontre de chaque côté de la tête un boyau filiforme, à parois fragiles et pellucides, ayant, lorsqu'il est déroulé dans son intégrité, la longneur de tout le corps de l'insecte. Dans mes recherches antérieures sur ce même sujet, j'avais, à tort, pris ce boyau pour le réservoir de la double glande que je viens de décrire, et j'avais mal saisi son origine et ses connexions. Mieux servi aujourd'hui par une plns grande habitude des dissections délicates, j'ai clairement reconnu que ce boyau, dont plusieurs replis sont renfermés dans le crâne, aboutissait à une très petite glande logée dans la profondeur de la tête et composée d'une donzaine environ d'utricules arrondies. De cette glande part un conduit excréteur d'une finesse plus que capillaire et ayant la structure propre à ces sortes de canaux, c'est-à-dire offrant un tube inclus. Ce conduit, que j'ai positivement constaté, s'unit avec son congénère du côté opposé, et le col commun qui résulte de cette union va s'ouvrir à l'origine du bec. On serait tenté de comparer ce petit appareil salivaire de la Cigale aux glandes sublinguales des grands animaux.

Chacune des glandes salivaires de la Fulgore se présente sons la forme d'un filet tubuleux se prolongeant jusque dans la cavité abdominale, et garni, sur un de ses côtés, d'utricules ovalaires diaphanes, peu pressées entre elles et disposées en une seule série longitudinale. Ce filet tubuleux m'a paru dégarni d'utricules un peu avant son entrée dans la tête. Je n'ai point découvert de réservoir salivaire, et je sens le besoin de nouvelles dissections pour avoir des notions positives sur cet appareil.

Les glandes de la sécrétion salivaire de l'Issus m'ont paru avoir moius d'analogie avec celles de la Fulgore qu'avec celles des Cicadelles. Dans le petit nombre d'indi- 
vidus que j'ai pu sommettre au scalpel, je n'ai reconnu, pour chaque côté, qu'un seul petit groupe arrondi, et sans donte sessile, d'utricules sphéroïdes transparentes.

Dans la Lèdre, je ne vois non plus qu'une seule grappe salivaire arrondie, mais assez longuement pédicellée, composée de sept à huit utricules ovalaires diaphanes.

J'ai été à même de saisir avec assez d'exactitude la forme et la structure de l'organe salivaire de la Cercope sanglante, pour pouvoir en offrir et la description et la figure. Cet organe, compliqué et difficile à mettre en évidence, diffère beaucoup de celui des Cicadaires précédentes. On y distingue un corps glandulaire, deus conduits efférens et plusieurs réservoirs. Le corps glandulaire placé au centre de l'appareil rappelle, par sa texture et sa configuration générale, celui de quelques Géocorises, notamment des Pentatomes. Il est assez grand, de forme à peu près triangulaire, légèrement déprimé, semi diaplıne ou opaloïde, divisé en deux pièces contiguës, l'une antérieure, très petite, simple, ovale; l'autre postérieure, beaucoup plus grande, composée de boursonflures inégales plus ou inoins arrondies. Les deux conduits efférens ou excréteurs sont d'une ténuité capillaire et s'insèrent à la face inférieure du corps glandulaire, dans la ligne de contiguité des deux pièces ou lobes qui le constituent. L’un, celui qui paraît appartenir à la pièce antérieure, est fort court; l'autre, qui semble destiné à la pièce postérieure, se fléchit en plusieurs festons ou zig-zags. Ils se dirigent tous deux vers l'origine $d u$ bec, et lenr structure est analogue à celle des conduits excréteurs ordinaires des glandes salivaires; c'est-à-dire qu'ils offrent intérieurement un axe tubuleux, d'un blanc nacré à la loupe simple, et strié en travers an microscope. Les parties de cet appareil 
salivaire que j'ai mentionnées sous le nom de réservoirs, sont un certain nombre (peut-être huit seulement) de tubes filiformes blanchâtres, bien plus longs que le corps glandulaire, flottans par un bout, insérés par l'autre, soit en-dessus, soit en-dessous de la glande centrale. Ces tubes pourraient tout aussi bien être regardés comme des vaisseaux sécréteurs ou destinés à transmettre au corps central les matériaux pour la fabrication de la salive.

Nous retrouvons dans l'appareil salivaire de l'Aphrophore le même plan d'organisation que dans la Cercope, ainsi qu'on peut s'en convaincre par un coup d'œil comparatif jeté sur les figures qui les représentent. I a seule différence remarquable qui existe, c'est que les tubes, que j’ai désignés, avec quelque hésitation, sous le nom de réservoirs, sont ici bien plus courts que dans la Cercope, et comme terminés en massue. Les zootomistes seuls, ceux surtout qui se livrent avec ardeur à la dissection difficile des petits insectes, savent apprécier la satisfaction que procure la découverte de ces analogies d'organes dans les genres d'un mêne groupe.

Je n'ai point mis clairement à découvert l'organe sécréteur de la salive dans la $P$ sylle, malgré de nombreuses dissections dirigées vers ce but; mais j’ai reconnu dans la cavité thoracique des granulations arrondies assez distinctes, semi diaphanes, qui, suivant les apparences, se rattachent à cet appareil. La Dorthésie, dont l'organisation viscérale a plusieurs traits de ressemblance avec celle de la Psylle, m'a offert, de chaque côté de l'origine du bec, quatre ou cinq sphérules blanchâtres qui m’ont paru atténuées en un col propre et qui vraisemblablement constituent la glande salivaire.

Je n'ai pas été plus heureux dans mes investigations re- 
latives à l'appareil salivaire des diverses espèces de Pucerons soumises à mes dissections; je n'y en ai pas reconuu la moindre trace.

\section{ARTICLE III.}

\section{Du tissu adipeux splanchnique.}

Les viscères renfermés dans les trois cavités splanchniques des Hémiptères, c'est-à-dire dans l'abdomen, le tronc et la tète, sont entourés, plus on moins immédiatement, par une pulpe graisseuse dont l'abondance varie et suivant les régions da corps, et suivant les conditions auxquelles se tronvent soumis ces animaux. Mais c'est surtout dans la eavité abdominale qu'elle se trouve en plus grande quantité.

J'ai déjà signalé dans d'autres ouvrages sur l'añatomie des insectes, l'existence de cette pulpe graisseuse dans tous ces invertébrés en général, et j’ai fait connaître le rôle important qu'elle joue dans l'acte nutritif. Lorsqu'on la délaie dans l'eau pour en mieux saisir la contexture, on reconnaît, avec le secours de la loupe, qu'elle se compose de grumeanx, ou mieux de sachets de figure très polymorphe, remplis d'une graisse très fine et délicate. Mais ces sachets ne sont pas simplement déposés, isolés, abandonnés en quelque sorte dans les cavités; ils sont constamment en rapport avec des ramifications trachéennes, c'està-dire avec le seul organe véritablement circulatoire des insectes. Quand on saisit et qu'on soulève le tronc aérifère qui se distribue à ces sachets, ceux-ci y demeurent suspendus sous la forme de grappes, de guirlandes ou de guenilles. Les rapports immédiats et constans de ces utricules adipeuses avec un laeis, un canevas de trachées, annoncent une destination fonctionnelle incontestable. Je les considère donc comme de véritables réservoirs où les élé- 
mens adipeux peuvent être déposés, et repris ensuite par imbibition, pour servir ainsi à la nutrition. Mais ce but vraiment organique et vital n'exclut pas un autre usage accessoire de la pulpe graisseuse, qui par son interposition entre les viscères et leur enveloppe tégumentaire entretient une lubréfaction nécessaire, ralentit les secousses brusques, et s'oppose à des tiraillemens qui pourraient nuire à l'exercice normal des fouctions. L'abondance de cette pulpe m'a paru proportionnée au degré d'énergie vitale des insectes et à la faculté qu'ils ont de pouvoir supporter plus ou moins long-temps la privation des alimens. En appliquant cette considération aux insectes ailés, on trouve que les Coléoptères se placent en première ligne pour la quantité du tissu adipeux, puis viennent les Orthoptères, ensuite les Hémiptères, les Névroptères, les Hyménoptères, les Diptères, les Lépidoptères ( $\mathbf{I}$ ).

Je répéterai ici, relativement aux Hémiptères, une observation que j’ai déjà consignée dans mon travail sur l'anatomie des Coléoptères; c'est que les individus que l'on rencontre dans l'arrière-saison préseutent beaucoup plus de pulpe graisseuse que les autres. Dans le mois de novembre j’ai souvent disséqué des Pentatomes dont la majeure partie de la cavité abdominale était remplie par deux

(1) C'est aux depens de cette pulpe graisseuse que se nourrissent les larves qui vivent dans les cavités splanchniques de divers insectes. J'ai déjà fait comnaître dans les Annales des Sciences naturelles (t. X, 2827) celles de deux Diptères du genre Ocyptera, que l'on rencont:e, l'une dans la Pentatoma grisea, l'autre dans la Cassida viridis. Depuis lors j'ai trouvé aussi dans l'abdomen de la Scutellera maura une larve qui appartient au même genre de Diptères, mais j'ignore si elle est d'une espèce diffẻrente. Enfin la dissection du Reduvius stridulus in'a également fait découvrir dans ses entrailles une larve apode plus petite, plus allongée que les précédentes, mais fixée de même au stigmate pectoral: je la crois d'un Diptère, mais peut-être d'un autre genre que l'Ocypière. 
énormes guirlandes de granulations adipeuses suspendues aux trachées. Les organes digestifs, réduits alors à une espèce d'inaction, étaient presque entièrement dépourvus de pulpe alimentaire. N'est-on pas autorisé à penser que quelques-uns de ces Hémiptères, éclos tardivement, franchissent l'hiver dans des réduits à l'abri de l'air, de la lumière, en un mot, de tous les agens d'excitation; qu'ils s'alimentent aux dépens de cette graisse lentement reprise par imbibition; entin que, semblables aux marmottes, ils hibernent ( $\mathrm{t}$ )?

Le tissu adipeux splanchnique des Hémiptères n'est pas toujours exclusivement constitué par les sachets dont je viens de parler; il se présente parfois sous la forme d'une membrane fort mince, pellucide, enveloppant l'ensemble des viscères à la manière d'un péritoine.

Dans la famille ou la tribu des Géocorises, les Scutellères et les Pentatomes ont une pulpe adipeuse assez abondante comparativement aux autres Hémiptères. Elle est formée de sachets ovalaires ou arrondis, le plus souvent blanchâtres, quelquefois d'un vert ou foncé ou glauque, comme dans les Pentatoma juniperi et baccarum, rarement presque diaphanes, ainsi qu'on le voit dans la $P$. ornata. Les utricules adipeuses sont en bien moindre quan-

(1) Voici un fait observé postérieurement à la rédaction de cet article et qui résout d'une manière affirmative la question d'hibernage. Vers la fin de novembre 1829 j'incarcérai deux individus de la Pentatoma grisea dans un verre où j'avais mis du papier chiffonné pour leur servir d'abri. Je plaçai le verre dans un lieu exposé à l'air. Pendant les froids rigoureux de cet hiver où le thermomètre de Réaumur descendit, à Saint-Sever, lieu de ma résidence, jusqu’à onze degrés et demi au-dessous de zéro, j’allai visiter mes prisonniers ; je les trouvai vivans, mais dans un état d'inaction absolue, engourdis et dans une véritable léthargie. Aux premiers jours de mars 183o, c'est-à-dire trois mois après leur incarcération dans un vase où il n'y avait aucune espèce de nourriture, leur torpeur se dissipa peu à peu, et ils reprirent leur agilité ordinaire. 
tité chez les Corés et les Alydes; blanchâtres dans les C. marginatus et quadratus, d'une teinte verdâtre dans le $C$. chloroticus, semi translucides dans le $C$. nugax, presque nulles dans le $C$. hirticornis. Le Lygaus lagenifer ne m'a offert pour tissu adipeux qu'une toile pellucide péritonéiforme, tandis que celui du $L$. hyosciami consiste en granulations blanchâtres ou jaunâtres. La Pyrrhocore présente une pulpe adipeuse blanche, grumeleuse, abondante. Remarquons en passant que cet insecte est aptère et par conséquent d'un genre de vie moins actif, moins locomobile que les genres qui l'avoisinent. On trouve dans son prothorax, tout près de la tète, des sachets oblongs ou allongés, disposés symétriquement, qui peuvent en imposer à des yeux peu exercés, pour des bourses salivaires. Cette pulpe est rare dans les Miris, insectes qui voltigent beaucoup. Elle ne consiste dans la Phymate, qu'en un petịt nombre de guenilles membraniformes de couleur opaloïde. Celle de la Punaise des lits ne se rencontre guère que dans les flancs de la cavité abdominale, et en petite quantité. Enfin celle du Reduvius stridulus, insecte d'un genre de vie assez sédentaire, est blanche, abondante, se déploie tant en-dessus qu'en-dessous des viscères en une espèce de toile épiploïque qui voile ces derniers, et est enchevêtrée de trachées.

Le tissu adipeux splanchnique des $\Lambda \mathrm{mphibicorises} \mathrm{(Ger-}$ ris, Velia) est remarquable par sa couleur jaune et sa texture épiplö̈forme. Il s'étale comme un tablier sur la portion abdominale du canal digestif. Dans la Vélie j'ai trouvé ce tissu jaune dans le mâle, et blanc dans la femelle. L'intérieur du corselet offre une pulpe graisseuse assez abondante.

Les Hydrocorises ont un tissin graisseux fort peu abondant. Celui de la Nèpe et de la Ranatre consiste 
soit en une toile pellucide qui tapisse la paroi intérieure de la cavité abdominale, soit en sachets grumeleux répandus cà et là. Ces derniers sont dans la Naucore tantôt diaphanes, tantôt d'un jaune pâle, mais toujours rares; grisâtres dans la Corise, plus nombreux à l'origine du tube alimentaire; jaunàtres dans la Notonecte, et tout aussi peu abondans.

La pulpe adipeuse splanchnique est fort rare et d'une extrême délicatesse dans les Hémiptères de la section des Homoptères, insectes qui, comme on sait, ont un genre de vie tout aérien, et usent d'une nourriture légère et peu substantielle. Dans les Cigales on trouve quelques sachets graisseux d'une teinte glauque, dans la partie postérieure de la cavité abdominale, et plusieurs rameaux trachéens de celle-ci sont aussi enveloppés d'un fourreau de graisse. Mais indépendamment de ces sachets, une dissection adroite met en évidence une toile péritonéale qui revêt les parois intérieures de l'enceinte viscérale.

Le tissu adipeux est presque nul dans la Psylle. J'ai rencontré habituellement, en partie dans le thorax et en partie dans l'abdomen, une espèce de bourbillon ou de grumeau assez grand, d'un jaune vif, et au bout de l'abdomen quelques lobules, mais blanchâtres. Une pulpe graisseuse, formée de grumeaux arrondis, s'observe aussi dans la Dorthésie : elle est à peine apparente dans les Pucerons.

\section{CHAPITRE SECOND.}

\section{APPAREIL GÉNITAL}

Les Hémiptères ont, ainsi que les autres insectes, des sexes distincts qui procèdent à la reproduction par un accouplement. Si, dans une classification entomologique

4. Savans étrangers. 
qui aurait pour base l'anatomie, les organes digestifs fournissent des caractères de première valeur pour l'établissement des tribus et des familles, ceux de la génération n'offrent pas moins d'importance et de solidité pour la distinction des geures et des espèces.

Les entomologistes paraissent avoir entièrement négligé l'étude de la configuration et de la structure du bout de l'abdomen des Hémiptères, dans le signalement de leurs traits génériques. Cette étude, qui s'exerce sur des pièces externes, dépendantes des organes de la génération dans les deux sexes, est cependant féconde en caractères aussi solides que faciles à explorer, ainsi qu'on le verra par les recherches auxquelles je me suis livré sur ce point.

Ifin de procéder avec un ordre convenable à l'exposition des diverses parties constitutives de l'appareil reproducteur, j'examinerai, dans deux articles séparés, les organes générateurs du mâle et. ceux de la femelle.

\section{ARTICLE PREMIER.}

\section{Organes générateurs mâles.}

Les uns sont destinés à préparer, à élaborer les élémens fécondateurs ou le sperme; les autres à conduire, à émettre la liqueur prolifique dans l'acte copulateur. Dans les premiers sont compris les testicules avec les conduits déférens et les vésicules séminales; dans les seconds, le canal éjaculateur, la verge et l'armure copulatrice. C'est encore ici un exemple remarquable de conformité de composition organique entre l'appareil générateur mâle des Hémiptères et celui des grands animaux. Je vais développer les traits fonctionnels ou physiologiques de cette ressemblance.

Les organes qui, par l'effet d'une vitalité élective toute mystérieuse, ont pour fonction spéciale de séparer le sperme 
de la masse humorale, de le sécréter, en un mot, portent et doivent porter, dans l'homme comme dans la punaise, le nom de testicules. Dans les Hémiptères, ainsi que dans la plupart des grands animaux, ils sont binaires ou doubles. Situés à demeure dans la cavité abdominale, le plus souvent à sa base, quelquefois à son extrémité, toujours audessous des viscères digestifs, ils sont, comme tous les organes qui ont une haute importance vitale, en contact avec un grand nombre de vaisseaux aérifères. Ceux-ci non-seulement s'épanouissent, à leur surface, en élégantes broderies, mais ils s'insinuent entre les parties qui constituent la glande et pénètrent leur tissu. Tantôt claque testicule ne consiste qu'en un seul corps indivisé, et tantôt il résulte de la connivence, de la rénnion de deux on plusienrs gaînes que j’ai cru devoir désigner sous le nom significatif de capsules séminifiques. Le nombre de celles-ci varie suivant les familles et les genres, mais il est constant dans les individus d'une même espèce. Dans quelques Hémiptères, le testicule est enveloppé d'une tunique propre ou testiculaire, membraniforme, comparable à la tunique albuginée des grands animaux; dans d'autres il est tout-à-fait à nu. La forme et surtout le volume de ces glandes sont sujets, dans le mème individu, à quelques variations qui dépendent de leur turgescence séminale, et qui pourraient alors en imposer à des yeux peu exercés.

Lorsque le testicule, dans son état d'orgasme génital, a préparé une quantité surabondante de liqueur prolifique, celle-ci est transmise, hors de cette glande, dans des réservoirs spéciaux, par un canal particulier, appelé conduit léférent du testicule ou cordon spermatique. Ce conduit se rencontre dans tous les Hémiptères. Dans les uns il naît brusquement de l'organe sécréteur; dans les autres il n'en ust qu'une dégénération insensible. Sa longueur 
varie bea ucoup, suivant les familles et les genres. Elle peut égaler seulement celle du testicule ou la surpasser un grand. nombre de fois. Dans quelques cas, ses flexuosités s'agglomèrent en un peloton constant, qu'un scalpel adroit arrive à dévider complètement, et qui peut porter le nom d'épididyme, par analogie avec unc agglomération semblable qui s'observe dans les Mammifères.

La liqueur spermatique, immédiatement sécrétée par le testicule, est, comme je viens de le dire, transmise par le conduit déférent dans des réservoirs particuliers. Ceux-ci sont les vésicules séminales: le sperme est destiné à y subir, soit par son séjour, soit par une filtration répétée dans des canaux multipliés, soit enfin par la vitalité de ces organes, et peut-être aussi par son mélange avec d'autres humeurs, une nouvelle et dernière élaboration qui lui fait acquérir la qualité fécondante ou prolifique. Ces mêmes réservoirs, ce même but physiologique, se retrouvent dans les animanx les plus élevés de l'échelle organique, comme dans nos petits Hémiptères. Les vésicules séminales de ces derniers, tonjours placées entre les testicules et le canal éjaculateur, sont tantôt de longs boyaux filiformes assez rares et reployés, tantôt des vaisseaux courts et très nombreux, tantôt enfin, comme dans l'homme, des poches membraneuses assez considérables. Elles sont plus ou moins développées, plus ou moins apparentes, suivant leur degré de turgescence ou leur opportunité générative; mais leur nombre et leur configuration ne varient point dans les individus d'une même espèce.

Le canal éjaculateur est l'aboutissant, le tronc des diverses parties que je viens de mentionner. C'est lui qui livre passage au sperme lorsque celui-ci est convenablement élaboré, et que des conditions génératives favorables sollicitent son excrétion. Sa forme et sa longueur varient 
dans les Hémiptères, suivant les genres. En général il est bulbeux dès son origine, et cette portion bulbeuse est digne de toute l'attention du physiologiste qui se livre à l'étude comparative des animaux et à la recherche de la théorie des analogues. Les parois sont épaisses, fermes, presque élastiques, susceptibles d'une contractilité propre à remplir la fonction qui lui semble dévolue, et qui consiste à lancer, à projeter, à éjaculer, en un mot, la liqueur prolifique pendant le coït. Mais, indépendamment de cette fonction, n'est-il pas permis de croire que ce bulbe peut avoir aussi celle de sécréter quelque liqueur spéciale qui se combine avec le sperme; et, sans violenter l'invocation à la loi de l'analogie, ne retrouvez-vous pas ici un organe comparable à la glande prostate des grands animaux?

Tout l'appareil générateur mâle se termine dans les Hémiptères, comme dans tous les animaux en général, par le pénis ou la verge. Cet organe, qui dans les quadrupèdes sert et à l'excrétion du sperme et à celle de l'urine, est dans les insectes exclusivement destiné à s'introduire, pour l'acte copulatif, dans le vagin de la femelle, et à y éjaculer la liqueur séminale pour la fécondation. Il est habituellement renfermé dans la cavité abdominale, dont il occupe l'extrémité, et il n'en sort que pour l'exercice du coït. Pour le mettre en évidence hors du temps de ce dernier acte, il faut exercer sur l'ensemble des pièces plus ou moins cornées qui en sont le réceptacle, et dont je parlerai bientôt, nne compression expulsive graduelle: alors on le voit saillir sous l'apparence d'un corps grêle comme un fil, blanchàtre, mou et flexible. Dans quelques conditions génératives, favorables, j'ai même constaté l'existence bien positive d'un vestige de gland comme bilobé.

Autant que j’ai pu m'en convaincre en cherchant à prendre la nature sur le fait, je suis porté à croire que la 
verge des Hémiptères, ainsi que celle des autres insectes, n'est point susceptible d'acquérir complètement, pendant l'orgasme génital, cette raideur désignée sous le nom d'érection. Mais la nature, toujours conséquente dans ses productions, toujours admirable dans la diversité des moyens qu'elle emploie pour atteindre un même but, a su obvier à cette espèce d'inhabilité à l'érection: un appareil en quelque sorte mécanique a été donné à tous les insectes, pour rendre exécutable l'acte important de la fécondation; c'est cet appareil qui porte le nom d'armure copulatrice. Diverses pièces la composent, et présentent, suivant les genres et les espèces, des différences que j'indiquerai plus bas. Les unes sont habituellement visibles à l'extérieur; les autres appartiennent à la verge elle-même, et l'accompagnent lorsque le coït doit avoir lien. Les pièces externes de l'armure copulatrice des Hémiptères se trouvent placées tout-à-fait à l'extrémité de l'abdomen, tantôt à la région ventrale et tantôt à la dorsale. Elles sont, en général, d'une texture analogue à celle des tégumens du corps, mais souvent plus dures encore. Elles constituent un ensemble rétractile, c'est-à-dire susceptible de sortir en tout ou en partie de sa position ordinaire, et d'y rentrer ensuite. Des muscles assez nombreux obéissent, à cet effet, à la volonté et aux besoius de l'insecte. Ces pièces, par leur contiguration, paraissent avoir pour but principal de saisir, d'accrocher, de fixer les parties externes de l'organe géuérateur femelle, pour l'accomplissement du coït. Les pièces copulatrices propres à la verge, forment, à cet organe, ume gaine, un véritable fourreau, j'allais lire un prépuce, d'uu tissu assez consistant, mais qui ne l'est pas uniformément, de manière à ce qu'il puisse jouir d'une certaine flexibilité. Ce fourreau, lors de la copulation, s'introduit en partie dans la vulve, et facilite 
ainsi l'intromission complète du pénis dans le vagin.

L'accouplement des Hémiptères et des insectes en général n'est point instantané, comme dans l'espèce humaine et la plupart des mammifères. Semblable à celıi du Chien, il est permanent pendant un certain temps. Le mâle et la femelle, ainsi que dans ce dernier quadrupède, sont placés horizontalement, bout à bout, par le partie postérieure du corps, et restent liés dans cette attitude jusqu'à ce que l'acte fécondateur ait été complété. On a voulu expliquer par l'absence des vésicules séminales dans le Chien, la nécessité de la durée de son accouplement; il faudrait chercher pour les Hémiptères une autre solution, car ces insectes sont pourvus de réservoirs spermatiques très développés ou fort nombreux.

Au lieu de destiner, comme je l'ai déjà fait dans d'autres ouvrages de cette nature, un paragraphe particulier à l'examen isolé de chacune de ces parties dans les diverses espèces, il m'a paru plus convenable, pour abréger et sinplitier mon travail, d'exposer l'eusemble de l'appareil génital mâle dans chacun des Hémiptères soumis à mes recherches anatomiques.

\section{GÉOCORISES.}

Scutellera nigro-lineata. - Le sexe mâle de cette espèce se reconnaît extérieurement à ce que la région anale, vue en-dessous, présente une excavation semi circulaire ou parabolique, et deux paires de saillies ou d'apophises, le tout formé par l'armure copulatrice.

Les testicules, fixés tout-à-fait à la base de la cavité abdominale, sont constitués par deux glandes assez grandes, fort remarquables par leur couleur d'un rouge vif, en partie obliquement croisées l'une sur l'autre dans leur situation naturelle, le plus souvent en forme de massue ovale-ob. 
longue et obtuse, plus renflées dans certains cas de turgescence séminale. La couleur rouge ou cinabre de ces organes appartient exclusivement à une inembrane fort mince et d'un tissu peu résistant qui forme sa tunique testiculaire ou albuginée. On voit plusieurs trachéoles étaler sur ce fond de pourpre d'élégantes arborisations nacrées. Quand on a dépouillé le testicule de sa tunique colorée, on met à nu son parenchime, qui est une pulpe blanchâtre, homogène, visqueuse, plus ou moins compacte, suivant son degré d'élaboration. Cette pulpe, soumise aux investigations microscopiques les plus réitérées, ne m'a offert aucune trace de capsules ou de vaisseaux séminifiques. Ce testicule est unicapsulaire.

Je ferai, à ce sujet, une observation qui prouve combien il est nécessaire en entomotomie de multiplier les recherches, soit pour constater la texture de certains organes, soit pour saisir les analogies ou les transitions d'organisation. En juin 1828 je disséquai un individu de notre Scutellère, dont les testicules, très développés par l'effet d'une turgescence spermatique considérable, étaient décolorés à leur extrémité libre; et celle-ci offrait évidemment la trace, ou plutôt un faible trait de plusieurs divisions ou lobes peu marqués, ainsi que le témoigne la figure que j'en donne. Or, s'il est permis d'en appeler à la loi de l'analogie, on voit dans ce cas l'indice, le vestige de l'organisation des testicules de plusieurs Géocorises, dans lesquels ces organes sécréteurs du sperme sont, ainsi que nous le. verrons plus bas, composés de plusieurs capsules parfaitement distinctes.

Le conduit déférent du testicule n'est que la continuation de l'extrémité postérieure de cet organe. Revêtu comme lui d'une tunique rouge, il est filiforme, plus ou moins flexueux, environ deux fois plus long que le testicule lui- 
mème, et formé intérieurenıent par le nême parenchyme pulpeux blanchâtre. Il va se perdre dans le groupe des petites vésicules séminales, par un mode de connexion qu'il m'a été impossible de consta ier.

Les vésicules séminales sont de deux sortes: les unes, fort petites et très nombreuses, se confondent pour chaque côté en un groupe qui parfois semble bilobé. Ce sont des tubes fins et courts, libres et fermés par un bout, réunis par l'autre, d'une manière inextricable, vers un centre commun. Ils ont une texture fort délicate. J'ai souvent observé que les plus antérieurs étaient d'un blanc mat, et les postérieurs diaphanes. Les autres vésicules séminales sont bien différentes des premières, et se rapprochent par leur conformation de celles des grands animaux. Il n'y en a pour chaque côté qu'une seule, sous la forme d'une poche membraneuse, ovalaire, assez grande, remplie d'un sperme plus ou moins limpide. Elles reçoivent, par un mode d'insertion que l'exiguité et l'ex trême délicatessedes parties, ne m’ont pas mis à même de reconnaître positivement, les autres vésicules séminales et les conduits déférens; puis elles dégénèrent en arrière en deux cols tubuleux qui s'abouchent au canal éjaculateur.

Le canal éjaculateur, beaucoup plus court que le conduit déférent, présente, dès son origine, un renflement ovoïde ou ovalaire, et s'amincit en arrière pour pénétrer dans l'appareil copulateur.

L'armure copulatrice est une pièce cornée, à peine apparente, au bout inférieur de l'abdomen, dans l'état de repos. Elle a une forme à peu près carrée, échancrée en avant et en arrière. Les àngles de l'échancrure antérieure servent d'attache aux faisceaux musculeux qui font mouvoir l'armure; ceux de la postérieure forment une saillie obtuse garnie de quelques cils, et dans l'intervalle de ces 4. Savans étrangers. 
angles il y a au milieu une lame courte, bifide; puis, de chaque côté de celle-ci, un crochet en forme de spatule uni-épineuse au bord interne.

Sc. maura. - Son appareil générateur mâle offre des différences tranchantes avec celui de la $S c$. nigro-lineata et confirme l'observation que j'ai déjà émise, en parlant de la structure extérieure de cet insecte, sur la nécessité d'établir pour lui une division particulière dans le cadre des espèces, ou de l'ériger en genre propre.

Jobserve, relativement à la différence extérieure des sexes, que la région anale ne présente en-dessous qu'une plaque d'une seule pièce en forme d'écusson, à peine déprimée, arrondie en avant, largement tronqueée et légèrement échancrée en arrière, constituée par l'armure copulatrice.

Les testicules, bulbeux et arrondis à leur base, sont ensuite brusquement rétrécis en une sorte de bec allongé, cylindroïde, que j’ai toujours rencontré comme flétri et ridé. Dans leur position naturelle ils sout contigus et opposés par leurs bases respectives. Ainsi que ceux de la $S c$. rayée, ils sont revêtus d'une tunique testiculaire rouge, et ne présentent intérieurement qu'une pulpe homogène blanche, amorphe. Les conduits déférens ont aussi une enveloppe rouge. Ils sont grêles, à peine de la longueur du testicule, et confluent en arrière en un réservoir arıondi formant le bulbe du canal éjaculateur, et où viennent s'aboucher, comme dans un sinus commun, les vésicules séminales. Celles-ci, au nombre de cinq bien distinctes, mais fort difficiles à isoler, sont filiformes, diaphanes, fragiles, très repliées et flottantes par un bout. Leurs nombreuses flexuosités sont parfois, surtout dans'la condition opposée à la turgescence spermatique, si déprimées et si contiguës, qu'elles semblent constituer une membrane oì 
la loupe a de la peine à saisir la trace de leur existence. De ces cinq vésicules séminales, deux s'insèrent de chaque côtédu réservoir arrondi, dont je viens de parler, et la cinquième ou l'impaire s'implante vers le milieu du bord antérieur de ce réservoir, tout près du point où confluent les conduits déférens. Elles sont toutes d'une grosseur à peu près égale, mais l'impaire est un pèu moins longue que les autres, et l'antérieure des paires latérales est la plus longue. Leur insertion a lieu par un bout un peu effilé. Le canal éjaculateur débute, comme je l'ai déjà dit, par une dilatation arrondie qui sert de réservoir aux conduits déférens et aux vésicules séminales. Il devient ensnite brusquement grêle comme un fil, blanchâtre, fort court, et va, en passant sous l'intestin, pénétrer dans l'armure copulatrice. Cette dernière est une pièce cornée et rétractile dont la configuration et la structure diffèrent beaucoup de celles de la $\boldsymbol{S c}$. rayée. Elle présente en-dessus une légère excavation, dont le milieu est occupé par une espèce de soupape ovale-oblongue qui se relève pour le passage de la verge, et qui est flanquée à droite et à gauche par un crochet copulateur. Les figures qui accompagnent mon texte, me dispensent d'autres détails descriptifs.

Pentatoma dissimilis. - Le mâle diffère de la femelle par une plus petite stature, et parce que le dernier segment de l'abdomen a une large échancrure, arrondie et profonde, et est concave en-dessus pour loger l'armure copulatrice.

Les testicules ne diffèrent guère que par la forme, de ceux des $S$ cutellères. Placés comme eux sous les viscères de la digestion, et fixés à la base de la cavité abdominale par de nombreuses brides trachéennes, ils forment deux corps tantôt ovales, tantôt oblongs, suivant leur degré de turgescence; le plus souvent étranglés vers leur base et se 
regardant par celle-ci. La tunique testiculaire qui les revèt est aussi fortement colorée en rouge orangé ou en écarlate, et parcourue par des broderies vasculaires. Quoiqu'ils ne présentent extérieurement aucune trace de division, on reconnaît néanmoins, en les disséquant avec soin, que chacun d'eux est comme formé par un faisceau de capsules séminifiques allongées dont je n'ai pu déterminer le nombre, parce qu'elles sont confondues. Ces capsules ont une enveloppe propre, lavée de rouge, qui m'a paru le dédoublement de la tunique testiculaire, et j'ai bien reconnu que de fines trachéoles s'insinuaient entre elles. Le sperme qu'elles renferment est blanchâtre. Le conduit déférent, filiforme, rouge, et bien plus long que le testicule, est à son origine collé contre la base de celui-ci, qu'il déborde un peu comme un bourrelet. Il se fléchit en une double sinuosité, et va s'insérer à la naissance du canal éjaculateur, en se rapprochant de son congénère sans s'unir à lui. Avant cette insertion il présente un petit renflement oblong, décoloré, précédé d'une légère contracture. Les vésicules séminales sont fort compliquées, et il faut une patience éprouvée pour mettre en évidence leur disposition et leurs connexions. On peut les diviser en trois ordres. On en voit d'abord une impaire fort considérable sous l'aspect d'un vaste sac transversal, le plus souvent réniforme, quelquefois bilobé, suivant certaines conditions génératives. Ce sac, plus ou moins rempli d'une humeur limpide, visqueuse, cache en grande partie les autres vésicules. Celles-ci sont tubulaires, disposées en arbuscules ramifiés qu'il n'est pás facile d'isoler. Les antérieures, plus courtes, plus petites, plus nombreuses, plus inextricables, ont leur insertion aux conduits déférens, dans cette légère contracțure que j'ai dit précéder un renflement terminal de ceux-ci. Elles forment, pour chaque côté, un fais- 
ceau à plusieurs branches aboutissant à un tronc commun, court et étroit. La liqueur séminale qu'elles contiennent est blanche, opaque, et m'a paru plus élaborée. Les vésicules tubulaires postérieures sont constituées par un groupe bien plus simple de conduits, dont quelques-uns sont divisés en une ou plusieurs digitations. Elles s'implantent, par un pédicule commun fort court, de chaque côté du bulbe du canal éjaculateur, et sont pleines d'ane humeur spermatique limpide. Le canal éjaculateur se renfle, dès son origine, en un bulbe allongé, claviforme, d'une consistance comme calleuse, et sensiblement courbé. Ce bulbe recoit à son bout antérieur les deux conduits déférens; un peu au-dessous de ce bout s'abouche le grand sac séminal; et de chaque còté, vers sa partie moyenne, a lieu l'insertion des vésicules tubulaires postérieures. Le canal en question devient filiforme après le bulbe, et pénètre sous le rectum pour s'enfoncer dans l'armure de la verge. Celleci est une capsule cornée, courte, arrondie, avec une échancrure semi lunaire en arrière.

$P$. smaragdula. - Une configuration du segment anal de l'abdomen, à peu près analogue à celle de la $P$. dissimilis, distingue dans cette espèce le mâle de la femelle. Observons seulement qu'ici l'échancrure a ses angles moins arrondis, qu'elle est garnie intérieurement d'une légère villosité, et que le segment où elle est pratiquée offre endessous et en arrière une fossette particulière.

L'appareil génital mâle a la plus grande conformité d'organisation avec celui de l'espèce précédente. Voici les seules différences, et elles ne tiennent point à la structure intime. $\mathrm{I}^{\circ}$ Le testicule est ici plus obtus, comme tronqué ; les trachées qui s'étalent à sa surface y présentent des branches rapprochées et presque parallèles qui imitent des galons d'argent. $2^{\circ}$ La tunique testiculaire est d'un roux 
pâle et non rouge. $3^{\circ}$ Les vésicules séminales, insérées au conduit déférent, sont moins nombreuses et très entortillées. $4^{\circ}$ Celles implantées sur le bulbe du canal éjaculateur sont plus longues, disposées sur un même plan et terminées par uue extrémité effilée. $5^{\circ}$ Enfin le bulbe du canal éjaculateur est moins prononcé, moins calleux et non sensiblement courbé.

$P$. grisea. - On reconnaîtra le mâle à ce que l'armure copulatrice, logée dans le dernier segment de l'abdomen, présente, vue en-dessous, une dépression semi lunaire dont les angles sont obtus, brièvement velus, et dont la ligne intermédiaire a une petite échancrure médiane et quelques inégalités peu marquées.

Quoique cet insecte se rencontre fréquemment dans nos contrées, quoiqu'il soit le premier Géocorise qui apparaisse au printemps, puisque dès les premiers jours de mars il me fournissait ordinairement l'occasion de reprendre mes investigations anatomiques, j'avais vainement cherché, pendant plusieurs années consécutives, à le disséquer dans des conditions favorables à l'étude de ses organes mâles de la génération. Dans les diverses saisons où les autres Pentatomes offraient ces organes dans un état de turgescence spermatique plus ou moins prononcé, je trouvais constamment les testicules de celle-ci ratatinés, flétris, déformés, sans parenchyme appréciable, et les vésicules séminales vides, affaissées, inextricables. Ce n'est que tout récemment, en novembre $\imath_{2}$, que j'ai enfin pu constater d'une manière positive la forme et la structure de l'appareil génital mâle de la $\boldsymbol{P}$. grisea. J'en ai tiré la conséquence assez naturelle que l'accouplement de cette espèce a lieu beaucoup plus tard que celui des autres Géocorises, et à l'époque dont je viens de parler. On peut aussi, sans trop hasarder, tirer cette autre conséquence que, puisqu'on 
rencontre cet insecte à la fin de l'hiver avec les organes génitaux flétris, c'est que vraisemblablement il franchit cette saison et qu'il hiberne.

Ses testicules, mollement assis sur une couche épaisse de grumeaux adipeux blancs, et d'un rouge éclatant rehaussé de broderies nacrées, ressemblent trait pour trait à ceux de la $\boldsymbol{P}$. dissimilis. Je puis en dire autant des conduits déférens, des vésicules séminales et du canal éjaculateur; en sorte que la description de toutes ces parties serait un véritable double emploi.

$P$. ornata. - C'est encore ici le même plan d'organisation pour l'appareil génital mâle. Le seule différence un peu remarquable que m'ait fournie son étude consiste dans une forme plus oblongue du testicule, qui dans quelques cas de turgescence spermatique, est dénudé, à son extrémité, de sa tunique rouge, et présente alors la trace de deux capsules séminifiques accolées, dont l'une déborderait un peu l'autre en longueur. Le canal éjaculateur débute par un bulbe ovale.

$P$. aparines. - On ne saurait disconvenir que cette Pentatome revêt une physionomie différente de celle des espèces précédentes, et nous allons trouver dans l'organisation de son appareil mâle de la génération quelques traits particuliers qui sembleraient déposer en faveur du sentiment de Fabricius, qui a placé cet insecte dans son genre Edessa.

Les testicules ont aussi une tunique propre, d'un rouge vif, couleur qui se communique parfois aux fines arborisations trachéennes épanouies à leur surface. Ils sont ovalaires, obtus à leur extrémité libre, qui, dénudée lors d'une exubérance séminale, offre l'indice de plusieurs digitations, et, rétrécis en arrière, pour se relever ensuite en une espèce d'apophise ou de talon d'où naît le conduit déférent. 
Toutes mes tentatives pour isoler les capsules séminifiques que la trace des digitations précitées pourrait faire soupconner, ont été entièrement infructueuses : les dissections les plus soigneuses ne m'ont démoutré, dans le testicule, qu'une pulpe prolifique homogène où l'œil, armé des plus forts verres amplifians, n'a pu découvrir ni gaîne ni diaphragme. Ces apparences de digitations incomplètes ne sont donc, aux yeux du zootomiste habitué à étudier la marche graduelle de la configuration et de la texture des organes dans les divers êtres de l'échelle animée, que de simples vestiges, des indices précurseurs, l'ébauche, en un mot, d'une organisation plus compliquée, plus parfaite peut-être.

Les conduits déférens sont rouges, filiformes, flexueux, de moyenne longueur. Un peu avant leur insertion au canal ejaculateur, insertion qui a lieu tout-à-fait au bout antérieur de celui-ci, leur couleur rouge s'efface.

Les vésicules séminales sont tellement développées dans l'état de turgescence, qu'elles recouvrent presque entièrement les testicules. 11 y en a de deux ordres : les unes, au nombre de trois, ont la forme de grandes vessies ovoïdes, à peu près égales entre elles, à parois minces et pellucides, remplies d'une liqueur transparente; les autres sont vasculaires ou tubulaires, diaphanes on opaloïdes, la plupart rameuses, d'une texture si délicate, si fragile, et tellement enlacées avec les trachéoles, que leur déroulement complet est impossible. Des trois vessies séminales, l'une, centrale et quelquefois comme échancrée, s'abouche d'une manière sessile à l'origine supérieure du canal éjaculateur; les deux autres sont latérales, atténuées en arrière en un col qui m'a paru s'insérer de chaque côté de la vessie centrale, mais à sa face inférieure. Les vésicules séminales vasculaires constituent pour chaque côté un groupe de conduits tu- 
buleux, ramifiés en arbuscule, dont les branches sont entortillées. Elles s'implantent de part et d'autre par un tronc commun, près de l'extrémité du col des vessies latérales. Mais, indépendamment de ces vésicules vasculaires rameuses, il y en a de chaque côté de la face inférieure de la vessie centrale, au tour du point d'insertion des conduits déférens, quatre ou cinq supplémentaires fort petites, simples, très difficiles à nıettre en évidence, et qui sont là comme collées. Le canal éjaculateur est fort court, renflé dès son origine et à peu près droit. L'armure copulatrice a la plus grande ressemblance de forme et de contexture avec celle de la $\boldsymbol{S}$ cutellera maura. Elle présente une échancrure semi lunaire, excavée, an centre de laquelle est une pièce ovalaire en forme de soupape, destinée à se relever pour le passage de la verge.

Coreus marginatus. - Les Corés, ainsi que plusieurs des genres qui les suivent dans le cadre entomologique, vont confirmer, par la structure de leurs organes sécréteurs du sperme, la réflexion que je viens d'émettre relativement aux vestiges ou ébauches de ces parties, comme signes précurseurs d'une organisation qui doit se perfectionner dans des espèces plus élevées dans l'échelle.

Le mâle se reconnaît extérieurement à ce que l'extrémité de l'abdomen est largement tronquée et entière.

Les testicules du C. marginatus, placés pour ainsi dire à nu, à la base de la cavité abdominale, sont composés chacun de sept capsules séminifiques bien distinctes, allongées, d'un jaune orangé vif, disposées le plus souvent sur un mệme plan, en un faisceau flabelliforme, déprimé et confluê̂t, ou soudé en arrière pour la formation du conduit déférent. Ces capsules, d'une texture un peu raide, sont, dans quelques circonstances, reployées sur ellesmêmes, de manière à représenter une double rangée; mais

4. Savans étrangers. 
ce n'est là qu'une exception, un accident. Le conduit déférenı naît brusquement du testicule; il est blanc, d'abord grêle et filiforme, ensuite dilaté en un renflement ovoïde ou oblong, suivant son degré de plénitude, et se terminant par un conduit tubuleux qui va s'insérer, isolément de son congénère, à l'origine du canal éjaculateur. Les vésicules séminales n'offrent point dans les Corés ce nombre, cette diversité, cette complication, qui caractérisent celles des Géocorises précédens. Elles se réduisent à un ou deux réservoirs très simples, mais susceptibles de varier dans leur forme et leur volume, suivant certaines dispositions génératives. La principale est une grande vessie centrale, presque globuleuse quand elle est pleine, tantôt diaphane, tantôt opaloïde, selon le degré d'élaboration de la liqueur spermatique qui la remplit. Elle est accolée par un de ses côtés à une autre vessie allongée qui la déborde et la couronne, et que sa diaphanéité dérobe quelquefois aux investigations. Le canal éjaculateur est court, filiforme, flexueux. L'armure copulatrice n'est point ici, comme dans les Pentatomes, une pièce logée dans une échancrure du dernier segment de l'abdomen. Ce segment est, comme je l'ai dit, tronqué en arrière, simple et entier. C'est à sa face ventrale et non dorsale qu'est placée l'armure. Celleci est une sorte de boîte cornée, ovalaire, légèrement convexe en-dessous, plane en-dessus. Sa base, qui est sa partie antérieure, est noire et plus dure, recouverte, à l'endroit où elle reçoit le canal éjaculateur, par une coiffe cornée, membraneuse, formée de deux paneaux. Sa surface plane est grisâtre, nembraneuse ou scarieuse, couverţe, au microscope, d'uu duvet couché, blond. La vergê, dont j’ai procuré l'exsertion en comprimant d'une manière expulsive l'armure, est grande, comparativement à la taille de l'insecte. Elle est cylindroïde et charnue. On lui reconnaît 
une sorte de prépuce dont le bord libre est finement cilié, et un gland bien marqué, comme bilobé.

C. hirticornis. - En parlant de l'organe digestif de cet insecte, j'ai dejà signalé l'exception remarquable qu'il formait, sous ce rapport, dans le genre Coré. Les signes extérieurs qui caractérisent les sexes le placent aussi dans une exception; car, à l'opposé de la plupart des autres espèces, l'abdomen du mâle est profondément échagncré à son extrémité, et les angles de l'échancrure se prolongent en une dent saillante qui dépasse de beaucoup une partie intermédiaire, bombée en-dessous, et bordée de quatre très petits festons arrondis. Les testicules ressemblent à ceux de l'espèce précédente. Les sept capsules séminifiques qui le constituent forment un éventail proportionnellement plus petit, plus arrondi et jaunâtre. Le canal déférent est plus court, et peu après sa naissance, il se renfle subitement, mais moins que dans le $C$. marginatus. Je u'ai su reconnaître qu'une seule vésicule séminale, grande, en forme d'utricule bilobée.

Alydus Geranii. - Dans le mâle, le dernier segment veutral de l'abdomen présente une large et profonde échancrure arrondie, qui décrit les trois quarts d'un cercle, et dans laquelle est logée l'armure de la verge.

Les testicules de cet Alyde se composent aussi de sept capsules séminifiques, allongées, rangées en un faisceau flabelliforme tronqué, d'un beau rouge-carmin à l'extérieur, contiguës entre elles dans toute leur longueur, et soudées en arrière. Le conduit déférent est blanc, plus court que le testicule, et représente une massue dont le gros bout serait à sa naissance. Il s'engage bientôt sous la vésicule séminale, et, avant de s'insérer un peu en arrière de l'origine du canal éjaculateur, il se confond avec son congénère en un tronc commun fort court, en une sorte de bulbe ova- 
laire. Il n'y a, comme je viens de le faire pressentir, qu'une seule vésicule séminale dans cet insecte; mais elle est fort grande et remplie d'un liquide prolifique diaphane. Elle est placée au centre de l'appareil génital, dont elle recouvre une bonne partie. Elle paraît oblongue et convexe quand on l'envisage dans sa situation naturelle; mais, si on la renverse sur le côté, on se convainct qu'elle est comprimée et réniforme. Ce n'est qu'en opérant ce déplacement qu'on peut cohstater ses connexions avec les autres parties de l'appareil. Le canal éjaculateur, d'abord renflé à son origine, puis filiforme, a peı de longueur et s'insère par une sorte d'enchatonnement dans l'échancrure de la vésicule séminale. En s'introduisant dans l'armure copulatrice, il s'accompagne d'un organe particulier et festonné, d'une glande des sécrétions excrémentitielles, dont je parlerai ailleurs. Liarmure copulatrice est ovale-arrondie, cornée comme à l'ordinaire, et enfoncée, ainsi que je l'ai dit plus haut, dans l'échancrure du deruier segment ventral de l'ahdomen. Elle paraît composée de deux pièces articulées ou enchatonnées l'une dans l'autre. La plus antérieure de celles-ci, et en mêtne temps celle qui n'est point visible à l'extérieur dans l'état d'inaction, est glabre, lisse et arrondie. L'autre, apparente, mème dans l'insecte mort, est velue, légèrement trilobée en arrière et terminée vers son milieu par deux pointes cornées, à peine arquées, couchées dans l'état de repos, mais susceptibles de se redresser et de servic de crochets lors de l'acte reproductif.

A. apterus. - J'ai déjà, en traitant du tube alimentaire des Alydes, fait ressortir la différence considérable qui s'observe, sous ce point de vue anatomique, entre les deux espèces soumises à mon scalpel. L'étude comparative de leurs organes de la génération confirme encore cette différence, et autorise à penser que ces deux Géo- 
corises méritent d'être placés dans deux genres distincts.

Le bout postérieur de l'abdomen du mâle de l'A. apterus présente, vu par-dessus, comme deux excavations séparées par une pointe épineuse centrale, dépendantes de l'armure copulatrice. L'organe spécial de la sécrétion du sperme a ici une configuration différente de celui de l' $A$. geranii, quoiqu'il soit composé du même nombre de capsules séminifiques, c'est-à-dire de sept. Mais celles-ci, au lieu d'être rangées sur un même plan horizontal, sont réunies en un faisceau ovale, conoïde, qu'enveloppe pareillement une tunique testiculaire rouge. Une dissection adroite peut isoler ces capsules séminifiques les unes des autres, et les étaler en étoile, ainsi que les représente une des figures que j'en donne. On voit alors que ces capsules sont blanches, effilées aux deux extrémités, et renflées au milieu, c'est-à-dire à peu près filiformes. Dans quelques cas de turgescence séminale, le faisceau testiculaire laisse apercevoir à l'extérieur la trace des capsules qui le composent. Lesconduits déférens, un peu plus longs que dans l'espèce précédente, et blancs, ont le même mode d'insertion au testicule et se terminent en arrière par un bulbe oblong. La vésicule séminale est unique et a la plus grande ressemblance avec celle de l' $A$. geranii.

Pyrrhocoris aptera. - Le bout de l'abdomen du màle laisse à découvert, en-dessous, une portion convexe et lisse de l'armure copulatrice, marquée d'une rainure ou coulisse transversale que domine un léger rebord supérieur fort brièvement duveté.

Nous allons retrouver dans les parties essentielles de l'appareil génital mâle de la Pyrrhocore le même plan d'organisation que dans les Corés, mais avec des différences et des modifications qui peuvent être regardées comme des 
traits génériques. Les testicules, au lieu d'être rouges, son t blancs ou semi diaphanes, et le plus souvent d'un aspect nacré. Les sept capsules séminifiques qui constituent chacun d'eux, sont allongées, contiguës, mais bien distinctes et disposées en un éventail élégant. Les conduits déférens sont filiformes et s'insèrent brusquement au testicule, comme le pédoncule au calice d'une fleur. Ils s'amincissent un peu en arrière avant de s'aboucher isolément de chaque côté de l'origine du canal éjaculateur. On ne retrouve pas ici cette grande vésicule séminale, unique, qui caractérise les Alydes. Il y a, vers la terminaison de chaque conduit déférent, une vésicule ovalaire, sessile, diaphane, qui paraît boursouflée comme si elle était formée par l'agglomération et la soudure de plusieurs utricules arrondies. Le canal éjaculateur est assez court; il débute par une sorte de tête arrondie ou de bulbe, et s'amincit ensuite comme un fil pour pénétrer dans l'armure copulatrice.

Celle-ci est une pièce arrondie, noire, une sorte de capsule cornée, enchâssée en grande partie dans le dernier anneau de l'abdomen, et articulée avec un demi-segnent bordé de rouge, qui en recouvre une portion en-dessous. Ce demi-segment, qu'on pourrait croire, au premier coup d'ceil, dépendant de la paroi ventrale de l'abdomen, est entraîné, par une compression expulsive, hors du corps, à la suite de la pièce copulatrice principale. La face inférieure de cette dernière est convexe, très lisse, glabre, luisante et sans aucune trace de division. Sa face supérieure, entièrement abritée dans l'état de repos, sous la dernière plaque dorsale de l'abdomen, est horizontale, déprimée, garnie d'un court duvet dans son contour, et on observe, vers son milieu, deux petites pièces cornées, noirâtres, lancéolées, contiguès, mais distinctes par une rainure médiane, et dont les pointes sont dirigées en avant. Ces pièces, 
susceptibles d'un mouvement de bascule sur leur base, paraissent destinées à jouer un rôle de préhension dans l'acte copulatif. C'est un peu en avant de leurs pointes que la compression expulsive fait saillir la verge dans l'insecte vivant.

Capsus tricolor. - Les Capses présentent dans la forme comme dans la structure de leursorganes générateurs mâles des traits qui les distinguent parfaitement des genres précédens.

Le mâle se reconnaît à ce que l'extrémité de son abdomen est formée dans une assez grande étendue, tant en dessus qu'en-dessous, par une seule pièce conoïde très obtuse, appartenant à l'armure copulatrice, convexe endessous, et sans aucune trace de division.

Les testicules forment de chaque côté de la base de la cavité abdominale une glande assez grosse, ovale, conoïde, qui rappelle celle de l'Alydus apterus. Cette glande, d'une teinte vert - jaunâtre plus ou moins foncée, est maintenue en place par de fines trachéoles, et offre extérieurement les traces linéaires de leur composition intime. Quand on cherche à constater celle-ci, on reconnaît que chacun des testicules est essentiellement constitué par un faisceau, non de sept, mais bien de huit capsules séminifiques, allongées, cylindroïdes, unies entre elles par un tissu adipeux et trachéen, et susceptibles, sans beaucoup de difficultés, d'être isolées les unes des autres. Le conduit déférent, d'une finesse capillaire et un peu plus long que le testicule, est à peu près droit. Les vésicules séminales ont une forme très différente de celle des Hémiptères que nous venons d'examiner, et qui se rapproche de celle deces réservoirs du sperme dans les Coléoptères. 11 y en a une paire pour chaque côté. Elles sont filiformes, cylindriques, flexueuses, souvent même contournées, dirigées en arrière de l'appareil, plus 
ou moins contiguës ou adossées dans leurs flexuosités, blanches ou opaloïdes, remarquables par une texture d'une certaine raideur. Je n'ai pu constater leur mode de connexion avec les conduits déférens. Le canal éjaculateur, qu'il m'a été impossible de mettre en évidence, doit être excessivement court. L'armure copulatrice, dont j'ai déjà dit quelque chose en parlant des signes extérieurs qui caractérisent les mâles, est une espèce de cornet conoïde ou turbiné, grand, noir, brièvement velu, qui recèle la verge. A la partie supérieure de son extrémité, est une légère dépression arrondie, où l'on découvre quelques petites aspérités et une pointe saillante, conoïde, un peu arquée, servant de crochet copulateur.

Miris carcelii. - Le mâle des Miris se reconnaît extérieurement, ainsi que celui des Capses, à la configuration du bout de l'abdomen, qui est d'une seule pièce obtuse, convexe en-dessous, et offrant en-dessus une légère dépression où se trouvent et l'anus et l'ouverture qui donne issue à l'organe copulateur.

Les testicules ont ici la même grandeur, la mème forme conoïde que ceux du Capse. Ils sont revêtus d'une tunique adipeuse d'un vert émeraude, et ressemblent au premier aspect à deux pelotons de graisse. Ce qui les distingue surtout de ceux de l'espèce précédente, c'est qu'ils ne sont composés que de sept capsules séminifiques allongées, au lieu de huit. Le conduit déférent est capillaire, mais infiniment plus court que le testicule. Les vésicules séminales sont de deux ordres; il y en a de chaque côté une paire fort a nalogue à celles des Capses, c'est-à-dire tubulenses, vermiformes, assez raides, arquées de manière que leurs bouts flottans regardent en arrière, et. sont presque partout contigus. Indépendamment de ces vésicules, on en trouve une impaire, sous la forme d'une vessie blanchâtre, arrondie, 
assez grosse, placée au milieu de l'appareil, et au-dessous de laquelle s'engagent les conduits déférens. Je ne me sens pas suffisamment éclairé sur ce corps intermédiaire, qui pourrait bien être aussi le bulbe du canal éjaculateur.

Aradus avenius. - La forme et la composition des organes génitaux mâles de ce Géocorise diffèrent sensiblement de celles de ce même appareil dans les Hémiptères que nous venons d'examiner, et justifient ce que j'ai dit à l'article de la Phymate, sur la nécessité de constituer en famille quelques genres qui, avec celui-ci, forment un groupe naturel.

L'abdomen du mâle de notre Aradus se termine par un mamelon obtus, noir, assez gros, placé dans une échancrure du dernier segment dorsal, et flanqué à droite et à gauche par un très petit lobe saillant qui fait partie des pièces copulatrices.

Les capsules séminifiques, qui constituent le testicule, ne m'ont paru qu'au nombre de cinq seulement, réunies en un faisceau. Mais la dissection de ce petit insecte s'accompagne de tant de difficultés, que je ne saurais avancer une assertion positive sur ce point d'anatomie qui semble faire une exception spéciale. Ce testicule n'est point enveloppé par une tunique colorée, et les capsules dont il se compose sont oblongues, fusiformes, blanchâtres, assez semblables, pour leur disposition, au calice d'une fleur dont les divisions seraient un peu conniventes. Le conduit déférent est plus long que le testicule, droit, blanchâtre. Il débute par une sorte de bulbe qui semble résulter de la soudure des capsules séminifiques; puis il s'amincit, pour se renfler ensuite brusquement et pour recevoir, en cet endroit, une vésicule séminale filiforme, flexueuse, flottante, blanche, insérée à son côté externe. Les conduits déférens s'engagent au-dessous d'une dilatation intermé-

4. Savans étrangers. 
diaire et ovalairt qui peut être considérée comme un bulbe très developjé du canal éjaculateur.

Cimex lectularius. - Le caractère extérieur qui dans ce puant insecte distingue le mâle, est fourni par le dernier segment dorsal de l'abdomen, qui est plus saillant, plus détaché, plus velu que celui de la femelle.

Le testicule est un faisceau de sept capsules séminifiques bien distinctes, ovales-oblongues, diaphanes ou blanchâtres, contiguës, tantôt disposées sur un même plan flabelliforme, tantôt comme doublées sur elles-mêmes et représentant deux rangées. Cet organe est, pour ainsi dire, à nu; il n'est revêtu d'aucune tunique bien marquée. Le conduit déférent est d'abord grêle, capillaire; il se renfle ensuite brusquement en un gros boyau allongé, conoïde, rempli d'un sperme plus blanc, plus compact. Avant leur insertion au canal éjaculateur, chacun de ces conduits reçoit une vésicule séminale de forme ovoïde, oblongue, au bout antérieur de laquelle s'implante un arbuscule à rameaux divergens, capillaires et diaphanes, qui peut être considéré comme un autre ordre de réservoirs du sperıne, à moins qu'on ne les regarde comme des vaisseaux chargés de quelque sécrétion spéciale. Le canal éjaculateur, fort difficile à mettre en évidence, paraît très court, et débute par un bulbe ovalaire qui résulte de la confluence des deux conduits déférens.

Reduvius stridulus. - L'organisation deson appareil génital mâle se rapproche de celle de la Punaisedes lits, mais elle en diffère génériquement. Le testicule se compose de sept capsules séminifiques blanchàtres, allongées, terminées en pointe, disposées en un faisceau élégant flabelliforme. Le conduit déférent est capillaire, de la longueur au moins du testicule. Je nai aperçu de chaque côté de l'appareil qu'une seule résicule séminale filiforme, flexueuse, subulée. 
Je renvoie à l'article des organes générateurs de la femelle, ce qui concerne les signes extérieurs distinctifs des sexes.

Pelogonus marginatus. - L'appareil mâle de la génération va nous offrir, dans le $P$ élogone, une forme et une structure qui éloignent cet insecte des autres Géocorises, et justifient les réflexions que nous avons émises relativennent à la nécessité de le colloquer dans une famille particulière avec I'Acanthia et le Leptopus. Le dernier segment dorsal de l'abdomen du mâle se distingue de celui de la femelle en ce qu'il est fornıe de trois pièces à bouts très obtus, qui le font paraître faiblement trilobé. De ces pièces, les latérales dépassent un peu l'intermédiaire, et sont bordées d'un léger duvet. Cette dernière est bilabiée pour le passage de la verge

L'organe que j'appelle testicules dans le Pélogone, pourrait tout aussi bien être regardé comme les vésicules séminales, et celles-ci, à leur tour, pourraient être prises pour les véritables testicules. J'avoue même qu'il serait difficile de produire des raisons solides pour justifier la préférence de la dénomination. Il me reste encore à moi-même des doutes, de l'incertitude sur ce point. Toutefois, guidé par mes nombreuses dissections d'insectes, je me suis déterminé à imposer le nom de testicule à cette partie de l'appareil génital qui, par sa composition, se rapprochait davantage de l'organe sécréteur du sperme, dans les autres Géocorises. Dans tous les cas, l'erreur, s'il y en a, ne saurait entrainer aucune conséquence physiologique sérieuse.

Les testicules, placés à la partie postérieure de la cavité abdominale, et suffisamment distans l'un de l'autre, ne consistent pas, comıne ceux de la plupart des Hémiptères précédens, en une série flabelliforme de capsules spermiliques égales entre elles, mais en une sorte de frange pres-

38. 
que unilatérale, que les verres amplifians démontrent être composée de douze à quinze capsules séminifiques plus ou moins diaphanes et d'inégale longueur. Les unes, vers la base de l'organe, sont courtes, ovalaires ou arrondies; les autres, bien plus longues que les premières, qu'elles débordent, sont filiformes, flexueuses ou droites; le canal déférent est assez court. Les vésicules séminales, situées loin des testicules, tout-à-fait à la base de l'abdomen, se présentent, pour chaque côté, sous la forme de deux tubes diaphanes roulés en spirale, confluens en arrière en un conduit fin comme un cheveu, fort long, replié en quatre ou cinq grandes flexuosités assez constantes, presque contiguës au testicule. Ce conduit se renfle avant de recevoir le canal déférent. Le conduit éjuculateur est un peu plus long que ce dernier, et cylindrique.

\section{AMPHIBICORISES.}

Nous allons trouver dans la configuration et la texture de l'appareil reproducteur mâle des Hémiptères Amphibicorises, plusieurs traits anatomiques bien prononcés qui vienneut à l'appui de mon opinion sur le rétablissement de cette famille naturelle d'insectes.

Gerris paludum. - Indépendamment de la taille, qui est sensiblement moindre dans le mâle, le dernier des segmens ventraux stigmatifères de l'abdomen, celui qui, de chaque côté, se termine en pointe, présente au milieu une petite échancrure semi circulaire qui n'existe point dans la femelle. Entre les deux pointes en question, il y a dans le màle trois pièces ou petits anneaux supplémentaires visibles en-dessous, et deux seulement dans la femelle. La seconde de ces pièces, enchatonnée dans la première, est arrondie, un peu bombée, et fait partie de l'armure copulatrice. La dernière ou la terminale est fort petite. J'observe 
aussi que le tubercule roussàtre placé au centre de la région sternale du métathorax, est plus grand et conıme formé par la réunion de deux saillies dans le mâle. Le G. canalium n'offie pas, dans le mâle, la petite échancrure semi circulaire dont je viens de parler.

Les testicules de cet insecte sont en quelque sorte à nu et libres dans la cavité abdominale, où ils sont retenus vers la base de celle-ci par quelques brides trachéennes, rares et fort déliées. Chacun d'eux consiste en une paire de capsules séminifiques oblongues, cylindroïdes, et contiguës latéralement l'une à l'autre. Le conduit déférent naît, non de l'extrémité postérieure de ces capsules, comme c'est l'ordinaire, mais du milieu de leur longueur et du bord par lequel elles se touchent. Ce conduit est formé en cet endroit par la confluence de deux cols excessivement courts. Il est d'abord capillaire, puis il présente une dilatation oblongue, constante, d'un blanc opaloïde, redevient ensuite capillaire, se fléchit pour se renfler de nouveau et s'unir enfin avec son congénère pour la formation du canal ejaculateur. Toutes mes investigations pour la découverte des vésicules séminales dans les deux espèces de Gerris soumises à mon scalpel, ont été sans résultat positif. Ces réservoirs, destinés au sẻjour et à l'élaboration de l'humeur prolifique, manquent absolument dans ces insectes, ainsi que dans la Vélie; en sorte que ce caractère négatif forme un des traits saillans de l'organisation viscérale des Amphibicorises. Au reste, il est fort probable que les vésicules séminales sont représentées dans les Gerris par la double dilatation et les inflexions du conduit que j’ai appelé déférent. Il est facile de concevoir que ces dernières conditions peuvent remplir le but physiologique attribué aux vésicules séminales ordinaires. Dans cette supposition qui, je le répète, n’est pas dénuée de probabilité, il faudrait 
réserver le nom de conduit déférent seulement à ce col, d'une extrême briéveté, qui sert à dégorger directement le sperme du testicule dans le conduit à double renflement. Le canal éjaculateur est assez court, presque diaphane. L'amnure copulatrice est un étui corné, ovoïde, noir, luisant, assez gros, échancré en avant, pointu et légèrement velu en arrière. En le comprimant, on fait saillir en-dessons de sa pointe postérieure une espéce de fourreau charnu d'où sort un petit filet blanchâtre qui est la verge.

Velia currens. .. J'ai déjà signalé, dans la description de cet insecte, les différences extérieures qui caractérisent les sexes. Dans le mâle les cuisses supérieures sont bien plus renflées, a vec des dents et des dentelures en-dessous; l'abdomen présente dans l'échancrure qui le termine une pièce assez grosse, saillante, dépendante de l'armure copulatrice, et qui ne s'observe point dans la femelle.

Son appareil reproductif mâle a une grande analogie d'organisation avec celui des Gerris, mais il en diffère aussi par quelques traits qui ont de la valeur comme caractères génériques. Ses testicules, au lieu d'être composés de deux capsules séminifiques, comme dans le genre précédent, sont simplement formés chacun par un seul sachet oblong, cylindroïde, blanchâtre, obtus à son bont antérieur, terminé en arrière par un prolongement subuliforme, une sorte d'appendice vermiculaire. Ces organes sécréteurs de la semence reposent, presqu'à nu, sur le tissu adipeux splanchnique qui revêt la paroi ventrale de la cavité de l'abdomen. Le conduit déférent prend brusquement naissance, comme dans les Gerris, vers le milieu de la longueur du testicule. Il est fort long d'abord, de la ténuité d'un cheveu, puis dilaté en un renflement oblong qui simule le testicule lui-même; il redevient ensuite capillaire, sefléchit, et va s'insérer isolément de son congénère 
à l'origine du canal éjaculateur. Je ne rencontre pas plus de traces de vésicules séminales dans la Vélie que dans les Gerris, et dans l'une conme dans l'autre, les renflemens et les inflexions du conduit déférent semblent en tenir lieu. Le conduit éjaculateur, plus long que dans le genre précédent, débute par un bulbe arrondi, s'amincit ensuite insensiblement en arrière, et après quelques légères flexuosités, s'engage dans l'armure copulatrice. Celle-ci est formée de deux pièces principales cornées, dont la postérieure, très courte, arrondie, velue et noirâtre, s'enchâsse dans l'antérieure qui est plus grande et représente une portion de cylindre. La pièce postérieure forme, avec une semblable placée au-dessous d'elle, un orifice bilabié qui, par la compression expulsive de l'armure, donne issue à un fourreau de consistance parcheminée qui renferme la verge.

\section{HYDROCORISES.}

Naucoris aptera. - Les testicules de cet Hémiptère se font remarquer parmi les autres viscères abdominaux par une couleur jaune foncé tranchante. Celle-ci est exclusivement propre à une tunique mucoso-adipeuse qui, dans la situation naturelle de l'organe, en masque et la configuration et la structure intime. Un faisceau trachéen assez considérable, qui s'épanouit à la face inférieure de ces glandes, fixe chacune d'elles à la base de la cavité abdominale. Quand on dépouille les testicules de leur enveloppe extérieure, on voit qu'ils se composent chacun de quatre capsules séminifiques blanchâtres, allongées, bien distinctes les unes des autres, insérées isolément, par une sorte de col tubuleux, à l'origine du conduit déférent. Mais, indépendamment de ces quatre capsules qui forment le corps du testicule, on découvre, 
à l'aide d'une dissection soigneuse, sur la convexité d'une anse $d u$ conduit déférent, tout près de la naissance de celui-ci, trois autres capsules séminifiques ovalesoblongues, fort petites, en quelque sorte rudimentaires, et assez difficiles à mettre en évidence parce qu'elles sont aussi cachées sous la tunique jaune. Ces petites capsules, qui sont de véritables vestiges, complètent numériquement les sept dont se compose le testicule de l'autre espèce de Naucore dont je parlerai bientôt. On voit qu'ici, pour me servir de l'expression vieillie de Leibnitz, la nature ne fait pas de saut, la transition est graduelle, et pent-être trouvera-t-on, dans quelque genre voisin des Naucores, des testicules exclusivement formés par quatre capsules séminifiques. Le conduit déférent est filiforme, flexueux, et enveloppé d'une gaîne jaune semblable à celle du testicule. Les vésicules séminales sont, contre l'ordinaire, en nombre impair, et agglomérées en un paquet très difficile à démêler. Il y en a trois, savoir : une de chaque côté, et la troisième au centre. La vésicule latérale se fait remarquer par une dilatation considérable, utriculiforme, sphéroïdale, remplie d'un liquide spermatique diaphane. Cette utricule reçoit l'insertion du conduit déférent qui lui correspond, un peu avant sa confluence avec sa congénère, pour la formation du canal éjaculateur. Par son bout antérieur elle se continue en un long boyau filiforme, blanc, très replié, borgne, et flottant par un bout. Ce boyau pourrait être d'autant plus facilement pris pour une vésicule séminale particulière, que son insertion au renflement utriculaire se fait au ceutre de celui-ci et d'une manière brusque. La troisième vésicule séminale, ou l'impaire, est tubuleuse, filiforme, semblable au boyau de la précédente; elle s'insère à l'origine et à la face inférieure du canal éjaculateur. Ce dernier 
présente à son début un renflement, un bulbe oblong, puis il devient grêle comme un fil.

L'armure copulatrice de cette Nancore est fort compliquée. Elle se compose de plusieurs pièces cornées mobiles, susceptibles de former la pince, et destinées à saisir, à accrocher les parties génitales externes de la femelle, pour l'accomplissement de l'acte reproductif: je vais essayer d'en donner la description. On observe d'abord à la face dorsale de l'armure deux espèces de paneaixx couchés à côté l'un de l'autre et susceptibles de s'éloigner et de se rapprocher au gré de l'animal Ces paneanx, égaux entre eux et de texture cornée, sont traversés vers leur milieu par un petit trait blanchâtre, moins consistant, qui semble le diviser en deux articles et permettre un monvement obscur. L'article terminal, ovale-triangulaire, est garni à tout son bord interne et dans une grande partie de l'externe, de cils assez raides. Le basilaire est glabre. Lorsqu'on a enlevé ou écarté ces paneaux, on découvre deux crochets principaux, inégaux entre eux, croisés l'un sur l'autre dans l'état de repos, et articulés sur les angles antérieurs du dernier segment dorsal de l'abdomen. De ces deux crochets, l'un, unidenté au-dessous de son extrémité, est hérissé sur un de ses bords de cils on de piquans dirigés en arrière; l'autre se termine par une lame en demi-fer de flèche obtus. C'est au-dessous et un peu en arrière de cette dernière que j’ai vu saillir par la compression un corps ovale-oblong, charnu, rétractile, qui m'a paru être ou le pénis ou le fourreau qui le renferme.

$N$. cimicoüdes. - Cette espèce, que quelques traits entomologiques bien prononcés distinguent de la $N$. aptera, en diffère encore bien davantage quand on examine comparativement leurs organes mâles de la génération.

4. Savans etrangers. 
Chacun de ses testicules se présente sous l'apparence d'un sachet ovalaire en raquette ou oblong, suivant son degré de turgescence séminale, n'offrant extérieurement aucune trace de division. Une tunique adipo-membraneuse blanchâtre ou d'une teinte verdâtre, forme l'enveloppe de sept capsules séminifiques dont le testicule est essentiellement composé. Ces capsules sont égales entre elles, allongées, diaphanes ou blanches, suivant le degré d'élaboration de l'humeur prolifique, diversement reployées ou contournées, et plus ou moins boursouflées. Il n'est pas rare qu'elles aient à leur base un renflement particulier, séparé du reste de la capsule par un léger étranglement, et plein d'un sperme plus blanc; mais ce trait est loin d'être constant. Le conduit déférent, bien plus long que celui de la $\boldsymbol{N}$. aptera, puisqu'il égale trois fois la longueur de tout le corps de l'insecte, offre à son origine une dilatation, un sinus où débouchent les capsules séminifiques. Après cette dilatation, il est fort délié et presque capillaire dans l'étendue de deux à trois lignes, puis il acquiert assez brusquement un calibre plus prononcé, et il se replie en nombreuses circonvolutions. Il est toutà-fait nu, et non enveloppé, comme celui de l'espèce précédente, par une gaîne analogue à la tunique testiculaire. Diaphane dans sa partie antérieure, il est rempli dans le reste de son étendue par un sperme d'un blanc nacré. Il débouche, par une implantation brusque, à la partie inférieure et postérieure des vésicules séminales. Celles-ci ont heaucoup d'analogie avec celles de la $N$. aptera, ainsi qu'on peut s'en convaincre en jetant un coup d'œil comparatif sur les figures qui accompagnent mon texte; mais je n'ai pu en découvrir qu'une seule paire, et elles correspondeut aux latérales de l'espèce précédente. II n'y en a point d'impaire. Elles se renflent en arrière en 
une grosse utricule ovoïde et sont filiformes par ailleurs. Le canal éjaculateur ressemble à celui de la $N$. aptera; il commence par un bulbe allongé et se termine par un tube filiforme qui pénètre dans l'arnuure copulatrice. Cette dernière, fort différente de l'espèce précédente, se compose, $\mathbf{I}^{\circ}$ de deux pièces latérales falciformes, obtuses, velues, coriacées, mobiles sur leur base; $2^{\circ}$ d'une plaque intermédiaire en forme de lozange, coriacée, velue, paraissant commune au dernier segment dorsal de l'abdomen et à l'armure copulatrice; $3^{\circ}$ enfin, d'une espèce le dard corné mobile, dont la pointe, dirigée en arrière, est en lancette acérée, et qui paraît être l'étui spécial de la verge.

Ranatra linearis. - Chacun de ses testicules se présente extérieurement sous la forme d'un corps oblong blanchâtre, aminci en avant, prolongé en arrière en une sorte de talon arroudi, enveloppé d'une tunique mucosoadipeuse non colorée qui en masque la texture intime. Cet organe est essentiellement composé de l'agglomération de cinq capsules séminifiques fort longues, filiformes, très repliées sur elles-mêmes, et renflées à leur origine en un bulbe ovalaire. Le conduit déférent est fort long; il est grêle comme un fil de soie pendant une certaine étendue, soit après sa naissance, soit avant sa terminaison; mais il présente vers son milieu un renflement cylindroïde qui semble le résultat d'une agglomération. Du moins l'ceil attentif distingue là, dans quelques conditions génératives favorables, des replis intestiniformes pour le déroulement desquels toute ma patience a échoué. Cette agglomération me paraît remplacer les vésicules séminales ou constituer un épididyme, et mes présomptions sur ce point s'étaient avec avantage d'une disposition presque analogue dans la Nèpe; disposition que 
j'ai parfaitement mise en évidence. Le canal éjaculateur est aussi délié que le conduit déférent à son origine, mais moins long que lui. L'armure copulatrice est un étui membrano-corné, oblong, muni de chaque côté d'une pièce palpiforme, d'un seul article, recourbée en crochet à sa pointe et mobile sur son point d'insertion. La verge est capillaire, et quand on détermine forcément son exsertion, elle paraît enveloppée d'une sorte de fourreau d'un tissu mou.

Nepa cinerea. - Il y a déjà plus d'nn siècle et demi que Swammerdam a, le premier, décrit et figuré l'appareil génital mâle de cet insecte, qui est l'un de ses Scorpions aquatiques ailés; et ses recherches, quoique incomplètes, témoignent hautement de l'exactitude de ce profond observateur.

Les testicules de la Nèpe se présentent de chaque côté de l'abdomen sous la forme de déux corps distincts, blanchâtres ou subdiaphanes, de configuration et de grandeur variables suivant leur état de turgescence séminale. Ils sont essentiellement constitués par l'agglomération de capsules spermifiques filiformes, très longues, tantôt renfermées dans une enveloppe comme adipo-nembraneuse, sorte de tunique vaginale ou, si l'on veut, de scrotum où rampent et que pénètrent des ramuscules trachéens fort déliés; tantôt presqu’à nu. Ce dernier état est celui où ces organes sont turgescens. Ainsi il y aurait en apparence, dans chaque individu, deux paires de testicules. Mais si l'on dégage ces capsules spermifiques des trachées et des lambeaux adipeux qui les maintiennent pelotonnées, et si l'on déroule soigneusement leurs circonvolutions, on se convainct qu'il y a deux capsules dans l'un de ces corps testiculaires et trois dans l'autre. Il n'est pas rare, surtout dans les individus où les testicules 
sont très développés et à nu, que ces agglomérations présentent extérieurement la trace de leur composition intérieure. Ainsi l'une, qui est un peu plus petite, paraît bilobée, et l'autre semble se partager en trois lobes. La figure qui accompagne mon texte représente les testicules de la Nèpe dans une condition remarquable de turgescence spermatique, et avec les lobes dont il vient d'être question. Chacune de ces capsules séminifiques a une longueur qui égale au moins celle de tout le corps de l'insecte, et avant leur confluence pour former le conduit déférent, elles offrent, dans le cas de l'aptitude à la copulation, un renflemeut plus ou moins prononcé. C'est principalement dans les mois d'août et de septembre qu'on les observe ainsi. Ce sont ces renflemens, qui sont nuls ou effacés hors de la condition de pléthore séminale, que Swammerdam appelle des corps glanduleux, et qu'il a grossièrement représentés.

Le conduit déférent du testicule, lorsqu'on le dévide en entier, est grêle, filiforme, plus long que tout le corps de l'insecte; mais, alans son état naturel, il présente bientôt après sa naissance un paquet oblong ou allongé, formé par l'entortillement, l'agglomération spirale des replis de ce conduit. C'est un véritable épididyme semblable à ceux que j’ai déjà signalés dans plusieurs Coléoptères, notamment dans les Carabiques, le Dytique, etc.

Il n'y a qu'une seule paire de vésicules séminales dans la Niepe. Aussi grèles, mais bien plus courtes que le conduit déférent, elles consistent, pour chaque còté, en un simple boyau, en partie engagé dans le paquet épidiảymique. Leur insertion aux conduits déférens a lieu à l'endroit où ceux-ci s'unissent pour la formation du canal éjaculateur. Celui-ci, que Swammerdam désigne sous la dénomination de racine ou corps nerveux de la verge, est 
court, et de même dianètre que le conduit déférent. L'armure copulatrice, plus grosse et plus courte que celle de la Ranatre, consiste extérieurement en une espèce de capsule ovalaire cornéo-membraneuse, commune à la verge et au rectum. Arrondie en avant, où de forts muscles la fixent aux segnens abdominaux, elle est légèrement convexe à sa face supérieure qui est duvetée, marquée d'une raie blanchâtre, médiane, et terminée en arrière par un prolongement obtus. Vers le milieu de chacun de ses côtés se voit, sous la forme d'un appendice, une petite tige d'une seule pièce, brune, cornée, terminée par une pointe fortement courbée en hamecon. Ce crochet copulateur, habituellement collé contre l'enveloppe extérieure que je viens de décrire, y est inséré par une articulation qui lui permet quelques légers mouvemens d'écartement.

Mais, indépendamment de cette armure extérieure, il y a en dedans de celle-ci un étui allongé, essentiellement propre à la verge de l'insecte; la partie antérieure ou basilaire de cet étui est formée par deux paneaux susceptibles de quelques mouvemens d'expansion. U se termine en arrière par deux lames glabres, légèrement spatulées, conniventes à leur extrémité, de manière à former la pince ou le forceps. Au-dessous de cet étui est le fourreau spécial de la verge, roussâtre, tubuleux, corné, présentant près de son extrémité un renflement sphéroïdal, terminé par un bec court, percé d'un trou rond et béant pour le passage du pénis.

Corixa striata. -- Ses testicules, dans l'état de turgescence spermatique où je les observai en mai 1828 , étaient énormes, vu la grandeur de l'insecte, et remplissaient presque toute la capacité abdominale. Ils se présentaient sous la forme de deux faisceaux ovales, conoïdes, blancs, presqu’à nu, c'est-à-dire dépourvus de tunique adipo- 
membraneuse, composés chacun de sept capsules séminifiques allongées, cylindrico-conoïdes, assez semblables à des gaînes ovigères, infécondes, faciles à isoler et à étaler, à cause de la rareté des trachéoles et du tissu adipeux. Ces capsules, bordées chacune d'une fine trachée, se terminent par un petit filet capillaire, sorte de ligament suspenseur qui leur donne encore plus de ressemblance avec une gaîne ovigère. Le conduit déférent, bulbeux à son origine, est ensuite filiforme et plus long que le testicule. Je n'ai point d'observations assez précises sur les vésicules séminales, le canal éjaculateur et l'armure copulatrice, pour entreprendre de les décrire. C'est une lacune que je me propose de remplir plus tard.

Notonecta glauca. - Son appareil génital màle a une organisation très différente de celle des Hydrocorises dont je viens d'exposer l'anatomie; et il est nécessaire, pour s'en faire une idée exacte, de l'étudier aux diverses phases de la vie de l'insecte; car il subit une espèce de métamorpliose à l'époque marquée par la nature, pour l'acte de la reproduction. Ainsi, au commencement du printemps, lorsque la Notonecte n'a point encore ressenti l'aiguillon qui sollicite le rapprochement des sexes, le testicule, dont la vitalité générative est encore endormie, est fort difficile à reconnaître, à cause de sa petitesse. C'est alors un corps blanchâtre, comme affaissé, d'une forme indéterminée, prolongé en arrière en un talon court et obtus, partagé en avant en deux filamens tubuleux tantôt simplement flexueux ou ployés, tantôt roulés en spirale, soit en dedans, soit en dehors. Ces filamens, d'une consistance un peu raide et comme élastique, sont d'un blanc nacré luisant; ce qui en imposerait à des yeux peu attentifs, pour deux troncs trachéens. Dans le mois de juillet, époque de l'accouplement des Notonectes, l'organe spécial de la sécrétion 
du sperme ne se présente plus avec l'aspect que je viens de décrire. Chacun d'eux consiste en deux gros cordons arrondis, saillans, turgescens, semi diaphanes, contournés en spirale, connivens en arrière pour la formation du conduit déférent. Lorsqu'on ouvre on qu'on déchire avec circonspection cet organe, dans le but d'en constater la composition intérieure, on ne retrouve point ces capsules séminifiques, plus ou moins faciles à isoler, qui caractérisent les testicules des genres précédens. Ici la texture intime est bien autrement compliquée, et n'est point facile à mettre en évidence. Ce que je vais dire sur ce point délicat d'anatomie, est le résultat de dissections faites au mois de mai 1825 , sur des individus dont les testicules n'étaient point dans des conditions propres à l'acte copulatif. On reconnaìt alors, à la faveur des verres âmplifians, que l'intérieur de ces organes est composé de conduits capillaires, fibrilliformes, longitudinaux, d'un aspect nacré, rayés, striés ou rugueux en travers, et en nombre indéterminable. Ces conduits se continuent jusque dans les deux lilamens tubuleux qui terminent en avant le testicule, et en suivent les flexuosités. Une bonne loupe suffit pour constater cette texture fibrillaire. Celle-ci est exclusivement propre au testicule, et cesse brusquement à la naissance du conduit déférent. J'ai cru remarquer que les conduits fibrilliformes se réduisaient à quatre, un peu avant cette naissance, et qu'alors ils perdaient leur aspect ridé. Quand on soumet à une forte lentille du microscope une des fibres constitutives dont je viens de parler, on y aperçoit des espèces d'étranglemens ou de cloisons comme dans les filamens des conferves articulées. Cette texture compliquée et vraiment remarquable des testicules de la Notonecte, texture qui s'accommode à l'explication du but physiologique de cette glande, ne semble-t-elle point au- 
toriser à regarder cet insecte comme un peu supérieur à ses congénères, pour le degré de son organisation?

Le conduit déférent du testicule de notre Hydrocorise est un cordon fort grêle, presque capillaire, d'une longueur qui surpasse quatre ou cinq fois celle de tout le corps de l'insecte, d'un aspect blanc satiné, d'abord simplement flexueux, puis roulé sur lui-mème en anneaux spiroïdes, làches, et s'accompagnant dans ces circonvolutions d'une vésicule séminale de même diamètre, et qui lui est adhérente. On compte quatre paires de vésicules séminales. De celles-ci, trois dirigées en avant ressemblent à des boyaux filiformes, flottans et fermés par un bout, semi translucides, irrégulièrement boursouflés, flexueux ou reployés, et deux fois plus longs que le corps de l'insecte. Elles vont s'insérer isolément à l'origine du canal éjaculateur. La quatrième paire, bien plus grêle, plus consistante que les précédentes et nullement boursouflée, est, comme je l'ai dit plus haut, accolée à la moitié postérieure du conduit déférent, dont elle suit les boucles spiroïdes. Le canal éjaculateur, ou le tronc de tout l'appareil génital, est cylindroïde, un peu courbé, blanchâtre, à peine de la longueur du tiers de l'abdomen, plus gros et surtout plus compact que les vésicules séminales. Il débute par un bulbe ovalaire où s'insèrent ces dernières et les conduits déférens.

L'armure copulatrice de la Notonecte, une fois dégagée de quelques pièces ou appendices ahdominaux, ciliés et barbus, est un corps de texture cornée, brun-luisant, oblong, cylindroïde, un peu arqué, garni d'un léger duvet à son extrémité postérieure. Celle-ci est obtuse et offre à sa face inférieure une espèce de panneau mobile. Une compression expulsive, exercée sur le corps de l'armure, fait saillir, entre le bout de celle-ci et le panneau dont je viens

4. Savans étrangers. 
de parler, une partie molle trilobée qui m'a paru devoir ètre le fourreau de la verge. Vers le milieu de la convexité de l'armure pend une pièce palpiforme, d'un seul article allongé, pubescent et pâle, dont j'ignore l'usage.

\section{CICADAIRES.}

Cicada orni. - La forme et la texture des organes génitaux mâles établissent, entre les Cicadaires et les familles précédentes, des différences aussi tranchantes que celles qui sont fournies par les caractères extérieurs ou entomologiques. Les testicules de la Cigale sont situés vers le milieu de la cavité abdominale, sous le paquet des viscères digestifs. Dans la condition favorable à la production du sperme, ils consistent en deux grappes arrondies (une pour chacun ) contiguës, et presque confondues entre elles, composées chacune d'une centaine au moins de petites capsules séminifiques ovoïdes, blanchâtres, disposées par glomérules, qui s'abouchent à un axe tubuleux ramifié. Le conduit déférent naît du centre de l'organe. Il est grêle, filiforme, reployé sur lui-même, et deux fois aussi long que tout le corps de l'insecte. Il n'y a qu'une paire de vésicules séminales; elles sont tubuleuses, filiformes, aussi longues que le conduit déférent, et enlacées avec lui dans leurs circonvolutions. Elles reçoivent ce dernier avant de devenir confluentes pour la formation du canal ejaculateur. Celui-ei, bulbeux à son origine, devient ensuite grêle comme un fil, et se fait remarquer par une texture ferme, comme élastique. L'armure copulatrice est un étui corné, ovalaire, composé de deux pièces principales, unies par une articulation ginglymoïdale ou en genou. La plus antérieure de ces pièces est oblongue, arrondie aux deux bouts, et creusée en-dessus pour recevoir le rectum et le canal éjaculateur. L'autre, plus dure et plus noire, placée 
aı-rlessous de la précédente, se termine par deux forts crochets arqués, dirigés en bas. La verge sort d'entre ces derniers. C'est un filet cylindrique, disposé à se contourner en spirale, marqué de stries annulaires, et dont l'extrémité offre le vestige d'un gland.

\section{FUIGORELLES.}

Issus coleoptratus. - C'est la seule espèce de la famiile des Fulgorelles dont j’aie pu étudier l'appareil générateur. Le mâle se distingue extérieurement de la femelle, en ce que la région anale est recouverte par une plaque ovaleoblongue, au milieu de laquelle on aperçoit une dépression particulière où se trouve une petite pièce en forme de soupape. Les testicules se font remarquer à l'instant par la couleur rouge de la tunique adipo-membraneuse qui les revêt, et qui rappelle celle des Pentatomes. Situés à la base de la cavité abdominale, sous les viscères de la digestion, ils consistent extérieurement en deux glandes ovoides, assez grosses dans l'état de turgescence, fixées par de rares trachéoles et quelques filets nerveux imperceptibles. Si l'on cherche, en les dépouillant de leur enveloppe, à constater leur structure intime, on reconnait que chacun des testicules esi essentiellement constitué par un groupe d'une vingtaine environ de capsules séminifiques allongées, pointues, semi diaphanes, qu'un scalpel adroit peut étaler en étoile comme une fleur. Ces capsules convergent en arrière, en un même point, pour la formation du conduit déférent. Celui-ci naît soudainement du bout postérieur du testicule. II est d'abord grêle comme un fil, puis il semble enfiler un peløton ovalaire, revêtu aussi d'une tunique rouge, et parcouru par une rainure longitudinale. Au premier aperçu, on prendrait ce peloton pour un testicule supplémentaire, analogue à celui qui caractérise la $\mathrm{Nau}$ - 
core aptère; mais le scalpel dissipe cette illusion, et l'on se convainct qu'il est formé intérieurement par une agglomération des replis du conduit déférent lui-même; enfin que c'est un véritable épididyme. C'est à la saillie d'un de ces replis qu'est due la rainure extérieure dont je viens de parler. Le conduit déférent redevient filiforme à sa sortie du peloton épididymique, et va s'insérer à la base et endessous de la vésicule séminale correspondante. Il n'y a qu'une paire de vésicules séminales, et dans leursituation naturelle, elles se cachent presque entièrement sous les testicules. Elles sont grêles comme un fil, diaphanes, fort longues, reployées en plusieurs circonvolutions, que leur fragilité et les trachéoles imperceptibles qui les enlacent, rendent fort difficiles à dérouler intégralement. Je me suis assuré que chacune d'elles a quatre fois la longueur de tout le corps de l'insecte. Leur bout flottant est arrondi, et par l'extrémité opposée elles sont à peine atténuées. Le canal éjaculateur n'a pas la sixième partie de la longueur d'une vésicule. Il est filiforme, mais avant de pénétrer dans l'armure copulatrice, il se renfle légèrement en un bulbe ovalaire.

\section{CICADELLES.}

Aphrophora salicina. - Le mâle se reconnaît à son abdomen, terminé par une pointe conoïde, un pen comprimée, velue, armée de chaque côté de sa base d'un très petit crochet corné. Chacun des testicules, organisé à peu près sur le même plan que celni de la Fulgorelle précédente, mais sans enveloppe adipo-membraneuse, est formé d'un faisceau assez lâche et presqu'à nu, d'une vingtaine environ de capsules séminifiques, bien distinctes, ovalesoblongues, semi diaphanes, obtuses et arrondies en avant, atténuées en arrière en un col délié par lequel elles convergent pour s'aboucher au conduit déférent. Ce dernier, 
d'une longueur vraiment démesurée, puisqu'il égale sept à huit fois celle de tout le corps de l'insecte, est fort reployé sur lui-même, d'une ténuité partout capillaire, d'un blanc nacré, et d'une consistance un peu élastique lorsqu'il est bien rempli de sperme. Il y a deux paires de vésicules séminales, et elles sont longues, tubuleuses, filiformes, reployées sur elles-mêmes. L'une, l'interne, moins longue que l'autre, présente à son extrémité un renflement courbé en crosse, où s'insère brusquement le conduit déférent. Ce mode d'insertion, au bout flottant de la vésicule, et non, comme c'est l'ordinaire, à sa base, m'avait fait hésiter sur la dénomination qu'il fallait donner à ce boyau tubuleux. Je l'avais d'abord regardé comme la continuation du conduit déféreut; mais sa position, sa ressemblance avec l'autre vésicule, et le changement soudain de diamètre au point de connexion, ont déterminé ma préférence. Au reste, ce trait anatomique est peut-être particulier au genre Aphrophore; car je l'ai rencontré semblable en tout dans l'Aphrophora spumaria. L'autre vésicule séminale, ou l'externe, est plusieurs fois fléchie sur elle-même, blanche et sensiblement plus grosse daus sa moitié postérieure, plus grêle et diaphane dans l'antérieure. Son bout flottant est renflé en une utricule sphéroïdale. Le canal éjaculateur est court, renflé en un grand bulbe cordiforme qui recoit, de chaque côté de sa partie antérieure, la tige commune aux vésicules séminales.

\section{PSYIIIDES.}

Psylla ficus. - L'organisation des viscères générateurs mâles de la Psylle justifie pleinement ceque j’ai déjà avancé relativement au rétablissement et au maintien de la famille des Psyllides. Le mâle se distingue extérieurement de la femelle par la configuratiou du bout de l'abdomen, qui 
présente deux crochets bien détachés, noirâtres, durs, glabres; l'un supérieur, l'autre inférieur, susceptibles de s'écarter et de se rapprocher comme les branches d'une pince, par le jeu des segmens abdominaux sur lesquels ils sont articulés. On les distingue difficilement lorsque l'insecte les tient pressés l'un contre l'autre. Le crochet supérieur est plus long, à peine arqué, cylindroïde, et sa pointe aiguë est dirigée en arrière et un peu en bas. L'inférieur est obtus, à peu près droit, légèrement renflé en massue. C'est dans l'entr'ouverture des segmens qui supportent et meuvent ces crochets, que se trouvent ct l'anus et l'orifice qui donne issue à la verge.

Dans presque tous les Hémiptères dont je viens d'exposer l'anatomie des organes mâles de la génération, les capsules séminifiques du testicule, lorsqu'il y en a un nombre déterminé, sont impaires. Dans la Psylle, il en est autrement. Les testicules, situés vers le milien de la cavité abdominale, se composent chacun de quatre capsules séminifiques seulement. Ces capsules, tout-à-fait à nu, c'est-à-dire dépourvues de tunique testiculaire, sont allongées, conoïdes, pointues, tantôt droites, tantôt fléchies ou contournées, réunies en un faisceau lâche, et remplies d'un sperme plus ou moins diaphane, ou comme moucheté. Le conduit déférent naît du point où les capsules séminifiques convergent par leur base. Il est d'une finesse, d'une pellucidité, qui échappent souvent à l'œil armé de la plus forte loupe. Il m'a été impossible de constater son mode d'insertion avec les vésicules séminales. Celles-ci, au nombre de deux seulement, se présentent sous la forme de vessies ovalaires, diaphanes, situées en' arrière de tout l'appareil, et susceptibles d'un plus ou moins grand développement, suivant l'état de turgescence séminale. Elles deviennent considérables, au moins dans quelques individus, à l'é- 
poque de l'accouplement. C'est dans cette condition que je les dessinai en octobre 1829 .

Au-dessus et entre ces vésicules séminales, on trouve deux corps ovoïdes, fort remarquables par leur couleur jaune-orangé, et sur la dénomination desquels je n'ose point me prononcer. Leur couleur, leur forme, leur position, leur texture apparente, me firent d'abord présamer que c'étaient les testicules; mais la découverte tardive de ceux-ci, parfaitement bien caractérisés, me jeta dans l'incertitude où je me trouve encore. Ces corps, constans pour leur existence, et invariables pour leur forme, leur grandeur, leur couleur, sont contigus et peut-être adhérens par leur bord interne, qui répond à la ligne médiane du corps de l'insecte. L'espèce d'enduit ou de pigmentum jaune qui les recouvre, disparait par une macération prolongée, et alors ils se présentent sous l'apparence utricnlaire, de manière que je suis plus porté à les regarder comme une seconde paire de vésicules séminales.

Nota. Je me vois obligé de répéter ici mes regrets de n'avoir pas été à même de disséquer des individus mảles de la Dorthésie. C'eût été pour moi une véritable bonne fortune que de porter le scalpel dans leur appareil de la géuération; mais ces insectes ont éludé jusqu'à ce jour toutes mes perquisitions réitérées. Je sens vivement l'importance de cette lacune.

\section{ARTICLE II.}

Organes générateurs femelles.

L'appareil génital femelle des Hémiptères se compose en général, $\mathbf{x}^{\circ}$ de deux ovaires; $2^{\circ}$ d'un oviducte; $3^{\circ}$ d'une glande sébifique de l'oviducte; $4^{\circ}$ de diverses pièces vulvaires plus ou moins externes; $5^{\circ}$ enfin des produits de la fécondation, qui sont le plus souvent des $2 u f s$, rarement des petits vivans. 
Les ovaires sont situés dans la cavité abdominale, audessous du paquet des viscères digestifs. Ils consistent, ainsi que ceux des insectes en général, en deux faisceaux semblables, composés chacun d'un certain nombre de boyaux tubulés, destinés, dans les espèces ovipares, à la formation, au développement, au sejjour des œufs. Je désigne ces boyaux sous le nom de gaînes ovigères. Celles-ci remplissent le même but physiologique que la matrice des quadrupèdes. Lorsque la fécondation a eu lieu, on les trouve partagées, suivant leur longueur, par des étranglemens successifs d'autant plus prononcés que la gestation est plus a vancée, et qui interceptent des cellules ou des loges toujours monospermes, c'est-à-dire ne renfermant jamais qu'un seul germe ou un seul œuf. Dans l'état de virginité elles n'offrent aucune trace d'étranglemens. Le nombre des gaînes et des loges est constant dans les individus d'une même espèce, mais it varie suivant les familles et les genres. Ces gaînes peuvent être uni ou multiloculaires.

Le sommet ou l'extrémité antérieure de la gaîne ovigère est formé par un corps d'apparence charnue, compact, c'est-à-dire non vésiculeux, dont la configuration est différente suivant les genres. Cet article terminal est d'ordinaire fixé, suspendu au moyen d'un filet propre d'une grande ténuité, qui mérite le nom de ligament suspenseur. Les sept ligamens suspeuseurs convergent en un ligament commun qui va s'implanter dans le thorax. Ce corps charnu se rencontre constamment dans les ovaires de tous les insectes en général. Daus les divers écrits qui ont précédé celui-ci, j’ai gardé le silence sur ses fonctions, parce que je ne me croyais pas suffisamment éclairé, et le petit nombre d'entomotomistes qui se sont occupés de l'appareil génital des insectes n'y ont porté qu'une atten- 
tion fort superficielle. Je suis peut-être plus à même aujourd'hui de m'expliquer sur les attributions physiologiques de ce corps, que je n'hésite point à qualifier du nom d'organe. Je le considère comme le réceptacle des ovules ou germes imperceptibles des ceufs, et je propose pour lui la dénomination d'ovulaire. Par sa position, ses rapports, ses fonctions, peut-être même sa texture, il présente, suivant nous, la plus grande analogie avec l'ovaire des quadrupèdes. Dans les femelles vierges, où les gaînes ovigères n'offrent point encore la trace des loges, l'ovulaire est très prononcé, souvent même plus développé que dans la condition contraire.

Les gaînes ovigères qui constituent chaque ovaire s'abouchent souvent en arrière dans un réservoir commun qu'on peut appeler calice. Celui-ci est plus ou moins marqué, suivant l'époque de la gestation et la quantité d'œufs à terme qu'il contient. Ordinairement il se termine par une portion tubuleuse d'une longueur variable à laquelle j’ai donné le nom de col de l'ovaire. Les deux cols confluent ensemble pour la formation de l'oviducte.

L'oviducte est un canal ou conduit commun aux deux ovaires, dont il est pour ainsi clire le tronc. Il est destiné soit à livrer passage aux ceufs à terme pour être pondus, soit à faire l'office du vagin dans le coït. 11 varie pour sa forme et sa longueur, et il n'est pas toujours facile de le mettre en évidence.

J'ai désigné ailleurs sous le nom de glande sébacée, et je désigne aujourd'hui sous celui, plus approprié, de glande sébifique de l'oviducte, un petit appareil sécréteur qui fait partie de l'organe génital femelle de tous les insectes ovipares en général, et qui est constamment implanté sur le trajet du canal éducateur des œufs. Je lui attribue, avec Swammerdam, la fonction de sécréter une

4. Savans étrangers. 
humeur sébacée spéciale, destinée, lors de la ponte, à enduire les œufs d'un vernis qui en durcit la coque et les prémunit ainsi contre les ontrages du temps. Dans mon travail sur l'anatomie de l'Hippobosque (Annal. des Sc. nat., I 825 , t. VI), j'ai combattu avantageusement, je pense, l’opinion qui tendait à faire considérer cet organe comme une poche simplement copulatrice. La position de cet appareil, qui dans ce Diptère pupipare est placé tout-à-fait en avant de la matrice, par conséquent hors de la portée du pénis du mâle, est un argument sans réplique. Les Hémiptères vont nous en offrir un autre tout aussi solide; car dans les Pucerons, qui sont décidément vivipares, et chez lesquels, par conséquent, un appareil organique propre à sécréter un vernis pour les cufs eût été superflu, la glande sébifique manque absolument.

Je comprends sous la dénomination générique de pièces vulvaires un ensemble de plaques ou d'écailles plus ou moins étroitement articulées au voisinage de la vulve, extérieures, ou susceptibles de se produire au dehors au gré de l'insecte. Les unes forment la vulve proprement dite; d'autres consistent en de simples crochets qui favorisent l'acte copulatif; enfin il en est qui constituent un instrument assez compliqué, destiné à introduire les œufs dans un milieu plus ou moins résistant, et on a désigné cet instrument sous le nom d'oviscapte. Ces pièces établissent, par la diversité de leur configuration et de leur développement, des différences saillantes dans les familles et les genres des Hémiptères.

Les produits de la génération sont bien plus diversifiés pour leur nature et leur configuration dans les Hémiptères que dans aucun autre ordre d'insectes, et il nous reste encore beaucoup à acquérir sous ce rapport. Dans la plupart ces produits sont des œufs, mais les Pucerons, comme 
on sait, sont vivipares dans toute la valeur de ce terme, et la Dorthésie, comparable en quelque sorte à la Sarigue, porte dans un sac attaché à son corps sa progéniture, jusqu’à ce que celle-ci soit en état de pourvoir d'elle-même à sa subsistance. Cet insecte semble donc intermédiaire aux ovipares et aux vivipares. Quant aux œufs, ils ont des formes extrèmement variées et parfois élégantes. Ainsi il en est de ronds, d'ovales, d'allongés, de pointus, de tronqués; quelques-uns ont a un de leurs bouts des soies dont le nombre est déterminé; plusieurs s'ouvrent par des opercules réguliers, tantôt eu segment de sphère, tantôt plats; il y en a de glabres et de velus, de jaunes, de bronzés, d'irisés, etc. Mais n'anticipons point sur des détails qui concernent les espèces.

Par les mêmes motifs que j’ai exposés à l'article des organes mâles de la reproduction, je vais décrire, à l'occasion de chaque espèce, l'ensemble des parties qui constituent l'appareil génital femelle.

\section{GÉOCORJSES.}

Scutellera nigro-lineata. - La région anale de la femelle, vue en-dessous, présente un espace non stigmatifère formé exclusivement par l'ensemble des pièces vulvaires. Cet espace est arrondi et bombé en avant, déprimé, tronqué et un peu dilaté en arrière. Il se compose de sept écailles étroitement appliquées les unes contre les autres, comme une mosaïque, douées d'un mouvement peu étendu, mais bien sensible sur l'insecte vivant. De ces pièces, deux sont en avant, deux en arrière, et trois intermédiaires. Les pièces antérieures forment par leur réunion la portion bombée dont je viens de parler. Ce sont deux espèces de panneaux, larges, semblables entre eux, contigus à la ligne médiane du corps, dans l'état de repos, 
et susceptibles, lors du coït ou de la ponte, de s'entr'ouvrir et de présenter une fente plus ou moins béante. Voilà une véritable vulve dont les panneaux représentent exactement les grandes lèvres. On observe même dans cette espèce une villosité bien marquée en dehors de celles-ci, une sorte de mont de Vénus. Les deux pièces postérieures, aussi d'une configuration uniforme, sont triangulaires, pointues, placées à droite et à gauche de l'anus. Je les crois destinées à favoriser, par la saillie facultative de leur pointe acérée, l'acte copulatif. Quant aux pièces intermédiaires, un examen peu scrupuleux les regarderait comme ne formant qu'une seule plaque dont le bord postérieur présente dans son milieu une échancrure assez profonde qui correspond à l'anus. Les angles de cette échancrure sont obtus, à peine recourbés en crochet, et une bonne loupe y apercoit des aspérités. Ces angles sont les bouts, l'extrémité des pièces latérales, et le sinus correspond à une plaque médiane dont le bout libre est noir et rude comme les angles. Cette plaque médiane m'a paru formée de deux articles habituellement contigus. Ces pièces jouent sans doute un rôle actif dans la copulation; mais, sans forcer les rapprochemens, ne trouvons-nous pas dans cette portion tégumentaire qui sépare l'anus de la vulve, l'analogue du périnée des Mammifères? Qu'il me soit perınis de rappeler à cette occasion, le principe de l'unité de composition organique si savamment discuté par M. Geoffroi de SaintHilaire.

Si je suis entré dans quelques détails sur la structure curieuse de l'appareil vulvaire de la Sc. rayée, c'est que jai voulu, pour abréger mon texte, que cette description servît de type pour les espèces et les genres analogues; en sorte que je n'aurai plus, en abordant ce même article 
dans ces derniers, qu'à signaler les modifications ou les différences.

Les ovaires de notre Scutellère consistent en deux faisceaux conoïdes, composés chacun de sept gaînes ovigères, assez courtes, triloculaires, lorsqu'on les étudie dans un état de gestation avancée. Les ovulaires sont allongés, cylindroïdes ou légèrement renflés en massue. Les sept ligamens suspenseurs des gaînes ovigères, parfaitement distincts les uns des autres, convergent en un seul lien commun qui va s'implanter, avec son congénère, dans le thoras de l'insecte. L'oviducte est court et cylindroïde. La glande sébifique se compose, $\mathrm{I}^{\circ} \mathrm{d}^{\prime}$ un organe essentiellement sécréteur en forme de tète arrondie blauchàtre, munie d'une espèce de col fort court qui en est le conduit efférent; $2^{\circ}$ d'un réservoir ovale-oblong, pareillement blanchàtre, d'une texture charnue, d'une consistance comme callense; $3^{\circ}$ enfin d'un canal excréteur grêle qui sert de pédicelle au réservoir, et qui s'insère sur le trajet de l'oviducte. J'exposerai plus bas, à l'article de la Pentatome grise, ce qui est relatif à la structure intime, à la disposition intérieure de toutes ces parties.

Sc. maura._L'appareil vulvaire de cette espècc est fait absolument sur le même plan que celui de la précédente, et se compose du même nombre de parties. J'observe seulement que les lèvres ou panneaux de la vulve sont beaucoup moins bombés et presque glabres; que les pointes des pièces postérjeures se croisent un peu réciproquement, et que la plaque médiane des pièces intermédiaires est entièrement cachée par les latérales.

Les ovaires et le nombre des gaînes ovigères sont les mêmes que dans la $S c$. rayée; mais nous allons trouver dans quelques dépendances de l'appareil génital femelle, des traits anatomiques qui établissent entre ces deux Géo- 
corises des différences non-seulement spécifiques, mais peut-être génériques, comme je l'ai déjà insinué en parlant des organes mâles de la génération. L'oviducte est court, dilaté, et de chaque côté de son origine, ou plutôt à la terminaison de chacun des cols des ovaires, il y a une espèce de collerette ou de manchette formée par de nombreux petits tubes courts, blanchâtres ou semi diaphanes, la plupart simples, disposés en franges. Ces vaisseaux tubuleux, d'une petitesse qui ne permet point d'en saisir les connexions, sont sans doute chargés d'une sécrétion particnlière lors de la ponte. Peut-être aussi ne sont-ils là que comme vestiges d'un organe qui peut exister mieux condition né dans d'autres genres d'Hémiptères voisins de notre Scutellère. Au lieu d'une glande sébifique, conformée comme celle de la Scutellère rayée, on observe ici, de chaque côté de l'oviducte, une poche vésiculaire, arrondie ou ovalaire, suivant son degré de plénitude, fixée au moyen d'un col fort court, et remplie d'une humeur limpide. On rencontre quelquefois ces poches vésiculaires vides, affaissées, déformées; elles ressemblent alors à des caroncules ou oreillettes, et prennent une teinte blonde. Sur le disque même de l'oviducte, on observe un organe pyriforme blanchàtre, qui dégénère en arrière en un col bien distinct, au moyen duquel se fait son insertion. Cet organe correspond au réservoir de la glande sébifique de la précédente espèce, et, étudié à la loupe par sa face inférieure, on reconnaît dans son intérieur, à travers son enveloppe, un corps globuleux d'une nuance obscure, vraisemblablement une espèce de sac interne, dont le canal excrétcur aurait, dès son origine, deux petites dilatations.

Les $e u f s$ de la $S c$. maure sont globuleux, glabres, rangés en séries contiguës, sur le support où ils ont été pondus, et ils sont proportionnellement plus gros que ceux de la 
$S c$. rayée. Ils ont, soit quand ils sont encore renfermés dans les gaînes ovigères, soit quand ils viennent d'ètre pondus, une couleur vert-émeraude. Ils s'ouvrent par ui opercule en forme de calotte sacerdotale, et la circonscription de celle-ci est marquée par une rangée circulaire de très petits points blancs qu'une bonne loupe découvre facilement. Les petites $\boldsymbol{S}$ cutellères, quand elles viennent d'éclore, sont d'un noir bronzé obscur.

Pentatoma grisea. - Les pièces vulvaires sont aussi an nombre de sept, mais sensiblement plus développées, moins serrées entre elles, plus distinctes que dans le genre précédent. Les lèvres de la vulve sont velues, déprimées plutôt que convexes. Les pièces postérieures ou celles qui flanquent l'anus, nullement inclinées l'une vers l'autre et bien plus grandes que dans les $S$ cutellères, sont carénées dans le milieu et se terminent par une pointe en épine, velue, qui fait saillie au-delà du dernier segment dorsal de l'abdomen. Les plaques latérales des pièces intermédiaires sont bieu moins obliques que dans les Géocorises précédens, et leur extrémité dépasse, sous la forme d'une dent velue, le bout de l'abdomen. La plaque médiane est bien distincte et en carré long. On reconnaît visiblement qu'elle est formée de deux articles, dont le basilaire, plus large, est en partie cachë par les lèvres de la vulve.

Chacun des ovaires de notre Pentatome se compose, ainsi que celui de la plupart des espèces de ce genre soumises à mes investigations anatomiques, de sept gaînes ovigères bi ou triloculaires, dont la forme, la texture et la disposition sont les mèmes que dans les Scutellères. Les ovulaires sont ovoïdes-pointus. Les cols des ovaires se terminent par une collerette frangée, semblable à celle de la $S$ cutellère maure, mais un peu plus développée. L'oviducte est dilaté, ovalaire. La glande sébifique se compose des mèmes parties 
essentielles que celle de la Scutellère rayée, et je vais, comme je l'ai promis, me livrer à l'examen de sa texture intime.

Avant d'exposer celle-ci, il est bon de se rappeler que la Pentatome grise, ainsi que la plupart des espèces de ce genre et des genres voisins, en pondant ses cufs, non-seulement les fixe, au moyen d'une colle ou d'une gomme noire, sur le support, mais qu'elle les enduit d'un vernis imperméable, gris de perle, irisé ou métallique. Ce vernis n'existe point dans les cufs renfermés dans l'ovaire, quoique parvenus à terme. Ceux-ci sont alors jaunâtres et paraissent plus grands qu'après avoir été pondus.

La collerette frangée serait-elle l'organe qui sécrète spécialement la gomme noire qui colle les œufs sur leur support, et la glande sébifique serait-elle celui qui fournit les vernis qui les enduit? C'est une double question que je n'oserais pas résoudre définitivement, quoique j’incline pour l'affirmative.

Quoi qu'il en puisse être, l'organe, qui dans l'appareil sébifique paraît plus essentiellement sécréteur, se présente sous la forme extérieure d'un bouton ou plutôt d'un gland pédicellé situé à l'extrémité du réservoir, et penché, couché sur lui. Ce gland, ovalaire, avec un bourrelet assez prononcé à sa base, qui imite la cupule de ce fruit, ressemble, au premier aspect, à cause de la pellucidité de son tissu, à un corps utriculaire. Mais un examen plus attentif fait reconnaitre que ses parois sont charnues, épaisses, d'une consistance presque calleuse; et on distingue au travers, à la faveur de la loupe, un axe intérieur d'une nuance plus olsscure, qui n'atteint pas tout-à-fait le bout du gland. Si , après une macération de quelques heures, on cherche à constater par la dissection la structure intime de ce gland sécréteur, on trouve que son axe est une capsule centrale 
jaunâtre, opaque, d'un tissu fibro-membraneux. La tunique charnue, qui enveloppe cette capsule, adhère à toute sa surface, de manière qu'on ne peut point parvenir à l'en dégager complètement. C'est sans doute à cause de cela que la capsule paraît, au microscope, comme velue. Quand on poursuit cette dissection jusque dans le pédicelle, on découvre vers le milieu de celui-ci, qui offre le même tissu fibro-membraneux que la capsule elle-même, une sorte de godet on de bourrelet circulaire, ayant la forme d'une virole enfilée par le pédicelle. Ce dernier doit être considéré comme un conduit efférent destiné à transmettre au réservoir l'humeur sécrétée.

Le réservoir de l'lıumeur sébacée est un corps ellipsoïdal assez grand, muni d'un pédicule, revêtu extérieurement par un pannicule charnu, contractile, semi pellucide, plus ou noins ridé, inégal ou plissé, suivant son degré de dilatation. Cette première tunique musculeuse enveloppe un sac central, une vessie d'un tissu serré, blanchâtre, d'une consistance élastique, d'une surface lisse ou très finement striée, peu ou point adhérente à l'enveloppe. La demi transparence des parois de cette vessie permet d'apercevoir dans son centre un axe linéaire sétacé d'une teinte brunâtre. Lorsqu'on isole ce dernier en déchirant. l'enveloppe, et qu'on le soumet à une forte lentille du microscope, on s'assure que c'est une tige tubuleuse de texture coriacée, renflée à son bout antérieur où s'insère le conduit efférent du gland sécréteur, et terminée à l'extrémité opposée en pointe de lancette tronquée. Cette pointe s'engage dans l'origine du canal excréteur ou pédicelle du réservoir. C'est indubitablement par ce tube capillaire que se filtre peu à peu le vernis dont la Pentatome enduit ses œufs en se servant de sa pointe acérée comme d'un pinceau.

La $P$. grise, en pondant ses $œ u f s$, les dispose de manière 4. Savans étrangers. 
à ce qu'ils soient contigus, mais jamais entassés. lls ont une couleur gris de perle, une forme ovalaire ou plutôt en court cylindre, dont le bout collé sur le support est tronqué, tandis que l'autre est arrondi en segment de sphère. Ce dernier, observé à la loupe, offre une ligne circulaire qui circonscrit une opercule en calotte. Celui-ci se détache lors de la naissance de la larve, et le limbe de l'ouverture est bordé de cils fort petits que le microscope met en évidence, et qui sont destinés à retenir le couvercle avant l'époque de la maturité de l'œuf.

P. Smaragdula. - L'appareil vulvaire ne préseute, comparativement à celui de la $P$. grise, que de légères différences purement spécifiques. Les pièces sont un peu moins développées : les postérieures et les latérales des intermédiaires ne forment point une saillie, et ne se terminent pas en une pointe.

Les ovaires ont aussi sept gaînes ovigères chacun; mais ces gaînes, dans l'état de fécondation, m’ont paru quinqueloculaires, et les ovulaires se terminent par un bouton en forme d'olive. L'appareil sébifique est organisé comme celui de l'espèce précédente, mais avec quelques différences spécifiques que je vais signaler, et dont je produis les figures. Le réservoir est un peu plus court, plus gros, et son conduit excréteur est légèrement bulbeux à son origine. L'organe chargé plus spécialement de la sécrétion se présente sous l'apparence extérieure d'une sorte de caroncule irrégulièrement crénelée et presque sessile. Mais, par sa dissection, on trouve que cette partie incluse, qui a la forme d'un gland, est ici bien plus courte, tandis que la cupule, ou le bourrelet de sa base, est proportionnellement plus grosse que dans l'espèce précédente. Le conduit efférent de ce gland sécréteur ne m'a pas offert le godet ou la virole qui caractérise celui de cette dernière Pentatome. 
()uant au tube sétacé qui forme l'axe du réservoir, il est le mème à peu près que daus la $P$. grise.

$P$. baccarum. - Les seules différences que j'aie observées dans l'examen comparatif de l'appareil génital femelle de ce Géocorise avec celni des précédens, sont des gaînes origères bi ou triloculaires, et des aufs d'une forme ellipsoidale, excisés et échancrés sur un côté. Ces œufs n'acquièrent cette configuration que lorsqu'ils sont bien à terme; car, avant cette époque, ils paraissent simplement ovales dans la gaîne.

$P$. ornata. - Les lèvres de la vulve sont ici plus grandes et plus convexes; les autres pièces ne forment point de saillie dentiforme, et la plaque médiane est évidemment composée de deux articles. Les diverses espèces de Pentatomes que j’ai disséquées ont toutes sept gaínes ovigères à chaque ovaire. La $P$. ornée fait seule une exception à cette règle : elle n'en a très positivement que six. Ces gaînes ont du reste une conformation et une texture qui ne diffèrent point de celles que je viens de décrire, ainsi qu'on peut s'en convaincre par l'inspection des figures. Le calice de l'ovaire est bien plus distinct que dans les Géocorises précédens. L'oviducte est dilaté et d'une forme ovalaire. Une double collerette frangée, presque confondue en une seule, le précède, et les vaisseaux tubuleux qui la constituent sont, les uns simples, les autres bi ou trifides. La glande sébifique, moins développée que celle de la $P$. grise, est d'ailleurs organisée sur le même plan. Les légères différences qu'elle présente sont suffisamment exprimées par les figures.

Les $\alpha u f s$ de la $\boldsymbol{P}$. ornée ont une forme et une structurre tout-à-fait élégantes. Rangés en séries pressées et contiguës, ils représentent de courts cylindres tronqués, et ne ressemblent pas mal à de petits barillets placés de42. 
bout. Ils varient pour la couleur : souvent ils sont d'un noir plombé, uniforme d'un côté, tandis que de l'autre ils présentent dans le milieu une large bande transversale blanche, au centre de laquelle il n'est pas rare de voir un gros point noir qui imite la bonde du baril. L'opercule n'est pas bombée comme celui de la $P$. grise; il est plane, noir, avec un cercle autour et un point an centre blanc. Le contour de la coque, où l'opercule est enchassée, est bordé de cils courts, régulièrement espacés comme dans la péristome de l'urne de certaines mousses.

$P$. aparines.-Les ovaires ont sept gaînes ovigères, bi ou triloculaires; l'ovulaire est en massue. Le réservoir de la glande sébifique est gros, sphéroïdal, et le conduit excréteur qui lui sert de pédicelle est grêle, capillaire. Le gland sécréteur est en forme de tête ovale-obtuse, et son axe intérieur, que la translucidité de ses parois permet d'apercevoir, est d'uu jaune safrané.

Cette Pentatome fait sa ponte, vers la fin de juiu, sur les tiges du grateron. Ses œufs, ovales-arrondis, sont remarquables par le duvet court dont ils sout hérissés. Ils s'ouvrent par une opercule en calotte, et le tissu de la coque, examiné au microscope, paraît réticulé comme celui des feuilles de quelques mousses.

Coreus marginatus. - La composition et la structure de l'appareil vulvaire des Corés, et en général des Géocorises, qui u'ont que quatre articles aux antennes, sont très différentes de celles de ce même appareil dans les genres précédens. J'ai déjà dit dans les généralités relatives à ces Hémiptères, que dans plusieurs le bout de l'abdomen des femelles présentait ou des dents, ou des lobes, tandis que celui des mâles est tronqué et entier. Cet appareil dans le C. marginatus est logé, enchâssé dans une échancrure profonde du dernier segment ventral de l'abdomen, et l'on 
voit dans un large sinus du segment dorsal correspondant, deux petits segmens supplémentaires qui n'existent point dans le mâle, qui par conséquent ne font point partie essentiellement constitutive de l'abdomen, et qui forment la table supérieure ou le couvercle de l'appareil qui nous occupe. Une disposition semblable s'observe dans les autres espèces que j'ai dit former avec le $C$. marginatus un groupe naturel. Les Corés femelles de cette division ont un oviscapte peu développé et non apparent extérieurement.

On ne compte que quatre écailles vulvaires dans le $C$. marginatus, au lieu de sept ou huit qui s'observent dans les $\boldsymbol{S}$ cutellères et les Pentatomes. Mais elles sont assez développées, et disposées par pièces rapprochées; les antérieures, qui constituent les panneaux ou les lèvres de la vulve, sont relevées en une carène commune qui correspond à la ligne médiane du corps, et à moitié engagées sous le dernier segment ventral. Celui-ci est fendu longitudinalement dans son milieu, qui correspond directement à la vulve; mais la fente n'atteint pas tout-à-fait son bord antérieur; elle s'arrête à une saillie transversale près de celui-ci. Cette fente, qui se rencontre aussi dans toutes les espèces du groupe dont je viens de parler, sert lors du coït, mais surtout à l'époque de la ponte, à permettre la dilatation de la vulve. La portion des panneaux de cetle dernière qui est habituellement à découvert, a l'aspect pointillé, chagriné des tégumens généraux; l'autre est lisse, imponctuée, glabre. Les deux écailles postérieures, contiguës par leur bord interne qui forme la ligne médiane du corps, présentent en arrière une grande échancrure angulaire, communeà toutes deux, et qui correspond à l'anus. Leur bord externe présente vers sa base comme une petite pièce triangulaire qui s'avance parfois en une dent. Cette pièce, qui semble le vestige uu le représentant de celle qui daus les Géocorises 
précédens flanque l'anus, n'est ici qu'uu repli, une doublure latérale du premier petit segment supplémentaire dont je viens de parler. Mais ce qu'il y a de fort remarquable daus ce repli, c'est qu'il est stigmatifère; en sorte que la femelle de cet insecte a une paire de stigmates de plus que le mâle.

Les ovaires du $C$. marginatus ne diffèrent que bien peu de ceux des Scutellères et des Pentatomes. Ils se composent chacun d'un faisceau de sept gaînes ovigères courtes, biloculaires, blanchâtres dans les premiers temps de la fécondation, prenant une teinte orangée par les progrès de la gestation. Les ovulaires sont en massue allongée. Le col de l'ovaire est bien plus long que dans les genres que nous venons d'examiner. Il renferme quelquefois trois ou quatre œufs à terme, placés à la file. L'oviducte est court, dilaté à droite et à gauche dès son origine.

La glande sébifique de ce Géocorise diffère beaucoup de celle des Pentatomes: je n'y ai reconnu que deux vaisseaux ou deux filets tubuleux, un pour chaque côté, peu développés, repliés sur eux-mêmes, d'un calibre à peu près semblable à celui des canaux hépatiques, offrant des rameaux courts, rares, inégaux, dont quelques-uns ne semblent que des bourgeons. Ces vaisseaux sont semi diaphanes, avec un axe linéaire blanc. Mes recherches sur ce point sont sans doute fort incomplètes, car je n'ai pu encore mettre en évidence le réservoir de cet appareil.

Les $œ u f s$ sont remarquables par leur grandeur et leur contiguration. Ils représentent un sphéroïde comprimé dans son contour, et tronqué d'un côté. lls sont roussâtres, glabres, lisses, parfois irisés. A la loupe simple, ils paraissent pointillés ou finement chagrinés; an microscope, la coque présente un tissu aréolaire. 
C. chloroticus. - Mème contexture de l'appareil vulvaire que dans l'espèce précédente, seulement le repli latéral du premier petit segment abdominal supplementaire est ici plus développé et forme de chaque côté une dent prononcée. Les ovaires sont organisés comme ceux du C. marginatus.

C. quadratus. - Appareil vulvaire et ovaires comme dans le Coré ci-dessus.

C. nugax. - Le ventre de la femelle présente dans son tiers postérieur une carène médiane qui n'existe point dans le mâle. Cette carène, limitée en avant par une légère protubérance, est pourfendue comme dans les Corés précédens et recèle un oviscapte. Mais ce dernier commence ici à être un peu apparent à l'extérieur, car on l'aperçoit au bout de l'abdomen, niché dans une coulisse entre les panneaux de la vulve. Je ferai ici une remarque qui n'est pas sans intérêt physiologique, c'est qu'à mesure que l'oviscapte se perfectionne, le nombre des pièces constitutives de l'appareil vulvaire va en diminuant. C'est ainsi que dans les Scutellères et les Pentatomes, où on ne déconvre encore aucune trace de cette espèce de tarrière, il y a sept ou huit plaques vulvaires; dans le groupe des Corés que j’ai signalé plus haut, et qui présente un petit oviscapte caché, le nombre des plaques est réduit à quatre; enfin, dans le $C$. nugax, où cet instrument a acquis un degré marqué de perfection, il n'existe que les deux panneaux de la vulve, et encore sont-ils bien moins développés que dans les autres espèces. Cette décroissance graduelle est digne d'attention.

Les ovaires du C. nugax ressemblent à ceux des Géocorises que nous venons d'examiner. Ils se composent de sept gaînes ovigères biloculaires, et l'ovulaire qui termine celles-ci est ovale-conique très pointu. Les aufs sont 
oblongs, et je n'ai pas reconnu qu'ils fussent tronqués au bout.

C. hirticornis. - Les pièces vulvaires sont encore ici au nombre de quatre, comme dans les espèces qui forment un groupe avec le $C$. marginatus; il y a aussi un petit oviscapte caché.

C. Panzeri. - La configuration du bout de l'abdomen et la structure de l'appareil vulvaire présentent dans cette espèce et dans celles qui constituent le groupe générique dont j'ai parlé à l'article de sa description, des différences tranchées avec celles des autres Corés. Le seul trait extérieur distinctif des sexes est fourni par le dernier segment ventral de l'abdomen, qui est comprimé, saillant et caréné dans la femelle seulement. Mais ce segment n'est plus pourfendu comme dans les précédentes espèces, et les plaques vulivaires ne sont plus en évidence à la paroi ventrale, et étalées. Tout l'appareil dont il est ici question est assez profondément enfoncẻ entre le segment dont je viens de parler et le dorsal qui lui correspond.

Les gaines ovigères sont au nombre de sept pour chaque ovaire, et elles ne m'ont paru qu'uniloculaires. Mais la base de ces gaînes présente dans cette espèce, ainsi que dans quelques autres, un gros bourrelet particulier, d'une consistance comme calleuse et d'une couleur obscure, dont les fonctions ne me sont point connues.

Les ceufs du C. Panzeri sont oblongs, cylindroïdes, obliquement tronqués à un bout.

Alydus geranii et apterus. - On se convaincra par l'étude attentive de l'organe génital femelle des Alydes, non-seulement que dans le cadre entomologique ils doivent être colloqués après les Corés; mais que si dans ces derniers on convertit en genres les divers groupes naturels que j’ai signalés, il faudra que les Alydes suivent im - 
médiatement la division générique à la tête de laquelle sérait placé le $C$. marginatus. Peut-être même qu'un examen sévère érigera en genre propre l'Alyde que j'appelle apterus.

Le dernier segment ventral de l'abdomen des Alydes est pourfendu comme dans la plupart des Corés, mais cette fente est beaucoup moins longue. Les panneaux de la vulve sont grands, velus en dehors, et suivis d'une autre paire de pièces qui termine le ventre. On voit de chaque côté de ces dernières un repli triangulaire fourni par l'un des segmens supplémentaires de la région dorsale. Enfin la composition de l'appareil vulvaire est la même que celle que j'ai décrite dans le $C$. marginatus.

Les oraires, que j'ai plus particulièrement étudiés dans l'A. apterus, ont sept gaínes ovigères assez courtes, biloculaires; l'ovulaire est allongé, cylindroïde; il y a un calice assez marqué, et le col de l'ovaire est long comme dans le Coré que je viens de nommer. Les aeufs non encore à terme, et observés dans les gaînes ovigères, sont d'un bleu lapis tranché; ils prennent une teinte châtain clair bronzé lorsqu'ils sont pondus. Ils ont une grosseur considérable vu l'étroitesse du corps de l'insecte; leur forme est celle des cufs du C. marginatus; mais au lieu d'avoir un côté simplement tronqué, ce còté est échancré on excavé.

Pyrrhocoris aptera. - On ne trouve dans la Pyrrhocore aucun vestige d'oriscapte, et cette considération, qui n'est point sans valeur, contribue à justifier sa séparation générique. Le bout de l'abdomen de la femelle présente comme une troncature un peu déprimée, occupée par les pièces vulvaires. Celles-ci sont au nombre de trois paires. Les panneaux de la vulve sont grands, de forme à peu près quadrilatère. La fente linéaire et médiane qui les sépare, et qui constitue la vulve proprement dite, est

4. Savans élrangrers. 
placée dans une fossette naviculaire. Deux autres plaques beaucoup plus petites suivent immédiatement les panneaux dont je viens de parler et s'engrènent avec le bord postérieur de ceux-ci. Elles sont à peu près triangulaires et ont leurs bords relevés. C'est au-dessus d'elles que s'ouvre l'auus. Enfin ces plaques anales sont flanquées à droite et à gauche par une autre pièce triangulaire.

Sept gaînes ovigères quadriloculaires et fort longues eomposent chacun des ovaires de la Pyrrhocore. L'ovtlaire est conoïde-pointu. Le col de l'ovaire présente une dilatation constante qui tient lieu de calice. L'oviducte est renflé dès son origine. La glande sébifique consiste en un réservoir arrondi brièvement pédicellé, et pour chaque eôté en un organe singulier, semblable à une fraise élégante d'une teinte jaunâtre. Je n'ai point de notions assez positives sur la structure et les fonctions de cet organe, pour entreprendre sa description.

Lygaus lagenifer.-L'appareil vulvaire des Lygées a bien plus de rapports avec celui des Corés qu'avec celui de la Pyrrhocore. Le dernier segment ventral de l'abdomen est pourfendu dans sa ligne médiane comme dans les premiers de ees Géoeorises; ce qui est l'indice de la présence d'un oviscapte.

L'ovaire se compose de sept gaînes ovigères fort longues, multiloculaires (à sept ou huit loges environ). L'ovulaire est oblong, conoïde, pointu. Le col de l'ovaire est largement dilaté. La glande sébifique a de l'analogie avec celle des Pentatomes; mais je sens la nécessité de renouveler mes dissections pour être fixé sur cet organe. Les œufs sont ovales.

L. hyosciami. - Les gaînes ovigères ne sont ici que biloculaires, et elles se terminent par un ovulaire allongé. 
Le col de l'ovaire est long et tubuleux comme dans le Coreus.

Miris Carcelii. - Les Miris et les Capsus vont nous présenter une organisation toute particulière de l'appareil générateur femelle, et comme cette organisation est commune aux deux genres, je me bornerai à l'exposer dans l'espèce dont il est ici question.

Ia région ventrale de l'abdomen se compose, ainsi que je l'ai dit ailleurs, de sept segmens stigmatifères, indépendamment des pièces qui constituent l'appareil vulvaire. Cette région offre un trait anatomique distinctif dont $\mathrm{j}$ 'ai déjà fait une simple mention, mais qui mérite de nous occuper un instant. Je veux parler de l'oviscapte. Le long de la ligne médiane du ventre, à partir d'une petite gilobosité située au centre de cette région, on voit une fente linéaire qui se continue jusqu'à l'anus. Cette fente, susceptible de s'élargir on de se resserrer suivant la volonté ou les besoins de l'insecte, est formée par les bords tranchans de deux longues vulves coriacées, parallèles, formant une gaîne ou espèce de coulisse qui loge l'oviscapte. Dans les Miris et les Capsus, ainsi que dans les $\mathrm{Co}_{0}$ reus, le dernier segment ventral stigmatifère (ici le septième), est divisé par une fente médiane, et la gibbosité centrale dont je viens de parler paraît appartenir spécialement au pénultième segment. Une grande pièce vulvaire, un large panneau termine de chaque còté l'abdomen et ne paraît qu'un dédoublement du dernier segment dorsal. L'oviscapte, logé dans la coulisse médiane, ne semble à la première vue qu'une simple tige plate et cornée, une lame tranchante à pointe aiguë; mais c'est un véritable sabre, pour me servir de l'expression usitée pour désigner cet instrument dans quelques Orthoptères. Ce sabre, attaché ou plutôt articulé par sa base, un peu di- 
latée, à la gibbosité centrale, est formé de deux longnes lames ou vulves semblables, simplement appliquées l'une contre l'autre et susceptibles de s'entr'ouvrir, de s'écarter même beaucoupà l'époque de la ponte. La composition de cet instrument annonce que les Miris et les Capsus doivent enfoncer leurs cufs soit dans la terre, soit dans les plantes. Les entomologistes gardent un silence absolu sur ce point intéressant de l'histoire naturelle de ces insectes. Il était réservé à l'anatomie d'éveiller leur attention, de provoquer leurs recherches relativement aux mœurs et aux habitudes de ces Géocorises.

Chacun des ovaires des Miris et des Capsus est un faisceau allongé, non de sept, mais de huit gaînes ovigères, longues, tri ou quadriloculaires, terminées par un ornlaire ovale-oblong. Le calice est peu marqué, et le col de l'ovaire présente in renflement ovoïde entièrement caché, ainsi que l'oviducte, qui est excessivement court, par la glande sébifique.

Celle-ci forme par son développement, sa configuration et sa structure insolites, un des traits anatomiques les plus remarquables des Géocorises dont nous nous occupons, et autorise à présumer qu'elle a des attributions spéciales. Elle se compose d'un réservoir et d'un vaisseau sécrétenr. Le réservoir est une grande vessie placée au centre de l'appareil génital, à peu près carrée, avec ses angles arrondis , et dont les parois fibro-membraneuses sont pellucides. II m'a été impossible de constater d'une manière positive le mode de connexion de ce réservoir, soit avec l'oviducte, soit avec le vaisseau sécréteur. En déchirant ses parois, j'ai toujours rencontré dans sa cavité un corps d'un blanc nacré, d'une consistance céracée, qui ne m'a offert aucune organisation. Ce corps ne m'a paru que de la matière sébacée concrète ayant toute l'apparence de l'adipo-cire. Le 
vaisseau sécréteur entoure comme une guirlande le bord dn réservoir, auquel il ne tient que par quelques rares trachéoles. Son tronc principal, grêle, flexueux et diaphane, émet à droite et à gauche de courts rameaux simples ou divisés, droits ou repliés. Ce vaisseau est tont-à-fait simple dans le Capsus tricolor, mais fléchi en nombreux pelits festons qui couronnent aussi le pourtour du réservoir. Certainement les fonetions d'un appareil sébifique ainsi organisé ne sè bornent pas à enduire les œufs d'un vernis, et je ne serais point surpris quand on découvrirait que ces Géocorises forment à leurs cufs une enveloppe commune, une espèce de cocon analogue à celui des Mantis.

Les oufs des Miris el des Capsus, que je n'ai jamais vus pondus, et que je ne juge que d'après cenx que j’ai rencontrés à terme dans le col de l'ovaire, sont allongés ? cylindroïdes, tronqués à un bout et légèrement arqués.

Plymata crassipes. - Je n'ai point parlé des organes générateurs mâles de ce bizarre Géocorise, parce que je n'ai point encore trouvé l'occasion de me livrer spécialement à son étude anatomique. Par la même raison, je ne suis pas plus avancé pour la connaissance de ces mêmes organes dans la femelle. C'est une lacune à remplir ; mais je dirai deux mots sur les signes extérieurs qui servent à distinguer les sexes.

Dans le mâle l'armure copulatrice est tout-à-fait inférieure et enchatonnée dans le centre du dernier segment ventral de l'abdomen. Elle y circonscrit un espace en ovale régulier, saillant, convexe, légèrement caréné dans la ligne médiane, et d'une texture analogue à celle du segment luimême. La situation aussi inférieure de cette armure fait naître l'idée d'un mode d'accouplement différent de celni de beaucoup d'antres Géocorises.

Dans la Phymate femelle, l'abdomen est tronqué net 
au même point de la région ventrale indiqué pour le mâle. Cette troncature, formée par les pièces vulvaires, est tout-à-fait indépendante du dernier segment stigmatifère, et débordée par l'aile que forment les parois abdominales. On n'apercoit dans cet insecte aucune trace d'oviscapte; en sorte que, sous ce point de vue, la transition des Miris et des Capsus aux Phymata est des plus brusques. La composition, et surtout la disposition des plaques vulvaires, ne ressemblent plus à celles que j’ai décrites jusqu'à présent. Ces plaques sont an nombre de trois senlement, dont deux latérales et une médiane. Cette dernière, bien plus large que les autres, est glabre, lisse, triangulaire, et la pointe du triangle est dirigée en avant. Les latérales, étroites et obliques à l'axe du corps, sont couvertes d'aspérités. Dans tous les Géocorises précédens, la vulve, ou l'ouverture extérieure du vagin, est une fente placée dans la ligne médiane du corps, comme dans l'espèce humaine, par conséquent longitudinale. Dans la Phymate, elle est transversale et tout-à-fait antérieure. Cette direction insolite de la vulve confirme ce que je viens de dire relativement à la singularité présumée du mode d'accouplement et de la ponte des ceufs. Elle est faite pour piquer la curiosité du physiologiste.

Aradus avenius. - Au lieu du mamelon assez gros qui termine le ventre du mâle, on ne trouve dans la femelle qu'un très petit segment supplémentaire en carrélong transversal, débordantà peine le contour arrondi du bout' de l'abdomen. La vulve, autant qu'il est permis d'en juger sur un insecte aussi petit et aussi plat, ne m'a point paru longitudinale, et est placée, je crois, tout-à-fait à l'extrémité de l'abdomen. Je ne vois d'autre pièce vulvaire que le segment supplémentaire signalé plus haut, et l'on ne reconnaît aucun indice de l'existenced'un oviscapte. 
Chacun des ovaires de l'Aradus ne m'a paru composé que de quatre gaînes ovigères biloculaires. Les opulaires sont ellipsoïdaux, pointus. Le col de l'ovaire est dilaté, et l'oviducte a une grosseur assez remarquable. Les oufs sont oblongs.

Le nombre quaternaire des gaînes ovigères est si insolite dans les Géocorises, que c'est avec une extrême défiance que j'avance ce fait.

Cimex lectularius. - Les organes reproducteurs femelles de la Punaise des lits ont plus de rapports avec ceux des Corés qu'avec ceux des Miris et des Capsus. Les ovaires consistent en deux faisceaux obtus, presque arrondis, composés chacun de sept gaines ovigères courtes, à deux loges. L'ovulaire est gros, ovale-conoïde. Le calice de l'ovaire est bien marqué et dégénère en un col tubuleux de moyenne longueur. L'oviducte est très court. Malgré les investigations les plus soigneuses, les plus réitérées, je n'ai pu reconnaitre pour l'appareil sébifique que denx vessies, une pour chaque côté, ovoïdes ou globuleuses, pellucides, munies d'un col excessivement court par lequel elles s'insèrent non sur l'oviducte, mais au côté externe de chacun des cols tubuleux des ovaires. Cette situation au-delà de l'oviducte ou du vagin, et ce nombre binaire, sont, il faut en convenir, bien peu favorables à l'opinion de ceux qui ne veulent voir dans l'appareil sébifique qu'une poche copulatrice. Les vessies dont je viens de parler contiennent une matière sébacée plus ou moins coagulée. Elles sont comparables, à n'en pas douter, au réservoir des glandes sébifiques ordinaires. Mais, je le répète, je n'ai pu découvrir dans les nombreuses dissections que j'ai faites de cet insecte, aucun vaisseau, aucun corps particulier qui puisse représenter un organe sécréteur. La petitesse de celui-ci l'a-t-elle dérobé à mes yeux armés de verres amplifians à 
divers degrés, ou bien existe-t-il dans cette Punaise une anomalie relativement à ce petit appareil? Les parois de ces vessies seraient-elles chargées en même temps de sécréter et de contenir l'humeur sébacée? Des entomotomistes plus heurenx ou plus adroits que moi pourront éclaircir ces doutes.

Les œufs de la Prunaise des lits, lorsqu'on les observe encore enfermés dans les ovaires, et non à terme, sont ovales et gros. Mais quand ils sont pondus ou à la veille de l'être, ils ont une forme oblongue légèrement rétrécie vers le bout antérieur. Celui-ci présente un petit opercule arrondi, à peine convexe, qui convre l'ouverture par laquelle la larve doit éclore. Soumise à une forte lentille du microscope, la coque de ces ceufs paraît toute couverte extérieurement de petites aspérités piliformes, destinées à favoriser leur adhérence contre les corps et les tissus où ils sont déposés. C'est surtout à la découverte et à la destruction des cufs qu'il faut s'attacher pour préserver des Punaises les lits.

Reduvius stridulus. - Les pièces externes de l'appareil copulateur des Réduves se présentent avec une composition et une structure particulières. La région de l'anus est noire daus les deux sexes, ainsi que je l'ai exprimé dans le signalement de l'espèce, mais elle est convexe et arrondie dans le mâle, en saillie conoüde dans la femelle.

L'armure copulatrice du mâle est enchatonnée dans le dernier segment ventral de l'abdomen (le sixième stigmatifère), et circonscrit un espace ovalaire mais pointu en arrière, de manière que sa pointe touche au bord anal du segment. La couleur et la texture de son tiers postérieur diffèrent de celles du reste de l'armure. On y reconnaît deux panneaux assez grands, triangulaires, d'un brun obscur, d'une consistance bien moins coriacée, rap- 
prochés ou contigus à la ligne médiane par leurs bords libres. Ces panneaux ressemblent à ceux de la vulve de plusieurs Géocorises femelles, et en imposeraient facilement à ceux qui n'étudient pas le scalpel à la main. Je présume que ces panneaux de l'appareil copulateur mâle forment la seule partie essentiellement mobile de l'armure, et c'est par leur entr'ouverture médiane que doit sortir la verge pour le coït. Rien de semblable ne s'est présenté dans les Géocorises précédens; mais je dois prévenir que ce trait singulier est pent-être simplement spécifique, car il ne se rencontre ni dans le $R$. personatus ni dans quelques autres espèces que j’ai examinées comparativement.

La région anale de notre Réduve femelle est composée de plusieurs pièces vulvaires symétriquement rapprochées. La vulve s'apercoit à la ligne médiane, en avant de la saillie conoïde. Elle est formée par deux petits panneaux oblongs ou triangulaires, adossés à leur base à deux grandes plaques l'une à droite, l'autre à gauche. Par l'extréinitéopposée, c'est-à-dire en arrière, les petits panneaux vulvaires forment avec nne autre pièce anale du dos, une sorte de bec court et gros que je viens de mentionner sous le nom de saillic conoïde, et entre les mandibules de ce bec se trouve l'anus. J'ai vainement cherché à découvrir un oviscapte, tandis que cet instrument conducteur des cufs est assez apparent dans les $\mathrm{Nabis}$, genre qui dans le cadre entomologique suit immédiatement celui des Réduves.

Les ovaires de notre Réduse se composent chacun de sept gaînes ovigères qui ne m'ont paru que biloculaires. Les ovulaires ont la forme d'une massue oblongue; le calice est bien apparent, et le col de l'ovaire est un long conduit tubuleux; l'oviducte est dilaté; la glande sébifique ne m'est pas bien connue.

4. Savans étrangers. 
Les rufs sont ovales, arrondis aux deux bouts, tandis que ceux du Nabis dorsalis sont allongés, cylindroïdes, tronqués et même un pell évasés à une extrémité, et le contour de la troncature est rebordé, comme crénelé en dedans.

Pelogonus marginatus. - Lorsque, dans le mois de septembre, je me livrai à la dissection du Pélogone, je trouvai toutes les femelles vierges, ou du moins leurs ovaires n'offraient aucun indice de fécondation. Dans cet état, chaque ovaire est formé par un faisceau de sept gaines ovigères d'une médiocre longueur, terminées par un bout obtus, et qui m'ont paru bi ou triloculaires. Chacune des gaînes est maintenue par un filet assez long, d'une ténuité qui échappe même à la loupe. Ces filets convergent à un ligament suspenseur commun qui va se fixer, isolément de son congénère, dans l'intérieur du métathorax; le col de l'ovaire est deux fois plus long que le faisceau des gaines ovigères, et peu flexueux.

La glande sébifique de l'oviducte consiste, $\mathrm{I}^{\circ} \mathrm{en}$ un corps sécréteur vésiculeux, courbé sur lui-même de manière à paraître orbiculaire au premier coup d'ceil ; $2^{\circ}$ en un conduit efférent capillaire très replié sur lui-même, sept à huit fois plus long que le corps sécréteur, et s'insérant d'une part à l'un des bouts de celui-ci, de l'autre à l'origine de l'oviducte; ce dernier est d'une excessive briéveté.

\section{AMPHIBICORISES.}

Gerris canalium et G. paludum. - La composition et la structure de l'appareil reproducteur femelle des Gerris confirment ce que j'ai déjà avancé relativement à la légitimité de la nouvelle famille des Amphibicorises. Je ne reviendrai pas sur les signes extérieur's qui caractérisent le sexe femelle; ils sont faciles à déduire d'après ce que j'ai exposé à l'article du mâle. 
Les ovaires de ces deux espèces forment chacun un faisceau allongé de quatre gaînes ovigères seulement.Ce nombre constitue un trait caractéristique. Ces gaînes, qui ont la forme de longs tubes grêles, atteignent jusque dans la eavité prothoracique, et sont multiloculaires.J'y ai reconnu le plus souvent einq ou six cufs fécondés, et tout autant de traces d'articles ou de loges à la suite de l'ovulaire. Celui-ei est allongé, eylindroïde. Le ligament suspenseur. commun des ovaires, c'est-à-dire eelni qui résulte de la connivence de tous les ligamens propres des gaînes ovigères, se fixe dans les masses musculaires qui garnissent le contour occipital on cosophagien de la tête. Cette insertion, que j’ai bien constatée, est digne de remarque. Le calice de l'ovaire n'existe presque pas, et son col est fort conrt. Je ne trouve d'antre trace de glande sébifique qu'un corps arrondi on obtusément carré, d'un tissu dense et serré, cachant entièrement l'oviduete. Ce corps n'est-il qu'nn simple réservoir de l'humenr sébacée, et l'organe spéeialement chargé de la sécrétion? aurait-il éludé mes investigations réitérées? Je n'oserais émettre un jugement définitif; mais la texture de ce corps me paraît propre à remplir le double but physiologique de sécréter cette humeur et de la tenir en réserve.

Les œufs des Gerris sont allongés, cylindroïdes, non tronqués à un de leurs bouts. Au lieu de s'ouvrir par le décollement, la chute d'un opercule régulier, comme cela a lieu pour la plupart des Géocorises que nous venons d'examiner, ils se feudent, ou peut-être ils se déchirent longitudinalement dans leur tiers antérieur, et e'est par cette fente que sort la larve. J'ai conservé dans des bocaux remplis d'eau et de mousses aquatiques des femelles pleines dn G. paludum, et je me suis assuré qu'elles pondent leurs ceufs à la suite les uns des autres, mais non conti- 
gus ni serrés entre eux, dans une espèce de bourre mucilagineuse fixée sur des brins de plantes immergées. J'ai assisté à la naissance des larves, et j’ai quelquefois trouvé engagée dans la fente de l'œuf une fine membrane qui était sans doute l'enveloppe immédiate de la larve, ou qui revêtait intérieurement la coque de l'œuf.

Velia currens. - A l'article de la description de cet insecte j'ai fait connaitre ses différences sexuelles extérieures. Quant aux ovaires et à leurs dépendances, ils sont organisés comme ceux des Gerris.

\section{HYDROCORISES.}

Naucoris cimicoüdes. - Ses ovaires forment deux faisceaux làches et allongés, composés chacun de sept gaînes ovigères longues, tubuleuses, multiloculaires, c'est-à-dire à plus de six loges. L'ovulaire est allongé, comme fusiforme, et terminé en pointe. Il n'y a pas de calice distinct, mais le col de l'ovaire forme un canal tubuleux assez long destiné à contenir un certain nombre d'œufs à terme. L'oviducte, qui remplit sans doute aussi les fonctions de réservoir de la glande sébifique, est renflé et ovalaire. Les cols s'insèrent l'un à droite, l'autre à gauche de l'extrémité antérieure de l'oviducte, de manière que celui-ci déborde un peu entre ces deux insertions.

L'appareil sébifique de la Naucore ne consiste eu apparence, ainsi que celui de la Ranatre, qu'en un vaisseau filiforme simple, plus ou moins replié ou flexuenx, inséré vers le tiers postérieur de l'oviducte. Comme ce dernier a une texture plus consistante, plus compacte que les oviductes ordinaires, il est bien possible qu'il y ait dans son épaisseur un réservoir pour l'humeur sébacéc.

Les œufs sont oblongs, cylindroïdes, un peu courbés, blanchâtres, très lisses, obliquement tronqués à leur bout 
antérieur. Cette troncature est circonscrite par un filet sursaillant; ce qui lui donne ane certaine ressemblance avec l'ouverture de ces petites coquilles terrestres appelées Pupa.

L'oviducte de cette Vaucore se termine par un oviscapte corné. Celui-ci est formé de deux tiges séparées et divergentes dans les deux tiers antérieurs, soudées dans l'antre tiers. Son extrémité postérienre, au lieu d'être pointue, est tronquée ou plutôt échancrée, et les angles de l'échancrure sont en forme d'épine. Les bords externes de ces tiges sont armés de dents assez fortes, courtes, crochues, dirigées d'arrière en avant, de manière que cet oviscapte représente une double scie.

N. aptera. - Les entomologistes savent combien il serait diflicile de distinguer cette espèce de la précédente, si ou n'avait point recours à un caractère négatif qui n'avait pas encore été signalé, je veux parler de l'absence des ailes. Mais aux yeux du zootomiste, les traits spécifiques sont uombreux et solides. Ainsi l'ovaire de la $N$. aptère n'est composé que de cinq gaînes ovigères, tout au plus quadri ou quinqueloculaires. L'omulaire est ellipsoïdalpointu. Les oufs sont ovales-obtus, nullement tronqués, et la texture de leur coque, examinée à une forte lentille du microscope, paraît réticulée, avec des mailles arrondies, traversées de raies ou de lignes parallèles, tandis que la coque des cufs de la $\boldsymbol{N}$. cimicö̈le, soumise aux mêmes verres amplifians, n'offre aucune espèce de réticulation.

J'ai conservé long-temps des $N$. aptères dans des vases pleins d'eau, et je me suis assuré qu'elles pondent leurs œufs vers la fin d'avril, en les collant contre des brins de plantes aquatiques.

Ranatra linearis et Nepa cinerea. - Les ovaires de ces Népides sont encore plus allongés que ceux des Gerris. 
Ils se composent chacun de cinq gaînes ovigères longues, tubuleuses, multiloculaires, réunies en un faiscean très lâche, enlacé de quelques brides trachéennes. L'ovulaire est elliptique-obtus, oviforme, d'une grosseur qui surpasse de beaucoup le tube qu'il termine. Le col de l'ovaire est fort court, et n'est pas précédé d'un calice apparent. L'ovidncte a également peu de longueur. Il s'engage avec le rectum dans un étui cornéo-membraneux composé de plusieurs pièces susceptibles de jouer les unes sur les autres. et se terminant par deux lames cornées contiguës, lancéolées, ciliées, qui constituent un oviscapte.

La configuration des œufs est un des traits les plus remarquables de l'organisation de ces Népides. Ils se termiuent en avant par des prolongemens sétiformes, dont le nombre varie suivant les genres, et qui ne sont bien apparens que lorsqu'ils sont pondus ou tout-à-fait à terme. Ces ceufs dans la Ranatre sont allongés, terminés par deux longues soies seulement. Ceux de la Nèpe sont ovales et couronnés par sept soies plus ou moins conniventes. Je renvoie pour d'autres détails au travail que j'ai déjà publié sur ces Hydrocorises en r 82 r. (Annal. gén. des Sc. Physiq. de Bruxelles.)

Corixa striata. - L'ovaire de la Corise se compose de sept gaînes ovigères làches, multiloculaires. Les loges, au nombre de plus de douze, sont courtes, rapprochées, moniliformes. L'ovulaire est ovale-arrondi et gros. Le col de l'ovaire est un tube allongé, tandis que l'oviducte est excessivement court. La glande sébifique consiste en un vaisseau sécréteur simple, court, et en un réservoir arrondi, sessile, à parois charnues.

Les œei fs sont pondus çà et là sur les tiges immergées des plantes aquatiques. Ils sont sphérö̈daux, mais terminès en avant en pointe courte ou en un petit bec; leur base, 
par laquelle ils sont fixés, présente une espèce de bourrelet circulaire comme crénelé. Ceux de la $C$. hieroglyphique sont ovales-oblongs, pointus, mais fixés cornme les précédens.

Notonecta glaucu. - Les ovaires forment deux faisceaux allongés et lâches, composés chacun de sept gaínes ovigères fort longues et multiloculaires. Ces gaines ont plus de dix loges, et se terminent par un ovulaire ellipsoïdal - obtus. Le col de l'ovaire est fort court, assez large, et serait plutôt un calice. L'oviducte a aussi très peu de longuenr.

La glande sébifique a une forme et une texture fort singulières. L'organe chargé spécialement de la sécrétion est un bouton calloso-charnu, ovale-oblong, tronqué, et comme ombiliqué à son extrémité libre, et marqué un peu avant celle-ci d'une ligne annulaire d'un brun pâle. Il est main tenu en place par des brides trachéennes rayonnantes. Dans les individus vierges, où les gaînes ovigères n'offraient aucune trace de loges et étaient de simples tubes cylindrico-conoïde, cet organe sécréteur était pyriforme. Un condnit efférent, d'une ténuité presque capillaire, et assez long, communique du bouton sécréteur an réservoir. Celui-ci est un sac membraneux, diaphane ou opaloïde, contourné en spirale, de manière que les tours de spire, en forme de disques orbiculaires comme crénelés sur les bords, sont superposés et se débordent un peu les uns les autres. Cette disposition élégante donne à ce réservoir de la ressemblance, pour la configuration, avec le fruit de certaines espèces de luzerne (medicago).

Les ceufs de la Notonecte sont oblongs, cylindroïdes, non tronqués, jannàtres. 


\section{CICADAIRES.}

- Cicada orni. - La présence d'un oviscapte très appareut, occupant à peu près le tiers postérieur de la région ventrale de l'abdomen, et l'absence de l'appareil musical, servent à distinguer facilement les Cigales femelles des mâles. L'oviscapte, composé d'instrumens tranehans et perforans fort curieux, a été décrit par Réaumur avec son exactitude accoutumée, dans le quatrième de ses immortels Mémoires, du tome $\mathbf{V}$.

Chacun des ovaires de la Cigale est un faisceau sphéroïdal de soixante - dix à quatre - vingts gaînes ovigères, autour desquelles s'épanouissent de nombreuses et brillantes trachées. L'ovnlaire est un bouton renflé en massue. Le col de l'ovaire est assez long, cylindroïde. L'oviducte est courbé en crosse d'avant en arrière, et en bas à l'endroit où s'insèrent les cols des ovaires.

Si pour étudier la composition intime de l'ovaire de la Cigale, on le dégage avec soin et de son eriveloppe adipotrachéenne et des ligamens propres qui maintiennent agglomérées les gaînes ovigères, on se convaincra que cet ovaire est décidément rameux, et que ces dernières y sont disposées par petits faisceaux. La figure que je donne de cette disposition rend superflus d'autres détails descriptifs. Les gaînes ovigères sont biloculaires, et l'ovulaire est renflé en massue.

Les vaisseaux sécréteurs de l'humeur sébacée sont an nombre de trois, et non de deux seulement, ainsi que je l'avais cru d'abord. Ces vaisseaux, qui égalent en longueur la moitié du corps de l'insecte, sont des boyaux membraneux semi diaphanes, flexeux, flottans par un bout. Deux d'entre eux sont antérieurs et s'insèrent à côté l'un de l'autre, immédiatement après le point de confluence 
des deux cols des ovaires, par conséquent à l'origine de l'oviducte et avant l'insertion du réservoir sébacé. Quant au troisième vaisseau, il est placé fort loin des deux autres, et bien en arrière de ce réservoir. Il s'implante vers la terminaison de l'oviducte, et ses fonctions sont peut-être indépendantes de l'appareil sébifique qui le précède. C'est ce vaisseau que j'avais cru autrefois faire partie des glandes excrémentitielles qui existent dans les deux sexes de la Cigale; mais il est certain qu'il ne se rencontre pas dans le mâle, et il est plus que probable qu'il fournit, lors de la ponte, une humeur spéciale destinée à enduire les œufs.

Les æuufs, et je n'ai eu occasion de les observer que dans les ovaires, sont oblongs, cylindrö̈des, blanchâtres.

Malgré l'extrême fréquence de la Cigale de l'orne dans nos forêts de pins maritimes, et malgré ma persévérance à étudier son genre de vie et ses mœurs, je n'ai jamais été à mème de constater les observations de Pontedera et de Réaumur, relativement à l'habitude qu'ont les femelles d'enfoncer, au moyen de la tarière ou oviscapte, leurs œufs dans des branches d'arbre (1).

(1) Lorsque la Cigale s'envole du tronc d'arbre où elle est surprise, ou bien lorsque, déjà captive, on l'inquiète, elle lance, elle éjacule par le bout de l'abdomen un liquide excrémentiticl jaunàtre, unc sorte d'urine. Prévenu déjà de l'existence d'un organe spécial pour la sécrétion d'un liquide semblable dars un grand nombre d'insectes, et notamment parmi les Coléoptères, dans l'immense famille des Carabiques, je me livrai avec confiance à la recherche de cet organe dans les Cigales. Je découvris en effet, dans les deux sexes, de chaque côte, et un peu au-dessous du rectum, une glande granuleuse consistant en une agglomeration peu serrée d'une cinquantaine de sachets blanchâtres ou grisâtres. La configuration la plus ordinaire de ceux-ci semble au premier coup d'œil ètre sphéroïdale; mais quand on y porte une loupe scrupuleuse, on y en reconnait d'ovalaires, d'arrondis, d'irréguliers ou de non symétriques, et d'inégale grandeur. La plupart sont sessiles, mais quelques - uns semblent s'atténuer en une sorte de col fort

$$
\text { f. Savans cilrangers. }
$$




\section{FULGORELLES.}

Cixius 5-costatus. - L'oviscapte est ici proportionnellement moins long et plus à découvert que celui de la $\mathrm{C} i$ gale. Indépendamment de ce trait caractéristique du sexe, les femelles de ce Cixius présentent, ainsi que celles de plusieurs autres Fulgorelles, à l'extrémité de l'abdomen, surtout à l'époque de la gestation, un paquet souvent assez grand non pas d'une bourre, ce qui suppose des brins entremêlés ou enchevêtrés, mais de filamens blancs comme la neige et superposés longitudinalement. Je présume, d'après ce qui se passe dans la Dorthésie, que les cufs sont pondus et couvés dans cet édredon. Je n'ai reconnu dans chaque ovaire du Cixius, que quinze à dix-huit gaînes ovigères à trois loges, dont l'ovulaire est en massue allongée. L'ovaire a un calice bien marqué en forme de cupule, dégénérant en un col assez court. Je n'ai pu étudier qu'imparfaitement la glande sébifique. J'observe un réservoir assez volumiuenx, en cône tronqué, renversé ou turbiné, et deux corps ovalairęs d'une consistance calleuse, semi diaphanes, destinés peut-être à la sécrétion du duvet blanc dont il vient d'ètre question.

conrt. Quand on les observe dans une Cigale mâle, ils peuvent en imposer pour des capsules spermifiques du testicule, dont ils ont l'apparence et qu'ils avoisinent, mais un examen attentif dissipe cette illusion, et comme je l'ai dejà dit, ces granulations se retrouvent aussi dans la femelle.

Le mode de counexion réciproque de ces sachets, leur conduit efférent, leur réservoir, ont éludé jusqu'à ce jour l'opiniâtreté de ınes investigations. Cette glande a souvent pour axe un tronc trachéen dont les ramuscules semblent former un pédicelle à chaque sachet.

Le conduit tubuleux que, dans mon premier travail sur l'anatomie de la Cïgale, j'avais soupçouné être un réservoir de la glande excrémentitielle, n'existe que dans la femelle, et appartient positivement à l'appareil sébifique de l'oviducte. 
En août ${ }_{1} 829$ je trouvai le mâle et la femelle accouplés. Ils étaient unis à la manière des chiens; et après les avoir séparés, je vis que l'extrémité de l'abdomen du mâle était conme saupoudrée du duvet blanc qui garnit la région anale de la femelle.

\section{CICADELLES.}

Ledra aurita. - Il n'y a que dix à douze gaínes ovigères à chaque ovaire, et elles sont à trois ou quatre loges. L'ovulaire est ovale. Le col de l'ovaire est assez marqué. L'oviducte présente deux renflemens. La glande sébifique se compose de denx vaisseaux sécréteurs longs, filiformes, reployés, et d'un réservoir ovale-oblong, pélicellé, c'est-à-dire terminé par un col grêle. Les aufs sont oblongs.

L'ovaire de la Cercopis sanguinolenta est un faisceau court et gros d'une trentaine environ de gaînes opigères quadriloculaires. Celni de l'Aphrophora salicina n'en a qu'une quinzaine, et elles ne m'ont paru que biloculaires. Daus l'une et dans l'autre les aufs sont oblongs et atténués à un bout.

\section{PSYLLIDES.}

Dorthesia characias. - Cet insecte a ses deux ovaires tellement rapprochés, qu'ils semblent confondus en un seul. Chacun d'eux est un faiscean court, arrondi, composé de dix à douze gaînes ovigères courtes et assez grosses, qui m'ont paru simplement uniloculaires. J'ai souvent reconnu au centre de ces gaînes étalées en rosette, des granulations ou vésicules que je présume n'ètre que des gaînes d'où les ceufs sont sortis, et qui sont affaissées sur elles-mêmes. Observés dans des conditions favorables de 
gestation, peut-être trouvera-t-on que les ovaires sont composés d'un plus grand nombre de gaînes que celui que je leur ai assigné. L'ovulaire est ovale-oblong. Je n'ai reconnu, pour l'appareil sébifique, qu'un réservoir ovoïde, diaphane, rétréci en un col grêle, inséré sur l'oviducte. Les vaisseaux sécréteurs ont sans doute éludé mes recherches.

Quoique j'aie eu occasion de disséquer des ovaires parvenus au dernier terme de la gestation, je n'ai jamais rencontré dans les gaînes ovigères des petits emmaillottés ou des fotns comme on les voit dans celles des Pucerons. Ainsi la Dorthésie est ovipare, tandis que le Puceron est décidément vivipare. En pondant ses ceufs, qui sont ovales et blanchâtres, elle les dépose au milieu de la bourre cotonneuse qui garnit l'intérieur du sac caudal, dont j'ai donné la description; j'y en ai compté une trentaine. Les petits éclosent successivement dans ce sac. Ils ressemblent à la ñère pour le nombre et la conformation des parties; mais ils sont nus, c'est-à - dire 'qu'ils ne présentent aucune trace de ces écailles amylacées dont le corps des femelles adultes est caparaçonné. Je présume que lorsque toute la couvée est née, les petits quittent leur retraite.

Le 15 juillet 1829 je trouvai une femelle dont le sac proligère présentait à son extrémité, en-dessus, une ouverture assez large, irrégulière, par où je peuse que les petits doivent sortir, et par où ils pouvaient peut-être aussi rentrer. Je n'ai point été à même de constater cette double présomption, qui établirait un rapport assez curieux entre la Dorthésie et la Sarigue; mais je trouvai dans cette femelle, dont je viens de parler, tous les petits bien vivans, assez agiles, et pas un seul œuf.

Psylla ficus. - L'abdomen de la femelle se termine 
en un cône pointu, comprimé, à la face dorsale duquel on aperçoit près de sa base un espace ovale, légèrement creusé, dont le fond est fermé par une membrane blanche, une sorte de diaphragme où la loupe découvre cà et là quelques vestiges d'une bourre cotonneuse.

Les ovaires paraissent confondus, comme ceux de la Dorthésie, en un seul peloton arrondi; mais il n'est pas difficile de se convaincre que celui-ci est formé par la réunion de deux faisceaux que l'on peut séparer. Chacuu de ces derniers se compose d'un nombre de gaînes ovigères qu'il m'a été impossible de déterminer au juste, mais que j'évalue à une trentaine environ. Celles-ci sont uniloculaires, courtes, et comme sessiles. L'ovulaire, en massue oblongue, est tout-à-fait dépourvu de ligament suspenseur. Ce dernier trait négatif, qui lui est commun avec la Dorthésie et les Pucerons, annonce une filiation généalogique entre ces trois genres d'Homoptères. La brièveté des gaînes ovigères, et la circonstance d'être uniloculaires, par conséquent de peu de pesanteur, semblent bien justifier l'absence du ligament suspenseur dans la Psylle et la Dorthésie; mais cette explication ne saurait être admise pour les Pucerons.

Le col de l'ovaire de la Psylle est fort long, dilaté dans sa moitié antérieure, tubuleux dans la postérieure. L'oviducte est bien distinct et assez grêle. J'ai reconnu, pour l'appareil sébifique, $\mathrm{I}^{\circ}$ une utricule assez grosse, ovoïdeobtuse, diaphane, munie d'un col capillaire par lequel elle s'insère à l'oviducte, et comparable au réservoir de la glande sébifique de la Cigale; $2^{\circ}$ du côté opposé à cette utricule, un corps (glanduleux?) ellipsoïdal, d'une texture différente du réservoir, d'une apparence spongieuse, d'une teinte jaunâtre, dont je n'ai pu clairement découvrir les connexions. Je soupçonne que ce corps est une glande 
chargée de quelque sécrétion spéciale, lors de la ponte.

Malgré ce qu'ont écrit Réaumur, Geoffroi, et tous les entomologistes postérieurs à ceux-ci, il reste encore beaucoup à faire pour compléter l'histoire naturelle de la Psylle du figuier. Ils ne nous ont rien dit des œufs de cet insecte; je vais chercher à remplir cette lacune. A la fin d'octobre 1829 , je disséquai des femelles très avancées dans la gestation, et dont les cufs, à en juger par leur grosseur, devaient être à terme. Je fus frappé de la configuration de ceux-ci. Ils étaient blancs, ovales - conoïdes, pointus par un bout, arrondis par l'autre, et munis audessous de ce dernier, d'un bec latéra! assez prononcé qui leur donnait de la ressemblance avec certaines cornues des chimistes. Sachant d'avance, contre le soupçon de Réaumur, que ces œufs étaient loin d'avoir une petitesse microscopique, je me mis à scruter journellement, pendant tout le mois de novembre, les feuilles et les sommités de l'arbre qu'habitaient ces insectes, sans pouvoir déconvrir où ils les déposaient. Je redoublais avec d'autant plus de zèle mes perquisitions à ce sujet, que cette configuration singulière des œufs renfermés dans les ovaires piquait vivement ma curiosité et excitait mes conjectures relativement à la manière dont ils devaient être placés sur leur support. Enfin, en désespoir de cause, je revins encore à mes figuiers dans les premiers jours de décembre, lorsque ces arbres étaient tout-à-fait déponillés de leurs feuilles; je furetai plus scrupuleusement, avec le secours de la loupe, et j'eus la satisfaction de découvrir ces œufs tant désirés. C'est dans les éraillemens ou les fentes qui avoisinent les bourgeons, très rarement sur ceux-ci mêmes, 'qu'on les rencontre. Ils sont à nu, c'est-à-dire sans duvet ni coton qui les abrite, et disposés sans ordre, tantôt isolés, tantôt rapprochés. Ils sont couchés suivant leur 
longueur, de manière que le bec latéral n'est pas apparent et s'enfonce un peu dans l'écorce pour les fixer. Ces ceufs, moins gros que dans l'ovaire, et d'un roux jaunâtre, ont à peine un tiers de ligne de longueur. Leur forme présente quelques légères modifications exprimées par les figures que j'en donne. Leur bont pointu se termine par un filet capillaire, presque aussi long qu'eux, et plus ou moins flexueux. Ce filet n'existe point dans l'œuf encore renfermé dans les gaìnes ovigères, et il est sans doute fourni, lors de la ponte, ou par la glande sébifique ou par le corps glanduleux dont j'ai parlé. C'est un fait bien digne d'admiration, que des cufs si petits et si nus soient en état de braver, pendant tout l'hiver, les rigueurs excessives du froid et de l'humidité, sans que le germe vital qu'ils recèlent en reçoive aucune atteinte.

\section{APHIDIENS.}

Je suis forcé d'avouer que je n'ai point recueilli sur l'anatomie de l'appareil génital des Pucerons des matériaux suffisans pour en donner une description en harmonie avec celle des insectes précédens. Les femelles sont, comme on sait, les unes vivipares, les autres ovipares. La multiplicité de mes occupations ne m'a pas encore laissé le loisir de disséquer des individus de ces dernières, qui, d'après le témoignage des auteurs, sont immédiatement fécondées par un accouplement dans l'arrière-saison. C'est avec un regret vivement senti que je laisse cette lacune, et je prends l'engagement de la combler plus tard.

La génération spontanée des Pucerons est un fait trop connu et rendu trop authentique par les expériences des Bonnet, des Degéer, des Réaumur, pour que j'en fasse ici l'objet d'un examen particulier. M. Aug. Duvau, dans ses intéressantes recherches sur ces insectes, publiées en 1825 , 
prétend a vec raison que cette découverte, qui date de $\mathbf{} 74^{\circ}$ à 1750 , devrait former, dans l'histoire des sciences, une époque, comme i 665 est l'époque de la gravitation. Cet observateur, dont la sagacité et l'exactitude rappellent celles des illustres naturalistes que je viens de citer, a repris, après une lacune de soixante ans, les expériences de Bonnet; il les a confirmées par les siennes, et a obtenu une génération de plus que ce dernier; en sorte que dans le cours de sept mois, M. Duvau a pu constater onze générations spontanées eu ligne directe.

Nous venons de voir que dans la Psylle et dans la Dorthésie les deux ovaires étaient presque confondus en un seul paquet, mais qu'avec un peu d'adresse on parvenait cependant à les isoler. Dans les Pucerons, du moins dans les vivipares, malgré tous les soins que j’ai mis à leur dissection, je n'ai point pu constater l'existence de deux faisceaux de gaînes ovigères, ct je me sens porté à croire qu'il n'y en a qu'un seul. Ces gaînes ne m'ont paru, dans le Puceron du rosier, qu'au nombre de dix à douze en lout. Elles sont à cinq ou six loges, et, ainsi que celles des deux genres précédens, elles nese terminent point par un ligament suspenseur. Dans la gestation un peu avancée, la base de ces gaînes, c'est-à-dire les loges les plus rapprochées de l'oviducte, renferme de véritables fœtus bien caractérisés, ou l'on distingue en avant deux points bruns qui représentent les yeux, et dont les pattes sont ployées contre le corps. Ces foetus, lors de l'accouchement, arrivent à reculons à la vulve, de manière que leur derrière sort le premier, et la tête la dernière.

Malgré des autopsies soigneuses, je n'ai jamais pu découvrir dans les Pucerons vivipares le moindre vestige de la glande sébifique de l'oviducte. Si, comme je l'ai dëjà avancé, ce dernier organe a pour fonction essentielle lors 
de la ponte, d'enduire les œufs d'un vernis particulier, on concevra son inutilité dans les Pucerons, qui mettent au jour des petits vivans. C'est ici que la dissection des Pucerons ovipares serait devenue intéressante pour éclairer ce point de physiologie.

\section{CHAPITRE TROISIÈME.}

\section{APPAREIL DE LA RESPIRATION.}

Depuis Malpighi on sait que les insectes, deshérités d'une véritable respiration par les naturalistes de l'antiquité, jouissent de cette fonction, et que celle-ci s'exerce chez eux au moyen de stigmates et de trachées. Les Hémiptères sont par conséquent dans ce cas. Jes trachées ou les canaux aérifères se distribuent dans les diverses parties du corps, pénètrent tous les viscères, s'insinuent dans tous les tissus, soit sous la forme de vaisseaux ramifiés, soit sous celle de réservoirs utriculaires, et l'acte respiratoire devient ainsi une circulation d'air au moyen de laquelle ce fluide vital va se mettre en rapport avec les élémens nutritifs, et leur imprimer la condition nécessaire au but del'organisme. La seule circulation générale qui existe dans les insectes est donc celle de l'air; et M. Cuvier, dont l'opinion est et sera long-temps une autorité imposante, a eu raison d'avancer que toutes les fois que le sang ou l'humeur nutritive ne va pas chercher l'air, il faut que ce soit l'air qui aille le chercher. Payons encore ici un tribut d'admiration à cette unité de plan dans les lois qui régissent ces milliers de petits êtres, et dans celles qui gouvernent les animaux à organisation plus compliquée, et placés aux sommités de l'échelle. Dans les uns comme dans les autres la respiration consiste à inhaler de l'air atmosphérique, à lui sous-

4. Savans étrangers. 
traire, par une opération de chimie organique, un principe indispensable à l'existence, et à l'exhaler ensuite par la même voie, comme impropre pour en introduire de nouveau.

Quoique parmi les Hémiptères les uns soient habitans de l'air, les autres aquatiques, et quelques autres amphibies, il n'y a cependant pour tous qu'un seul mode de respiration : tous respirent l'air de l'atmosphère. Ceux qui se tieunent dans l'eau ne décomposent pas celle-ci pour en séparer ce dernier fluide ou quelqu'un de ses principes constitutifs; aussi les voyez-vous venir souvent à la surface du liquide pour humer l'air, ou bien, comme la plupart d'entre eux sont pourvus d'ailes, quitter le sein des eaux pour respirer dans l'atmosphère. On rencontre d'ailleurs dans tous les Hémiptères sans exception des stigmates et des trachées, et l'existence de ces deux organes entraîne comme conséquence rigoureuse la respiration de l'air en nature.

Les stigmates ou les orifices extérieurs de l'appareil respiratoire, comparables à la glotte des a nimaux à poumons, sont toujours binaires, c'est-à-dire disposés par paires symétriques, l'un à droite, l'autre à gauche de la ligne médiane du corps, sur des parties similaires. On peut les distinguer en thoraciques et en abdominaux, suivant leur situation à lun ou à l'autre de ces deux grands segmens du corps. La tête ne m'en paraît point pourvue.

Les stigmates thoraciques ne different pas seulement par leur siége de ceux de l'abdomen, ils s'en distinguent surtout par une configuration et une structure particulières. Il n'y en a qu'une seule paire, et elle occupe cette région latérale et inférieure du thorax qui porte le nom de flancs de la poitrine. Leůr structure me paraît avoir échappé aux recherches des zootomistes qui ont parlé de ces organes. Ils ne sont représentés par aucune des nombreuses formes 
décrites et élégamment figurées par le savant Sprengel ( $\mathrm{I}$ ). On ne saurait y rapporter les stigmates trémaères de M. Marcel deSerres (2), qui se composent de deux panneaux propres, cornés, mobiles, mis en jeu par des muscles spéciaux. Les stigmates thoraciques des Hémiptères, et en particulier ceux des Géocorises, n'ont que des bords empruntés aux pièces de la poitrine qui les circonscrivent; ils manquent du cerceau corné que M. Audouin appelle péritrème. Il n'est pas facile, dans les individus privés de la vie, d'en constater l'existence; et dans l'insecte vivant, il faut une attention soutenue, la loupe à l'œil, pour saisir les mouvemens bornés et obscurs de cette houche respiratoire. Ils sont situés dans la ligne même de séparation du mésothorax et du métathorax, un peu en arrière de l'articulation des pattes intermédiaires. Les bords, presque habituellement contigus de ces deux segmens, forment les lèvres du stigmate. Ils peuvent s'entr'ouvrir, se refermer, et c'est ce hiatus étroit, cette scissure linéaire, qui constituent l'ostiole pneumatique du thorax. Comme les soins conservateurs de la nature ne sont jamais en défaut, ces bords respectifs sont garnis intérieurement de cils courts, mais bien fournis, dont l'entre-croisement forme comme un fin tamis qui s'oppose à l'abord des atomes hétérogènes dont la présence pourrait offenser la délicatesse des trachées, et qui ne donne accès qu'au fluide subtil de la respiration.

Les stigmates abdominaux des Hémiptères présentent, quant à leur situation, une différence très remarquable avec ceux des Coléoptères. Dans les insectes de ce dernier ordre ils sont placés à la région supérieure ou dorsale de

(2) Curt. Sprengegel. Commentarius de partibus quibus insecta spiritus ducunt.-Lipsia, 1815 .

(2) Observations sur les usages du vaisseau dorsal, etc., page 48 . 
l'abdomen, sur une membrane souple, mais résistante, interposée aux segmens coriacés du dos et à ceux du ventre, tandis que dans les Hémiptères ils occupent la région inférieure ou ventrale, nichés dans le tégument coriacé luimême. Quelques espèces du genre Ligaus, notamment le L. equestris, semblent faire une exception à cette règle; mais nous verrons plus bas que cette exception n'est qu'apparente. Le nombre des stigmates abdominaux n'est pas le même dans tous les Hémiptères, et il se trouve ordinairement en rapport direct avec celui des segmens qui constituent essentiellement la paroi ventrale de l'insecte. Je dis essentiellement, parce qu'il ne faut pas comprendre parmi les segmens constitutifs de cette paroi, ceux qui, placés à la partie postérieure de l'abdomen, servent à caractériser extérieurement les sexes. Le plus souvent, il y a six paires de stigmates abdominaux; mais il est des genres qui en ont moins, et d'autres qui en ont sept. Ils sont placés à droite et à gauche sur deux lignes longitudinales et parallèles, à peu de distance du bord externe des segmens ventraux. Ils sont en général fort petits, ronds, punctiformes, et peuvent être classés parmi ceux que $\mathbf{S}$ prengel appelle simplicissima, c'est-à-dire composés d'un trou ou ostiole nu, entouré d'un péritrème corné. Il y a peu d'exceptions à cette règle; cependant les Nèpes nous en offriront une.

On retrouve dans les Hémiptères, ainsi que je l'ai déjà fait pressentir, les deux espèces de trachées qui s'observent dans la plupart des autres ordres d'insectes, savoir: les trachées tubulaires ou élastiques, et les trachées utriculaires ou membraneuses. Les premières, ainsi que l'indique leur double dénomination, sont des tubes divisés en ramifications décroissantes, essentiellement constitués par un filet élastique roulé en spirale. Elles sont spécialement destinées à la transmission, à la circulation de l'air. 
M. Marcel de Serres, d'après ce dernier trait fonctionnel, les appelle aussi trachées artérielles. Les secondes, sous la forme de poches plus ou moins développées, sont dépourvues du filet élastique dont je viens de parler, et jouissent d'une texture uniformément membraneuse, de manière qu'elles peuvent et se gonfler et s'affaisser. Elles paraissent avoir pour fonction de se prêter au séjour plus ou moins prolongé, sans doute aussi à la digestion de l'air, et l'auteur que je viens de nommer les désigne sous le nom de trachées pulmonaires. Ces deux sortes de vaisseaux aérifères ne se rencontrent pas indistinctement dans tous les Hémiptères, et leur présence simultanée ou l'absence de l'une d'elles fournissent des caractères anatomiques constans, et d'une grande valeur pour la distinction des familles et des genres.

Mais, indépendamment de ces espèces de trachées, on rencontre dans le thorax de quelques Hémiptères, spécialement dans celui de la $N$ èpe et de la Ranatre, un appareil vasculaire trachéen particulier, un organe parenchymateux , circonscrit, je dirais presque une ébauche de poumon dont les entomotomistes n'avaient point parlé avant que j'en eusse consigné la description dans mon mémoire précité sur ces Hydrocorises. J'y reviendrai à l'article de celles-ci.

Dans le but de simplifier et d'abréger mon travail, je me dispenserai d'examiner dans deux articles séparés les stigmates et les trachées, et je me bornerai à passer simplement en revue l'ensemble de l'appareil respiratoire dans les diverses familles ou tribus, et dans les genres qui les composent.

\section{GÉOCORISES.}

C'est un fait digne de remarque, que dans la tribu si 
naturelle des Géocorises, les genres dont les antennes sont composées de cinq articles, comme les Scutellères et les Pentatomes, présentent en même temps des trachées tubulaires et utriculaires, tandis que ceux qui, comme les Corés, les Ligées, etc., ont seulement quatre pièces aux antennes, n'offrent que des trachées tubulaires. Voyons si l'on peut se rendre raison de cette différence. Les trachées utriculaires, indépendamment des fonctions purement respiratoires, ont aussi pour but de diminuer la pesanteur spécifique du corps, par la faculté qu'ont les insectes de les gonfler d'air; et elles sont, d'après la remarque judicieuse de M. Marcel de Serres, l’apanage plus spécial des espèces qui ont besoin d'une force musculaire prépondérante pour exercer un vol plus étendu ou plus répété. Or, en examinant comparativement et la complexion, et la myologie, et les habitudes de ces diverses Géocorises, on se convaincra que cette dernière considération est parfaitement applicable au cas dont il est ici question. Ainsi les Scutelleres et les Pentatomes ont un corps épais et lourd, des tégumens durs et compactes, un système musculaire fourni et développé, un vol assez bourdonnant; circonstances qui justifient la nécessité de poches pneumatiques pour la locomotion aérienne. Au contraire les Corés, les Lygées, les Arades, les Syrtis, etc., ont la plupart beaucoup de surface et peu d'épaisseur, un corps presque papyracé, conséquemment très léger; des muscles grêles; enfin un concours de conditions qui rendent moins nécessaires ou inutiles les vessies trachéennes.

Je ne reviendrai pas sur les stigmates thoraciques des Géocorises, que j’ai fait connaître dans les généralités de l'appareil respiratoire.

A en juger seulement par l'inspection des parties qui sont habituellement à découvert, on croirait que les $\mathbf{S} c u$ - 
tellères, les Pentatomes et autres genres voisins n'ont que cinq paires destigmates abdominaux; mais une exploration plus attentive fera reconnaître qu'il y en a six bien distinctes. Le premier des segmens de la région ventrale ne déborde que fort peu le limbe postérieur du métathorax, au-dessous duquel il se trouve en grande partie enchâssé, de manière qu'on est obligé d'enlever cedernier pour mettre en évidence le premier stigmate abdominal, qui est tout aussi grand que les autres.

Dans la Scutellera nigro-lineata, les stigmates abdominaux sont d'une extrême petitesse, punctiformes, noirs, placés chacun au centre d'une des taches orbiculaires noirę, dont le ventre de cet insecte est parsemé; en sorte qu'il faut le secours de la loupe et une certaine habitude pour les découvrir. Ils ont une singulière ressemblance avec l'ostiole de quelques espèces de cryptogames du genre spharia. Quant au système trachéen, en voici la disposition. De chaque côté de la cavité abdominale on observe une série d'utricules pneumatiques ovalaires ou sphéroïdales blanches, correspondant directement aux stigmates abrlominaux, par conséquent au nombre de six, et communiquant avec ceux-ci ou plutôt en naissant au moyen d'un col fort court qui n'est qu'une trachée élastique capillaire. La première paire de ces utricules, ou celle qui est à la base de l'abdomen, est constamment plus grande que les autres, et s'engage en partie dans le métathorax. Toutes émettent de leur périphérie des troncs tubulaires qui vont épanouir leurs fines et nombreuses ramifications sur les viscères de la génération et de la digestion. Toutes ces trachées sont parfois revêtues d'une espèce de fausse membrane fournie par le tissu adipeux. Il n'y a dans la cavité abdominale de cette Scutellère d'autres utricules trachéennes que les six paires que je viens de signaler. L'in- 
térieur du thorax ne m'a présenté que des trachées tubulaires dont les branches principales sont pressées entre elles sur les masses musculaires qui garnissent cette cavité.

Les stigmates abdominaux de la $\boldsymbol{S} \boldsymbol{c}$. maura sont des pertuis tout aussi petits que ceux de l'espèce précédente, mais pâles ou jaunâtres. Mais ses vaisseaux aérifères offrent des traits distinctifs de ceux de cette dernière, et il faut se rappeler à cette occasion, que j'ai déjà signalé, soit dans la structure de quelques parties extérieures, soit dans les organes génitaux, des caractères qui pourraient autoriser à placer dans un sous-genre particulier la $S$ cutellère maure. Quoi qu'il en soit, à la place occupée dans la Scutellère rayée par six paires d'utricules pneumatiques, il n'y a dans la maure qu'un seul grand tronc trachéen de chaque côté de la cavité abdominale; et de ce tronc, qui s'abouche par de fines radicules aux stigmates, partent des branches qui émettent des vésicules ovales beaucoup plus nombreuses que celles dont je viens de parler, et qui n'affectent point une disposition sériale. Dans l'intérieur du métathorax et dans un point correspondant justement à la base de l'écusson, il y a plusieurs utricules pneumatiques plus ou moins contiguës, de couleur rouillée, qui, à la faveur de diverses branches, s'anastomosent soit avec d'autres utricules prothoraciques, soit avec les grandes poches trachéennes de la base de l'abdomen. Ces utricules sous-scutellaires, qui existent aussi dans tous les Pentatomes, et que je n'ai pas su découvrir dans la $S$. rayée, quoique je présume qu'elles doivent s'y rencontrer, ont une organisation particulière qui rappelle ces ébauches de branchies ou de poumons que j'ai signalées et décrites dans mes recherches anatomiques sur les Coléoptères longicornes et sur les Népides. Elles émettent latéralement des espèces de franges, ou plutôt une bourre fine dont les 
brius, observés au microscope, sont des vaisseaux trachéens rameux. Ces brins enchevêtrés constituent un vestige de tissu parenchymateux dans les filtres duquel il est présumable que l'air est soumis à une sorte de digestion. Ces poches trachéennes métathoraciques méritent une étude particulière, intéressante sous le rapport physiologique, à laquelle je me propose de me livrer.

Les stigmates abdominaux des diverses espèces du genre Pentatome soumises à mes investigations anatomiques, se présentent sous la forme de petits boutons orbiculaires à peine saillans, enchatonnés dans le tégument, constitués par un péritrème cartilagineux dont le centre est ouvert, béant, parfaitement nu. Ces stigmates sont fixes, immobiles pendant l'acte respiratoire. lls sont noirs dans le $P$. gris, et dans le $P$. du genévrier; d'un gris plombé dans le $P$. dissemblable; d'un jaune pâle ou verdâtre dans le $P$. émeraude; noirs et presque imperceptibles dans le $P$. orné, avec cette particularité que l'ostioleest situé sur le côté d'une légère éminence; fort petits, noirs et de niveau avec le tégument dans le $P$. acuminé; moins planes, mais aussi petits et noirs dans le $P$. du grateron. Les trachées abdominales des Pentatomes ont la même forme, la mème disposition que celles de la Scutellère rayée. Ainsi il y a six paires d'utricules stigmatiques, d'où prennent naissance des trachées élastiques en arbuscules. La dissection du métathorax met en évidence, ainsi que je viens de le dire à l'occasion de la $S c$. maure, des boursouflures trachéennes ferrugineuses qui s'anastomosent avec celles de l'abdomen et du prothorax.

Dans les genres Coreus, Alydus, Lygaus, Pyrrhocoris, Capsus, Miris, Plymata, Cimex, Aradus, Reduvius, Géocorises qui diffèrent surtout des Scutellera et des Penttatoma, parce qu'ils n'ont que quatre articles aux anten4. Savans étrangers. 
nes, on n'aperçoit ni dans le thorax ni dans l'abdomen, aucune trace de l'existence d'utricules pneumatiques. Toutes les trachées sont tubulaires ou élastiques, généralement remarquables par leur finesse et leur rareté. Les Réduves forment peut-être une exception, car je crois avoir reconnu dans le métathorax du $R$. stridulus des boursouflures trachéennes.

Les stigmates abdominaux sont au nombre de six paires dans les diverses espèces du genre Coré, médiocrement petits, d'un gris plombé, et bien ombiliqués dans le C.bordé; plus petits et d'une couleur analogue à celle des tégumens dans le $C$. ictérique; d'un gris roussâtre, et plus rapprochés du bord externe dans le $C$. folâtre; très éloignés de ce bord dans le $C$. paradoxal; pâles, mais bien exanthématiques et occupant la portion dilatée de l'abdomen dans le C. carré, également pâles et punctiformes dans le C. hirticorne; de cette même nuance et $\mathrm{du}$ même dianètre, mais plus près du bord externe dans l'Alycle du géranium; presque contigus à ce bord dans l'A. aptère.

Ces spiracules ont une petitesse microscopique, sont colloqués sur un léger exanthème, et sont rouges dans la Pyrrhocore; en forme de points saillans et rougeâtres dans le Lygée de la jusquiame. On les chercherait vainement, même à l'aide des verres amplifians, à la région ventrale de l'abdomen dans le $L$. équestre. Cette espèce semble commettre une infraction à la loi générale. Cependant les stigmates ne sont pas non plus situés aux segmens dorsanx. Il y a entre ces deux régions une lisière qui, dans le fait, n'est qu'un repli de la paroi ventrale, avec laquelle il est continu; et ce repli est séparé de la paroi dorsale par une strie ou ligne enfoncée. Ces stigmates, d'une petitesse qui les dérobe presqu'à la loupe, occupent le milieu des intersections de la lisière. 
Dans les nombreuses espèces des genres Capse et Miris, on compte à la région ventrale de l'abdomen sept segmens bien apparens, sans y comprendre celui ou ceux qui appartiennent à l'appareil génital externe, et il y a sept paires de stigmates bien distinctes, par conséquent une de plus que dans les genres précédens. C'est un trait anatomique fort remarquable. Ces stigmates sont en forme de très petits points, placés dans une dépression et quelquefois cachés par l'imbrication des segmens.

La Plymate n'a que six paires de stigmates abdominaux. Ils sont tous six bien à découvert, blanchâtres, établis sur un exanthème assez marqué, à la partie interne, d'une empreinte linéaire qui sépare la portion dilatée de l'abdomen, de celle qui appartient essentiellement au ventre. Le même nombre de ces ostioles pneumatiques existe dans l'Arade, mais il faut la plus forte lentille du microscope pour les découvrir. Chacun d'eux est un pore rond, placé à une certaine distance du bord externe. ll ne faut point les confondre avec certains points saillans ou déprimés, assez symétriquement disposés à la région ventrale, et visibles à la loupe. Ceux des Réduves, au nombre de six paires, sont petits, saillans, blanchâtres, tous à découvert, placés tout près et en dedans d'une rainure linéaire qui sépare une lisière marginale de la région ventrale. Dans les Nabis, les stigmates sont situés en dehors de la rainure dont je viens de parler, mais semblables du reste à ceux des Réduves.

\section{AMPHIBICORISES.}

Les stigmates abdominaux des Gerris et des Velia ont une petitesse microscopique, et sont fort difficiles à constater, à cause du duvet lustré, soyeux et ras qui revêt les tégumens. Ils sont au nombre de six paires, placés tout près 
du bord externe de la région ventrale, en dehors de quelques linéoles enfoncées. Leurs trachées sont toutes tubulaires ou élastiques, d'une ténuité plus que capillaire, et peu nombreuses. Ces deux dernières circonstances, qui prouvent que l'appareil respiratoire des Amphibicorises est beaucoup moins développé, moins étenda que celui des Géocorises, prouvent aussi qu'ils respirent moins que ces derniers, qu'ils jouissent par conséquent d'une vitalité moins active. Ces insectes rameurs ont effectivement un genre de vie assez paisible, assez monotone. Non-seulement on ne les voit pas souvent quitter la surface de l'eau ou sa rive, mais le théâtre de leur ambulation natatoire est fort restreint. Plusieurs d'entre eux sont aptères, et ceux qui sont pourvus d'ailes en font rarement usage pour s'envoler.

Cette rareté, cette ténuité des vaisseaux aérifères des Amphibicorises, constituent un trait organique dont la valeur doit être appréciée dans une classification anatomique.

\section{HYDROCORISES.}

Quoique ces Hémiptères soient habitans de l'eau, ainsi que l'indique leur dénomination; quoique parmi eux il en soit de constamment aptères, qui par conséquent ne quittent point l'élément qui les a vus naître, cependant ils sont tous pourvus de stigmates et de trachées, ils respirent tous l'air en nature. Leurs couduits aérifères appartiennent uniquement à l'espèce des trachées tubulaires ou élastiques; ils sont d'une finesse extrême et peu abondans; en sorte que l'on peut dire des Hydrocorises ce que j’ai déjà avancé à l'occasion des Amphibicorises, qu'ils respirent moins que les Géocorises, qu'ils ont une locomobilité moins énergique. 
Le stigmate thoracique des Naucores est placé dans l'articulation linéaire du mésothorax avec le métathorax. Cette fente ne présente extérieurement rien qui ressemble à un de ces orifices respiratoires; mais en désarticulant les deux segmens du thorax qui la constituent, il m'a semblé reconnaître l'existence d'une sorte de soupape membraneuse blanchâtre, dont chaque moitié, ou pannean, serait fixée au bord qui lui correspond. Les stigmates abdominaux de cet insecte sont au nombre de six paires, très petits, ronds, punctiformes, beaucoup moins marginaux que ceux des Hémiptères que nous venons d'examiner.

Lorsqu'en r82 x (Annales générales des Sc. Physiq. de Bruxelles), je signalai la structure singulière des stigmates de la Nèpe, et la disposition curieuse d'un système trachéen spécial, renfermé dans le thorax de cet insecte, je ne dissimulai ni mon embarras pour l'explication physiologique de la respiration dans ces animaux, ni le besoin vivement senti de renouveler mes recherches entomotomiques sur ce point. J'ai donc soumis de nouveau au scalpel et au pinceau cet Hydrocorise, et je suis enfin parvenu à dissiper la plupart des incertitudes. Occupons-nous d'abord de faire connaitre la forme, la position, la texture et la distribution générale de l'appareil respiratoire; nous chercherons ensuite à jeter quelque jour sur les attributions physiologiques des diverses parties qui le constituent.

C'est un fait incontestable que la Nìpe et la Ranatre n'offrent aucune trace de l'existence de stigmates thoraciques.

Quant aux stigmates abdominaux, ils diffèrent considérablement de ceux des autres insectes, et quoiqu'ils ne remplissent, ainsi que nous le dirons plus bas, aucune fonction dans l'acte respiratoire; quoiqu'ils soient, dans 
la force du terme, faux, postiches ou vestigiaires, leur grandeur, leur structure, méritent de fixer toute notre attention. Comme ceux des autres Hémiptères, ils occupent la face inférieure ou ventrale de l'abdomen. A l'article des généralités, nous avons dit que le nombre des paires de stigmates de l'abdomen était ordinairement en rapport direct avec celui des segmens essentiellement constitutifs de la paroi ventrale. Les Népides font une exception à cette règle; elles n'ont que trois de ces stigmates de chaque côté du ventre, quoique celui-ci compte six segmens distincts. Nous n'y comprenons pas les stigmates du siphon respiratoire, qui, nous le verrons plus bas, est indépendant des segmens propres de l'abdomen. Le premier, le second et le sixième (ou dernier) des segmens ventraux n'offrent, ni en dehors ni en dedans, aucun vestige de l'existence des stigmates. Le troisiène, le quatrième et le cinquième, sont les seuls, et leur grandeur les rend aussi apparens à l'extérieur qu'à l'intérieur. Ils sont situés vers le tiers antérieur de chacun des segmens stigmatifères sur un point qui est à égale distance $d u$ bord externe du ventre et d'un pli linéaire longitudinal placé en-deçà de ce bord.

Les stigmates abdominaux de la Nèpe sont les plus grands de ceux que j'aie encore eu occasion d'observer dans les insectes, et malgré cette condition avantageuse pour l'anatomiste, ce sont ceux dont la structure m'a paru la plus difficile à bien déterminer. Ils ont une figure ovalaire un peu moins large en arrière qu'en avant, et leur bord interne, au lieu d'être convexe comme l'externe, est presque droit ou à peine échancré. Quoique nullement circonscrits, ils ne forment ni relief ni enfoncement notable, et sont, pour ainsi dire, de nivean avec les tégumens où ils siégent. Ils n'offrent ni fente médiane, ni disposition valvulaire, ni cils, ni villosités. Ils sont essentiellement constitués par 
un diaphragme de consistance cornée, en touré d'une marge ou bordure peu ou point saillante dont l'organisation est très distincte de celle du disque, qu'elle paraît enchatonner, et se rapproche un peu de celle des tégumens. Ce diaphragme stignatique est partout d'une texture homogène, et, étudié à une forte loupe, il est en dehors d'un doré pâle, métallique, avec des points plus brillans. Ceux-ci, plus on moins arrondis, m'ont paru tantôt creux, tantôt saillans, tantôt comme offrant une réticulation irrégulière, et je ne suis point encore parvenu à dissiper cette illusion d'optique. I a plus forte lentille du microscope, dans les conditions les plus favorables, comme, par exemple, lorsque la lumière donne le plus de diaphanéité possible au diaphragme stigmatique, m'a représenté les points dont je viens de parler, munis d'un contour demi transparent.

Telle est la structure, au moins apparente, des faux stigmates abdominaux de la $N$ 'epe, étudiés par leur face externe. Celle de leur face interne ou viscérale n'offre pas de différence appréciable, mais ils ne brillent pas de la couleur dorée qui se remarque au dehors. Une portion assez large, qui longe le bord externe de cette face, est abritée sous une lisière membrano-cornée, lisse et unie, qui en masque la texture. Cette lisière, bien visible au microscope, ne semble que le rudiment, le vestige d'un second diaphragme stigmatique. La première fois que je la découvris, je crus d'abord qu'elle n'était que le lambeau accidentel d'une membrane qu'on pouvait supposer appliquée sur toute la surface interne du stigmate; mais l'observation directe, plusieurs fois réitérée, a laissé dans mon esprit la conviction que cette lisière n'était poiut le résultat d'un déchirement; et son bord libre, loin d'offrir des dentelures ou des découpures, m'a constamment paru entier et uni. 
Chacuu de ces faux stigmates intérieurs reçoit à son bord antérieur et un peu interne un tronc trachéen assez considérable dont nous indiquerons plus bas et le mode d'insertion et l'origine.

Le siphon qui termine en arrière l'abdomen des Népides, et la paire de stigmates placée à sa base, constituent le véritable, le seul appareil extérieur de la respiration dans ces insectes. Ce siphon respiratoire, et cette dénomination physiologique est exacte, n'est point dans la Nèpe un de ces traits qui dans plusieurs insectes sont l'attribut de l'un des sexes : il existe, avec les mêmes caractères, dans le mâle comme dans la femelle. L'analogie qu'il semblerait d'abord offrir avec l'oviscapte des Ichneumons et celui de quelques Orthoptères n'est qu'apparente et se dissipe à l'épreuve du moindre examen. Ce siphon, délié comme une soie de porc, droit et assez raide, a la couleur et la consistance cornée du reste du corps. Il égale en longueur l'abdomen de la Nèpe. Il est formé par la contiguité, l'adossement de deux tiges sétacées, canaliculées ou creusées en gouttière sur la face par laquelle elles s'adaptent l'une à l'autre. Cette gouttière a ses deux bords garnis intérieurement de poils très fins.

La base du siphon respiratoire est logée entre le dernier segment dorsal de l'abdomen et une plaque ventrale correspondante légèrement concave. Elle est indépendante des segmens constitutifs de l'abdomen, et ne tient à celui-ci que par des muscles qui lui sont propres. Cette base intersegmentaire est formée par deux pièces semblables qui se continuent avec les tiges canaliculées. Ces pièces sont le siége des stigmates caudaux. Elles sont garnies de poils roussâtres, fins, longs, et plus ou moins couchés, abondans surtout à leur côté interne. En-dessous elles présentent une gouttière qui fait suite à celle de la tige 
canaliculée du siphon. Au point où celle-ci s'unit à la pièce intersegmentaire, il y a un léger coude dont le tissu plus flexible forme une demi-articulation qui favorise l'écartement, la déduction des deux tiges, lors de l'acte respiratoire.

Les stigmates caudaux ou du siphon respiratoire ont une configuration et une texture qui les font différer beaucoup de ceux qui siégent à l'abdomen. Ce sont là les véritables stigmates des Népides, les seuls orifices extérieurs qui servent à leur respiration. Il n'y en a qu'une paire. Chacun d'eux est situé à l'origine de la gouttière pratiquée à la face inférieure de la pièce intersegmentaire du siphon. Ce stigmate est fort petit, rond, orbiculaire, entouré d'un limbe ou cercean corné brunâtre. Il est béant, c'est-à-dire constamment ouvert. Mais cette forme, cette structure, sont, dans l'état ordinaire, masquées par un duvet abondant, couché sur le stigmate, et qu'il faut soigneusement enlever ou raser avec un fin scalpel, pour les mettre en évidence.

Dans la description que nous venons de donner des stigmates faux et vrais de la Nèpe, nous croyons avoir suffisamment établi, par des preuves anatomiques, que les seuls d'entre enx qui donnent accès à l'air pour la respiration, sont ceux qui siégent à la base du siphon respiratoire. C'est donc à ces deux derniers orifices que commence l'appareil des vaisseaux destinés à faire circuler le fluide atmosphérique jusque dans les profondeurs des viscères et de tous les tissus. Il nous reste donc à décrire cet appareil. Nous n'entrerons pas dans de minutieux détails sur les rameaux et ramuscules destinés à tel ou tel tissu. Une figure, que nous avons cherché à rendre exacte, y suppléera avantageusement. Disons d'abord qu'il y a une symétrie parfaite dans la distribution des vaisseaux aérifères, et que 4. Savans étrangers. 
le système trachéen résulte de la réunion par anastomose de deux moitiés en tout semblables.

Les trachées, qui se distribuent dans l'abdomen et dans la tête, appartiennent toutes à l'ordre des trachées tubulaires ou élastiques. Indépendamment de celles-là, il y a dans le thorax un petit nombre de trachées utriculaires, et une disposition particulière de quelques branches de ces vaisseaux qui constituent une espèce de tissu parenchymateux que nous avions signalé autrefois, et qui sera l'objet d'un examen spécial.

De chaque stigmate caudal part un tronc trachéen qui forme la souche, l'axe principal de l'appareil. Ce tronc suit les flancs des cavités abdominale et thoracique. Dans son trajet dans l'abdomen, il fournit six troncs secondaires assez courts, de chacun desquels naissent deux branches principales récurrentes, dont l'une, très ramifiée, se distribue aux viscères abdominaux, et dont l'autre, simple et située profondément au-dessous de tous les organes, se continue avec sa congénère du côté opposé, et forme ainsi une arcade qui traverse l'abdomen. Cette arcade établit la communication des deux moitiés de l'appareil trachéen. Le premier, le cinquième et le sixième de ces troncs secondaires, à partir du stigmate caudal, viennent se fixer non loin du bord externe des sixième, second et premier segmens ventraux de l'abdomen. Cette insertion a lieu sur des points qui dans la plupart des autres insectes présentent des stigmates; mais ceux-ci sont effacés dans la

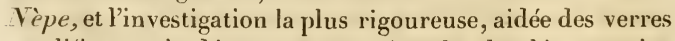
amplifians, n’y découvre pas même le plus léger vestige de l'existence de ces ostioles pneumatiques. Le tronc s'insère là, à nu, sur le tégument ventral, et il n'y a aucune issue. Le second, le troisième et le quatrième de ces troncs secondaires aboutissent, comme nous l'avons déjà insinué 
plus haut, au bord antérieur et un peu interne de chacun des trois faux stigmates, et leur mode d'implantation, malgré des apparences trompeuses, est semblable à celui des précédens.

Cette insertion trachéenne borgne, obturée ou en culde-sac, loin d'être une observation stérile, devient au contraire pour nous un fait anatomique très significatif. C'est une de ces preuves ajoutées à cent autres, que la nature, dans l'immense série de ses productions, ne procède point par des transitions brusques, ne fait pas de saut, pour me servir du terme consacré. Ce n'est que graduellement qu'elle passe d'un mode d'organisation à un autre; et sans sortir de notre sujet, n'est-ce pas un fait bien digne de remarque que, sur les six stigmates abdominaux qui existent dans les Hydrocorises en général, la $N e ̀ p e$ nous en offre trois simplement obturés, et trois entièrement effacés ou oblitérés? Il est présumable que dans des genres voisins des Nèpes qui ne nous sont point encore connus, ou dont le scalpel n'a pas dévoilé la splanchnologie, on en trouvera où les faux stigmates seront remplacés par de véritables, ou auront tout-à-fait disparu, et d'autres où les insertions à $\mathrm{nu}$ des troncs trachéens secondaires aboutiront à des bouches respiratoires, ou dont ces troncs, à défaut de l'existence de celles-ci, prendront une autre direction.

Poursuivons la distribution générale de l'appareil trachéen. Avant de franchir les limites de la cavité abdominale, le tronc principal envoie un tronc secondaire simple et court à un sachet utriculiforme, visible à l'extérieur de l'insecte, et situé près de l'angle postérieur et externe du métathorax. Il en fournit d'autres, soit aux sachets parenchymateux que nous décrirons bientôt, soit aux pattes et aux ailes, et parvenu à la partie antérieure du prothorax, ce tronc principal se divise en un faisceau de branches qui 
pénètrent dans la tête. Justement au-dessous du ganglion nerveux métathoracique, par conséquent au centre de ce compartiment du thorax, se trouve un sinus trachéen formé par la confluence de quatre grandes branches qui s'y rendent en sautoir. Ce sinus remplace dans le thorax les arcades trachéennes de l'abdomen, et devient, comme celles-ci, le moyen de communication entre les deux moitiés du système des trachées thoraciques.

Nous allons maintenant passer à l'étude des trachées utriculaires et des tissus trachéens particuliers, dont j'ai indiqué le siége dans la cavité thoracique.

En promenant une loupe attentivement sur les divers compartimens du thorax de la $N$ èpe, dans le but d'y découvrir des stigmates, je ne tardai pas à constater, tout près de l'angle postérieur et externe de la région dorsale du métathorax, l'existence constante d'un petit sachet transversalement ovalaire, d'un blanc terne, d'une consistance souple, formant là comme un commencement de hernie, et marqué de quelques légères plissures dirigées dans le sens de son petit diamètre. Les bords correspondans de la base de l'abdomen et du métathorax sont en cet endroit échancrés, et la scissure ou l'hyatus résultant de ces deux échancrures, est le siége du sachet. J'ai reconnu que dans certains cas celui-ci était plus saillant et utriculiforme, et que dans d'autres il paraissait au contraire affaissé, ridé. Je soupçonnai alors que ces changemens étaient sous l'influence de la fonction respiratoire, et les vivisections m'ont paru le confirmer. Nous avons déjà dit que ce sachet recevait une branche trachéeune assez considérable. Il paraît même que cette dernière forme là une souche d'où partent les troncs trachéens destinés soit aux pattes intermédiaires et postérieures, soit aux ailes. Je présume que ce sachet peut servir à la 
Nèpe, ou pour favoriser le vol ou pour gagner la surface de l'eau.

Immédiatement au-dessous de l'écusson de cet Hydrocorise, on rencontre deux corps semblables, oblongs, placés à côté l'un de l'autre, et séparés seulement par la ligne médiane. Ces deux corps simples, et un peu plus gros à leurs extrémités, se font remarquer le plus souvent par une enveloppe lisse et d'un blanc satiné presque nacré. Fixés par leurs bouts à la face inférieure de la région scutellaire, ils sont libres entre ces deux points. $\mathrm{Si}$ on les arrache avec précaution, en les saisissant par leur centre, il n'est pas rare que leurs bouts entraînent une sorte de calotte brunâtre et cornée qui se détache comme une épiphyse. Cette calotte est leur point d'attache propre. Quand.on déchire ce corps, qui est d'une consistance très souple, on voit qu'il renferme une espèce de bourre ou de parenchyme que le microscope démontre formé par des ramuscules trachéens : on dirait un sachet rempli d'un tissu parenchymateux. Une forte trachée qui naît du tronc principal des vaisseaux aérifères, règne le long du bord externe de chacun de ces sachets, où elle est en partie enchâssée, et en sort par leur bout antérieur pour aller de nouveau confluer avec le tronc principal. Si l'on poursuit cette trachée dans l'intérieur du sachet, on se convaincra que c'est elle qui fournit tout le tissu parenchymateux qui le caractérise. Mais les branches qui forment ce dernier, ne naissent pas de toute la périphérie de la trachée. Une face du tronc de celle-ci est tout-à-fait à nu, et c'est cellelà qu'on apercoit le long du sachet. Lorsque cette trachée est débarrassée de l'enveloppe du sachet, et étalée, elle ressemble à un panache, ou à un plumet d'autruche, qui ne se termineraient pas en pointe. Les deux figures qui accompagnent le texte expriment cette disposition. Tel est 
l'état le plus ordinaire de ces deux corps sous-scutellaires de la Nèpe. Dans des conditions plus propres à nous révéler leur véritable texture; conditions rares à la vérité, mais qui se sont présentées deux fois dans le cours de mes nombreuses dissections de cet insecte, je me suis convaincu de leur organisation musculaire, au moins à l'extérieur. Le parenchyme trachéen se trouvant, dans ces conditions, moins pénétré d'air, la couleur d'un blanc satiné ou nacré disparaît, et au lieu d'une enveloppe lisse, j'ai distinctement reconnu, sous la forme de stries longitudinales, les rubans ou faisceaux musculenx grisâtres qui se portent d'un bont à l'autre de ce corps.

Dans la Ranatre les panaches trachéens existent presqu'à nu au milieu des masses musculaires du thorax.

Dans leur position normale, les sachets sous-scutellaires de la Nèpe se trouvent situés au-dessus de denx autres corps placés sur la table inférieure du métathorax, et en grande partie musculo-parenchymateux comme eux. Ces sachets métathoraciques recoivent aussi du tronc principal des trachées une branche volumineuse; mais ils présentent cette différence essentielle av ec les précédens, qu'ils ont chacun deux utricules trachéennes plus ou moins développées. L'une de ces utricules s'observe un peu avant le bout antérieur du sachet, où elle est un peu latérale; l'autre termine directement le bout postérieur, et pour peu qu'elle soit gonflée, elle pénètre dans la cavité abdominale. Ces utricules, soit qu'on les trouve dilatées par de l'air, soit qu'on les rencontre affaissées sur elles-mêmes, sont toujours formées par une membrane d'un blanc pur sans aspect satiné ou nacré. Elles me paraissent remplir l'office de vessies natatoires, dans les cas rares où l'insecte, dépourvu de supports, est obligé de s'élever à la surface de l'ean pour y respirer. 
On rencontre encore dans le métathorax une paire d'utricules trachéennes, mais petites, oblongues, et indépendantes d'un tissu parenchymateux.

La structure extérieure des animaux, leur genre de vie, leurs habitudes, doivent être, pour le scrutateur du but final de l'organisme, des considérations d'une grande valeur, qui, combinées avec celles fournies par la conformation, la texture intime, la positiou des organes, et les expérimentations, le mettent sur la véritable voie des solutions physiologiques. Examinons, d'après ces principes, la fonction respiratoire de l'insecte dont je viens de décrire le stigmate et l'appareil trachéen.

La grandeur et la structure insolites des fanx stigmates de la $N$ ìpe, avant que je leur eusse imposé cette épithète, et la coïncidence assez insidieuse des sachets parenchymateux du thorax, m'avaient autrefois, je l'avone, fait naitre la pensée d'un mode spécial de respiration que j’inclinais à croire au moins semi branchial. Mais une étude sévère de cet insecte, tant sous le rapport de l'anatomie que sous celui de l'entomologie, m'a enfin placé dans le sentier de la vérité.

Quoique la Nèpe soit un insecte aquatique, on n'aperçoit dans sa structure extérieure, rien, absolument rien qui puisse la faire reconnaître pour un insecte nageur. Ses pattes glabres et arrondies ne sont propres qu'à l'ambulation ou à la préhension; son corps plat, cuirassé et compact, gagne promptement le fond de l'eau, et ses tégumens habituellement salis par la boue, annoncent assez son habitude de ramper dans la vase. Aussi ces Hémiptères choisissent-ils pour leur habitation ordinaire les eaux tranquilles ou un fond vasenx où les plantes aquatiques abondent. A la faveur de ces dernières, ils peuvent grimper pour se rapprocher de la surface du liquide, où on les 
voit émerger de temps en temps la pointe de leur siphon respiratoire, pour y puiser l'air atmosphérique. J'ai conservé pendant plusieurs mois ces insectes dans des bocaux qui réunissaient les deux conditions dont je viens de parler, et j'ai pu ainsi étudier à loisir leurs habitudes. Je les ai vus passer des heures entières le bout du siphon à fleur d'eau, et le corps immergé, comme suspendu sur les plantes qui lui servent de support. J'ai été à même de constater alors, avec le secours de la loupe, le mouvement presque insensible de l'inhalation de l'air, et l'attention la plus soutenue ne m’a jamais décelé le moindre travail, la moindre action dans les faux stigmates. Cette observation cent fois répétée me donnait déjà la presque certitude que cet insecte respirait uniquement par le siphon caudal. Cependant je voyais aussi la Nèpe gagner le fond de l'eau et $y$ demeurer long-temps, ou immobile en guettant sa proie, ou rampant pour l'atteindre. Une expérience décisive devait lever tous mes doutes. II s'agissait de placer des Nèpes dans l'eau, de manière à priver celle-ci du contact de l'air atmosphérique, et à mettre l'insecte dans la nécessité, pour le maintien de son existence, de retirer de l'eau même son élément vital, si la nature l'avait organisé pour cette opération de chimie animale. Je renfermai donc deux Nèpes bien portantes dans un flacon assez large, rempli d'eau jusqu'au goulot, et hermétiquement bouché, de manière à ue laisser aucune couche d'air entre le bouchon et le liquide. Voulant d'ailleurs respecter les autres habitudes de l'insecte, j'eus le soin de laisser au fond du flacon et de la vase et des détritus végétaux; conditions favorables aussi aux animalcules dont les $N \grave{e}-$ pes peuvent se nourrir. Au bout de deux heures de cette réclusion, ces insectes donnèrent des signes non équivoques de malaise et de souffrance. Après avoir vainement 
redressé leur siphon, on les voyait faire jouer, l'une sur l'autre, les deux tiges de celui-ci, les entr'ouvrir, les refermer, pour les tenir de nouveau écartées. Un vide considérable qui s'observait entre la région dorsale de l'ahdomen et les élytres, témoignait de l'oppression extrême de l'insecte. Enfin, an bout de dix heures, les deux Nèpes étaient mortes sans retour, et les branches du siphon demeuraient dans le plus grand état de divergence. Ja renouvelai deux fois cette expérience, et jobtins le même résultat avec quelque légère différence pour l'heure de la mort.

De tout ce que nous venons d'exposer sur l'appareil respiratoire de la Nèpe, il résulte ce fait rigoureusensent établi et nouveau pour la science, que cet insecte ne respire que par les stigmates du siphon caudal.

L'appareil respiratoire des Notonectes et des Corises s'éloigne beaucoup de celui des Nèpes, et se rapproche davantage de celui des Amphibicorises. Les stigmates abdominaux, au nombre de six paires, sont fort petits, ronds, semblables à des points, et situés sur deux séries longitudinales, le long des côtés du ventre, un sur chaque segment. Les trachées de ces Hydrocorises sont toutes tubulaires et d'une finesse capillaire. On trouve aussi dans leur thorax une ébauche d'organe pulmonaire. Les trachées y sont disposées en rangées presque contiguës; comme des tuyaux d'orgue, et il est possible, avec un peu d'adresse, de les détacher en un seul faisceau qui prend la forme d'un panache.

\section{CICADAIRES.}

La multiplicité de mes occupations n’a fait négliger, à mon vif regret, l'étude des orifices respiratoires dans les Hémiptères de la section des Homoptères, et malheureu4. Savans étrangers. 
sement je ne trouve point dans les auteurs de quoi suppléer à mon insuffisance sur ce point.

Les stigmates abdominaux de la Cigale $(\boldsymbol{C}$. orni), situés, comme ceux de tous les Hémiptères, à la région inférieure ou ventrale de l'abdomen, sont au nombre de six paires, une pour chaque segment, et disposés au côté interne d'une ligne longitudinale enfoncée, qui est une espèce de pli. Leurs ostioles m'ont paru dénués de péritrème, et sont placés, un peu latéralement, sur un petit espace arrondi, blanchâtre, peu ou point saillant, de texture analogue à celle des tégumens.

Les Cigales sont pourvues des deux ordres de trachées, les tubulaires et les utriculaires. Les premières se distribuent plus spécialement aux viscères abdominaux, et sont très fines. Celles qui sont affectées aux organes digestifs sont pour la plupart enveloppées d'un fourreau adipeux, tandis que la couleur nacrée brille de tout son éclat dans les trachées de l'appareil génital. La cavité thoracique offre deux troncs aérifères assez grands, qui vivifient les glandes salivaires et pénètrent dans la tête. Les trachées utriculaires sont en général de fort petites bulles, les unes globuleuses, les autres polymorphes, plus ou moins groupées. On en trouve, avec cette dernière condition, sur la membrane péritonéale de l'abdomen et sur la surface des masses musculaires qui garnissent la poitrine. Indépendamment de ces petites bulles, on voit une utricule conoïde plus grande de chaque côté de la cavité mésothoracique.

Nous avons dit qu'en général les trachées utriculaires étaient d'autant plus nombreuses ou d'autant plus développées, que les insectes avaient un système musculaire plus puissant, une locomobilité plus énergique. A en juger par leurs habitudes aéricoles et par l'ampleur de 
leurs ailes, on pourrait croire que les Cigales ont un vol fréquent, un genre de vie très actif, et on devrait être surpris alors du petit nombre de leurs utricules aérifères. Mais les naturalistes à portée d'observer les mœurs de ces insectes, se convaincront que, contre les apparences, ils ont des habitudes sédentaires. On les voit se tenir des heures, immobiles, comme collés contre les troncs ou les branches des arbres; et quand on les oblige à changer de place, ils le font par un vol peu prolongé et mou, c'est-àdire non bourdonnant.

\section{APHIDIENS.}

L'insuffisance de mes instrumens amplifians ne m'a pas mis à même de constater l'existence des stigmates dans les Pucerons. Leurs vaisseaux aérifères appartiennent tous aux trachées tubulaires, et sont d'une finesse telle, qu'il faut le secours du microscope pour les reconnaître. Ce n'est qu'à une forte loupe et à un jour favorable qu'on peut s'assurer de l'aspect nacré ou argenté de ces vaisseaux. Ils n'apparaissent que comme les brins les plus ténus de la soie.

\section{CHAPITRE QUATRIÈME.}

APPAREIL SENSTTIF.

Les insectes, tout privés qu'ils sont de colonne vertébrale et de cœur, reçoivent, ainsi que les animaux du premier rang, des sensations, exercent des volitions, et un appareil particulier préside à ces deux actes de l'organisme, comme il participe à l'exercice de toutes les fonctions viscérales. Cet appareil, parfaitement circonscrit, est le système nerveux, et la nature ne s'est pas écartée, pour son organisation, du plan adopté généralement, car les insectes ont un cerveau, un prolongement 
rachidien, des ganglions et des nerfs, et ces diverses parties paraisseut avoir les mêmes attributions physiologiques que dans les êtres les mieux organisés.

Les auteurs de traités généraux sur les animaux, en parlant du système nerveux des insectes, n'ont eu en vue que celui de quelques grandes larves et des grands Coléoptères ou Orthoptères; personne, jusqu'ici, n'avait fait connaître cet appareil dans les Hémiptères et autres insectes suceurs; en sorte que dans leurs généralisations ils se sont laissé entraîner sur ce point à des erreurs inévitables. L'organe sensitif des Hémiptères est très différent de celui des Coléoptères. Au lieu d'avoir, comme ces derniers, une série de huit à dix ganglions distribués dans les deux grandes cavités splanchniques, c'est-à-dire dans le thorax et l'abdomen, les Hémiptères n'ont que deux ganglious logés tous deux dans le thorax, et la seconde de ces cavités n'en a point. Mais le cordon médian ou rachidien se divise en plusieurs paires de nerfs très développés, dont les subdivisions se distribuent dans les viscéres de la cavité abdominale. L'ensemble de cet apparcil est parfaitement symétrique, c'est-à-dire qu'il fournit à droite et à gauche un même nombre de nerfs semblables, et qu'il est partageable, par une section médiane, en deux moitiés identiques.

Ce peu de mots sur le système nerveux des Hémiptères est applicable, en général, à tous les insectes de cet ordre. Je n'ai point l'intention d'entreprendre une névrologie détaillée des familles et des genres; travail qui exigerait de nombreux matériaux qu'il m'a été impossible de recueillir, et je me bornerai à l'exposition succincte de ce système, dans la Pentatome grise, la Nepe et la $\mathrm{Ci}$ gale.

Le cerveau ou le ganglion céphalique de cette Penta- 
tome est arrondi, modérément convexe, mais non sphérique, d'une couleur grisâtre, d'une texture fibreuse extérieurement, pulpeuse à l'intérieur. Il n'a présenté à mes investigations attentives aucune trace d'anfractuosités ni de division. Il fournit de chaque côté un bulbe assez développé pour les nerfs optiques principaux, en avant et latéralement les nerfs optiques des ocelles, et en arrière l'origine du prolongement rachidien. La ténuité des nerfs qui se distribuent aux antennes les a sans doute dérobés à mes recherches; mais de chaque côté du cerveau, en arrière $\mathrm{du}$ bulbe des grands nerfs optiques, le microscope m'a fait découvrir trois nerfs rapprochés, mais distincts, qui prennent peut-être leur origine à la face inférieure de ce bord de l'encéphale, et que je suppose destinés aux diverses parties du bec.

Chacun des grands yeux de la Pentatome (j'entends parler des yeux réticulés ou à facettes) reçoit deux nerfs optiques rapprochés et contigus. Ces nerfs naissent tous deux d'un bulbe ovalaire fourni, comme je viens de le dire, par le cerveau, et séparé de celui-ci par une espèce de col. Ils se terminent du côté de l'œil par deux expansions arrondies, d'un aspect grenu ou papilleux, contiguës, presque confondues ensemble, et remarquables par une couleur rouge violacée, sorte d'enduit que M. Muller appelle pigmentum (I). Ces expansions des nerfs optiques constituent de véritables rétines, et l'aspect papilleux dont j'ai parlé est sans doute produit par les cónes vitrés qui, d'après le savant professeur que je viens de nommer,

(1) Recherches sur la physiologie comparée du sens de la vision; par M. F. Muller, professeur à l'universite de Bonn. - Leipsig, 1826. - Extrait sur les yeux et la vision des Insectes, des Arachnides, etc, inséré dans les Annales des Sc, nat., juillet, août, septembre, 1829 . 
forment l'intérieur de l'œil des insectes. L'existence de deux nerfs optiques et de deux rétines pour un seul œil est un fait digne de remarque et qui me semble nouveau.

Les nerfs optiques des ocelles ou stemmates sont simples, d'une finesse capillaire d'un bout à l'autre, et proportionnellement plus longs que les précédens. Ils prennent directement leur origine à la partie antérieure et latérale du cerveau, tout près du bulbe des grands nerfs optiques. Ils se terminent par une rétine arrondie, pareillement enduite d'un pigment rouge violacé, et qui m'a aussi paru papilleuse.

Le prolongement rachidien naît de la partie postérieure et moyenne du cerveau, dont il n'est que la continuation, et se termine, en se divisant en plusieurs troncs nerveux, vers le milieu de la cavité abdominale. A son origine il consiste en deux cordons fort courts et contigus qui émettent une paire de nerfs pour les muscles cervicaux et l'œsophage. Aussitôt après il est remplacé par les deux ganglions dont je parlerai bientôt, et qui rompent ainsi sa continuité. Il reparaît à la suite du ganglion postérieur, sous la forme d'un cordon déprimé qui suit la ligne médiane du corps. A son entrée dans l'abdomen, il donne successivement naissance à quatre paires de petits nerfs récurrens, puis il semble se partager en quatre autres paires de troncs nerveux assez considérables, et rapprochés à leur origine, qui vont épanouir leurs divisions dans les viscères de la digestion et de la génération.

Les ganglions nerveux de la Pentatome ne sont qu'au nombre de deux, ainsi que je l'ai dejà avancé en parlant de l'appareil sensitif des Hémiptères en général. Ils sont tous deux renfermés dans la cavité thoracique, placés sur la ligne médiane, fort rapprochés l'un de l'autre, et séparés seulement par un étranglement peu prononcé. Ils 
ne se ressemblent ni par leur forme, ni par leur grandeur, ni par le nombre des nerfs qui y prennent leur origine. En considérant le segment du thorax auquel ils correspondent plus particulièrement, on peut désigner le plus antérieur sous le nom de ganglion mésothoracique, et le postérieur sous celui de métathoracique. Le premier est le plus petit, et d'une forme arrondie. Il fournit trois paires de nerfs dont les ramifications paraissent principalement destinées aux muscles des premières pattes, aux glandes salivaires et à l'origine du canal alimentaire. Le ganglion métathoracique est presque cordiforme. Il émet dix paires de nerfs qui se distribuent soit aux muscles nombreux qui meuvent les pattes, les ailes et les hémélytres, soit aux glandes salivaires, à l'estomac et à l'organe odorifique.

D'après cet exposé du système nerveux de la Pentatome, on voit que le nombre des paires de nerfs de cet Hémiptère, indépendamment $\mathrm{du}$ cerveau, $\mathrm{du}$ prolongement rachidien et des ganglions, se monte au moins à vingtsept, savoir : cinq au cerveau, neuf au prolongement rachidien, et treize aux ganglions.

Le systène nerveux de la $N$ èpe présente une différence essentielle avec celui des antres Hétéroptères et des Homoptères, c'est la distinction bien tranchée, la séparation parfaite des deux ganglions thoraciques.

Le ganglion céphalique, lorsqu'on l'a dégagé des parois du crâne sans l'endommager, ce qui n'est pas toujours facile, apparaît avec une configuration, un volume peu en rapport avec ceux de la boîte qui le renfermait. Cette différence du contenu au contenant prouve, d'une part, que cet organe cérébriforme est très compressible; et, de l'autre, que lorsque la cause comprimante cesse, il manifeste son expansibilité. Ce ganglion est formé de deux 
sphéroïdes largement confondus à la ligne médiane. II se prolonge de chaque côté en un nerfoptique renflé dans son milieu en un bulbe ellipsoïdal, et se termine par une rétine transversalement ovale, enduite d'un pigmentum d'un violet foncé comme pointillé. De la partie postérieure $\mathrm{du}$ ganglion céphalique partent deux nerfs rachidiens d'une excessive briéveté, formant un collier dans lequel est engagé l'œesophage.

Le premier ganglion qui suit, ou le ganglion prothoracique, est assez grand, lenticulaire, arrondi, en partie engagé dans la tête, et en partie dans le prothorax. Il émet latéralement trois paires de nerfs principaux, et deux prolongemens rachidiens établissent sa communication avec le second ganglion.

Celui-ci, ou le ganglion métathoracique, est séparé du premier par tout l'intervalle du mésothorax. Il est ovalaire, et fournit sur ses côtés cinq paires de nerfs considérables et quelques autres de moins importans. Il se prolonge en arrière en deux forts cordons rachidiens. Ceuxci, dans leur trajet dans l'abdomen, donnent naissance à plusieurs paires de petits nerfs, et en approchant de la région postérieure de cette cavité, ils se partagent en grandes branches qui se divisent et se subdivisent. La figure dira le reste.

Le système nerveux de la Cigale, insecte qui, sous ce rapport, peut être pris pour type de la grande division des Homoptères, présente les traits généraux que j'ai assignés à l'ordre des Hémiptères; mais il offre aussi, comparativement aux Hétéroptères, quelques modifications qui exigeaient et une description et une tigure spéciales. Cet appareil se compose, ainsi que dans les Hétéroptères, d'un ganglion céphalique, de deux ganglions thoraciques, et l'un grand nombre de paires de nerfs 
destinés aux viscères et aux divers tissus de l'insecte. Le ganglion céphalique, ou le cerveau (quoique par sa texture il démente cette dernière dénomination), est formé par la réunion de deux lobes hémiş̧héroïdes semblables, qui, vus extérieurement, paraissent simplement contigus; mais la rainure longitudinale et médiane qui semble les séparer n'est que superficielle. La partie antérieure de chacun de ces lobes donne naissance au nerf optique principal, destiné aux grands yeux, au nerf oculaire. Ce nerf, pyramidal ou plutôt en forme de courte et grosse massue, vient embrasser le bulbe oculaire. Le bout de celui-ci, dégagé de dessous la cornée réticulée et ovalaire qui constitue l'œil extérieur, se présente sous l'aspect d'une lentille arrondie, dont la rétine semble, à l'ceil nu, simplement pointillée d'un brun sanguin sur un fond gris, mais où une étude attentive, avec le secours d'une forte loupe, fait apercevoir une réticulation très fine dont les mailles sont des polygones arrondis. Entre les origines des nerfs oculaires, et un peu en-dessous de la ligne médiane qui forme la démarcation des denx lobes céphaliques, naît un nerf trifide, un véritable trépied, dont les branches sont les petits nerfs optiques des trois ocelles, les nerfs ocellaires. La rétine du bulbe de ces yeux lisses est bordée d'un rouge vif, et le disque lenticulaire est lavé d'une teinte rosée pâle, avec un pointillement imperceptible.

Du bout postérieur et un peu inférieur des lobes du ganglion céphalique, partent deux cordons nerveux rachidiens assez courts, dont l'écartement forme une sorte d'anneau ou de collier dans lequel s'engage l'œsophage. Ces cordons fournissent, vers leur milieu, une paire de nerfs dont la distribution m'a paru se faire particulièrement aux muscles destinés aux mouvemens de la tête.

Les ganglions thoraciques de la Cigale, loin d'être dis4. Savans étrangers. 
tincts et séparés l'un de l'autre, ainsi que nous venons de le voir dans les Népides, sont presque confondus en un seul, comme dans les Géocorises. A peine y reconnaît-on la trace d'une légère démarcation $d u$ ganglion antérieur, qui est arrondi et un peu échancré en cœur. L'ensemble de ces deux ganglions forme un corps oblong, profondément situé au-dessous des masses musculaires qui garnissent la paroi inférieure du thorax, et en quelque sorte enchâssé, engaîné dans un tissu fibreux comme aponévrotique; ce qui rend sa dissection, son isolement complet, extrêmement difficiles. Le ganglion antérieur donne naissance à quatre paires de nerfs principaux, et le postérieur à $\operatorname{six}$, sans y comprendre le double cordon rachidien qui est en arrière la continuation de ce ganglion. L'inspection de la figure qui représente le système nerveux de la Cigale suppléera pour le moment à des détails descriptifs sur la distribution de ces paires de nerfs. Les denx cordons rachidiens sont, vers leur origine, contigus et comme adhérens; mais en pénétrant dans la cavité abdominale, ils s'écartent plus ou moins l'un de l'autre, émettent dans leur trajet quelques paires de nerfs peu considérables, et parvenus vers le tiers postérieur de l'abdomen, ils se divisent et se subdivisent pour envoyer des nerfs très nombreux spécialement aux organes de la génération.

\section{CHAPITRE CINQUIÈME.}

ORGANE ODORIFIQUE.

La nature, qui attache le même intérêt, les mèmes soins à produire qu'à conserver les espèces, n'a pas voulu que le faible devînt, dans toutes les circonstances, la proie inévitable du fort. Elle a mis dans la distribution des armes destinées à l'attaque, à la défense ou à l'évasion, 
cette infinie variété, cette mesure calculée, qui témoignent en faveür de ses ressources comme de sa vigilance inépuisable. Dans mes recherches sur l'anatomie des Coléoptères, j’ai fait connaître un appareil des sécrétions excrémentitielles qui forme un des traits saillans de l'organisation de certaines familles de ces insectes, notamment de celle qui est en tète de cet ordre, et qui est peut-ètre la plus nombreuse en espèces: je veux parler de la famille des Coléoptères carnassiers. Cet appareil, toujours binaire, et comparable en tous points à l'organe urinaire des quadrupèdes, prépare, conserve et excrète une liqueur plus ou moins ầcre que l'anima! assailli ou menacé lance par des orifices placés près de l'anus, soit sous la forme d'une rosée imperceptible, soit par l'explosion avec bruit d'une fumée bien visible.

L'ordre des insectes Hémiptères, tout obscur qu'il paraît et tout négligé qu'il est, n'a pas été déshérité des sollicitudes de la nature sous ce rapport. Tout le monde connaît l'odeur puante et caractéristique à laquelle les Punaises doivent vraisemblablement leur dénomination. Cette odeur, que l'insecte exhale à volonté, est préparée dans l'intérieur du corps par un organe spécial dont la position et la structure diffèrent beaucoup de celles des Coléoptères, et que j'ai cru devoir désigner par le nom significatif d'organe odorifique.

La faculté d'émettre une odeur plus ou moins exaltée appartient exclusivement à cette première section des Hémiptères que M. Latreille appelle des Hétéroptères. Je ne me suis jamais aperçu, et aucun auteur à ma connaissance n'a remarqué, que les insectes compris dans la section des Homoptères répandissent de lodeur.

Les Cimex de Linnæus, dont M. Latreille a composé sa famille des Géocorises, sont les Hémiptères le plus 
spécialement pourvus de l'orgaue odorifique; mais ce n'est que lorsqu'on les irrite, ou qu'ils se sentent menacés d'un danger, qu'ils exhalent l'odeur subtile et pénétrante qui leur est propre. Si l'on vient à surprendre, sans en ètre aperçu, un de ces insectes, même d'entre les plus puans, comme la Pentatome grise, par exemple, et qu'on s'en approche assez pour le flairer, on se convaincra qu'il ne transpire de son corps aucune mauvaise exhalaison. Mais pour peu qu'on le manie, on est aussitôt infecté par une vapeur invisible. Saisissez avec une pince la Pentatome en question, et plongez-la dans un verre rempli d'eau claire; armez votre cil de la loupe, et vous verrez s'élever de son corps d'innombrables petites bulles qui, en venant crever à la surface du liquide, exhalent à l'instant cette effluve qui affecte si désagréablement l'odorat. Cette vapeur, essentiellement âcre, exerce sur les yeux, quand elle les atteint, une action irritante très prononcée. Lorsqu'on tient entre les doigts un de ces insectes vivans, de manière à ne point boucher les orifices odorifères, et à diriger vers un point déterminé de la peau les fusées de cette vapeur, on verra qu'il en résulte une tache ou brunâtre ou rutilante que les lotions répétées n'eulèvent pas d'abord, et qui produit dans le tissu cutané une altération analogue à celle qui succède à l'application d'un acide minéral. Si, dans la dissection des Cimex dans l'eau, ou s'attache à ne point porter le scalpel sur l'organe qui renferme l'odeur, celle-ci ne se fait que peu ou point sentir à l'opérateur. Mais si l'on fait à dessein une large incision à cet organe, on voit aussitôt s'en élever un globule assez gros, qui, parvenu à la surface de l'eau, y crève et s'y divise en une myriade de gouttelettes dont l'odeur n'est plus équivoque. Ces gouttelettes sont comparables à celles qui résultent du mélange d'une petite quantité 
d'huile fortement battue avec de l'eau. Toutes sont parfaitement orbiculaires, assez brillantes, et forment, pour me servir de l'expression vulgaire, des yeu $x$ plus ou moins contigus, mais bien circonscrits, et ne se fondant pas ensemble. Je regrette que l'analyse chimique de cette huile animale ne vienne pas compléter ce que l'observation anatomique a pu nous en apprendre.

Les Géocorises n'exhalent pas tous la même odeur. Celleci présente, soit dans sa qualité, soit dans son aboudance ou son intensité, des modifications que je ferai connaitre. Il est même des espèces, en petit nombre à la vérité, chez lesquelles nos sens deviennent inhabiles à constater une odeur quelconque, malgré l'existence d'un organe destiné à la produire.

Ce n'est pas à l'extrémité postérieure de l'abdomen, et près de l'anus, ainsi qu'on l'observe dans les Coléoptères, que se tronve relégué l'organe odorifique des Hémiptères, mais bien tout-à-fait dans le centre du corps de l'insecte. Cet organe est fort simple; il consiste en une bourse assez grande (fort rarement en deux), placée à la base de l'abdomen, immédiatement au-dessous des viscères digestifs, et couchée sur la paroi ventrale de cette cavité. Elle a une forme arrondie ou ovalaire, une texture en apparence membraneuse, une couleur le plus souvent d'un jaune plus ou moins orangé. Cette bourse est logée presque toute dans la cavité abdominale, mais son insertion a réellement lieu dans la région pectorale du métathorax, tout près de l'union de celui-ci avec l'abdomen. Toutes mes recherches pour découvrir dans son voisinage des vaisseaux, des glandes, ou un appareil propre à la sécrétion de l'humeur oléagineuse, ont été vaines. Ainsi cette bourse serait en même temps un organe sécréteur par ses parois, et un réservoir. 
Les orifices ou ostioles extérieurs qui donnent issue à l'odeur spécifique des Punaises sont placés sur la paroi pectorale externe du métathorax, justement entre les insertions des seconde et troisième paires de pattes. On découvre de chaque côté de cette région un pore, bien distinct des stigmates, pratiqué sur une éminence qui dans la Pentatome grise et dans plusieurs autres de ce genre, ressemble à un bout de conduit tubuleux auquel on aurait fait une excision en bec de plume à écrire.

Je vais exposer maintenant les différences qui s'observent soit dans l'organe, soit dans l'odeur des diverses espèces d'Hémiptères dans lesquelles j'ai eu occasion de les étudier.

La Scutellère rayée répand au moindre attouchement une odeur bien prononcée. Sa bourse odorifique a environ une ligne et demie de largeur, une couleur jaune, une forme arrondie, comme divisée en deux lobes par une impression médiane produite par un nerf couché sur elle. On peut manier la $\boldsymbol{S} c$. maure sans qu'elle exhale une odeur sensible, et l'on ne parvient à développer celle-ci, et encore à un faible degré, qu'en irritant fortement ou en blessant cet insecte. Du reste, son utricule à odeur ressemble à celle de l'espèce précédente, à la couleur près, qui est ici d'un jaune safrané.

La Pentatome grise est un des Géocorises dont l'odeur est la plus puante, la plus exaltée, la plus prompte à s'exhaler, la plus tenace. Sa poche à odeur est d'un jaune orangé. Les $\boldsymbol{P}$. émeraude, du genévrier, des baies, du grateron, sont presque aussi puantes que la $P$. grise, et n'en diffèrent point par leur organe odorifique. La bourse à odeur est d'un jaune pâle dans la $\boldsymbol{P}$. dissemblable. La $P$. ornée offre une singulière particularité, c'est que, malgréqu'on l'irrite, qu'on la blesse, qu'on la déchire, il 
ne s'échappe de son corps aucune exhalaison qui rappelle, mênıe au plus faible degré, celle des Punaises. Dans mes investigations sur ce point, j'ai même cru y démêler une odeur qui n'était point déplaisante. Je rappellerai à ce sujet que Fallen, dans sa monographie des Cimex de la Suède, observe que le Lygaus pastinacce répand odorem ferè gratum. Du reste l'organe odorifique de la $\boldsymbol{P}$. ornée existe comme dans les autres espèces, seulement la bourse, qui est d'un jaune safrané, est moins développée.

Les Corés exhalent une odeur d'une 'qualité différente de celle des Pertatomes, mais il est bien difficile d'exprimer cette différence. Dans le $C$. bordé et le $C$. chlorotique, l'organe odorifique ressemble à celui des Pentatomes; mais dans le $C$. hirticorne j'ai reconnu l'existence de deux bourses à odeur, arrondies, d'un orangé vif, munies chacune d'un petit col tubuleux. Cet exemplè d'une bourse double est, jusqu'à ce jour, isolé.

Les deux Alydes que j’ai disséqués répandent, quand on les touche, une odeur spéciale tirant vers l'acescence, et rappelant celle qu'exhale, parmi les Carabiques, le Chlcenius velutinus. Leur poche odorifique est assez grande, vu la taille des Alydes, ovale-oblongue, jaune.

Le Lygée porte-houteille fournit, lorsqu'on l'irrite, une odeur singulière et point désagréable d'éther acétique. La Pyrrhocore, pour bien qu'on l'inquiète, n'exhale aucune odeur appréciable. Le Miris de Carcel répand une odeur sui generis ou l'on démêle celle des fleurs du Hyacinthus racemosus. Sa bourse à odeur est pyriforme et d'un jaune vif. Le Capse tricolor affecte l'odorat de manière à rappeler l'odeur des feuilles du Groseiller noir.

La Phymate m'a paru inodore. Je ne dis rien de la Punaise des lits dont tout le monde connait la puanteur. 
On retrouve encore dans le Réduve stridulant l'odeur du Chlcenius cité plus haut.

La vapeur exhalée par les Gerris a quelque chose d'alcalescent.

L'odeur des Naucores a quelque chose d'âcre. Celle des Corises rappelle les Pentatomes. La Notonecte émet une exhalaison vulvaire analogue à celle des grands $D y$ tiques, mais faible. Je n'ai reconnu dans le métathorax de cet insecte aucun vestige d'organe odorifique, et je ne serais pas surpris qu'il en fût entièrement dépourvu. L'odeur fétide dont je viens de parler est peut-être fournie par un appareil des sécrétions excrémentitielles qui a échappé à mes recherches.

\section{CHAPITRE SIXIÈnE.}

DU CORDON DORSAL, APPELÉ VAISSEAU DORSAL.

C'est ici, sans contredit, le point le plus problématique, le plus conjectural et le plus controversé de l'anatomie et de la physiologie des insectes. Quoiqu'il soit devenu l'objet de dissections ardues, d'expérimentations répétées et de sérieuses explications de la part de divers zootomistes tant anciens que contemporains, on se demande encore si ce cordon est un organe ou un simulacre d'organe sans fonction, un simple vestige.

Dans les sciences exactes, l'application inconsidérée des termes peut entraîner des conséquences très funestes à leurs progrès. Les premiers observateurs qui se livrèrent à l'étude de l'organisation des insectes furent frappés des mouvemens alternatifs de contraction et de dilatation qui s'exécutaient le long de la ligne médiane dorsale de certaines larves rases. Les mots de sistole et de diastole, déjà consacrés pour exprimer des mouvemens analogues dans 
le cœur des grands animaux, les séduisirent, et ils ne manquèrent pas d'en faire l'application. La forme linéaire $\mathrm{du}$ cordon, qu'ils regardaient comme le représentant $\mathrm{du}$ cœur, leur fit préférer le nom de vaisseau dorsal à cette dernière dénomination. Ce terme de vaisseau entrânnait nécessairement l'idée d'un liquide contenu, et en même temps celle de circulation. Ainsi Malpighi et Sivammerdam regardèrent le cordon dorsal des insectes comme un cœur ou une série de cœurs. Lyonnet ne le considérant pas comme un organe circulatoire, dut lui donmer d'autres attributions; il lui supposa la faculté de fournir aux nerfs la substance qui leur est nécessaire. Notre illustre naturaliste, M. Cuvier, se contente de l'envisager comme un vestige de cœur qui ne remplit plus aucune des fonctions de cet organe. L'imagination de Comparetti y a vu une double circulation vasculaire. M. Marcel de Serres le décrit comme un canal presque cylindrique un pen rétréci aux deux extrémités; il prétend que l'humeur qu'il contientia constamment une coulenr analogue à celle de la graisse, et il finit par le considérer comme l'organe essentiellement sécréteur de celle-ci. Enfin, tout récemment, M. Straus, faisant revivre avec amplification l'opinion de Malpighi, veut que le cordon dorsal soit un cœur uniquement artériel, composé d'un certain nombre de chambres séparées par des valvules.

Ces zootomistes ne paraissent pas avoir fait une étude comparative du cordon dorsal dans les divers ordres d'insectes, et la plupart se sont laissé entraîner à des généralisations qui trahissent le défaut de faits assez nombreux et assez sévèrement constatés; car les traits anatomiques et les attributions physiologiques qu'ils lui assignent ne sauraient cadrer avec les caractères propres au cordon dorsal des Hémiptères.

4. Savans étrangers. 
Dans les insectes de ce dernier ordre, et plus spécialement dans la tribu des Géocorises, le cordon dorsal (dénomination assez significative de mon incertitude sur ses fonctions ) est fort remarquable, en ce qu'il est isolé, libre, excepté à ses deux extrémités, c'est-à-dire qu'entre cellesci il n'a aucune adhérence, aucune connexion avec les tissus circonvoisins. Il est là comme une corde tendue d'un bout du corps à l'autre, et dans ce trajet il est dépourvu de toute espèce de ramifications ou de prolongemens latéraux. 11 est situé le long de la ligne médiane du corps, sous les tégumens du dos, immédiatement au-dessus de tous les 'viscères, et couché plus particulièrement sur le tube alimentaire. Une couche adipeuse plus ou moins marquée est ordinairement interposée entre lui et le tégument dorsal. 11 présente le plus souvent, surtout dans sa portion abdominale, la trace plus ou moins superficielle d'une rainure médiane qui semble le partager, suivant sa longueur, en deux moitiés égales; mais cette rainure s'efface entièrement par une macération même peu prolongée. Il n'est point cylindrique, mais plus ou moins déprimé, constamment plus large dans sa portion abdominale, et atténué, aminci dans sa portion thoracique, qui elle-même s'élargit un peu en pénétrant dans la tête. Son point d'attache antérieur m'a paru avoir lieu au cerveau même, et le postérieur an voisinage de l'anus. J'ai plusieurs fois constaté que cette dernière extrémité du cordon dorsal présente plusieurs lanières ou radicules inégales d'une nature parfaitement semblable à celle du reste du cordon, et qui semblent destinées à la fixer. En arrachant avec précaution cette extrémité, on entraîne ces lanières.

Ce cordon est ou semi diaphane ou grisâtre, quelquefois d'une teinte jaunâtre ou rembrunie; mais ces nuances sont variables dans le même individu, sans qu'il soit fa- 
cile de s'en rendre raison. C'est ainsi que dans le Coré bordé je l'ai trouvé tantôt d'un gris obscur, tantôt d'un brun violet, sans que la pulpe adipeuse environnante revêtìt ces mèmes nuances. Sa texture est charnue, assez résistante pour ne point céder aux tractions modérées exercées en sens inverse; mais les plus fortes lentilles amplifiantes n'y ont décelé aucune disposition fibreuse, et je n'ai jamais pu y constater le moindre mouvement de contraction ou de dilatation, quelque attentif que j'aie été dans l'exploration de cette propriété vitale. Je n'ai su non plus y reconnaître ancune trace de canal intérieur ou de cavité, aucun indice de cloisons ou d'étranglemens. C'est un tissu partout homogène et identique; seulement, comme je l'ai déjà dit, la portion abdominale de ce cordon présente une ligne médiane plus claire et un peu enfoncée.

Dans la splanchnologie des insectes, l'abondance des trachées qui se distribuent dans un organe est la mesure de son importance fonctionnelle, comme dans les grands animaux la richesse vasculaire et nerveuse indique le degré de vitalité des tissus. J'ai donc mis un soin particulier dans la recherche des vaisseaux aérifères qui se portent au cordon dorsal des Hémiptères, et j'ai trouvé qu'ils y étaient fort rares. A peine aperçoit - on çà et là quelques petites branches trachéennes qui rampent à la surface, et plus spécialement sur les côtés de ce cordon; et je n'ai point reconnu qu'elles en pénétrassent le tissu. Je n'ai pas été plus heureux pour y découvrir des rameaux nerveux.

Je n'entreprendrai point de faire ici le parallèle, trait pour trait, des divers caractères anatomiques assignés par les auteurs au prétendu vaisseau dorsal des insectes, et de ceux que je viens d'exposer pour le cordon dorsal des Hémiptères; cette analyse comparative des détails m'en- 
trainerait au-delà des bornes de mon travail actuel. Il sera facile de se convaincre des nombreuses et essentielles différences qui existent entre elles.

S'il s'agissait maintenant de s'expliquer sur les attributions physiologiques de ce cordon, je dirais qu'une pratique de vingt années dans la dissection des insectes ne m'a fait reconnaître en lui aucun des traits qui sont propres ni à un appareil sécréteur, ni encore moins à un organe circulatoire. Je me rangerais donc de l'opinion de M. Cuvier, en considérant ce cordon comme le simulacre d'un organe déchu de ses fonctions, en un mot comme un vestige anatomique, et je me bornerais, pour appuyer ma manière de voir, à émettre les deux considérations suivantes.

$\mathrm{I}^{\circ}$ C'est un fait établi, je crois, en principe, que dans les animaux où il y a une circulation générale d'air, celleci remplace ou exclut la circulation générale du sang ou d'un liquide analogue. Ces deux systèmes circulatoires simultanés sont incompatibles. Je m'abstiens d'énumérer les conséquences qui découlent naturellement de cette proposition; elles sont par trop évidentes.

$2^{\circ}$ J'ai déjà avancé que, dans l'échelle entomologique, les Hémiptères, comme insectes suceurs, avaient une organisation moins compliquée, moins parfaite que celle des insectes hroyeurs. La considération du cordon dorsal vient à l'appui de mon assertion, car il est encore plus simple, plus grèle, plus rudimentaire chez eux que dans les insectes à mandibules. 


\section{ESSA I}

D'UNE

\section{CLASSIFICATION ANATOMIQUE DES HEMIPTERES.}

Ainsi que je l'ai annoncé dans les premières pages de mon travail, je vais présenter dans un tableau raccourci et dans un style aphoristique, les traits les plus saillans des appareils organiques des Hémiptères soumis à mon scalpel. Ce tableau sera, autant que le permet l'état actuel d'une science à peine ébauchée, l'expression des caractères anatomiques comparatifs des insectes de cet ordre avec ceux des ordres qui l'avoisinent dans le cadre entomologique. Dans cette exposition succincte, j'ai placé les appareils organiques suivant l'ordre de leur valeur dans la classification anatomique. Je ne me dissimule point l'imperfection de ce travail, et son titre m'excuse d'avance; mais je cherche à en démontrer la possibilité.

\section{CINQUIÈME ORDRE \\ DES INSECTES HEXAPODES. \\ HÉMIPTÈRES.}

Appareil sensitif composé d'un cerveau de deux ganglions seulement, placés tous deux dans le thorax; d'un prolongement rachidien et de plusieurs paires symétriques de nerfs. 
Appareil respiratoire formé de stigmates toujours placés à la paroi inférieure du corps, et de trachées ou tubulaires ou utriculaires, quelques - unes constituant une espèce de parenchyme palmonaire; une paire de stigmates pectoraux, quatre, six ou sept paires de stigmates abdominaux.

Appareil digestif constitué, $\mathrm{I}^{\circ}$ par des glandes salivaires, tantôt en sachets bi ou trilobés, tantôt en utricules agglomérées en pelotons ou en grappes, avec des bourses ou réservoirs salivaires plus ou moins développés; $2^{\circ}$ par un tube alimentaire de longueur variable selon le genre de vie, dépourvu de gésier et de papilles extérieures ou villosités, offrant plusieurs dilatations plus ou moins constantes, et dans quelques familles, une portion récurrente qui, en venant s'aboucher de nouveau au point de départ, forme un véritable anneau ou cercle; $3^{\circ}$ par un organe hépatique consistant en une ou deux paires de vaisseaux biliaires, toujours insérés sur une seule partie du canal digestif, soit immédiatement, soit par l'intermède d'une ou deux vésicules biliaires (organe hépatique nul dans les derniers Hémiptères ); $4^{\circ}$ par un tissu adipeux splanchnique plus ou moins abondant suivant le genre de vie.

Appareil génital composé, $\mathrm{I}^{\circ}$ dans le sexe mâle, d'une paire de testicules uni ou multicapsulaires, de conduits déférens plus ou moins repliés, de vésicules séminales variables pour leur nombre et leur configuration, d'un canal ejaculateur, et d'une verge enfermée dans une armure copulatrice; $2^{\circ}$ dans le sexe femelle, de deux ovaires, dont les gaînes ovigères, tantôt en nombre déterminé, tantôt innombrables, sont uni ou multiloculaires; d'un oviducte, d'un organe sébifique, d'un oviscapte dans plusieurs genres, enfin d'œufs de configuration et de structure très diverses. (Génération vivipare dans les Aphidiens.) 
Appareil odorifique particulier à quelques familles d'Hémiptères, et s'abouchant au métathorax.

Cordon dorsal consistant en un filet charnu simple, libre, excepté à ses deux extrémités, sans aucune trace de cavités ni d'étranglemens.

\section{SECTION I. HÉTÉROPTÉRES.}

Glandes salivaires formées le plus souvent de sachets bi, tri, ou quadrilobés, à lobes tantôt simples, tantôt divisés, munies de deux conduits efférens, dont l'un ordinairement plus long. Bourses salivaires dans plusieurs. Tube alimentaire n'ayant pas plus de trois ou quatre fois la longueur de l'insecte, pourvu d'un jabot plus ou moins marqué, d'un ventricule chylifique dont la première dilatation porte le nom d'estomac, d'un intestin proprement dit, ou sac stercoral toujours beaucoup plus court que le ventricule précédent. Deux ou quatre vaisseaux hépatiques avec ou sans vésicule biliaire. Tissu adipenx splanchnique bien marqué. Testicules à une, deux ou sept (rarement huit) capsules séminifiques plus ou moins allongées. Vésicules séminales tubulaires ou utriculaires. Canal éjaculateur ordinairement court. Ovaires à quatre, cinq, sept ou huit gaînes ovigères. Un appareil odorifique dans tous, constitué par une bourse sécrétrice qui s'ouvre à l'extérieur par un pore placé de chaque côté de la région pectorale du métathorax.

\section{FAMILLE PREMIERE. GÉOCORISES.}

Testicules à une ou sept (rarement huit) capsules séminifiques. Ovaires à sept (rarement six ou huit) gaînes ovigères. Oviscapte nul dans les uns, apparent dans un petit nombre. OEufs operculés. 


\section{GENRE SCUTELLERA.}

Trachées en même temps tubulaires et utriculaires. Six stigmates abdominaux punctiformes. Le plus long des conduits efférens des glandes salivaires très flexueux et uniformément capillaire. Quatre cordons valvuleux enveloppant la dernière portion du ventricule chylifique. Une seule paire de vaisseaux hépatiques à anses. Une vésicule biliaire. Testicules unicapsulaires revêtus d'une tunique rouge. Deux sortes de vésicules séminales, les unes utriculaires, les autres tubulaires. Ovaires à sept -gainnes ovigères bi ou triloculaires.

Espìce I. Sc. nigro-lineata. - Six paires seulement d'utricules pneumatiques abdominales correspondantes aux stigmates. Lobe antérieur de la glande salivaire sinple. le postérieur digité. Deux vésicules séminales, utriculiformes, et une quantité innombrable de vésicules tubulaires fort courtes.

Espèce 2. Sc. maura. - Utricules pneumatiques en nombre indéterminé. Les deux lobes de la glande salivaire digités. Vésicules séminales au nombre de cinq, toutes tubuleuses, longues, filiformes.

\section{GENRE PENTATOMA.}

Les mêmes caractères que dans la $S$ cutellera.

Espèce I. P. grisea. -- Les deux lobes de la glande salivaire très simples. Cordons valvuleux, avec une teinte rose, terminés en arrière par un renflement oliviforme. Une très grande vésicule séminale utriculiforme, et une quantité innombrable de vésicules tubulaires grêles et courtes. Cols des ovaires avec une collerette frangée.

Espèce 2. P. aparines. - Lobe postérieur de la glande salivaire, digité à sa base. Trois grandes vésicules sémi- 
nales utriculiformes, et une quantité innombrable de vésicules tubulaires courtes. Glande sébifique sphéroïdale. OEnfs ovales-arrondis, briévement velus, à opercule en calotte.

Espèce 3. $P$. ornata. - Six gaînes ovigères seulement à chaque ovaire. Oviducte gros et court, précédé d'une collerette frangée. OEuf́s en cylindre tronqué, à opercule plane, à péristome cilié.

\section{GENRE COREUS.}

Trachées toutes tubulaires. Six stigmates abdominaux punctiformes. Le plus long des conduits efférens de la glande salivaire renflé daus une grande partie de sou étendue. Cordons valvuleux du ventricule chylifique au nombre de deux seulement, ou nuls. Deux paires de vaisseaux hépatiques à bouts flottans. Testicules composés de sept capsules séminifiques disposées en éventail. Une seule vésicule séminale utriculiforme fort grande. Ovaires à sept gaînes ovigères biloculaires.

Espèce 1. C. marginatus. - Glande salivaire trilobée. Deux paires de bourses salivaires. Deux cordons valvuleux au ventricule chylifique. Conduit déférent du testicule renflé vers son milieu. Col de l'ovaire très allongé. OEufs en sphéroïde comprimé, tronqué latéralement. Un appareil des sécrétions excrémentitielles.

Espèce 2. C. nugax. - Glande salivaire bilobée, à lobes simples. Deux cordons valvuleux au ventricule chylifique. Existence d'un oviscapte fort court.

Espèce 3. C. hirticornis. - Glande salivaire quadrilobée. Point de cordons valvuleux au ventricule chylifique.

Espèce 4. C. panzeri. - Idem.

4. Savans étrangers. 


\section{GENRE ALYDUS.}

Les mêmes caractères que dans le Coreus.

Espèce r. A. geranii. -- Glande salivaire quadrilobée. Point de cordons valvuleux au ventricule chylifique. Une seule et très grande vésicule séminale utriculiforme. Testicule flabelliforme de sept capsules séminifiques. Un appareil des sécrétions excrémentitielles.

Espèce 2. A. apterus. - Deux cordons valvuleux an ventricule chylifique. Testicule en faisceau conoïde de sept capsules séminifiques.

\section{GENRE PYRRHOCORIS.}

Trachées toutes tubulaires. Six stigmates abdominaux punctiformes. Glandes sulivaires quadrilobées, avec les conduits efférens uniformément capillaires. Une seule paire de vaisseaux hépatiques à anse. Deux vésicules biliaires distinctes. Testicule flabelliforme de sept capsules séminifiques. Vésịcules séminales agglomérées, boursouflées. Ovaire de sept gaînes ovigères quadriloculaires. Col de l'ovaire dilaté.

\section{GENRE LYGEUS.}

Trachées toutes tubulaires. Six stignates abdominaux. Conduits efférens des glandes salivaires uniformément capillaires. Une seule paire de vaisseaux hépatiques à anse. Une vésicule biliaire.

Espèce 1. L. lagenifer. - Glande salivaire bilobée; lobe postérieur divisé. Gaînes ovigères multiloculaires. Col de l'ovaire court et dilaté.

Espèce 2. I. hyosciami. - Glande salivaire trilobée, à lobes simples. Gaìnes ovigères biloculaires. Col de l'ovaire long. 
GENRE CAPSUS.

Trachées toutes tubulaires. Sept stigmates abdominaux. Glandes salivaires bilobées. Point de vésicule biliaire. Testicule en faisceau conoïde de huit capsules séminifiques. Conduit déférent capillaire. Deux paires de vésicules séminales tubuleuses, filiformes, repliées. Ovaire composé de huit gaînes ovigères. Un oviscapte bien marqué. OEufs allongés, tronqués. Glande sébifique composée d'un très grand réservoir utriculiforme, et d'un vaisseau sécréteur ramuleux.

\section{GENRE MIRIS.}

Ajoutez aux caractères du genre précédent : conduits efférens de la glande salivaire offrant un sinus à cinq branches.

\section{GENRE PHYMATA.}

Trachées toutes tubulaires. Six stigmates abdominaux. Deux paires de glandes salivaires, l'une simple, l'autre bilobée. Conduits efférens fort courts. Une paire de vaisseaux hépatiques à anse. Point de vésicule biliaire. Point d'oviscapte.

\section{GENRE ARADUS.}

$V$ aisseaux hépatiqués réunis deux à deux avant leur insertion. Testicule formé d'un faisceau de cinq capsules séminifiques. Une senle paire de vésicules séminales. Quatre gaînes ovigères pour chaque ovaire.

\section{GENRE CIMEX.}

Deux paires de glandes salivaires très simples, l'une à double conduit efférent excessivement court, l'autre à long conduit simple. Point de vésicule biliaire. Testicule 
flabelliforme, de sept capsules séminifiques. Conduit déférent renflé. Une paire de vésicules séminales utriculiformes, terminées par un faisceau de tubes ramuleux. Canal éjaculateur court et dilaté. Ovaire de sept gaînes ovigères biloculaires. Col de l'ovaire tubuleux. OEufs pubescens, à opercule en calotte. Appareil sébifique composé de deux utricules ovales.

GENRE REDUITIUS.

Deux paires de glancles salivaires, l'une à deux lobes et à deux conduits efférens courts, l'autre simple. Point de vésicnle biliaire. Testicnle flabelliforme de sept capsules séminifiques. Conduit déférent uniformément capillaire. Une seule paire de vésicules séminales filiformes, flexueuses. Ovaire de sept gaînes ovigères biloculaires. Col de l'ovaire tubuleux. Oviducte dilaté.

\section{FAMILLE SECONDE. AMPHIBICORISES.}

Trachées toutes tubulaires, très fines et assez rares. Deux paires de glandes salivaires, l'une en sachet bilobé à un seul conduit efférent, l'autre en utricules groupées, à deux conduits distincts. Une seule paire de vaisseanx hépatiques à anses. Une vésicule bilicire. Testicules uni ou bicapsulaires. Conduit déférent inséré vers le milieu ge la longueur du testicule. Vésicules-séminales nulles, remplacées par des flexuosités et des renflemens du conduit déférent. Ovaire de quatre gaînes ovigères, longues et multiloculaires. OEufs oblongs, s'ouvrant par une fente longitudinale.

\section{GENRE GERRIS.}

Lobes de la glande salivaire en sachet, terminés par des filets capillaires. Testicules bicapsulaires. Canal éjaculateur de moyenne longueur. 
GENRE $V E L I A$.

T'esticules unicapsulaires, appendiculés. Canal éjaculateur long, bulbeux à son origine. .

\section{FAMILLE TROISIÈME. HYDROCORISES.}

Trachées toutes tubulaires et très fines, constituant dans quelques espèces nne sorte de parenchyme pulmonaire. Glandes salivaires tantôt en utricules agglomérées en grappes, tantôt -en sachets bilobés. Une paire de vaisseaux hépatiques à anse. Point de vésicule biliaire. Une ou deux vessies natatoires. T'esticules à. deux, cing on sept capsules séminifiques. Ovaires à cinq ou sept gaînes ovigères allongées, multiloculaires.

\section{GENRE INAUCORIS.}

Glandes salivaires ntriculeuses, bilobées. Une paire de bourses salivaires allongées. Deux vessies natatoires. Testicules à sept capsules séminifiques. Conduits déférens longs. Vésicules séminales les unes tubulaires, les autres utriculaires. Ovaire à sept gaînes ovigères. Col de l'ovaire allongé. Un oviscapte.

Espèce I. N. cimicoides. - Testicule de sept capsules séminifiques allongées, égales entre elles. OEufs oblongs, obliquement tronqués à leur bout antérieur.

Espèce 2. $N$. aptera. - Testicule de sept capsules séminifiques oblongues, dont trois fort petites, rudimentaires. OEufs ovales non tronqués.

\section{GENRES NEPA ET RANATRA.}

Deux sachets trachéens, comme parenchimateux, dans le thorax. Quatre paires seulement de stigmates abdominaux très grands, dont trois sont peut-être postiches. 
Glandes salivaires en grappes utriculeuses allongées, bilobées. Deux paires de bourses salivairès, dont l'une renflée vers son milieu. Coecum prolongé latéralement en une vessie natatoire. Testicules de cinq capsules séminifiques tiliformes. Ovaires à cinq gaînes ovigères multiloculaires. OEufs terminés par des prolongemens sétiformes.

Espèce I. N. cinerea. - Capsules séminifiques du testicule, filiformes d'un bout à l'autre, et agglomérées, pour chaque côté, en deux pelotons. OEufs ovales, terminés par sept soies.

Espèce 2. R. linearis.-Capsules séminifiques du testicule renflées à leur base et agglomérées en un seul faisceau. OEufs oblongs, terminés par deux soies.

\section{GENRE $C O R I X A$.}

Six paires de stigmates abdominaux punctiformes. Une seule paire de glandes salivaires en sachets bilobés. Une paire de réservoirs terminés par une poche globuleuse. Testicule à sept capsules séminifiques allongées, subulées, agglomérées. Ovaire à sept gaînes ovigères.

EsPÈce 1. C. striata. - OEufs sphéroïdes subulés.

Espèce 2. C. hieroglyphica. - OEufs ovales-oblongs subulés.

\section{GENRE NOTONECTA.}

Six paires de stigmates abdominaux punctiformes. Une seule paire de glandes salivaires en sachets bilobés, ayant des connexions directes avec les réservoirs. Testicule à deux capsules séminifiques filiformes, plus ou moins roulées en spirale. Conduit déférent excessitement long et replié. Quatre paires de vésicules séminales filiformes. Ovaires à sept gaìnes ovigères. OEufs oblongs. 


\section{SECTION II. HOMOPTERES.}

Trachées tubulaires et utriculaires. Glandes salivaires formées d'utricules agglomérées, d'où naissent des appendices (bourses?) filiformes. Tube alimentaire tantôt sous la forme d'un canal qui, sans interruption, se porte de la bouche à l'anus, tantôt ayant une portion récurrente qui vient s'implanter de nouveau au point de départ, et constituer ainsi un anneau. Vaisseanx hépatiques tantôt au nombre de deux paires, à bouts flottans, tantôt à une seule paire annuliforme, tantôt nuls. Testicule formé dans les uns par une agglomération de capsules séminifiques utriculiformes en nombre indéterminé, et tantôt constitué par quatre capsules séminifiques distinctes. Ovaire composé d'un nombre indéterminé de gaînes ovigères agglomérées.

\section{FAMILLE QUATRIEME. CICADAIRES.}

Deux paires de vaisseaux hépatiques à bouts flottans. Testicule formé par une agglomération de capsules séminifiques, ovoïdes ou oblongues, eu nombre indéterminé. Conduit déférent excessivement long. Vésicules séminales toutes filiformes, très longues, reployées, peu nombreuses.

- Ovcaire formé par une agglomération d'un grand nombre de gaînes ovigères, bi, tri ou quadriloculaires. Un oviscapte.

\section{GENRE $C I C A D A$.}

Deux grappes salivaires de chaque côté. Tube alimentaire huit à dix fois plus long que le corps de l'insecte, ayant une portion récurrente qui forme un anneau. Intestin proprement dit long et grêle. Une paire de vésicules séminales. Canal éjaculateur bulbeux à son origine. Ovaire 
composé de plus de quarante gaînes ovigères biloculaires. Oviducte courbé en crosse. Oviscapte très développé. Réservoir de la glande sébifique fort grand.

\section{$\checkmark$ GENRE FULGORA.}

Une paire de glandes salivaires formées par un filet garni, sur un seul côté, d'utricules. Tube alimentaire n'ayant pas plus de trois ou quatre fois la longueur du corps de l'insecte, sans portion récurrente, annuliforme, mais coudé latéralement. Testicule formé de capsules séminifiques oblongues, agglomérées en peloton.

\section{GENRE CIXIUS.}

Vaisseaux hépatiques réunis deux à deux avant leur insertion. Glandes salivaires en utricules agglonérées. Les autres caractères coumme ci-dessus.

\section{$\checkmark$ GENRE ISSUS.}

Vaisseaux hépatiques à quatre insertions distinctes. Les autres caractères comme dans le Cixius.

\section{$\checkmark 6$ GENRE LEDRA.}

Une paire de glandes salivaires formées d'utricules ovoïdes agglomérées. Tube alimentaire cinq ou six fois plus long que le corps de l'insecte, ayant une portion récurrente annuliforme. Dix à douze gaînes ovigères triloculaires, pour chaque ovaire. Réservoir de la glande sébifique pédicellé.

\section{GENRE CERCOPIS.}

Une paire de glandes salivaires, avec un grand nombre de bourses salivaires filiformes. Tube alimentaire comme dans la Ledra. Une trentaine de gaînes ovigères quadriloculaires, à chaque ovaire. 


\section{GENRE APHROPHORA.}

Appareil digestif, comme dans la Cercopis. Une quinzaine de gaînes ovigères, biloculaires à chaque ovaire.

\section{FAMILLE CINQUIEME. PSYLLIDES.}

Bouche placée un peu en arrière de l'articulation des pattes antérieures. Une paire de glandes salivaires formées par un petit nombre d'utricules sphéroïdes. T'ube alimentaire à peine trois ou quatre fois plus long que le corps de l'insecte, ayant une portion récurrente annuliforme. Quatre vaisseaux hépatiques excessivement courts, rudimentaires. Testicule de quatre capsules séminifiques distinctes.Vésicules séminales utriculiformes. Ovaire formé d'un peloton de gaînes ovigères nombreuses, uniloculaires. OEufs munis d'un prolongement latéral en forme de bec.

\section{GENRE ISOLÉ. DORTHESIA.}

Bouche placée entre les articulations des pattes antérieures. Une paire de glandes salivaires à utricules rares et arrondies. Tube alimentaire trois fois plus long que le corps, ayant une portion récurrente annuliforme. Intestin grêle inséré sur le côté du cœecum. Vaisseaux hépatiques formant deux colliers complets, insérés par un col commun. Ovaire court, formé de dix à douze gaînes ovigères uniloculaires. OEufs pondus dans un sac fixé à la partie postérieure du corps de l'insecte où ils éclosent.

4. Savans étrangers. 


\section{FAMILLE SIXIÈME. APHIDIENS.}

Tube alimentaire à peine plus long que le corps de l'insecte, dépourvu de vaisseaux hépatiques, et sans portion récurrente. Génération vivipare.

FIN. 


\title{
EXPLICATION DES PLANCHES
}

\author{
DE L'ANATOMIE \\ DES HÉMIPTÈRES.
}

FIGURE 1 .

PI. I.

Tète, appareil digestif, cordon dorsal et bout de l'abdomen fort grossis de la Scutellera nigro-lineata.

$a c$, glandes salivaires avec les conduits excréteurs.

$b b$, bourses salivaires déjetées sur les cótés pour être mises en évidence.

$c$, première poche du ventricule chylifique ou estomac, précédée du jabot et de l'œesophage, suivie d'une portion tubuleuse filiforme quise termine par la seconde poche gastrique.

$d$, cordons valvuleux du ventricule chylifique.

$e e$, vaisseaux hépatiques s'abouchant à une vésicule biliaire. -

$f$, extrémité postérieure de l'abdomen d'un mâle.

$g$, cordon dorsal dévié de sa direction naturelle.

FIGURE 2 .

Portion encore plus grossie du tube alimentaire de ce même insecte, pour mettre en évidence les cordons valvuleux du ventricule chylifique.

$a$, seconde poche gastrique.

$b$, cordons valvuleux au nombre de quatre.

$c$, vésicule biliaire avec l'origine des vaisseaux hépatiques.

$d$, intestin ou sac stercoral.

FIGURE 3 .

Glande salivaire du même insecte, vue par sa face inférieure, et considérablement grossie. 
$a$, lobe antérieur de cette glande.

$b$, lobe postérieur.

$c$, trachée qui se distribue à la glande.

$d$, conduit excréteur du lobe postérieur.

$e$, conduit excréteur du lobe antérieur.

\section{FIGURE 4 .}

Portion fort grossie du tube alimentaire de la Pentatoma grisea, pour mettre en évidence les cordons valvuleux du ventricule chylifique.

$a$, portion filiforme de ce dernier organe.

$b$, seconde poche gastrique.

$c$, col de cette poche.

$d$, cordons valvuleux au nombre de quatre.

$e e$, portions des vaisseaux hépatiques, et vésicule biliaire presque affaissée, située au-dessous de l'organe.

$f$, intestin ou sac stercoral.

\section{FIGURE 5.}

Intẻstin et vésicule biliaire de cet insecte vus en-dessous. La vésicule est pleine et sphéroïdale. L'insertion des vaisseaux hépatiques y est brusque; celle de la vésicule avec l'intestin est en évidence.

$$
\text { FIGURE } 6 \text {. }
$$

Portion considérablement grossie de l'extrémité postérieure d'un des cordons valvuleux du même insecte. On y voit les contractures annulaires qui déterminent les valvules, le renflement olivaire, et sur un côté une portion membraneuse qui fait partie du tube alimentaire.

FIGURE 7 .

Glande salivaire du même insecte considérablement grossie et vue par sa face inférieure.

$a$, lobe antérieur. 
$h$, lobe postérieur.

$d$, conduit excréteur du lobe antérieur.

$$
\text { FIGURE } 8 \text { et } 9 \text {. }
$$

Glandes salivaires du même insecte vues par leur face inférieure, et fournissant l'exemple de deux légères modifications dans la forme du lobe antérieur.

$$
\text { FIGURE } 10 .
$$

Glande salivaire de la Scutellera maura, fơt grossie, et vue par'sa face inférieure.

$a$, lobe antérieur.

$b$, lobe postérieur.

$c$, conduit excréteur du lobe postérieur.

$d$, conduit excréteur du lobe antérieur.

FIGURE II.

Glande salivaire fort grossie de la Pantatoma aparines.

$a$, lobe antérieur.

$b$, lobe postérieur.

$c$, conduit excréteur du lobe postérieur.

$d$, conduit excréteur du lobe antérieur.

FIGURE I 2 .

$a$, Hémélytre, et $b$, antenne, grossies de la Scutellera maura.

FIGURE 13.

PL. II.

Tête, appareil digestif et extrémité de l'abdomen fort grossis du Coreus marginatus femelle.

$a a$, glandes salivaires vues par-dessous avec les conduits excréteurs. $b b$, bourses salivaires au nombre de deux paires.

$c$, portion tubuleuse et filiforme du ventricule chylifique, précédée de l'estomac, et suivie de la seconde poche gastrique.

$d$, cordons valvuleux du ventricule.

$e e$, vaisseaux hépatiques au nombre de quatre, s"insérant à une vésicule biliaire. 
$f$, intestin ou sac stercoral.

$$
\text { FIGURE } 14 .
$$

Fégion dorsale grossie de ce même insecte, pour mettre en évidence les lobes médians des troisième et quatrième segmens.

$$
\text { FIGURE } 15 .
$$

Glande salivaire du Coreus chloroticus fort grossie et vue pardessous.

$a$, lobe antérieur.

$b$, lobe postérieur.

$c$, conduit excréteur du lobe postérieur.

$d$, conduit excréteur du lobe antérieur.

$$
\text { FIGURE I } 6 \text {. }
$$

Alydus geranii grossi.

$a$, mesure de sa longueur naturelle.

$$
\text { FIGURE } 17 \text {. }
$$

Tète, appareil digestif et extrémité de l'abdomen fort grossis du mème insecte.

$a a$, glandes salivaires avec leurs conduits excréteurs.

$b b$, bourses salivaires au nombre de quatre.

$c$, portion tubuleuse et filiforme du ventricule chylifique, précédée de l'estomac et suivie de la seconde poche gastrique.

$d d$, vaisseaux bépatiques non entiers.

$e$, sac stercoral.

$f$, bout de l'abdomen.

FIGCRE 18.

Alydus apterus grossi.

$a$, mesure de sa longueur naturelle.

$b$, abdomen d'une femelle avancée dans sa gestation.

FIGURE 19.

Tête, appareil digestif et extrémité de l'abdomen fort grossis de la Pyrrhocoris aptera. 
$a a$, glandes salivaires avec leurs canaux excréteurs.

$b b$, bourses salivaires.

$c$, portion tubuleuse et filiforme du ventricule chylifique, précédée de l'estomac, et suivie de la seconde poche gastrique.

$d d$, vaisseaux hépatiques.

$e$, sac stercoral.

FIGURE 20 .

Glande salivaire du même insecte fort grossie et vue par-dessous.

FIGURE 21.

Portion considérablement grossie du tube alimentaire du même insecte.

$a$, portion tubuleuse du ventricule chylifique.

$b$, seconde poche gastrigue.

$c$, col de cette poche.

$d d$, utricules vestigiaires.

$e e$, vaisseaux hépatiques déroulés, avec les deux vésicules biliaires.

$f$, sac stercoral.

Tête et appareil digestif fort grossis du Ligæus lagenifer. $a a$, glandes salivaires avec leurs conduits excréteurs.

$b b$, bourses salivaires.

$c$, portion tubuleuse et filiforme du ventricule chylifique, précédée de l'estomac, et suivie de la seconde pocbe gastrique.

$d d$, vaisseaux hépatiques déroulés, insérés à la vésicule biliaire.

$e$, intestin ou sac stercoral.

FIGURE 23.

Région dorsale du corselet de ce même insecte fort grossie, pour mettre en évidence un de ses traits spécifiques.

FIGURE 24.

Glande salivaire du même insecte, considérablement grossie et vue par-dessous. 
$a$, lobe antérieur.

$b$, lobe postérieur.

$c$, conduit excréteur du lobe postérieur.

$d$, conduit excréteur du lobe antérieur.

$$
\text { FIGUKE } 25 .
$$

Tube alimentaire fort grossi du' Lygaus hyosciami.

$a$, œsophage et jabot.

$b$, estomac ou première poche du ventricule chylifique.

$c$, portion tubuleuse de celui-ci.

$d$, seconde poche gastrique et col qui la suit.

$e e$, vésicule biliaire et origine des vaisseaux hépatiques.

$f$, sac stercoral.

FIGURE 26.

Glande salivaire du nême insecte fort grošsie.

$a$, lobe antérieur.

$b$, lobe postérieur.

$c$, conduit excréteur du lobe postérieur.

$d$, celui du lobe antéricur.

FIGURE 27.

Tête et appareil digestif fort grossis du Miris Carcelii. $a a$, glandes salivaires avec leurs conduits excréteurs.

$b$, estomac.

$c$, seconde poche gastrique.

$d d$, vaisseaux hépatiques.

$e$, intestin ou sac stercoral.

FIGURE 28 .

Glande salivaire du même insecte vue par-dessous, et considérablement grossie.

$a$, lobe antérieur.

$b$, lobe postérieur.

$c$, sinus des conduits excréteurs.

$d$, bourse salivaire. 


\section{DES PLANGHES.}

\section{FIGURE 29 .}

Tube alimentaire fort grossi du Capsus tricolor.

$a$, estomac précédé de l'œsophage, ct suivi de deux renflemens variables.

$b b$, vaisseaux hépatiques.

$c$, sac stercoral.

FIGURE 30 .

Portion du tube alimentaire du même insecte considérablement grossie.

$a$, seconde poche gastrique.

$b \vec{b}$, vaisseaux hépatiques non entiers.

$c$, sac stercoral vu par-dessous, pour mettre en évidence le mode d'insertion latérale du ventricule chylifique, et celui des vaisseaux hépatiques.

$$
\text { FIGURE } 3 \text { I. }
$$

Glande salivaire du même insecte considérablement grossie et vue par-dessous.

$a$, lobe antérieur.

$b$, lobe postérieur.

$c$, bourse salivaire.

FIGURE 32 .

Bourse salivaire? du même insecte beaucoup plus grossie.

FIGURE 33.

Hemélytre grossie du même insecte, pour servir à l'étude des caractères génériques.

Tête et appareil digestif fort grossis de la Phymata crassipes.

лa, glandes salivaires avec leurs conduits excréteurs fort courts.

$b b$, bourses salivaires

$c$, ventricule chylifique.

$d d$, vaisseaux hépatiques déployés.

$e$, sac stercoral.

4. Savans étrangers. 
Palte antérieure du même insecte fort grossie.

$$
\text { FIGURE } 35 \text {. }
$$

Patte postérieure du même insecte fort grossie.

$$
\text { FIGURE } 36 .
$$

Aradus avenius fort grossi.

$$
\text { FIGURE } 37 \text {. }
$$

Mesure de sa longueur naturelle.

$$
\text { FIGURE } 38 .
$$

Hémélytre et aile rudimentaire de cet insecte.

$$
\text { FIGURE } 39 \text {. }
$$

Patte antérieure fort grossie.

$$
\text { FIGURE } 40 .
$$

Bout de l'abdomen du mâle.

$$
\text { FIGURE } 41 \text {. }
$$

Larve fort grossie de cet insecte.

$$
\text { FIGURE } 42 .
$$

Mesure de sa longueur naturelle.

FIGURE 43.

Tube alimentaire considérablement grossi du même insecte. $a$, œsophage.

$b$, ventricule chylifique.

$c$, vaisseaux hépatiques.

$d$, sac stercoral. 
DES PIANCHES.

FIGURE 44 .

Tête, appareil digestif et bout de l'abdomen considérablement grossis du Cimex lectularius.

$a a$, première paire de glandes salivaires.

$b b$, seconde paire de ces glandes.

$c$, estomac suivi de la portion tubuleuse du ventricule chylifique. $d d$, vaisseaux hépatiques non entiers.

$e$, sac stercoral.

$f$, bout de l'abdomen de la femelle.

$$
\text { FIGURE } 45 .
$$

Glande salivaire du même insecte fort grossie et isolée, pour mettre en évidence la bifurcation des conduits excréteurs.

$$
\text { FIGURES } 46 \text { et } 47 \text {. }
$$

Modifications de la seconde paire des glandes salivaires du même insecte.

$$
\text { FIGURE } 48 .
$$

Tête, appareil digestif et bout de l'abdomen fort grossis du Reduvius stridulus.

$a a$, glandes salivaires, au nombre de deux paires, avec leurs conduits excréteurs.

$b$, portion tubuleuse du ventricule chylifique, précédée de l'estomac.

$c c$, vaisseaux hépatiques déployés.

$d$, sac stercoral.

\section{FIGURE 49 .}

Première glande salivaire du même insecte considérablentent grossie et vue par-dessous.

$a$, lobe antérieur.

$b$, lobe postérieur.

$c$, conduits excréteurs.

$$
\text { FIGURE } 50 \text {. }
$$

Seconde glande salivaire de cet insecte considérablement grossie et vue par-dessous avec son conduit excréteur. 
Portion considérablement grossie du conduit excréteur de cette glande, pour mettre en évidence son tube inclus.

FIGURE 52 .

Antenne fort grossie de cet insecte.

$a$, rotule.

FIGURE 53.

Patte antérieure de cet insecte fort grossie et vue par-dessus.

$$
\text { FIGURE } 54 \text {. }
$$

Tibia et tarse de cette patte vus par-dessous.

$e$, pelote en brosse.

PL. V.

$$
\text { FIGURE } 55 .
$$

Nabis dorsalis fort grossi.

FIGURE 56.

Mesure de sa longueur naturelle.

$$
\text { FIGURE } 57 \text {. }
$$

Patte antérieure de cet insecte considérablement grossie.

FIGURE 58 .

Pelogonus marginatus fort grossi.

$a$, mesure de sa longueur naturelle.

$b$, antenne.

$c$, patte antérieure.

$d$, patte intermédiaire.

$e$, patte postérieure.

FIGURE 58 bis.

Tête, appareil digestif et bout de l'abdomen du Pelogonus marginatus, considérablement grossis.

$a$, Tête avec le bec dans un état d'extension forcée. 
$b b$, glandes salivaires.

$c c$, réservoirs salivaires.

$d$, première poche du ventricule chylifique.

$e$, renflement de sa terminaison.

$f$, coecum.

gg, vaisseaux biliaires.

$h$, glande salivaire vue en-dessous.

$i$, bourse salivaire.

$$
\text { FIGURE } 59 .
$$

Gerris canalium, femelle très grossie.

$$
\text { FIGURE } 60 .
$$

Mesure de sa longueur naturelle.

$$
\text { FIGUKE } 61 \text {. }
$$

Antenne de cet insecte considérablement grossie.

$$
\text { FIGURE } 62 \text {. }
$$

Portion de cette antenne encore plus grossie.

$a, b$, rotules ou articles supplémentaires.

$$
\text { FIGURE } 63 .
$$

Un tarse de cet insecte considérablement grossi, pour mettre en évidence l'insertion des ongles ou crochets.

$$
\text { FIGURE } 64 \text {. }
$$

Tête, appareil digestif et bout de l'abdomen du Gerris canalium considérablement grossis.

$a a$, première paire de glandes salivaires.

$b b$, seconde paire de glandes salivaires.

$c$, estomac suivi d'une portion tubuleuse.

$d$, seconde poche gastrique.

$e e$, vaisseaux hépatiques déployés, et vésicule biliaire.

$f$, sac stercoral.

$g$, bout de l'abdomen de la femelle. 
Velia currens mâle fort grossi.

$$
\text { FIGURE } 66 .
$$

Mesure de sa longueur naturelle.

$$
\text { FIGURE } 67 .
$$

Antenne encore plus grossie.

$a$, rotule.

$$
\text { FIGURE } 68 .
$$

Patte antérieure très grossie.

$$
\text { FIGURE } 69 .
$$

Patte postérieure du mâle très grossie.

FIGURE $7^{\circ}$.

Abclomen de la femelle fort grossi.

$$
\text { FIGURE } 71 \text {. }
$$

Glandes salivaires de cet insecte fort grossies. $a$, première glande.

$b$, seconde glande.

PL. II.

FIGURE 72 .

Tête et appareil digestif fort grossis de la Naucoris aptera. $a a$, glandes salivaires.

$b b$, bourses salivaires.

$c$, estomac ou première poche du ventricule chylifique.

$d$, portion tubuleuse de celui-ci.

$e$, seconde poche gastrique.

$f f$, vaisseaux hépatiques déployés.

$g$, sac stercoral, ayant à sa base les vessies natatoires.

$$
\text { FIGURE } 7^{3} \text {. }
$$

Tube alimentaire fort grossi de la Naucoris cimicoides. 
$a$, osophage.

$b$, estomac singulièrement boursouflé.

$c$, portion tubuleuse $\mathrm{du}$ ventricule chylifique.

$d$, seconde poche gastrique.

$e e$, origine des vaisseaux hépatiques.

$f$, intestin grêle.

$g$, sac stercoral, avec les vessies natatoires.

FIGURE 74 .

Appareil salivaire grossi du même insecte. $a$, glande avec les deux conduits excréteurs. $b$, bourse salivaire. FIGURE 75 .

Patte antérieure grossie du même insecte.

$$
\text { FIGURE } 76 \text {. }
$$

Patte postérieure du même.

$a$, hanche avec les muscles.

$b$, trochanter et cuisse. Celle-ci garnie au bord inférieur d'un duvet court et serré, et de deux rangées de spinules.

$c$, tibia hérissé de plusieurs rangées longitudinales de piquans, et garni en-dessous de lougs poils servant de nageoire. Extrémité tarsienne du tibia comme pectinée par des piquans.

$d$, tarse de deux articles allongés, presque égaux, garnis à droite et à gauche de longs poils ou barbes qui en font une véritable nageoire.

FIGURE 77 .

Ongles de ce même tarse longs, grêles, presque droits, concourant à la natation. FIGURE 78 .

Hémélytre grossie de la Naucoris aptera. Elle se termine en pointe mousse, est dépourvue de portion membraneuse, et d'une texture coriacée uniforme. 
Hémélytre grossie de la Naucoris cimicoïdes. Elle est pourvue d'une portion membraneuse, et largement tronquée à son extrémité.

$$
\text { FIGURE } 80 \text {. }
$$

Aile grossie du même insecte. Elle est ployée comme dans le repos, et vue par-dessous. Il n'y a que trois nervures.

$$
\text { FIGURE } 81 \text {. }
$$

Tète et appareil digestif fort grossis de la Ranatra linearis.

$a$, tête vue par-dessus et dans un état d'extension forcée. Bec de trois articles, nullement canaliculé en-dessus, servant de gaine au suçoir.

A, suçoir considérablement grossi et dégagé de la gaine. Il se compose de cinq pièces, et non de quatre seulement; savoir : deux à la base, plus courtes, plus larges, formant comme deux bractées engaînantes; deux autres sétiformes, canaliculées; la cinquième est la langue, sorte de stylet armé de dents dirigées en arrière.

$b, b$, tendons cornés, ou tiges noires terminécs par un faisceau de fibres musculaires, et destinées sans doute à mouvoir le suçoir. $c c$, glandes salivaires avec leurs conduits excréteurs.

$d d$, bourses salivaires.

$e$, ventricule chylifique.

$f$, sac stercoral.

$g$, vessie natatoire.

$h$, terminaison de l'intestin.

ii, vaisseaux hépatiques déployés.

FIGURE 82.

Tête, àppareil digestif et extrémité de l'abdomen fort grossis de la Nepa cinerea.

$a$, tête dans un état d'extension forcée.

$b b$, grappes salivaires.

$c c$, bourses salivaires.

$d$, ventricule chylifique, débutant par un estomac. 
$e$, intestin.

$f$, vessie natatoire, noiràtre.

gg, vaisseaux hépatiques déployés.

$h$, dernier segment de l'abdomen ct siphon respiratoire.

A, grappe salivaire plus grossie, pour nettre en évidence la texture granulense de la glande, les deux conduits excréteurs, et les deux hourses ovoïdes sessiles placées à la base de la grappe.

$B$, petite bourse salivaire rétrécie en col en avant.

$$
\text { FIGURE } 83 .
$$

Tête, appareil digestif et bout de l'abdomen fort grossis de la Corixa striata. $a$, tête vue en-dessous. Elle est concave, mince, en triangle obtus; yeux grands, triangulaires, avec une rétine violette.

$b b$, glandes salivaires.

$c$, œesophage et jabot.

$d$, ventricule clıylifique, débutant par l'estomac.

$e$, intestin.

$f$, cocum servant de vessie natatoire.

$g g$, vaisseaux hépatiques déployés.

$h$, bout de l'abdomen de la femelle.

A, glande et bourse salivaires fort grossies.

I, glande.

2 , bourse.

B, portions de vaisseaux hépatiques considérablement grossies, pour mettre en évidence leurs flexuosités et varicosités. Dans l'une on a représenté la portion du vaisseau, qui, au voisinage de linsertion au tube alimentaire, est plus grêle et non variqueuse.

C, anteune considérablement grossie, composée de trois pièces seulement, et non de quatre.

\section{FIGURE 84 .}

Pattes très grossies du mênı insecte.

$a$, patte antérieure.

$b$, patte intermédiaire.

$c$, patte postérieure.

4. Savans étrangers. 
Corixa hieroglyphica fort grossie:

FIGURE 86 .

Mesure de sa longueur naturelle.

$$
\text { FIGURE } 87 \text {. }
$$

Hémélytre détachée et plus grossie de ce même insecte.

FIGURE 88.

Hémélytre détachée et fort grossie de la Corixa striata, Latr., pour l'étude comparative des mouchetures ou linéoles qui la distinguent de la précédente.

$$
\text { FIGURE } 89 .
$$

Tête et appareil digestif fort grossis de la Notonecta glauca. $a$, tête vue en-dessous et dans un état d'extension forcée. Elle est très largement ouverte, pour son articulation avec le thorax. Les hords de cette ouverture forment une saillie. Antennes dirigées en avant, courtes, de trois artieles distincts. Bec de trois pièces. $b b$, glandes salivaires.

ic, bourses salivaires.

$d$, estomac uu première poche du ventricule chylifique.

$e$, portion tubuleuse de celui-ci.

$f$, seconde poche gastrique.

$g$, vessie natatoire précédée de l'intestin.

$h h$, vaisseaux hépatiques déployés.

FIGURE 90 .

Modification de forme du tube alimentaire de cet insecte. Liestomac n'est point boursouflé, et la seconde poche gastrique est à peine marquée.

FIGURE 91 .

A ppareil salivaire très grossi de cet insecte. 
$a$, glande.

$b$, bourse.

FIGURE $9^{2}$.

Portion de la mème glande encore plus grossie, pour mettre en évidence l'insertion des conduits excréteurs.

$a$, lobe antérieur.

$b$, base du lobe postérieur.

FIGLRF $9^{3}$.

Portion considérablement grossie du tube alimentaire de cet insecte, pour mettre en évidence l'insertion des vaisseaux hépatiques.

$a$, seeonde poche gastrique.

$b b$, vaisseaux hépatiques non variqueux, dans le voisinage de leur insertion. Celle-ci a lieu en avant d'un léger bourrelet annulaire. $c$, intestin.

FIGURE 94 .

Abdomen du même insecte, vu par sa face inférieure ou ventrale, afin de mettre en évidence et les stigmates et les barbes poilues qui servent de nageoires. Les trois derniers segmens ont uue légère carène médiane, garnie à droite et à gauche de barbes.

$$
\text { FIGURE } 9^{5} \text {. }
$$

Patte postérieure de cet insecte grossie.

$a$, hanche fort grande.

$b$, trochanter.

$c$, cuisse garnie en-dessous d'une rangée d'aspérités.

$d$, tibia hérissé d'aspérités noires, et garni en-dessous, ainsi que le tarse, de nageoires de barbes très fines.

$e$, tarse de deux articles, allongés, presque égaux, et terminé par deux ongles longs, presque droits, fort grêles.

$$
\text { Figure } 9^{5}, \mathrm{~A} \text {. }
$$

PL. VIII.

Tête et appareil digestif médiocrement grossis de la Cicada orni. $a$, tête vue en-dessus, et dans uue position horizontale forcée. $b b$, appareil salivaire. 
$c$, oesophage et jabot.

$d$, ligament suspenseur gastro-cesophagien.

$e$, anse duodénale du ventricule chylifique.

$f$, cul de sac latéral de cette anse.

$g$, poche du ventricule chylifique.

$h$, prolongement intestiniforme de ce dernier.

$i$, intestin.

$j i j$, vaisseaux hépatiques.

$k$, cœecuin.

$l$, glandes excrémentitielles.

$m$, dernier segment dorsal de l'abdomen du mále.

$n$, une glande excrémentitielle fort grossie.

$$
\text { FIGURE } 9^{5} \text {, B. }
$$

Portion considérablement grossie du tube alimentaire.

$a$, œesophage.

$b$, jabot.

$c$, anse duodénale du ventricule chylifique.

$d$, cul de sac latéral de cette anse.

$e$, ligament suspenseur gastro-œesophagien.

$f$, poche du ventricule chylifique, vue en-dessous, pour mettre en évidence les insertions des vaisseaux hépatiques, et celle du prolongement intestiniforme $g$.

$h$, origine de l'intestin.

$i$, vaisseaux hépatiques.

$$
\text { FIGURE } 9^{5}, \mathrm{C} \text {. }
$$

Petite glande salivaire sublinguale considérablenent grossie.

$$
\text { FIGURE } 9^{5} \text {, D. }
$$

Glandes salivaires, considérablement grossies.

$$
\text { Figure } 9^{5}, \mathbf{E} \text {. }
$$

Tête et appareil digestif fort grossis de l'Issus coleoptratus.

$a$, tête vue en-dessus; vertex large; point d'ocelles; antennes insérées sous les yeux. 
$b b$, glandes salivaires.

$c$, estomac.

$d$, portion tubuleuse du ventricule chylifique, formant une anse à branches contiguës.

$e e$, vaisseaux hépatiques.

$f$, intestin.

$$
\text { FIGURE } 9^{6 .}
$$

Tube alimentaire fort grossi du Cixius 5-costatus.

$a$, œesophage.

$b$, estomac.

$c$, portion tubuleuse du ventricule chylifique, disposée comme celle de l'insecte précédent.

$d d$, vaisseaux hépatiques.

$e$, intestin.

$$
\text { FIGURE } 97 .
$$

Un vaisseau hépatique isolé et considérablement grossi du même insecte.

$$
\text { FIGURE } 98 \text {. }
$$

Tête, appareil digestif et bout de l'abdomen fort grossis de l' $A$ phrophora salicina.

$a a$, glandes salivaires.

$b$, jabot.

$c$, estomac ou première poche du ventricule chylifique.

$d$, portion tubuleuse et récurrente de ce dernier.

$e e$, vaisseaux hépatiques déployés.

$f$, intestin.

$g$, bout de l'abdomen femelle.

FIGURE 99 .

Portion très grossie d'un vaisseau hépatique, pour mettre en évidence ses varicosités.

$$
\text { FIGURE IOO. }
$$

Glande salivaire de ce même insecte considérablement grossie et vue en-dessous.

$a a$, conduits excréteurs. 
PL. IX.

FIGURE IOI.

Glande salivaire du Cercopis sanguinolenta, vue en-dessous, et considérablement grossie.

I, glande proprement dite, ayant un lobe antérieur simple et un postérieur boursouflé.

222 , bourses salivaires? au nombre de huit.

3 , conduits efférens.

$a$, extrémité considérablement grossie d'une des bourses salivaires. $b$, portion extrêmement grossie d'un conduit efférent.

FIGURE 102.

Dorthesia characias femelle, fort grossie et dépouillée de son enveloppe céracéo-amylacée.

$$
\text { FIGURE } 103 .
$$

Mesure de sa longueur naturelle.

$$
\text { FIGURE I04. }
$$

Un œil considérablement grossi.

$$
\text { FIGURE } 105 .
$$

Sac céracéo-amylacé, placé à l'extrémité de l'abdomen, et renfermant les œufs dans une bourre cotonneuse.

$$
\text { FIGURE } 106 .
$$

Antenne de cet insecte grossie, composée de huit articles.

$$
\text { FIGURE } 107 .
$$

Patte intermédiaire de cet insecte, fort grossie.

$a$, hanche conoïde courte.

$b$, cuisse.

$c$, tibia, avec quelques aspérités rares.

$d$, tarse d'une seule pièce, allongée, terminée par un seul ongle allongé, presque droit. 
FIGURE 108.

Appareil digestif fort grossi de cet insecte.

$a a$, glandes salivaires.

A, une utricule isolée de la glande.

$b$, rostre.

$c$, œsophage.

$d$, estomac.

$e$, portion tubuleuse récurrente du ventricule chylifique.

$f$, intestin grêle.

$g$, coecum.

$h$, vaisseaux hépatiques.

FIGURE 109 .

Vaisseaux hépatiques du mème insecte, encore plus grossis.

$a$, portion tubuleuse $\dot{d} u$ ventricule chylifique où se fait l'insertion hépatique.

$b b$, vaisseaux biliaires, formant deux anses annulaires.

FIGURE I 10.

Tête, prothorax, appareil digestif et extrémité de l'abdomen fort grossis de la Psylla ficus.

$a$, orsophage.

$b$, portion annulaire du ventricule chylifique.

$c$, estomac, ou première poche de ce dernier.

$d$, intestin.

$e$, vaisseaux hépatiques.

$f$, bout de l'abdomen de la femelle.

$g$, portion récurrente du ventricule chylifique.

FIGURE III.

Hémélytre fort grossie de cet insecte.

FIGURE II 2.

Aile ayant à sa base une seule nervure discoïdale qui n'atteint pas son milieu, et à laquelle aboutissent deux autres nervures presque imperceptibles. 
Patte postérieure fort grossie du mème insecte.

$a$, épimère terminé par une pointe épineuse.

$b$, extrémité tarsienne du tibia, couronnée d'un còté par des dents.

$$
\text { FIGURE } 114 \text {. }
$$

Tète, appareil digestif et bout de l'abdomen fort grossis de l'Aphis papaveris.

$a$, estomac.

$b$, portion tubuleuse du ventricule chylifique.

$c$, infestin.

$d$, extrémité de l'abdomen.

$e$, tête avec le vertex très large, et une petite apophyse derrière chaque œil. Antennes composées de sept articles principaux, dont les deux premiers sont courts, gros et noirs, et les autres longs et grêles; l'avant dernier forme à son extrémité une petite saillie latérale; le dernier, qui est presque capillaire, paraît au microscope comme multi-articulé ou cloisonné.

$$
\text { FIGURE I } 15 \text {. }
$$

Portion du tube alimentaire de cet insecte, considérablement grossi.

$a$, oesophage.

$b$, estomac.

$c$, portion tubuleuse du ventricule chylifique.

$$
\text { FIGURE } 116 .
$$

Antenne considérablement grossie de l'Aphis longipes.

$$
\text { FIGURE } 117 .
$$

Patte postérieure fort grossie de cet insecte.

PL. X.

$$
\text { FIGURE } 1 \text { I } 8 .
$$

Appareil génital mâle fort grossi de la Scutellera nigro-lineata. $a a$, testicules; celui de la gauche, ouvert à son extrémité pour mettre en évidence la pulpe spermatique qu'il renferme. 
$b b$, conduits déférens.

$c c$, vésicules séminales utriculiformes.

$d d$, vésicules séminales tubuleuses.

$e$, canal éjaculateur.

$f$, armure copulatrice.

\section{FIGURE 119 .}

Testicule du mème insecte dans un état de turgescence séminale particulière, et avec les trachées qui s'épanouissent à sa surface.

FIGURE 120.

Appareil génital mâle fort grossi de la Scutellera maura. aa, testicules.

$b b b b b$, vésicules séminales.

$c$, portion de l'intestin.

$d$, armure copulatrice.

FIGURE $12 \mathrm{I}$.

Portion encore plus grossie de ce même appareil.

$a a$, conduits déférens des testicules.

$b b b b$, vésicules séminales.

$c$, bulbe du canal éjaculateur.

d, canal éjaculateur.

FIGURE 122.

Appareil génital mâle fort grossi de la Pentatoma dissinilis.

$a a$, testicules.

$b b$, conduits déférens.

$c c$, grande et petites vésicules séminales.

$d$, canal éjaculateur.

$e$, armure copulatrice.

$f$, portion du tube alimentaire.

FIGURE 123.

Portion considérablement grossie et déployée de ce même appareil, vue en-dessous.

$a a$, conduits déférens des testicules.

$b b b$, vésicules séminales tubuleuses arbusculées.

4. Savans élrangers. 
$c c$, antres vésicules séminales tubuleuses, insérées vers l'extrémité du bulbe du canal éjaculateur.

$d d$, grande vésicule séminale utriculiforme.

$e$, canal éjaculateur, débutant par mu bulbe conoïde.

FIGURE I 24.

Portion considérablement grossie et déployée de l'appareil génital màie de la Pentatoma smaragdula.

$a a$, conduits déférens des testicules.

$b$, un des groupes des petites vésicules séminales tubuleuses.

$c$, un des groupes des grandes vésicules séminales tubuleuses.

$l$, grande vésicule séminale utriculiforme.

$e$, portion bulbeuse du canal éjaculateur.

FIGURE 125 .

Appareil génital mâle fort grossi de la Pentatoma aparines. $a a$, testicules.

$b b$, conduits déférens.

$c c c$, vésicules séminales utriculiformes.

$d d$, vésicules séminales tubuleuses agglomérées.

$e$, armure copulatrice.

$f$, portion du canal digestif.

$$
\text { FIGURE } 126 .
$$

Portion considérablement grossie du même appareil, vuc en-dessous, pour mettre en évidence le mode d'insertion des vésicules séminales, des conduits déférens et du canal éjaculateur.

$a a$, conduits déférens.

$b b b$, vésicules séminales utriculiformes.

$c c$, origines des vésicules séminales tubuleuses.

$d$, canal éjaculateur.

\section{FIGURE 127 .}

Appareil génital mâle fort grossi du Coreus marginatus. $a a$, testicules.

$b b$, conduits déférens.

$c$, vésicules séminales.

$d$, canal éjaculateur. 
$e e$, vaisseaux dépendant d'un 'organe des sécrétions excrémentitielles.

$f$, armure copulatrice et verge.

$g$, Portion du canal digestif.

FIGURE 128.

Portion considérablement grossie de l'armure copulatrice de cet insecte.

$a$, canal éjaculateur.

$b$, pieces de l'armure.

$c$, verge avec un vestige de gland et un prépuce cilié.

FIGURE 129.

Appareil génital mâle fort grossi de l'Alydus geranii.

$a a$, testicules.

$b b$, conduits déférens.

$c$, vésicule séminale.

$d d$, organe dépendant d'un appareil des sécrétions excrémentitielles.

$e$, armure copulatrice.

FIGURE 130.

Portion considérablement grossie de ce mêne appareil, vue de côté, pour mettre en évidence le mode de connexion de la vésicule séminale avec les conduits déférens et le canal éjaculateur. $a$, conduits déférens.

$b$, vésicule séminale.

$c$, canal éjaculateur.

FIGURE 131 .

Organe des sécrétions excrémentitielles du même insecte, considerablement grossi.

$$
\text { FIGURE } 132 .
$$

Testicules considérablement grossis de l'Alydus apterus.

$a$, testicule dont les capsules séminales sont groupées en un faisceau conoïde.

$b$, le même, avec ces capsules étalées.

$c$, conduit déférent. 


\section{行}

EXPLICATION

PL. XI. FIGURE 133.

Appareil génital màle fort grossi du Pyrrhocoris aptera. $a a$, testiculcs.

$b b$, conduits déférens.

$c c$, vésicules séminales.

$d$, canal éjaculateur.

$\odot$, armure copulatrice.

FIGURE 134.

Appareil génital mâle fort grossi du Capsus tricolor. aa, testicules.

$b$, conduits déférens.

$c c$, vésicules séminales.

$d$, armure copulatrice.

$e$, portion du canal digestif.

$$
\text { FIGURE } 134, \text { A. }
$$

Testicule du même, avec les capsules séminifiques étalées.

$$
\text { FIGURE } 135 .
$$

Appareil génital mâle fort grossi du Miris Carcelii.

$a a$, testicules.

$b b$, vésicules séminales.

$c$, vésicule?

FIGURE 136.

Appareil génital mâle fort grossi de l'Aradus avenius. $a a$, testicules.

$b b$, conduits déférens.

$c c$, vésicules séminales.

$d$, bulbe da canal éjaculateur.

$e$, armure copulatrice.

$$
\text { FIGURE I } 37 \text {. }
$$

A ppareil génital mảle fort grossi du Cimex lectularius. $a a$, testicules. 
$b b$, conduits déférens.

$c c$, vésicules séminales.

$d$, canal éjaculateur.

$e$, armure copulatrice.

A, testicule dont les capsules séminifiques sont ployées sur deux rangs.

$$
\text { FIGURE } 137, \mathrm{~A} \text {. }
$$

Appareil génital mâle considérablement grossi du Pelogonus marginatus.

$a a$, testicules.

$b b$, vésicules séminales.

$c$, conduit éjaculateur.

$d$, derniers segmens abdominaux du mâle.

$$
\text { FIGURE I } 38 \text {. }
$$

A ppareil génital mâle fort grossi du Gerris paludum. $a a$, testicules.

$b b$, conduits déférens? et vésicules séminales.

$c$, canal éjaculateur.

$d$, armure copulatrice.

$e$, portion du canal digestif.

$$
\text { FIGURE } 139 \text {. }
$$

Appareil génital mâle fort grossi de la Velia currens.

$a a$, testicules.

$b b$, conduits déférens et vésicules séminales.

$c$, canal éjaculateur.

$d$, armure copulatrice.

$$
\text { FIGURE } 140 . \quad-\infty \text { PL. XII. }
$$

Appareil génital mâle fort grossi de la Naucoris aptera.

$a a$, testicules.

$b b$, conduits déférens.

$c c c$, vésicules séminales.

$d$, canal éjaculateur.

$e$, armure copulatrice.

$f$, portion du canal digestif. 
P'ortion du mêne appareil encore plus grossie, et vue en-dessons, pour mettre en évidence le mode de connexion des vésicules séminales et du canal éjaculateur.

$a a$, portion des conduits déférens.

$b b$, vésicules séminales latérales déployées.

$c$, vésicule séminale intermédiaire.

$d d$, renflemens utriculiformes des vésicules latérales.

$e$, canal éjaculateur, débutant par un bulbe oblong.

$$
\text { FIGURE } 142 .
$$

Testicule du même iusecte, avec les capsules séminifiques étalées. $a$, capsules séminifiques principales.

$b$, capsules séminifiques rudimentaires.

$c$, portion du conduit déférent.

\section{FIGURE 143.}

Un des panneaux cornés et ciliés de l'armure copulatrice.

$$
\text { FIGURE } 14 \text { 亿. }
$$

Pièce priucipale de l'arnure copulatrice du même insecte beaucoup plus grossie.

$a b$, deux crochets très écartés ici, mais cachés l'uu par l'autre dans l'état naturel de repos.

$c$, pièce molle et charuue que l'on fait saillir par une compression expulsive, et qui est ou la verge ou le fourreau de celle-ci.

$d$, pièce sous-jacente offrant en-dessus une paire de soies doubles, arquées, subuliformes, mobiles.

$e$, piece terminale de l'armure.

$f f$, deux apophyses de celle-ci, où s'articulent les crochets $a, b$.

FIGURE I 45.

Appareil génital mâle fort grossi de la Naucoris cimicoides. $a a$, testicules enveloppés de la membrane testiculaire.

$b b$, condnits déférens.

$c c$, vésicules séminales. 
$d$, canal éjaculateur.

$e$, armure copulatrice.

FIGURE $145, \mathrm{~A}$.

Testicule du même insecte, avec les capsules séminifiques déployées et à nu.

$a$, ces capsules.

$b$, conduit déférent.

FIGURE 146 .

Portion de ce même appareil, vue au-dessous et déployée, pour mettre en évidence le mode de connexion des vésicules séminales avec les conduits déférens et le canal éjaculateur.

$a a$, conduits déférens.

$b b$, vésicules séminales.

$c c$, renflemnes utriculiformes de ces vésicules.

$d$, canal éjaculateur.

$$
\text { Figure } 147 \text {, A. }
$$

Appareil génital mâle considérablement grossi de la $N$ epa cinerea. $a a$, testicules dégagés de la tunique adipeuse, et dans un état de turgescence séminale.

$b b$, conduits déférens.

$c c$, vésicules séminales.

$d$, canal éjaculateur.

$e$, portion intestinale.

$f$, armure copulatrice.

$$
\text { FIGURE } 147, \text { B. }
$$

Un testicule de cet insecte plus grossi et déroulé.

$a$, capsules séminifiques.

$b$, conduit déférent.

$c$, vésicule séminale.

$d$, canal éjaculateur.

FIGURE I 47, C.

Étui on fourreau de la verge de cet insecte, considérablement grossi.

$a a$, portions tronquées des conduits déférens des testicules. 
$b$, portions tronquées des vésicules séminales.

$c$, canal éjaculatenr.

$d$, étui basilaire de la verge.

$e$, lames spatulées.

$f$, renflement sphéroïdal du fourreau propre de la verge.

$$
\text { FIGURE } 148 .
$$

Appareil génital mâle fort grossi de la Ranatra linearis. $a$, testicule dans son état naturel.

$b$, le même avec les capsules séminifiques étalées.

$c$, vésicules séminales?

$d$, canal éjaculateur.

$e$, armure copulatrice.

Testicule de la Corixa striata, considérablement grossi, ạvec les capsules séminifiques étalées, et une portion du conduit déférent.

$$
\text { FIGURE } 150 .
$$

Appareil génital mâle fort grossi de la Notonecta glauca.

$a a$, testicules flétris ou non turgescens.

$b b$, couduits déférens, l'un roulé en boucles, l'autre déployé.

ccccce, vésicules séminales un peu flasques.

$d d$, autre paire de vésicules séminales ordinairement engagées dans les circonvolutions du conduit déférent.

$e$, canal éjaculateur.

$f$, armure copulatrice.

$g$, portion du canal digestif.

$$
\text { FIGURE } 151 .
$$

Un testicule du même insecte, considérablement grossi, dépouillé de sa tunique testiculaire, et dans un état de turgescence spermatique très prononcé.

$$
\text { F'GURE } 152 .
$$

L.e même organe encore plus grossi, plus turgescent, pour mettre 
en évidence sa texture fibrillaire intérieure, et la manière dont se formc le conduit déférent.

$$
\text { FigURE } 152, \text { A. }
$$

Appareil génital mâle fort grossi de la Cicada orni.

$a$, testicules.

$b b$, conduits déférens.

$c c$, vésicules séminales.

$d$, canal éjaculateur.

$e$, portion de l'intestin.

$f$, armure copulatrice.

$g$, anus.

$h$, verge.

$$
\text { FIGURE I } 52 \text {, B. }
$$

Un testicule considérablement grossi et mis à nu.

$a$, capsules séminifiques.

$b$, portion du conduit déférent.

$c$, un groupe isolé et encore plus grossi des capsules séminifiques.

FIGURE 153.

Portion de l'appareil génital mâle fort grossi de l'Aphrophora salicina.

$a$, un testicule avec les capsules séminifiques étalées.

A, une de ces capsules isolée.

$b$, conduit déférent.

$c c$, vésicules séminales.

$d$, tige commune aux vésicules séminales.

B, portions des conduits déférens et du canal éjaculateur.

$$
\text { FIGURE } 154 \text {. }
$$

Appareil génital fort grossi de l'Issus coleoptratus.

$a a$, testicules.

$b b$, conduits déférens et épididymes.

$c c$, vésicules séminales.

$d$, canal éjaculateur.

4. Savans élrangers. 


$$
\text { FIGURE } 155 .
$$

Un testicule du même insecte, dont les capsules séminifiques dépouillées de la tunique testiculaire sont étalées, et dont les replis épididymiques sont à nu.

$$
\text { FIGURE } 156 .
$$

Appareil génital mâle fort grossi du Psylla ficus. aa, testicules avec les capsules sćminifiques à nu.

$b b$, conduits déférens.

$c c$, vésicules séminales.

$d$, armure copulatrice.

PI. XIV.

FIGURE 157 .

Extrémité de l'abdomen de la Scutellera nigro-lineata femelle, fort grossie et vue en-dessous, pour mettre en évidence la forme et la disposition des pièces vulvaires.

$a a$, dernier segment stigmatifère de la région ventrale.

$b b$, portion de l'avant-dernier de ces segmens.

$c$, ensemble des écailles qui constituent l'appareil vulvaire.

I I, écailles antérieures constituant les panneaux ou lèvres de la vulve.

22 , écailles intermédiaires.

33, écailles postérieures.

4. plaque médiane.

FIGURE 158 .

Appareil génital fenılle fort grossi de la Scutellera nigro-lineata. $a a$, ovaires avec les gaînes ovigères groupées en faisceau.

$b$, oviducte.

$c$, glande sébifique.

$d$, derniers segmens dorsaux de l'abdomen.

$$
\text { FIGURE } 159 .
$$

Portion de l'appareil génital femelle fort grossi de la Scutellera maura.

$a$, origine tronquée de six gaines ovigères. 
DES PLANCHES.

$b$, la septième de ces gaînes entière.

$c c$, poches vésiculaires appartenant à l'appareil sébifique.

$d$, collerette de vaisseaux tubulaires, placée de chaque côté de l'origine de l'oviducte. - $d^{\star}$ la même partie très grossie.

$e$, oviducte sur lequel on voit la glande sébifique.

$f$, glande sébifique détachée et considérablement grossie, à travers les parois de laquelle on apercoit un corps inclus.

FIGURE 160 .

Gaînes ovigères et œufs grossis de la Pentatoma grisea.

$a$, gaîne ovigère à trois cufs.

$b$, gaîne ovigère à deux ceufs.

$c$, ouf considérablement grossi.

FIGURE I 6 I.

Diverses parties de l'apparcil sébifique de cet insecte.

$a$, la glande dans son état naturel, fort grossie.

$b$, la mêtne, avec sa tunique extérieure ouverte et renversée sur

les côtés, de manière à mettre en évidence le réservoir.

$c$, filet de l'axe de la glande considérablement grossi.

$d d$, gland sécréteur.

FIGURE 162 .

Gaîne ovigère et glande sébifique fort grossies de la Pentatoma smaragdina.

$a$, une gaine ovigère à six loges.

$b$, glande sébifique.

$c$, filet de l'axe de la glande considérablement grossi

FIGURE 163 .

Glande sébifique fort grossie de la Pentatoma aparines.

FIGURE 164 .

Appareil génital femclle fort grossi de la Pentatoma ornata.

$a$, ovaire dans l'état naturel, groupé en faisceau.

$b$, oraire avec les gaînes ovigères étalées. 
$c$, calice de l'ovaire.

$d$, collerette de vaisseaux tubulaires.

D, ceux-ci isolés et plus grossis.

$e$, oviducte et glande sébifique.

$\mathbf{E}$, cette dernière isolée et plus grossie.

$f$, dernier segment dorsal de l'abdomen.

FIGURE 165.

Un œuf du même insecte, considérablement grossi.

$a$, œuf fermé.

$b$, œuf dépourvu d'opercule et vide.

$c$, opercule détaché.

FIGURE 166.

Appareil génital femelle fort grossi du Coreus marginatus.

$a$, ovaire dans l'état naturel, les gaînes ovigères groupées en faisceau.

$b$, ovaire à gaînes étalées.

$c c$, cols des ovaires.

$d d$, vaisseaux sécréteurs de la glande sébifique.

$e$, derniers segmens dorsaux de l'abdomen.

$f$, portion d'intestin.

$g$, oufs pondus.

PL. XV.

FIGURE 167 .

Abdomen fort grossi du Miris Carcelii, vu en-dessous, pour mettre en évidence les stigmates et la structure des pièces vulvaires.

A, oviscapte détaché.

FIGURE 168.

Appareil génital femelle fort grossi de ce même insecte.

$a$, ovaire dont les gaînes ovigères sont groupées en faisceau.

$b$, ovaire à gaînes ovigères étalées.

$c$, glande sćbilique.

$d$, bout dorsal de l'abdomen.

FIGURE 169 .

Portion tronquée et grossie d'un ovaire du même insecte, pour 
mettre en évidence le nombre et la disposition des gainnes ovigères.

$a$, calice de l'ovaire.

$b$, col de l'ovaire.

$c$, œuf.

FIGURE 170.

Appareil génital femelle considérablement grossi du Cimex lectularius.

$a a$, ligamens suspenseurs.

$b b$, ovaires dans un état de gestation peu avancée, les œeufs étant ovales et gros.

$c c$, appareil sébifique.

$d$, derniers segmens de l'abdomen.

FIGURE I 7 I.

Un ovaire à terme, avec les gaînes ovigères étalées et uu œuf dans le calice.

$$
\text { FIGURE I } 72 \text {. }
$$

Gaîne ovigère vierge ou infécondée.

$$
\text { FIGURE } 173 .
$$

Un œuf pondu et grossi.

$$
\text { FIGURE I } 74 \text {. }
$$

Le même encore plus grossi, avec son opercule détaché.

$$
\text { FIGURE I } 74, \mathbf{A} \text {. }
$$

Appareil génital femelle considérablement grossi du Pelogonus marginatus.

$a a$, gaînes ovigères infécondes ou vierges.

$b b$, cols des ovaires ou oviductes propres.

$c$, oviducte commun.

$d$, appareil sébifique de l'oviducte.

$e$, derniers segmens abdominaux de la femelle. 
FIGURE $] 75$.

Appareil génital femelle fort grossi du Gerris canalium. $a a$, ovaires à terme.

$b$, glande sébifique.

$c$, bout de l'abdomen.

$d$, portion d'intestin.

FIGURE I 76 .

Une gaîne ovigère du même insecte, isolée et à terme.

FIG URE 177 .

OEufs fort grossis du Gerris paludum, placés sur un brin d'herbe aquatique.

$a$, une coque d'œuf d'où venait de sortir une larve de Gerris, avec une dépouille membraneuse à son ouverture.

$b$, un Gerris grossi, immédiatement après sa naissance.

FIGURE 178.

Larve de ce Gerris considérablenıent grossie. Elle n'a après sa naissance qu'une ligne et demie de longueur. La forme de son corps est ovale, elliptique, pointue en arrière. La tête et les antennes proportionnellement plus grosses que dans l'adulte; l'abdomen court, marqué de stries transversales qui sont l'indice de segmens. Les pattes postérieures, qui sont bieu plus courtes que les intermédiaires, semblent insérées au bout de l'abdomen, parce que la région sternale du métathorax se prolonge en arrière; les tarses paraissent d'un seul article.

PL. XVI.

FIGURE 179.

Appareil génital femelle fort grossi de la Naucoris cimicoides. $a a$, ovaires très avancés dans la gestation.

$b b$, cols des ovaires.

$c$, glande sébifique.

$d$, oviducte.

$e$, pièces vulvaires et copulatrices.

$f$, oviscapte. 
$g$, le même, détaché et encore plus grossi.

$h$, ouf très grossi.

$$
\text { FIGURE } 180 .
$$

Gaîne ovigère fort grossie de la Naucoris aptera.

$$
\text { FIGURE } 181 .
$$

OEufs de cet insecte fort grossis, et pondus sur une tige aquatique.

$$
\text { FIGURE I } 82 \text {. }
$$

Texture de la coque de ces oufs considérablement grossie.

$$
\text { FIGIJRE } 183 .
$$

Appareil génital femelle fort grossi de la Ranatra linearis. $a a$, ovaires très avancés daus la gestation.

$b b$, ligamens suspenseurs.

$c c$, calices des ovaires.

$d$, oviducte.

$e$, glande sébifique.

$f$, vessie,natatoire et intestin.

$g$, pièces vulvaires.

$h$, anus.

$i$, oviscapte.

$k$, pièce qui l'accompagne.

$l$, œuf fort grossi.

$$
\text { FIGURE I } 84 \text {. }
$$

Appareil génital femelle fort grossi de la Nepa cinerea. $a$, un ovaire très avancé dans la gestation.

$b$, ligament suspenseur.

$c c$, calices et cols des ovaires; l'un est tronqué.

$d$, oviducte.

$e$, glande sébifique.

$f$, vessie natatoire et portion d'intestin.

$g$, pièce vulvaire et copulatrice.

$h$, anus. 
$i$, oviscapte.

$k$, $œ u f$ considérablement grossi, couronné par sept soies.

$$
\text { FIGURE } 185 \text {. }
$$

Un ovaire fort grossi de la Corixa striata.

$a$, gaines ovigères multiloculaires

$b$, col de l'ovaire.

$c$, oviducte.

$d$, ovulaires.

$e$, ligament suspenseur.

FIGURE 186 .

OEufs considérablement grossis de cet insecte, placés sur un brin d'herbe aquatique.

$$
\text { FIGURE } 187 .
$$

OEufs considérablement grossis de la Corixa hieroglyphica, placés sur un brin d'herbe aquatique.

PL. XVII.

FIGURE 188 .

Appareil génital femelle fort grossi de la Cicada orni.

$a a$, ovaires dans un état avancé de gestation.

$b b$, cols des ovaires, ou oviductes propres.

$c$, oviducte commun, courbé en crosse à son origine.

$d d d$, vaisseaux sécréteurs de la glande sébacée de l'oviducte.

$e$, réservoir de cette glande.

$f f$, ligamens suspenseurs des ovaires.

$g$, portion de l'intestin.

$h$, dernier segment dorsal de l'abdomen.

$B$, une gaîne ovigère isolée.

$$
\text { FIGURE } 189 \text {. }
$$

Portion considérablement grossie d'un des ovaires de cet insecte, étalée, pour mettre en évidence ses divisions ramifiées.

FIGURE IgO.

Appareil génital femelle fort grossi de la Psylla ficus. 
$a a$, ovaires très avancés dans la gestation.

$b b$, cols des ovaires.

$c$, utricule de l'appareil sébifique.

$d$, corps appartenant peut-être au même appareil.

$e$, bout de l'abdomen de la femelle.

FIGURE IgI.

Gaîne ovigère considérablement grossie de la Psylla ficus.

$a$, œuf à terme, tel qu'il était dans la gaîne, mais représenté de manière à mettre en évidence son bec.

$b c$, œufs pondus.

FIGURE 192 .

Tube alimentaire, ovaires et extrémité de l'abdomen considérablement grossis de l'Aphis rosa.

$a$, œsophage.

$b$, estomac.

$c$, portion filiforme qui se termine en arrière par une poche intestinale.

$d d$, ovaire où l'on distingue et des oufs et des foetus.

$e e$, appendices tubulés de l'abdomen.

$f$, appendice anale.

FIGURE 193 .

Corps de la Pentatoma smaragdina femelle considéıblement grossi et vu par sa région inférieure, pour mettre en évidence les stigmates et les ostioles odoriferes.

$a a$, stignates thoraciques.

$b b$, ostioles odoriferes.

$1,2,3,4,5,6$, les six paires de stigmates abdominaux, La première paire n'est apparente que par une excision pratiquée à la lame du métathorax qui la recouvre habituellement.

$c$, pièces vulvaires.

\section{FIGURE 194 .}

Paroi ventrale de l'abdomen de la Scutellera nigro-lineata, vue par sa face viscérale et fort grossie, pour mettre en évidence l'appareil respiratoire et la bourse odorifique.

4. Savans etrangers. 
$a$, bourse odorifique.

$\mathrm{I}, 2,3,4,5,6$, les six paires de trachées utriculaires prenant naissance aux stigmates.

$$
\text { FIGURE I } 95 \text {. }
$$

Une des tiges considérablement grossie et renversée du siphon respiratoire de la Nepa cinerea.

$a$, stigmate caudal et origine du tronc principal de l'appareil trachéen.

$$
\text { FIGURE } 2 \mathrm{C} 4(\mathrm{I}) \text {. }
$$

Cordon dorsal considérablement grossi de la Pentatoma grisea. $a$, extrémité céphalique.

$b$, portion thoracique.

$c$, portion abdominale.

$d$, extrémité postérieure.

FIGURE 205.

Organe des sécrétions excrémentitielles considérablement grossi du Coreus marginatus.

Cet organe existe dans les deux sexes, et est situé tout-àfait au-dessous de l'appareil génital et au bout de l'abdomen. $a$, vaisseau sécréteur aggloméré.

$b$, le mème déployé.

Ces vaisseaux, d'une finesse capillaire, et très fragiles, offrent çà et là quelques rameaux courts irréguliers; ils sont souvent entremêlés avec les vaisseaux hépatiques, dont ils diffèrent surtout par leurs rameaux et leur extrême capillarité.

$c c$, bourses ou réservoirs.

Chacun des vaisseaux débouche en arrière dans une vésicule ovoïde ou oblongue, suivant son degré de plénitude, et les deux vésicules confluent en arrière pour s'ouvrir ou dans le rectum ou dans le voisinage de l'anus.

( 1 ) La disposition des dessins sur le cuivre a obligé de reporter à la Pl. XVIII les $n^{\text {os }} 196$ et suivans. 
FIGURE 206.

Deux espèces du genre Gregarina considérablement grossies, trouvées dans le tube intestinal de la Phymata crassipes.

$a$, Gregarina elongala. Nob.

b, Gregarina globosa. Nob.

$$
\text { FIGURE } 196 .
$$

PL. XVIII.

Appareil respiratoire très considérablement grossi de la $\mathrm{Nepa} \mathrm{ci-}$ nerea. Toute la paroi dorsale du thorax et de l'abdomen est enlevée, pour mettre en évidence et les stigmates et les trachées. $a a a$, les faux stigmates vus par leur face interne, avec le tronc trachéen secondaire qui s'insère à leur bout antérieur.

$b$, stignate caudal ou du siphon respiratoire. Une portion de celuici est représentée détachée de l'abdonien et dans une position renversée, pour mettre en évidence ses orifices respiratoires et le tronc principal des trachées qui y prend naissance. ( Voyez Pl. XVII, fig. 195.)

$c c c$, insertions borgnes et à nu des troncs trachéens secondaires, correspondant aux $1^{\text {er }}, 2^{e}$ et $6^{e}$ segmens ventraux de l'abdomen.

dddddd, deux trachées naissant du tronc secondaire, et destinées l'une aux organes, l'antre à former une arcade de communication.

$e$, sachet utricnliforme visible à l'extérieur et recevant du tronc principal unc trachée particulière.

$f$, trois trachées destinées aux ailes et élytres, aux pattes intermédiaires et aux postérieures.

$g$, sachet musculo-trachéen sous-scutellaire. Il est représenté ici déplacé de sa position ordinaire, qui devrait être inmédiatement à côté de la ligne médiane du corps. Ce déplacement a pour but de mettre en évidence d'autres sachets qu'il recouvre ordinairement.

$h$, sachet musculo-trachéen et utriculaire métathoracique.

ii, Deux utricules appartenant au sachet précédent.

$i$, utricule irachéenne isolée.

$k$, sinns trachéen central formé par la confluence de quatre trachées. 
$l$, trachée destinée aux pattes antérieures.

$m$, faisceau de trachées destinées à la tête.

$n$, portion de la tête.

$o$, portion de la patte antérieure.

$p$, portion d'hémélytre.

$q$, portion des pattes, intermédiaire et postérieure.

FIGURE I97.

Un faux stigmate vu par sa face externe et fort considérablement grossi.

$$
\text { FIGURE } 19^{8} \text {. }
$$

Un faux stigmate vu par sa face interne et fort considérablement grossi.

FIGURE I99.

Un sachet musculo-trachéen sous-scutellaire fort considérablement grossi. Son bout antérieur entier avec la calotte cornée où il s'insère; son bout postérieur déchiré de manière à mettre en évidence sa texture parenchymateuse.

FIGURE 200 .

Trachée en panache fort considérablement grossie, formant le tissu parenchymateux du sachet précédent.

PL. XIX.

FIGURE 201 .

Appareil nerveux considérablement grossi de la Pentatoma grisea. $a$, ganglion céphalique.

$b b$, bulbes des nerfs optiques principaux.

$c \dot{c}$, rétines et nerfs optiques doubles des yeux à réseaux.

$d d$, rétines et nerfs optiques des ocelles.

$e e$, trois paires de nerfs naissant du ganglion céphalique et destinés aux diverses parties du bec.

$f f$, une paire de nerfs naissant de l'origine du prolongement rachidien.

gghh, nombreuses paires de nerfs naissant des ganglions thoraciques. 
DES PLANCHES.

ii, quatre paires de nerfs récurrens, naissant du prolongement rachidien abdominal.

ji, continuation de ce dernier.

$k k$, quatre paires de nerfs terminant le prolongement rachidien.

FIGURE 202 .

Appareil nerveux considérablement grossi de la $\mathbf{N e p a}$ cinerea. $a$, ganglion céphalique.

$b b$, rétines et nerfs optiques.

$c$, oesophage qui s'engage dans le collier du prolongement rachidien.

$d d$, paires de ncrfs qui naissent du ganglion prothoracique.

$e e$, paires de nerfs qui naissent du ganglion métathoracique.

$f f$, paires de nerfs naissant du prolongement rachidien.

gg, paires de nerfs qui terminent le prolongement rachidien.

FIGURE 203 ( 1 ).

Appareil nerveux considérablement grossi de la Cicada orni.

$a$, ganglion céphalique.

$b b$, rétines et nerfs optiques des grands yeux.

$c$, rétines et nerfs optiques des ocelles.

$d d$, paires de nerfs naissant des ganglions thoraciques.

$e e$, paires de nerfs naissant du prolongement rachidien abdominal.

$f f$, paires de nerfs qui terminent le prolongement rachidien et qui se distribuent principalement aux organes de la génération.

(1) Voyez à la Planche XVII l'explication des $n^{0 *} 204,205$ et 206.

FIN DES RECHFRCHES SUR LES HÉMIPTÉRES. 







INSERT FOLDOUT HERE 

2.

$\bullet$ 
. 
- 









